\title{
Identifizierung und Charakterisierung von Genen für die Entwicklung des cerebralen Cortex
}

Dissertation zur Erlangung des Doktorgrades der MathematischNaturwissenschaftlichen Fakultäten der Georg-AugustUniversität zu Göttingen

\author{
vorgelegt von \\ Friederike Kirsch \\ aus Lemgo
}

Göttingen 2004 
Diese Arbeit wurde am Max-Planck-Institut für biophysikalische Chemie, Karl-Friedrich-Bonhoeffer-Institut, in der Abteilung für Molekulare Zellbiologie (Direktor: Prof. Dr. P. Gruss) durchgeführt.

D7

Referent: Prof. Dr. P. Gruss

Korreferent: Prof. Dr. H. J. Fritz

Tag der mündlichen Prüfung: 02.11.2004 


\section{Inhaltsverzeichnis}

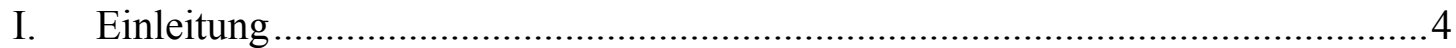

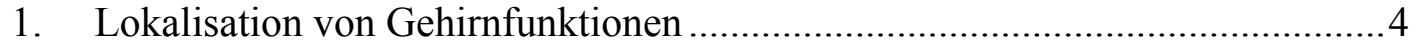

2. Klassische Modelle der corticalen Musterbildung.........................................

3. Signalzentren zur corticalen Musterbildung ......................................................6

4. Kontrolle der Arealisierung des cerebralen Cortex durch

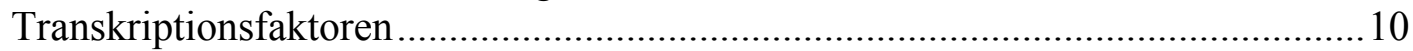

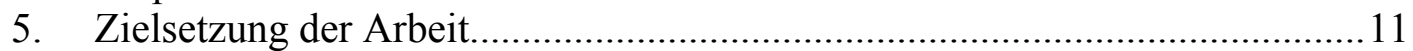

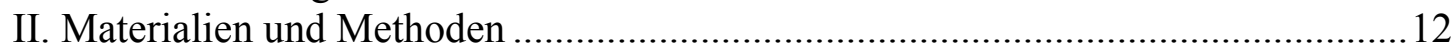

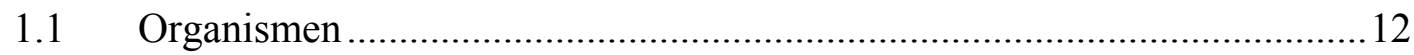

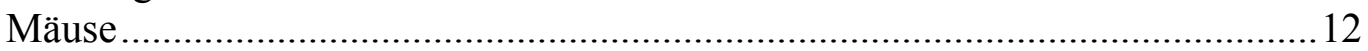

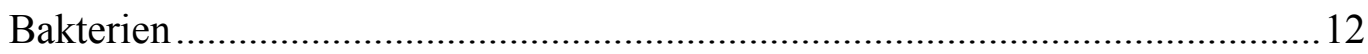

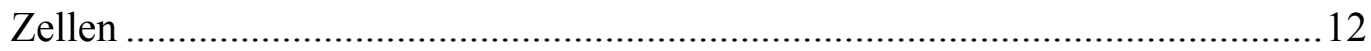

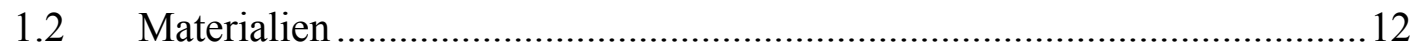

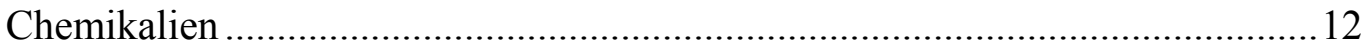

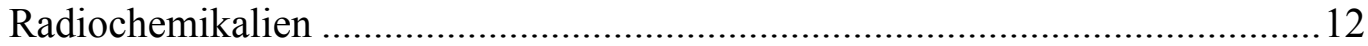

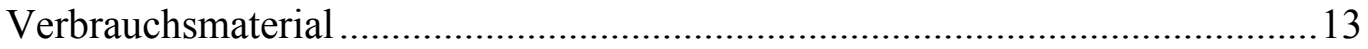

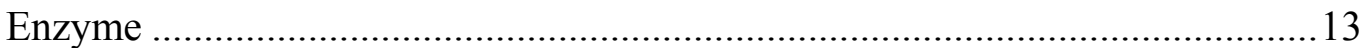

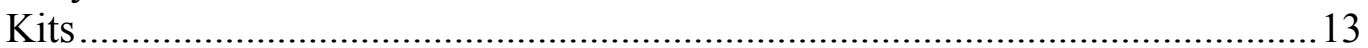

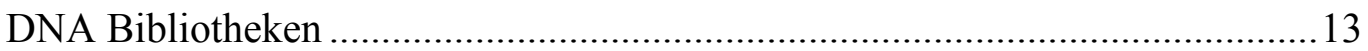

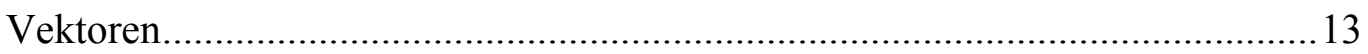

Oligonucleotide

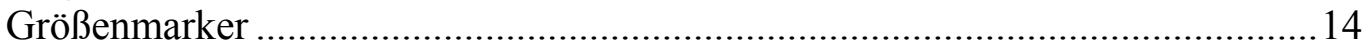

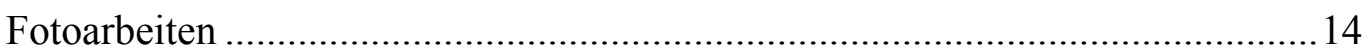

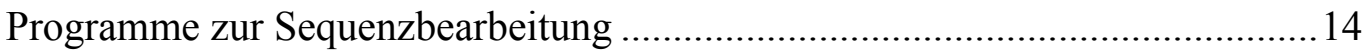

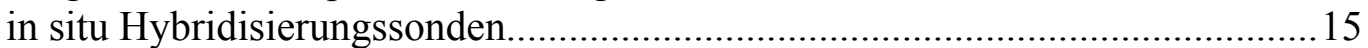

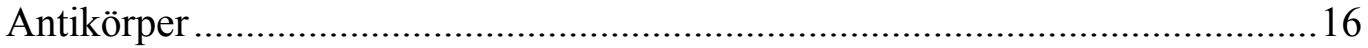

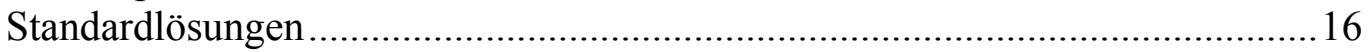

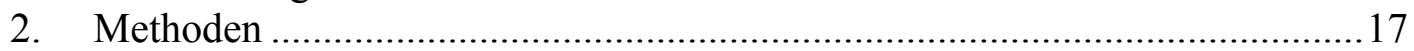

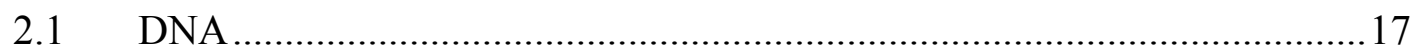

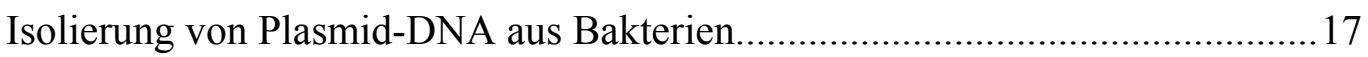

Konzentrationsbestimmung von Nucleinsäuren ............................................... 17

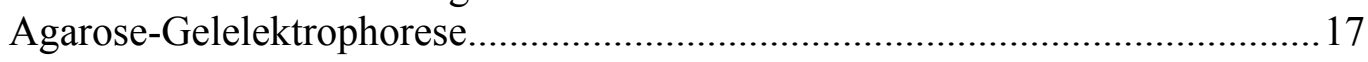

Verdau von DNA mit Restriktionsendonucleasen............................................ 18

Aufreinigung von DNA-Fragmenten aus Agarosegelen mit dem "Qiaquick Gel

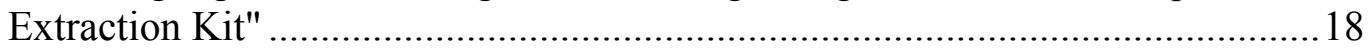

Aufreinigen von DNA durch Phenol-Chloroform-Extraktion ........................... 18

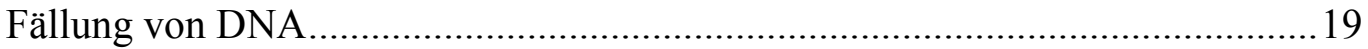

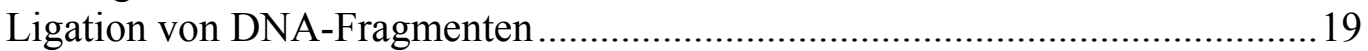

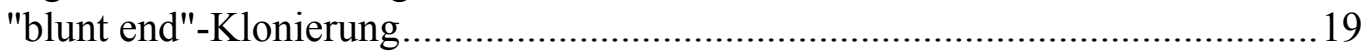

Alkalische Phosphatase-Behandlung von Vektoren mit überhängenden Enden .19

Transformation von Bakterien ............................................................................20

Durchmustern einer cDNA- oder genomischen Maus-DNA-Bibliothek nach rekombinanten Bakteriophagen und deren Isolierung ........................................21

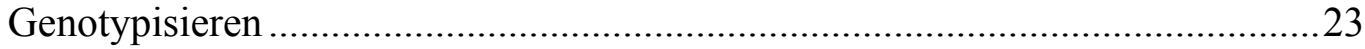

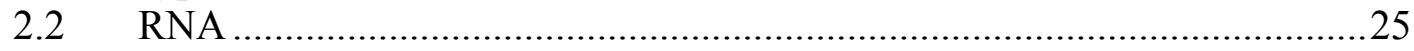

Isolierung von Gesamt-RNA mit TRIzol...................................................26

Isolierung von Gesamt-RNA mit RNeasy Total RNA Isolation Kit (Qiagen) ....26

Aufreinigung von poly A $^{+}$RNA aus Gesamt-RNA (Oligotex Kit, Qiagen)........26 
Northern Blot 26

mRNA in situ-Hybridisierung auf Cryoschnitten mit Digoxigenin (DIG)-

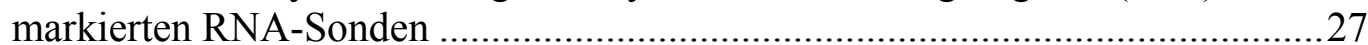

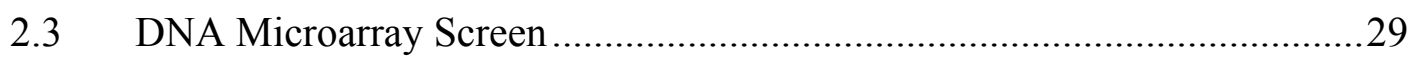

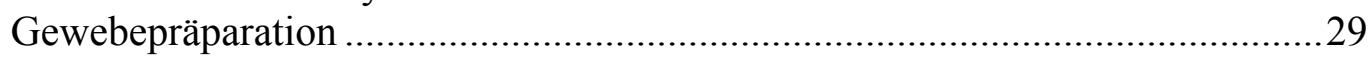

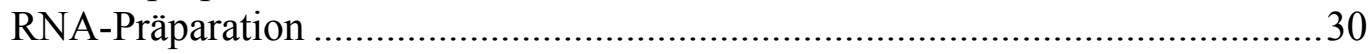

cDNA Synthese (SuperScript Choice System, GibcoBRL) .............................. 30

Synthese der biotin-markierten cRNA (BioArray High Yield RNA Transcript

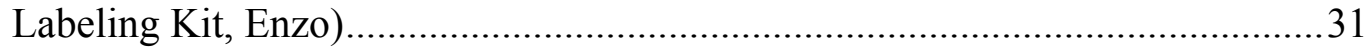

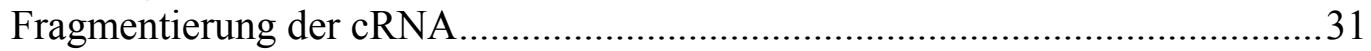

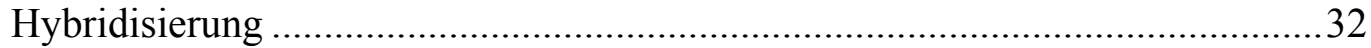

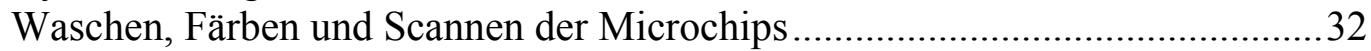

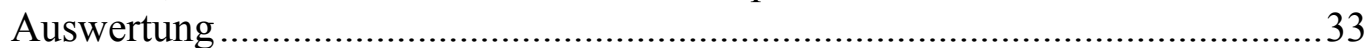

$2.4 \quad$ Protein

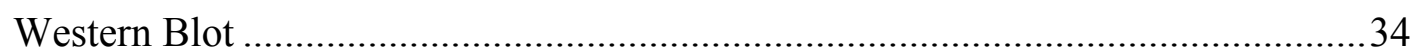

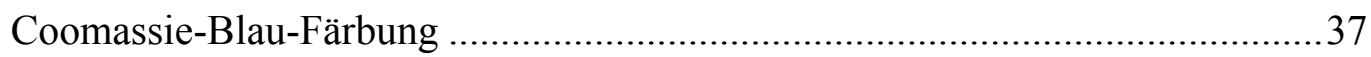

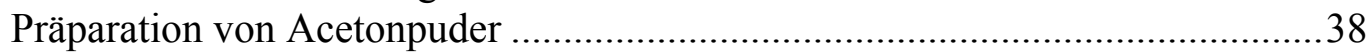

Präadsorption des Ratte-anti-PPPin-Antikörpers.............................................. 38

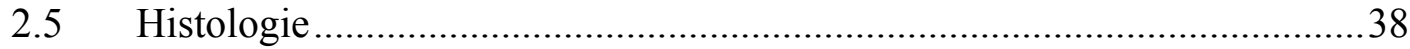

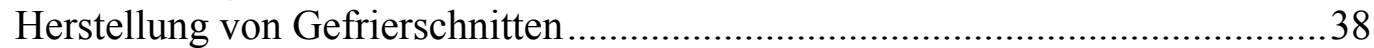

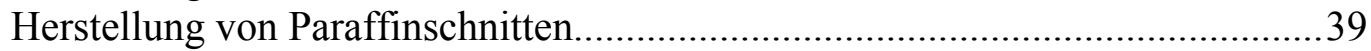

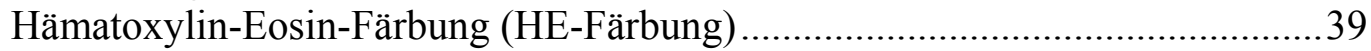

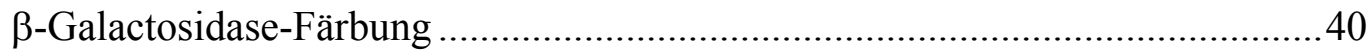

BrdU (5-Bromo-2'-deoxyuridin)-Aufnahmestudien .......................................40

2.6 in vitro Elektroporation embryonaler Gehirne und organotypische Kultur.42

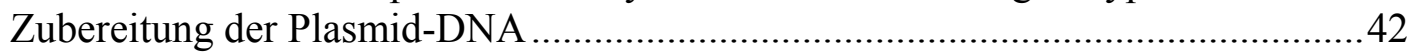

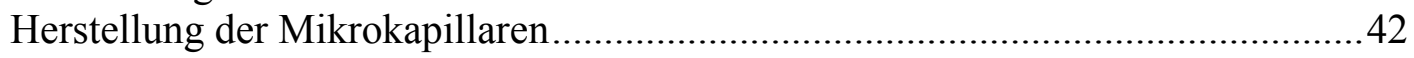

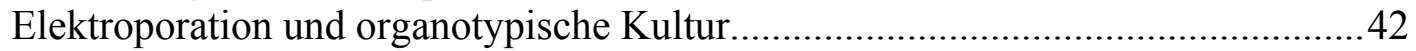

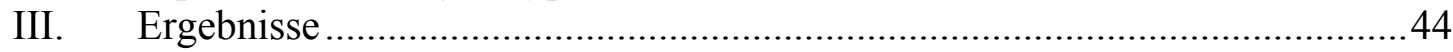

1. Microarray-Expressionsanalyse von verschiedenen Regionen des cerebralen Cortex zum Embryonaltag 16,5....

2. RNA-in situ-Hybridisierung ausgewählter Gene aus der Microarray-

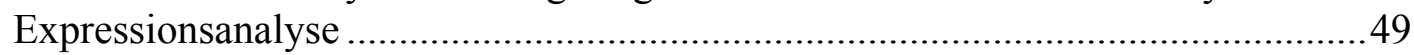

3. Auswahl des Gens Maus-PIPPin zur weiteren Charakterisierung ...................56

$3.1 \quad$ Expressionsstudie von Maus-PIPPin ..................................................58

3.2 Klonierung des Gens Maus-PIPPin und Sequenzanalyse der cDNA ......63

3.3 Die Proteindomäne von Maus-PIPPin ....................................................65

3.4 Genomische Organisation des Maus-PIPPin-Gens..................................6 67

3.5 Herstellen eines Rekombinationskonstruktes für die homologe

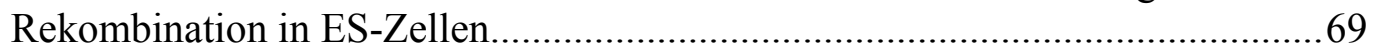

3.6 Gentransfer in ES-Zellen/ Der ES Zell-Screen .......................................72

3.7 Morula-Aggregation von ES-Zellen (Wood et al., 1993) und

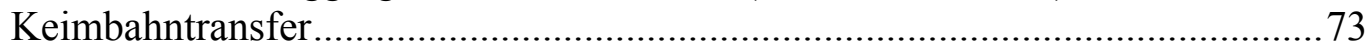

3.8 Bestätigung der homologen Rekombination in den Maus-PIPPin

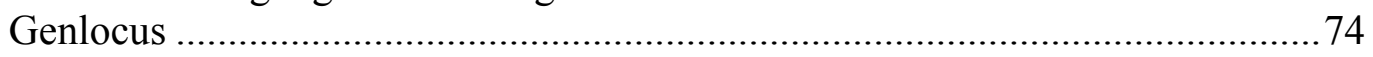

3.9 Fortpflanzungsstatistik der heterozygoten PIPPin-Mäuse ....................... 77

3.10 Analyse des Gehirns PIPPin-defizienter Mäuse ..................................... 77

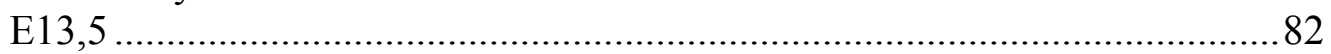

3.11 Identifikation und Analyse von regulatorischen Sequenzelementen des

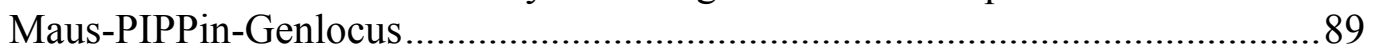


IV. Diskussion. 100

1. Microarray-Expressionsanalyse identifizierte Gene mit regionen- und schichtspezifischer Expression im cerebralen Cortex des Embryonaltags 16,5 .... 100 2. Bestätigung der meisten ausgewählten Gene in der RNA-in situHybridisierung, Kommentar der Microarray-Technologie.

3. Auswahl des Gens Maus-PIPPin zur weiteren Charakterisierung basierend auf Microarray-Expressions- und RNA-in situ-Hybridisierung-Analyse

3.1 Analyse der Expression von Maus-PIPPin während der

Embryonalentwicklung

3.2 Die "cold-shock"-Domäne und ihre verschiedenen Funktionen in

Zellproliferation und Entwicklung.

3.3 Entwurf für eine mögliche allgemeine Funktion PIPPins in der

Entwicklung des Nervensystems der Maus

3.4 Analyse des Gehirns der PIPPin-knock-out-Maus ergibt keinen offensichtlichen Phänotyp.

3.5 Identifikation eines Maus-PIPPin spezifischen Enhancers mit

Bindestellen für Transkriptionsfaktoren

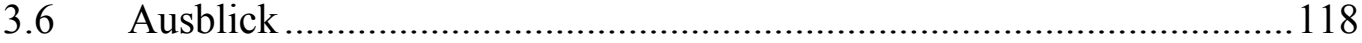

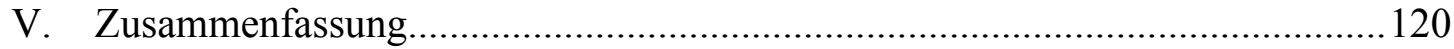

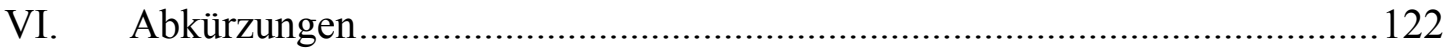

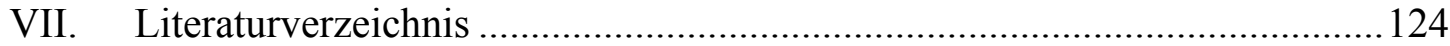

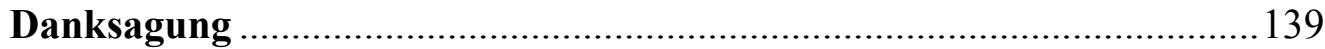

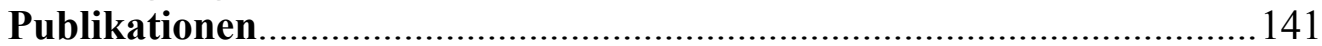

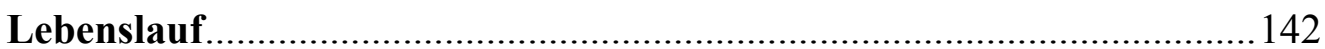




\section{Einleitung}

\section{Lokalisation von Gehirnfunktionen}

Als Monsieur Leborgne 1861 in die Behandlung des französischen Neurologen Paul Broca kam, konnte er nur so einen Laut wie "tan" von sich geben. Dieser Patient, der später in die Medizingeschichte als "Tan" einging (Finger, 1994), war in der Lage, Sprache zu verstehen oder auch Melodien zu singen. Auch lagen bei ihm keine motorischen Defizite der Sprechmuskulatur (Lippen, Zunge, Kehlkopf) vor. Dennoch litt Monsieur Leborgne an einem Verlust des Sprachvermögens, der es ihm nicht ermöglichte, in grammatikalisch korrekten, vollständigen Sätzen zu sprechen (Aphasie). Die postmortem-Untersuchung seines Gehirns durch Broca zeigte eine Läsion in der posterioren Region des Frontallappens der linken Hemisphäre. Diese Region wurde "Broca Areal" benannt und galt von dort an als Sitz des motorischen Sprachzentrums bei Rechtshändern. Broca gelang es mit seiner Arbeit als einem der Ersten (Eckart, 1994), eine Funktion einer bestimmten Gehirnregion zuzuordnen.

Korbinian Brodmann verfolgte Anfang des zwanzigsten Jahrhunderts die Idee, verschiedene funktionelle Bereiche des cerebralen Cortex basierend auf ihrer Cytoarchitektur zu unterscheiden. Er beobachtete Nervenzellen mit regionenspezifischer Struktur und charakteristischer Anordnung in Schichten. Auf diese Weise teilte er den humanen cerebralen Cortex in 52 Regionen ein und vermutete funktionelle Unterschiede dieser Areale.

Diese beiden Beispiele zeigen, daß die Aufteilung des cerebralen Cortex in funktionell spezialisierte Bereiche und die charakteristische Anordung der Zellen in Schichten bereits früh bekannt waren. Man wußte zu dieser Zeit allerdings nicht, welche molekularen Mechanismen zu dieser zweidimensionalen Gliederung des Cortex (tangential in funktionelle Areale, radial in sechs Hauptzellschichten) führen. Inzwischen wurden viele Prinzipien und molekulare Mechanismen entwickelt, denen die embryonale Musterbildung in Vertebraten und Invertebraten unterliegt. Ein klassisches Prinzip ist dabei die Existenz von Signalzentren (Wolpert, 1996), die Signalproteine oder Morphogene ausschütten. Diese diffundieren durch das Gewebe und verleihen durch den Aufbau eines Gradienten jeder Region eine bestimmte Positionsinformation. Zellen antworten auf diese unterschiedlichen Morphogenkonzentrationen durch die Expression spezifischer Transkriptionsfaktoren. 
Die regionale Expression spezifischer Transkriptionsfaktoren beeinflußt wiederum die Expression von "downstream"-Genen, die die lokale Differenzierung eines Gewebes kontrollieren. Es wird vermutet, daß auch die Musterbildung im cerebralen Cortex der Säuger ähnlichen Mechanismen unterliegt (Bishop et al., 2000; Bishop et al., 2002).

\section{Klassische Modelle der corticalen Musterbildung}

Das "Protomap" Modell

Das "Protomap" Modell (Rakic, 1988) geht von der Musterbildung der corticalen Anlage bereits bei seiner Entstehung aus. Dabei werden intrinsische Unterschiede, die durch molekulare Determinanten entstehen, in der Ventrikulärzone (der proliferativen, tiefsten Schicht) des Cortex gebildet. Verlassen neu entstandene Neurone die Ventrikulärzone und migrieren nach außen zur Bildung des corticalen Mantels (Corticalplatte), so führen sie ihre "Protomap"mit sich. Innervierende Axone können diese "Protomap" nicht modifizieren oder verfeinern.

\section{$\underline{\text { Das "Protocortex" Modell }}$}

Bei dem "Protocortex" Modell (O'Leary, 1989) wird die corticale Anlage als homogen betrachtet. Die Musterbildung in Regionen geschieht relativ spät in der Corticogenese durch einwachsende Axone aus dem Thalamus, die ihre Positionsinformation der Corticalplatte verleihen.

Die Ansicht des "Protocortex" Modells, den cerebralen Cortex im Zusammenhang mit dem Rest des sich entwickelnden Gehirns zu betrachten, wird immer noch akzeptiert. Allerdings gibt es immer mehr Hinweise, die die Gültigkeit des "Protomap" Modells unterstützen (Grove und Fukuchi-Shimogori, 2003). Die corticale Anlage ist z.B. trotz seiner homogenen Morphologie hochgradig heterogen. Gene wie das limbischeSystem assoziierte Membranprotein (LAMP), Latexin oder H-2Z1-Transgen werden jeweils nur im limbischen, im lateralen Cortex oder in der primären und sekundären somatosensorischen Area S1 und S2 exprimiert (Arimatsu, 1994; Levitt et al., 1997; Gitton et al., 1999). Andere Befunde zeigen, daß die corticale Musterbildung unabhängig von Innervationen aus dem Thalamus geschieht. Dies ist z.B. bei Mäusen der Fall, denen der Transkriptionsfaktor Gbx2 fehlt. Trotzdem die thalamocorticalen Projektionen sich bei diesen Tieren nicht ausbilden, entstehen dennoch wohldefinierte Genexpressionsdomänen (z.B. markiert durch Cadherin6, Id2 = Inhibitor of differentiation 2, EphrinA-7 und RZR- $\beta$ = retinoid Z receptor $\beta$ ) (Miyashita-Lin et al., 
1999). Ähnliche Beobachtungen wurden bei Mäusen gemacht, die nicht den Transkriptionsfaktor Mash-1 besitzen (Nakagawa et al., 1999).

Eine wichtiger Punkt wird durch das "Protomap Modell" nicht deutlich. Wie entstehen intrinsische Unterschiede in der corticalen Anlage und wie werden diese Unterschiede zum Aufbau der "Protomap" interpretiert?

\section{Signalzentren zur corticalen Musterbildung}

Beim Betrachten der Verteilung von corticalen Arealen einer erwachsenen Maus fällt eine Anordnung in longitudinalen Bändern entlang der medialen und lateralen Grenzen des Cortex auf (Ragsdale und Grove, 2001). Diese Anordnung läßt ein Signalzentrum vermuten, das die Ausbildung der medial-lateral-Achse veranlaßt. Ein anderes Signalzentrum kann in der anterior-posterior-Richtung die Musterbildung initiieren.

Musterbildung entlang der anterior-posterior-Achse

Dieser Prozeß wird bestimmt durch ein Signalzentrum, das sich am rostralen Ende des sich entwickelnden Embryos befindet: die "anterior neural ridge" (ANR, anteriore Neuralleiste, Abb.1a). Die ANR sekretiert das Signalmolekül FGF8 (fibroblast growth factor oder Fibroblastenwachstumsfaktor 8). Die Bedeutung dieses Signalmoleküls wurde mit Hilfe von in utero Mikroelektroporationen untersucht. Eine Überexpression von FGF8 anterior vergrößert dort corticale Areale während posteriore Areale schrumpfen und mehr zum posterioren Pol des Cortex verschoben werden. Man hat dies mit Hilfe der Lage der "barrel fields" des somatosensorischen Cortex untersucht, die normalerweise zentral im Cortex lokalisiert sind. Bei FGF8Überexpression anterior bewegen sie sich in die posteriore Hälfte der Hemisphäre (Fukuchi-Shimogori und Grove, 2001). Vermutlich spielen noch andere Mitglieder der FGF-Familie wie z.B FGF17 und 18 bei der anterior-posterior Positionsinformation der corticalen Anlage eine Rolle (Grove und FukuchiShimogori, 2003).

Medial-laterale Musterbildung der corticalen Anlage durch ein mediales $\underline{\text { Signalzentrum }}$

Als ein zweites Signalzentrum wird die sog. "cortical hem" (embryonale Fimbria) betrachtet, die sich am medialen Rand des Cortex neben dem Hippocampus befindet (Abb.1a). In dieser Region werden verschiedene Mitglieder der Wnt- (benannt nach 
dem verwandten Drosophilaprotein "wingless") und Bmp- (bone morphogenetic protein) Familie exprimiert. Die Bedeutung von Signalen der "cortical hem" wurde durch Studien an Wnt3a-defizienten Mäusen deutlich, deren Hippocampus massiv reduziert war oder komplett fehlte (Lee et al., 2000). Das Wnt-Signal wird weitergeleitet über Transkriptionsfaktoren der TCF/LEF ( $\mathrm{T}$ cell factor/lymphoid enhancer factor)-Familie. Daher zeigt auch eine mutante Mauslinie mit einem Defekt des Transkriptionsfaktors LEF1 einen ähnlichen Phänotyp im Hippocampus (Galceran et al., 2000).

Bmp-Signale, sie gehören zur TGF (transforming growth factor) $\beta$-Superfamilie, sind an der Entwicklung des Epithels des Plexus choroideus, ein medialer Abkömmling des corticalen Neuroepithels, beteiligt. Fehlt Mäusen ein bestimmter Bmp-Rezeptor (BMPR1a), so ist das Plexusepithel dünn (Hebert et al., 2002).
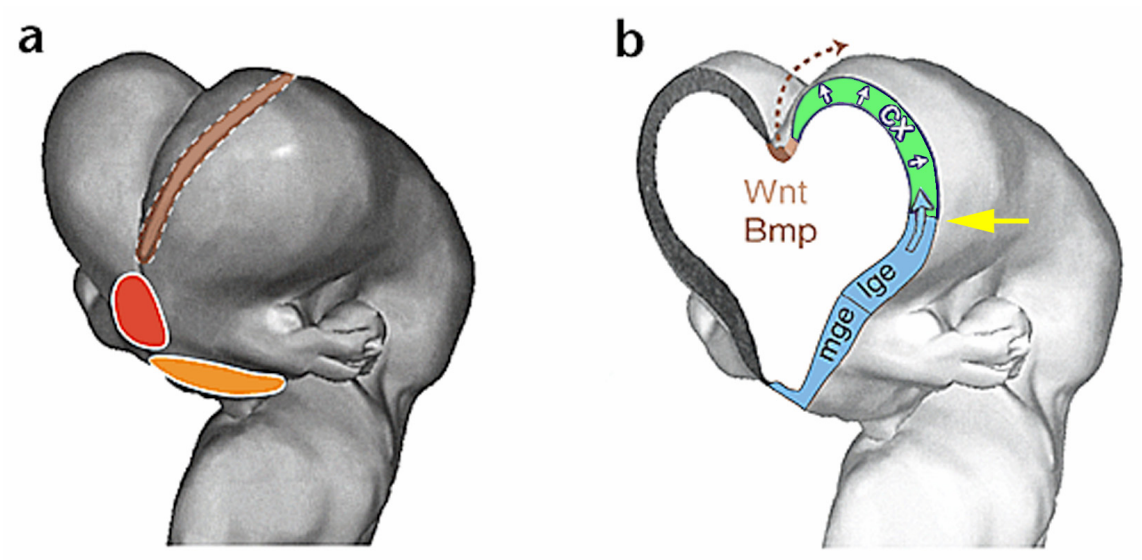

\begin{abstract}
Abb.1: Signalzentren der corticalen Ventrikulärzone
a: schematische 3-dimensionale Frontalsicht auf ein Telencephalon der Ratte (E13), eingezeichnet sind die Signalzentren: medial-ventrales Signalzentrum (orange), die "anterior neural ridge" (ANR, rot), die "cortical hem" (braun). Jedes Signalzentrum sekretiert Signalproteine: sonic hedgehog (medialventrales Signalzentrum), FGF8 (ANR), Proteine der Wnt- und Bmp-Familie werden von der "cortical hem" abgegeben.

b: schematische coronale Sicht auf ein Telencephalon der Ratte (E13): In braun sind die Signale der "cortical hem" (Wnt-und Bmp-Proteine) dargestellt, die auf die benachbarte corticale Ventrikulärzone wirken. Der grün dargestellte Bereich verweist auf corticale Vorläuferzellen, die eine "Protomap" bereitstellen. Diese wird radial in die äußeren corticalen Schichten übersetzt. Der hellblaue Pfeil stellt Neurone dar, die aus subcorticalen Bereichen in den Cortex migrieren und zusätzliche Positionsinformation mit sich bringen. Die Lage der "anti-hem", ein latereales Signalzentrum, wird durch den gelben Pfeil symbolisiert. (modifiziert nach (Monuki et al., 2001))
\end{abstract}

\title{
$\underline{\text { Signale der medialen ganglionären Eminenz }}$
}

Sonic hedgehog (shh) wird im medial-ventralen Bereich des Telenephalons exprimiert (Abb.1a) und gilt als sekretiertes Signalmolekül zur medial-ventralen Musterbildung im Telencephalon. Ein Verlust von shh bei Mäusen führt zu Holoprosencephalie 
(Chiang et al., 1996), eine Mißbildung des Gehirns, die durch eine fehlende Aufspaltung des Telencephalons in der Mitte in zwei Hemisphären gekennzeichnet ist. Dieser Phänotyp demonstriert, daß shh essentiell für die mediale Musterbildung des zentralen Nervensystems ist.

Die "anti-hem", ein laterales Signalzentrum

Forschungsergebnisse ließen die Existenz eines corticalen EGF (epidermal growth factor)-Signalzentrums vermuten, z. B. stellten in vitro Experimente eine Verbindung zwischen Mitgliedern der EGF-Familie und der Entwicklung des corticalen limbischen Systems her. In corticalen Zellen nicht limbischer Domänen wurde die LAMP-Expression als Reaktion auf einen EGF-Liganden (TGF $\alpha$ ) hochreguliert (Ferri und Levitt, 1995). Auch legt der Vergleich mit Drosophila die Existenz eines EGFSignalzentrums nahe. Hier kontrollieren die zwei EGF-Liganden "spitz" (TGF $\alpha$ ähnlich) und "vein" (entspricht der Neuregulin-Proteinfamilie der Vertebraten) die dorsal-ventral-Spezifzierung (Golembo et al., 1999). Die Expressionsstudie einiger Gene der EGF-Familie ergab ein Signalzentrum, das in der Ventrikulärzone gegenüber der "cortical hem" am lateralen Rand der corticalen Anlage liegt (Assimacopoulos et al., 2003). Wegen ihrer Lage wurde diese Region "anti-hem" benannt (Abb.1b) und wurde identifiziert durch die Expression der EGF-FamilienMitglieder TGF $\alpha$, Neuregulin1 und 3, durch die Expression von FGF7 und des WntAntagonisten Sfrp2 (secreted frizzled related sequence protein 2). In der Literatur kursieren auch andere Begriffe für diese Region. Da sie zwischen dem Neuroepithel des Striatums und des lateralen Palliums liegt (Abb. 2), wurde sie auch als "ventrales Pallium" bezeichnet (Puelles et al., 2000). Das ventrale Pallium stellt eine Grenze zwischen den beiden Hauptbestandteilen Pallium und Subpallium des embryonalen Telencephalons dar. Viele Transkriptionsfaktoren und regulatorische Moleküle halten in ihrem Expressionsmuster diese Grenze ein. Dlx2 (verwandt mit dem Drosophilagen distal-less) und Nkx2.1 gelten z.B als Marker des Subpalliums während die Gene Tbr1 und Emx1 im Pallium exprimiert werden. Ebenso wird der Transkriptionsfaktor Pax6 in der Ventrikulärzone des ventralen Palliums exprimiert (Stoykova et al., 2000), einige wenige Pax6-exprimierende Zellen finden sich auch in der Ventrikulärzone der lateralen ganglionären Eminenz (Subpallium). Da die Grenze zwischen Pallium und Subpallium von einigen Transkriptionsfaktoren respektiert 
wird, könnte sie daher eine biologische Funktion in der Regionalisierung des Telencephalons haben.

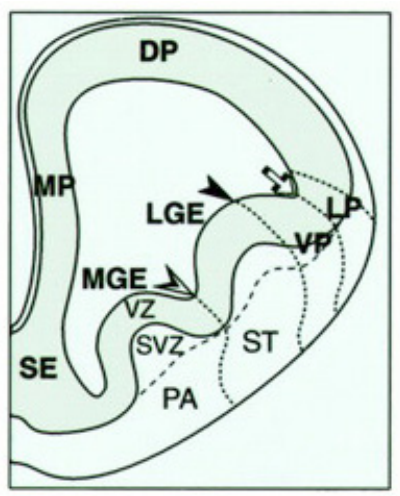

Abb.2: Das Schema einer Hemisphäre eines coronal geschnittenen Telencephalons $(E 12,5)$ zeigt die Lage des ventralen Palliums zwischen Striatum und lateralem Pallium.

Das ventrale Pallium gilt als Signalzentrum und als Quelle von Mitgliedern der EGF-Familie und des Wnt-Antagonisten Sfrp2.

$\mathrm{dp}$, dorsales Pallium; lge, laterale, ganglionäre Eminenz; lp, laterales Pallium; mge, mediale, ganglionäre Eminenz; mp, mediales Pallium; pa, Globus pallidus; se, Septum; svz, Subventrikulärzone; st, Striatum; vp, venrales Pallium; vz, Ventrikulärzone

Der weiße Pfeilkopf zeigt auf die Grenze zwischen medialer, ganglionärer Eminenz (Globus pallidus) und lateraler, ganglionärer Eminenz (Striatum). Die Grenze zwischen Pallium und Subpallium wird durch den schwarzen Pfeilkopf angedeutet. Der Pfeil gibt den corticostriatalen Sulcus an (Stoykova et al., 2000).

Das ventrale Pallium ist auch unter dem Begriff der "intermediate zone" (Intermediärzone) bekannt (Fernandez et al., 1998). Basierend auf der Expression der Homeobox-enthaltenden Gene der Emx-, Dlx- und Pax-Familie definierten Fernandez et al. eine Aufteilung des Telencephalons in Pallium, Intermediärzone und Subpallium. Diese Aufteilung findet sich in Maus-, Huhn-, Schildkröten- und Froschembryonen. Ebenso bestätigen andere Arbeiten die Existenz eines ventralen Palliums in Amphibien (Brox et al., 2004). Somit ist das Vorkommen des ventralen Palliums oder der Intermediärzone evolutionär konserviert.

Die eben vorgestellten verschiedenen Signalzentren verleihen durch Ausschüttung spezifischer Signalproteine jeder Region eine bestimmte Positionsinformation. Als Antwort auf diese unterschiedlichen Morphogenkonzentrationen werden regional Transkriptionsfaktoren und deren "downstream-Gene" exprimiert, wodurch die lokale regionenspezifische Differenzierung eines Gewebes entsteht. Im folgenden werden einige Transkriptionsfaktoren und ihre Bedeutung in der Musterbildung des Telencephalons vorgestellt. 


\section{Kontrolle der Arealisierung des cerebralen Cortex durch Transkriptionsfaktoren}

\section{$\underline{\text { Pax6 und Emx2 }}$}

Der Homeodomänen-enthaltende Transkriptionsfaktor Emx2 (ein Vertebratenhomolog des Drosophilagens "empty spiracles") und der paired-boxenthaltende Transkriptionsfaktor Pax6 (verwandt mit dem Drosophilagen "paired") werden in gegenläufigen Gradienten entlang der anterior-posterior-Achse der corticalen Anlage exprimiert. Emx2 kommt in der corticalen Ventrikulärzone in einem caudomedial (hoch)/ rostrolateral (niedrig)-Gradienten vor (Gulisano et al., 1996; Mallamaci et al., 1998), wogegen Pax6 dort in einem entgegengesetzten Gradienten (rostrolateral hoch/ caudomedial niedrig) vorliegt (Walther und Gruss, 1991; Stoykova und Gruss, 1994). Basierend auf diesen komplementären Expressionsmustern wurde vermutet, daß Emx2 corticalen Neuronen caudale und mediale Identität verleiht während Pax6 rostrale und laterale Eigenschaften vermittelt. In Emx2- und Pax6-Mutanten konnte an Hand von molekularen Markern eine gegensätzliche Disproportionierung der Arealisierung des Cortex demonstriert werden (Bishop et al., 2000). So waren rostrale Bereiche in Emx2-Mutanten vergrößert, caudale Areale dagegen waren geschrumpft. In der Pax6-Mutante wurde der komplementäre Effekt beobachtet. Wegen dieser Befunde wurde eine Kooperation der beiden Transkriptionsfaktoren Emx2 und Pax6 in der Regulation der corticalen Arealisierung vermutet (Bishop et al., 2000; Bishop et al., 2002). Es gibt allerdings keinen biochemischen Hinweis auf eine direkte Interaktion zwischen diesen beiden Proteinen. Ebenso scheint die Expression dieser beiden Gene nicht von demselben Signalmolekül kontrolliert zu sein. Beobachtungen sprechen für eine Kontrolle der graduellen Emx2-Expression durch FGF8 (Grove und Fukuchi-Shimogori, 2003). Eine Erhöhung der FGF8-Konzentration führt zu einer herunterregulierten Emx2Expression während umgekehrt ein Mangel an FGF8 die Emx2-Expression verstärkt. Neuere Befunde deuten auch auf eine Regulation der FGF8 und 17-Expression durch Emx2(Fukuchi-Shimogori und Grove, 2003). Dies würde eine antagonistische Beziehung zwichen Emx2 und FGF8 bedeuten und somit auch die klassische Sicht, daß Morphogene (z. B. FGF8) die Expression von Transkriptionsfaktoren (z. B. 
Emx2) beeinflussen, erweitern. Es wäre dann auch umgekehrt die Regulation eines Transkriptionsfaktors auf ein Signalzentrum denkbar. Eine Interaktion zwischen Pax6 und FGF8 wurde noch nicht identifiziert (Muzio et al., 2002; Garel et al., 2003).

Mäuse mit Mutationen in den Genen Emx2 und Pax6 sterben innerhalb weniger Stunden nach der Geburt (Hill et al., 1991; Pellegrini et al., 1996). Das Pax6-Gen spielt auch an anderen Stellen des zentralen Nervensystems eine entscheidende Rolle. Homozygote "Small eye" Mäuse besitzen eine Punktmutation im Pax6-Gen und zeigen neben den beschriebenen Defekten im Telencephalon ebenso Defekte im Auge, Cerebellum und Rückenmark.

\section{COUP-TFI (chick ovalbumin upstream transcription factor I)}

Dieser Transkriptionsfaktor gehört zur Familie der "orphan" Nuclearrezeptoren und wird in der Ventrikulärzone, der Sub- und Corticalplatte des Cortex in einem caudal (hoch)/ rostral (niedrig)-Gradienten exprimiert (Liu et al., 2000). COUP-TFIdefiziente Mäuse leben bis zur Geburt. In diesen Mäusen sind Gene, wie z. B. ROR $\beta$ (retinoic acid receptor-related orphan receptor $\beta$ ), Id2 und Cadherin8, die in der Corticalplatte graduelle Expressionsmuster besitzen, gleichmäßig exprimiert (Zhou et al., 2001). Dagegen ist die graduelle Expression von Pax6 und Emx2 in der Ventrikulärzone bei diesen Mutanten nicht betroffen. Dieses Ergebnis führte zu der Vermutung, daß COUP-TFI "downstream" von Pax6 und Emx2 auf die Regionalisierung des Cortex wirkt.

\section{Zielsetzung der Arbeit}

Die Existenz von corticalen Domänen, markiert durch LAMP, Latexin und H-2Z1Transgen, legt die Existenz noch weiterer corticale Areale nahe, deren Marker noch nicht identifiziert wurden. Im Zuge der Frage nach der Entstehung von definierten Arealen im Cortex wurde nach weiteren Transkriptionsfaktoren mit aneinandergrenzenden oder sich überlappenden Expressionsdomänen gesucht. Dennoch konnte die Frage, welche Gene bestimmte Areale in der "Protomap" definieren, nicht beantwortet werden. Ebenso sind die Verbindungen der bereits bekannten Faktoren untereinander wie z. B. Emx2, Pax6, COUP-TFI, FGF- und WntFamilienmitglieder noch nicht aufgeklärt. Ein wichtiger Schritt zur Bearbeitung dieser Fragen ist die Identifikation von neuen Transkriptionsfaktoren, die in die corticale 
Musterbildung und funktionelle Regionalisierung des cerebralen Cortex involviert sind. Dieses Ziel stand über einer großangelegten Suche nach neuen Genen basierend auf der "Affymetrix-Microarray-Expressions-Analyse", die in unserem Labor durchgeführt wurde. In die Expressions-Analyse wurden fünf verschiedene corticale Gewebe (Anlage des motorischen, visuellen und somatosensorischen Cortex, die Anlage des Hippocampus und des Cingulums) von drei embryonalen Entwicklungsstadien einbezogen. Mit der Wahl der Embryonalstadien sollten charakteristische Zeitpunkte der Corticogenese abgedeckt werden. So wurde der Zeitpunkt E14,5 ausgewählt, um Gene zu identifizieren, die für die Regionalisierung der frühen Corticalplatte zuständig sind. Mit dem Stadium E16,5 sollte ein Zeitpunkt abgedeckt werden, an dem der Einfluß einwachsender Axone aus dem Thalamus beginnt. Für die Analyse eines späteren Stadiums wurde E19,0 einbezogen. Dies ist der Zeitpunkt, an dem die thalamischen Axone die Corticalplatte erreichen und der Prozeß der funktionellen Arealisierung des Cortex abgeschlossen sein sollte.

Ich habe im Rahmen meiner Doktorarbeit die Microarray-Expressions-Analyse in Kollaboration mit einem weiteren Doktoranden zum Zeitpunkt E16,5 durchgeführt. Nach Auswertung der Daten sollten ausgewählte Kandidaten in ihrer regionenspezifischen Expression in einem "RNA-in situ-Hybridisierung-Screen" überprüft werden. Basierend auf diesen beiden Screens sollte ein neues Gen näher in seiner Expression und Funktion in der Corticogenese untersucht werden. Die funktionelle Analyse des Gens sollte mit dem "knock-out"-Ansatz geschehen. Dabei wird die Funktion eines Gens untersucht, indem man es gezielt ausschaltet und die mutierten Tiere mit Wildtyptieren vergleicht. 


\section{Materialien und Methoden}

\subsection{Organismen}

\section{Mäuse}

Für die vorliegende Arbeit wurde mit den Inzuchtstämmen C57 BL/6 und 129/Sv und den Auszuchtstämmen NMRI und CD1 gearbeitet. Zur Erzeugung von Embryonen wurden die Mäuse ü.N. verpaart und der Tag des Vaginalpfropfens als Tag 0,5 post coitum der Embryonalentwicklung (E0,5) gezählt. Der Tag der Geburt wurde als Tag 0 der postnatalen Entwicklung (P0) gezählt.

\section{Bakterien}

Transformationen wurden mit dem E. coli-Stamm DH5 $\alpha$ durchgeführt. Als Wirt für Phagen wurden die Bakterienstämme XL1-Blue MRA und MRF verwendet.

\section{Zellen}

Zur homologen Rekombination wurden die embryonalen Stammzellen der MPI II Linie verwendet (Doetschman et al., 1985). Sie entstammen dem Mausstamm 129/Sv.

\subsection{Materialien}

\section{Chemikalien}

Chemikalien wurden von den Firmen Sigma, Merck, Fluka, Roth, Invitrogen und Gibco Laboratories bezogen. Alle Chemikalien besaßen den Reinheitsgrad "p.a." (zur Analyse).

\section{Radiochemikalien}

Redivue ${ }^{32} \mathrm{P}-$ Nucleotide kamen von der Firma Amersham Biosciences. 


\section{Verbrauchsmaterial}

Das Plastikmaterial wurde von den Firmen Falcon, Greiner, Eppendorf, Sarstedt und Nunc bezogen.

\section{Enzyme}

Es wurden Enzyme der Firmen Roche, Promega, NEB und MBI Fermentas verwandt.

\section{Kits}

Es wurden folgende Kits benutzt:

\section{Kit}

Qiagen Plasmid Mini und Maxi Kit

Qiaquick Gel Extraction Kit

Oligotex Kit, Qiagen

RNeasy Total RNA Isolation kit

Super Script Choice system

BioArray High Yield RNA Transcript Labeling Kit

rediprime II, random prime labelling system

\author{
Hersteller \\ Qiagen \\ Qiagen \\ Qiagen \\ Qiagen \\ Gibco BRL \\ Enzo \\ Amersham Pharmacia Biotech
}

\section{DNA Bibliotheken}

genomisch: Lambda DASH II, Stratagene

cDNA: ZAP Express EcoRI, Mausembryo E10.5, Stratagene

\section{Vektoren}

pBluescript II KS+

Stratagene

pGEM-T-Easy

Promega

pKC414 (auf Bluescript-Basis mit LacZpA-pGKNeopA-Kassette)

pKC566 (auf pPolyIII-I-Basis mit $\beta$-Globin-Promotor und LaczpA-Kassette)

pCMV-EGFP

\section{Oligonucleotide}

Alle Primer wurden von der Firma IBA synthetisiert und sind hier in 5' $\rightarrow$ '-Richtung wiedergegeben.

zum Klonieren der 3 ' externen Sonde für den embryonalen Stammzell-Screen:

FK4: GTC TCT AGC TCT GGG TGC TAC AA

FK6: CAA CGT CTT TTC CTG TTG GAG T

für das Sequenzieren des Übergangs 5'-Homologie $\rightarrow$ LacZ:

FK7: ATC TAT CCA ATG GCA GTA TTG

zum Klonieren der 5 ' internen Sonde für den embryonalen Stammzell-Screen:

FK10: TCA ACT TGT GTC CCA GAG CTG 
FK11: AAC GTG GGC CAG ACG GGG G

zum Genotypisieren der knock-out Mäuse:

FK12: AAT TCT CTA GAG CTC GCT GAT CAG

FK 13: CAA AGC CAA ACT GGA TAC AGG AAA C

FK 14: CCT AAC TGT AGA ATG GGA ACG GTG

Oligonucleotide für LacZ-PCR:

FK15: TTG GCG TAA GTG AAG CGA C

FK16: AGC GGC TGA TGT TGA ACT G

Als Sequenzierprimer dienten T7-, T3 und Sp6-Primer.

\section{Größenmarker}

Für die DNA-Auftrennung wurden zwei verschiedene Größenmarker verwandt:

1 kb-Marker (Genecraft):

250 - $10000 \mathrm{bp}$

100 bp-Marker (Genecraft):

$100-1000 \mathrm{bp}$

Als Größenmarker für die RNA-Auftrennung wurde der RNA-Längenstandard II 1,5 -

$6,9 \mathrm{~kb}$ von Roche verwandt.

\section{Fotoarbeiten}

Die Fotos der Schnitte wurden digital mit dem Olympus-Binokular SZX12 und dem Olympus-Mikroskop BX60 aufgenommen ("AnalySIS" Software) und mit Hilfe des Bildbearbeitungsprogramms Adobe Photoshop 5.5 weiterbearbeitet.

\section{Programme zur Sequenzbearbeitung}

DNA-Sequenzbearbeitungen wurden mittels des Computerprogramms "Sequencher 3.0" der Firma Gene Codes und "BLAST" ("basic local alignment search tool") des "National Center for Biotechnology Information" (NCBI) (Altschul et al., 1997) durchgeführt. Für die Suche nach Proteindomänen wurde die Datenbank "InterPro" (Apweiler et al., 2000) des "European Bioinformatics Institute" benutzt. Das Sequenzalignment-Programm "Clustal W" (Thompson et al., 1994) des gleichen Instituts diente dem Vergleich von Proteinsequenzen. Mit dem Programm "MatInspector" (Quandt et al., 1995) wurden mögliche regulatorische Sequenzen nach Bindungsstellen für Transkriptionsfaktoren abgefragt. 


\section{in situ Hybridisierungssonden}

Für die aus der Microarray-Analyse ausgewählten Gene wurden für die Überprüfung in der in situ Hybridisierung folgende Klone des IMAGE Kosortiums benutzt:

\begin{tabular}{|c|c|}
\hline Affymetrix-Probenkennummer/ Annotation & $\underline{\text { IMAGE Klon }}$ \\
\hline 112175_at/ Tox & $5739675^{\prime}$ \\
\hline 108995_at & $12266935^{\prime}$ \\
\hline 107382_at & $3895805^{\prime}$ \\
\hline 116619_at/ Zfp 288 & $22361945^{\prime}$ \\
\hline 105572_at & $33288705^{\prime}$ \\
\hline 116382_at/ Nrp 2 & $34162265^{\prime}$ \\
\hline 117269_at/ Nef 3 & $3850635^{\prime}$ \\
\hline 116316_at & $8892325^{\prime}$ \\
\hline 116403_at/ Zic 5 & $6337403^{\prime}$ \\
\hline 100344_at & $7764435^{\prime}$ \\
\hline
\end{tabular}

Für die Expressionsanalyse des Maus-PIPPin-Gens wurde eine Sonde aus dem cDNA-Klon 116.2 subkloniert. Dazu wurde ein 520 bp großes XbaI-EcoRI-Fragment ausgeschnitten und mit pBluescript II KS+ ligiert. Die Sonde deckt den 3' nicht translatierten Bereich des Transkripts ab.

Die Sonde für das homologe PIPPin-Protein wurde aus dem IMAGE-Klon 5346967 5' erstellt.

Sonden für die Analyse der PIPPin-defizienten Maus:

Pax6: Plasmid-Nr.: 101106 der Plasmid Bibliothek unserer Abteilung (Walther und Gruss, 1991)

Nrg3: Klon 6811525 desIMAGE Konsortiums

Die folgenden Hybridisierungssonden wurden zur Verfügung gestellt:

Sfrp2 von A. Mallamaci (Muzio et al., 2002)

Nrg1 von CA. Ragsdale (Assimacopoulos et al., 2003)

Tgf $\alpha$ von JC Pascall (Vaughan et al., 1992)

Fgf7 von CA. Ragsdale (Assimacopoulos et al., 2003)

ER81 von V. Tarabykin (nicht publizierte Daten)

H1 ${ }^{\circ}$ von D. Doenecke (Schindehütte J, Dissertation 1998) 


\section{Antikörper}

\section{$\underline{\text { Primärantikörper }}$}

Der polyklonale anti-Maus-H1 ${ }^{\circ}$-Antikörper wurde von Prof. D. Doenecke zur Verfügung gestellt (Schindehütte J, Dissertation 1998).

Prof. I. Di Liegro schickte den anti-Ratte-PIPPin-Antikörper (Nastasi et al., 1999).

Die anti-Calbindin D-28K Immunfärbung wurde mit einem kommerziellen Mausantikörperder Firma Chemicon International durchgeführt.

$\underline{\text { Sekundärantikörper }}$

HRP-gekoppelter-Ziege-anti-Kaninchen-Antikörper (Dianova)

Alexa Fluor 488 Ziege-anti-Kaninchen-Antikörper (Dianova)

\section{Standardlösungen}

Alle Lösungen wurden mit Wasser angesetzt, welches über eine "Millipore-Anlage" gereinigt war. Danach wurden die Lösungen autoklaviert oder steril filtriert. Weitere Lösungen finden sich direkt bei der Beschreibung der entsprechenden Methode.

1x PBS-Puffer: $\mathrm{pH} 7,3$

$137 \mathrm{mM} \mathrm{NaCl}$

$2,7 \mathrm{mM} \mathrm{KCl}$

$4,3 \mathrm{mM} \mathrm{Na} \mathrm{HPO}_{4} \cdot 7 \mathrm{H}_{2} \mathrm{O}$

$1,4 \mathrm{mM} \mathrm{NaH}_{2} \mathrm{PO}_{4}$

Standard I-Nährbouillon (Merck) mit Ampicillin $(25 \mu \mathrm{g} / \mu \mathrm{l})$ als Selektionsmarker versetzt

20x SSC: $\mathrm{pH} 7,0$

$3 \mathrm{M} \mathrm{NaCl}$

0,3 M Tri-Natriumcitrat

TE-Puffer: $\mathrm{pH} 7,4$

$10 \mathrm{mM}$ Tris- $\mathrm{HCl}$

1 mM EDTA

(0,1 mM EDTA bei $0,1 \times$ TE) 


\section{Methoden}

\subsection{DNA}

\section{Isolierung von Plasmid-DNA aus Bakterien}

"QIAprep Miniprep" (Qiagen)

Nach dem Prinzip der alkalischen Lyse (Birnboim und Doly, 1979) werden mit diesem Kit kleine Mengen reiner Plasmid-DNA aus 5-7 ml E. coli-Kulturen gewonnen. Nach dem Lysieren der Bakterien folgt eine Affinitätsaufreinigung über eine Silikonmembran, die bei hohen Salzkonzentrationen DNA bindet und bei niedrigen eluiert. Die Zusammensetzungen und Verwendung der Puffer P1, P2, N3, $\mathrm{PB}, \mathrm{PE}$ und EB sind in den Herstellerangaben zu finden.

\section{"QIAfilter Plasmid Maxi Kit" (Qiagen)}

Zur Aufreinigung großer DNA-Mengen aus 100-200 ml Kulturen wurde der Maxiprep Kit verwendet. Er basiert ebenfalls auf der alkalischen Lyse der Bakterien, diesmal in Zusammenhang mit einer Anionen-Austauschersäule. Die Zusammensetzungen der Puffer P1, P2, P3, QBT, QC, QF und TE und ihr Einsatz sind in den Herstellerangaben zu finden.

\section{Konzentrationsbestimmung von Nucleinsäuren}

Die Ausbeuten von DNA und RNA wurden UV spektrophotometrisch bestimmt (Bio Photometer, Eppendorf). Dabei diente als Nullwert die Lösung, in der die Probe gelöst wurde z. B. 0,1x TE.

Bei besonders geringen Konzentrationen wurde der Gehalt durch einen optischen Vergleich der Ethidiumbromidfluoreszenz von Standard-DNA und Probe in Agarosegelen durchgeführt.

\section{Agarose-Gelelektrophorese}

Der aufzutrennenden Fragmentgröße entsprechend wurden 0,7-1,2\%-ige Agarosegele (in $0,5 \mathrm{x}$ TBE gelöst) mit $0,1 \mu \mathrm{g} / \mathrm{ml}$ Ethidiumbromid versetzt verwendet. Als 
Laufpuffer wurde 0,5x TBE benutzt. Vor dem Auftragen wurde die DNA mit Ladepuffer versetzt. Nach der Elektrophorese wurden die Gele bei kurzwelligem UVLicht $(285 \mathrm{~nm})$ fotografiert. Präparative Gele wurden zur Vermeidung von Strangbrüchen nur energieärmerem, langwelligem UV-Licht (366 nm) ausgesetzt.

1xTBE Elektorphoresepuffer:

89 mM Tris-Cl

89 mM Borsäure

2 mM EDTA, pH 8,0

Ladepuffer, 6x Ficoll Blue Juice:

$15 \%$ Ficoll 400

$60 \mathrm{mM}$ EDTA pH 8,0

$0,01 \%$ Bromphenolblau

$0,03 \%$ Xylencyanol

\section{Verdau von DNA mit Restriktionsendonucleasen}

Das enzymatische Schneiden von DNA wurde nach den Angaben des Enzymherstellers durchgeführt.

DNA in 0,1xTE (je nach Anwendung 0,2-25 $\mu \mathrm{g}$ )

10x Restriktionsendonuclease-Puffer

Restriktionsendonuclease (1-2 Units)

\section{Aufreinigung von DNA-Fragmenten aus Agarosegelen mit dem "Qiaquick Gel Extraction Kit"}

Hierbei wird ebenfalls die DNA bei hohen Salzkonzentrationen an eine Silikon-GelMembran gebunden während Kontaminationen weggewaschen werden. Die Elution der DNA erfolgt bei niedrigen Salzkonzentrationen. Die Zusammensetzung der Puffer und ihre Verwendung sind in den Herstellerangaben zu finden.

\section{Aufreinigen von DNA durch Phenol-Chloroform-Extraktion}

Es wurde $\mathrm{zu}$ einem Volumen einer wässrigen DNA-Lösung ein Volumen einer Phenol/ Chloroform/ Isoamylalkohol-Mischung (25:24:1) gegeben, kurz auf dem Vortexer gemischt und zur Phasentrennung bei RT 5 min. zentrifugiert (13 $000 \mathrm{rpm}$ ). Die DNA enthaltende, obere, wässrige Phase wurde abgenommen und in ein neues Röhrchen gegeben. Je nach benötigtem Reinheitsgrad der DNA wurde der Vorgang wiederholt. Um Phenolrückstände zu beseitigen, wurde eine weitere Extraktion mit Choloroform durchgeführt. 


\section{Fällung von DNA}

Zu der DNA-Lösung wurden 1/ 10 des Volumens 3 M Natriumacetat (pH 5) und 2,25 Volumina absoluten Ethanols zugegeben und gemischt. Die Fällung erfolgte für 30-60 min. bei $-20^{\circ} \mathrm{C}$. Anschließend wurde die DNA durch Zentrifugation (5 min., 13000 rpm) sedimentiert. Nach Abnahme des Überstandes wurde die DNA mit 70\%-igem Ethanol gewaschen, das Pellet getrocknet und die DNA in 0,1x TE gelöst.

Bei der Isopropanolfällung wurden 0,7 Volumina Isopropanol zur DNA-Lösung zugegeben. Weiter wurde wie bei der Ethanolfällung verfahren.

\section{Ligation von DNA-Fragmenten}

Ligationen wurden mit 50-100 ng Vektor und dem 3-fachen molaren Überschuß des entsprechenden Inserts in Ligase-Puffer und $1 \mathrm{U}$ T4-DNA-Ligase angesetzt. Der Ligationsansatz wurde ü.N. bei RT inkubiert und anschließend in E. coli transformiert.

10x Ligasepuffer:

$660 \mathrm{mM}$ Tris- $\mathrm{HCl}, \mathrm{pH}$ 7,5

$50 \mathrm{mM} \mathrm{MgCl}{ }_{2}$

$10 \mathrm{mM}$ Dithioerythrit (DTT)

$10 \mathrm{mM}$ ATP

\section{"blunt end"-Klonierung}

Bei Klonierung von DNA-Fragmenten mit überhängenden (sticky) Enden in einen Vektor mit glatten (blunt) Enden wurden 5'-Überhänge mit dem Klenow-Fragment der DNA-Polymerase I und einem Nukleotidmix aufgefüllt. 3'-Überhänge wurden mit Hilfe der T4-Polymerase abgebaut. Um die Enzyme wieder zu entfernen, folgte eine Phe/ Chl-Extraktion und die Fällung der DNA.

\section{Alkalische Phosphatase-Behandlung von Vektoren mit überhängenden Enden}

Zur Dephosphorylierung des Vektors wurden etwa $2 \mu \mathrm{g}$ Vektor, 10x Dephosphorylierungspuffer, 1 U SAP (alkalische Phosphatase, Shrimp) mit 0,1x TE auf $50 \mu \mathrm{l}$ aufgefüllt und für $30 \mathrm{~min}$. bei $37^{\circ} \mathrm{C}$ inkubiert. Nach erneuter Zugabe von 1 
U SAP und weiteren $30 \mathrm{~min}$. bei $37^{\circ} \mathrm{C}$ erfolgte eine Phe/ Chl-Extraktion und die Fällung des Vektors.

10x Dephosphorylierungspuffer:

0,5 M Tris- $\mathrm{HCl}, \mathrm{pH} 8,5$

$50 \mathrm{mM} \mathrm{MgCl} 2$

$\underline{\text { Klonierung der Konstrukte für die Analyse der regulatorischen Elemente des Maus- }}$ $\underline{\text { PIPPin-Gens }}$

Als Vektor für alle Konstrukte wurde pKC566 benutzt, der auf dem pPolyIII-I Klonierungsvektor (Lathe et al., 1987) basiert und mit einem schwachen $\beta$-GlobinPromotor und dem Gen für die $\beta$-Galactosidase (Pfeffer et al., 2000) modifiziert wurde. Die Klonierungen wurden alle mit einem HindIII-blunt-Vektor durchgeführt. $p F K 35$

Das 3,5 kb große Fragment wurde XhoI-HindIII-blunt in obigen Vektor kloniert. pFK36 sense / antisense

Dieses 1,7 kb-Fragment wurde XbaI-HindIII-blunt kloniert. pFK37

$0,7 \mathrm{~kb}, \mathrm{XbaI}-\mathrm{NdeI}-B$ luntklonierung

pFK38

NdeI-HindIII-Bluntklonierung $(1 \mathrm{~kb})$

\section{Transformation von Bakterien}

$\underline{\text { Herstellung elektrokompetenter Bakterien }}$

Hierfür wurde von einer Einzelkolonie E. coli (DH5 $\alpha)$ ausgehend eine $50 \mathrm{ml}$ ü.N.Kultur hergestellt. Davon wurde am nächsten Tag mit $5 \mathrm{ml}$ eine $500 \mathrm{ml}-\mathrm{Kultur}$ angeimpft und bei $37^{\circ} \mathrm{C}$ geschüttelt bis eine $\mathrm{OD}_{600}$ von $0,45-0,6$ erreicht wurde. Nach einer 10 minütigen Inkubation auf Eis wurden die Bakterien durch Zentrifugation (10min., $\left.4^{\circ} \mathrm{C}, 3600 \mathrm{rpm}\right)$ pelletiert. Die Bakterien wurden dann in kaltem sterilem Wasser resuspendiert und erneut zentrifugiert. Es folgte ein weiterer Waschschritt, bei dem die Bakterien mit 10\% Glycerin resuspendiert wurden. Nach einem weiteren Zentrifugationsschritt wurde das Bakterienpellet in $2-3 \mathrm{ml} 10 \%$ Glycerin resuspendiert und $\mathrm{zu} 100 \mu \mathrm{l}$ aliquotiert. Nach schnellem Einfrieren wurden die Bakterien bei $-80^{\circ} \mathrm{C}$ gelagert. 
$\underline{\text { Transformation durch Elektroporation }}$

Die kompetenten Bakterien wurden auf Eis aufgetaut und mit $1 \mu$ l Ligationsansatz gemischt. Nach Überführen des Ansatzes in eine kalte Elektroporationsküvette (BIORAD Gene Pulser Cuvette, 0,1 cm Elektrodenabstand) erfolgte die Elektroporation bei $1,8 \mathrm{kV}, 25 \mu \mathrm{FD}$ und $200 \Omega$ am Pulse Controller (BIO-RAD). Schnell wurde $1 \mathrm{ml}$ erwärmtes $\left(37^{\circ} \mathrm{C}\right) \mathrm{STI}$ zugegeben, die Bakterienlösung in ein steriles Reaktionsgefäß überführt und bei $37^{\circ} \mathrm{C}$ unter Schütteln für eine Stunde inkubiert. Dann wurden die Bakterien auf Selektivagar ausplattiert.

\section{Durchmustern einer cDNA- oder genomischen Maus-DNA- Bibliothek nach rekombinanten Bakteriophagen und deren Isolierung}

Vorbehandlung der Wirtsbakterien

Von dem Bakterienstamm XL1-Blue MRA (genomische Bibliothek) bzw. XL1-Blue MRF (cDNA-Bibliothek) wurde mit einer Einzelkolonie eine $50 \mathrm{ml}$ STI/ 1\% MaltoseKultur angeimpft. Am nächsten Tag wurden die Bakterien pelletiert (3000 rpm, 10, min, $4^{\circ} \mathrm{C}$ ) und anschließend in $25 \mathrm{ml} 10 \mathrm{mM} \mathrm{MgS0}_{4}$ resuspendiert. Die Bakterien wurden bei $4^{\circ} \mathrm{C}$ gelagert und blieben etwa 1 Woche für die Infektion mit LambdaPhagen kompetent.

\section{Titerbestimmung einer Phagenbibliothek}

Hierzu wurde ausgehend von einer 1:1000 Verdünnung der Bibliothek eine Verdünnungsreihe in SM-Puffer angesetzt. Diese Reihe umfaßte vier Verdünnungen von 1:10 $-1: 10^{7}$. Aus der Anzahl der Plaques ließ sich die Zahl der infizierenden Phagen pro ml berechnen. Pro Platte wurden 150000 pfu benötigt.

SM:

$0,1 \mathrm{M} \mathrm{NaCl}$

$8 \mathrm{mM} \mathrm{MgSO}_{4}$

0,05 M Tris-Cl, $\mathrm{pH} 7,5$

$0,01 \%$ Gelatine

\section{Ausplattieren der Phagenbibliothek}

Die Phagen wurden auf $24 \times 24 \mathrm{~cm}$ großen Platten (STI mit 1,5\% Bactoagar) ausplattiert. Dazu wurden die Phagen mit der berechneten Verdünnung für 15 min. 
bei $37^{\circ} \mathrm{C}$ mit je $200 \mu \mathrm{l}$ Bakterien inkubiert, mit Topagarose gemischt und auf die vorgewärmten Agarplatten plattiert. Nach Erstarren der Topagarose wurden die Platten umgekehrt für ca. $10-12 \mathrm{~h}$ bei $37^{\circ} \mathrm{C}$ inkubiert. Anschließend wurden die Platten bei $4^{\circ} \mathrm{C}$ gelagert.

Topagarose:

STI mit $0,7 \%$ Agarose

Transfer der Phagen auf Nylon-Filter und Hybridisierung

Die Filter (NEN, GeneScreen Hybridization Transfer Membrane) wurden beschriftet und für etwa 1 min. auf den Phagenrasen gelegt. Anschließend wurden die Filter mit der DNA-Seite nach oben in folgenden Bädern für 1 min. benetzt:

Denaturieren: $0,2 \mathrm{M} \mathrm{NaOH}, 1,5 \mathrm{M} \mathrm{NaCl}$

Neutralisieren: 0,4 M Tris-Cl, $\mathrm{pH} 7,6,2 \mathrm{xSSC}$

Äquilibrieren: 2xSSC

Nachdem die Filter luftgetrocknet waren, wurden sie für $2 \mathrm{~h}$ bei $80^{\circ} \mathrm{C}$ gebacken.

Zur Prähybridisierung wurden die Filter für $30 \mathrm{~min}$. bei $42^{\circ} \mathrm{C}$ mit $2 \mathrm{xSSC} / 0,5 \% \mathrm{SDS}$ inkubiert, anschließend für 1-2 h in Hybridisierungslösung. Dann wurde ü.N mit einer radioaktiv markierten Sonde hybridisiert (s. Hybridisierung Southern Blot). Es folgte die Posthybridisierung, bei der die Filter gewaschen wurden: viermal $15 \mathrm{~min}$. bei $65^{\circ} \mathrm{C}$ mit $2 \mathrm{xSSC} / 0,5 \%$ SDS und einmal $30 \mathrm{~min}$ bei $65^{\circ} \mathrm{C}$. mit $0,2 \mathrm{xSSC} / 0,5 \%$ SDS. Zur Auswertung der Hybridisierung wurden Röntgenfilmen (Biomax, Kodak) die Filter für etwa 3-4 Tage bei $-70^{\circ} \mathrm{C}$ exponiert.

HybridisierungslösungI: für 11

Formamid $480 \mathrm{ml}$

20xSSC 240ml

2 M Tris-Cl, $\mathrm{pH} 7,6 \quad 10 \mathrm{ml}$

100x Denhardt Lösung $10 \mathrm{ml}$

deion. Wasser $\quad 50 \mathrm{ml}$

$50 \%$ Dextransulfat $\quad 200 \mathrm{ml}$

$10 \%$ SDS $\quad 10 \mathrm{ml}$

Heringspermium DNA

$(5 \mathrm{mg} / \mathrm{ml}) \quad 200 \mu \mathrm{l}$

100x Denhardt:

2\% Ficoll 400

2\% Polyvinylpyrrolidon

$20 \mathrm{mg} / \mathrm{ml} \mathrm{BSA}$ 


\section{Aufreinigen positiver Phagen und Anlegen eines Phagenstocks}

Positive Phagen-Plaques wurden gepickt und in $1 \mathrm{ml}$ SM und einem Tropfen Chloroform für mehrere Stunden bei RT unter Schütteln zur Elution der Phagen inkubiert. Zur Vereinzelung der Phagen wurde erneut in verschiedenen Verdünnungen auf kleine Platten ausplattiert, Filter abgezogen, hybridisiert und positive Einzelplaques gepickt. Die Phagen wurden wieder in SM mit Chloroform eluiert, auf diese Weise entstand eine hochkonzentrierte Lösung (high titer stock) der isolierten Phagen. Die Phagenüberstände wurden bei $4^{\circ} \mathrm{C}$ gelagert.

\section{DNA-Isolierung aus Lambda-Phagen (Plattenlysat-Methode)}

Der entsprechende Phagenklon wurde auf einer $14 \mathrm{~cm}$ Petrischale (STI mit 1,5\% Agarose) ausplattiert. Anschließend wurden die Phagen mit $10 \mathrm{ml}$ SM und einigen Tropfen Chloroform für $1-2 \mathrm{~h}$ bei $37^{\circ} \mathrm{C}$ von der Platte gewaschen. Nach Transfer dieses Lysats in $50 \mathrm{ml}$ Röhrchen und Zentrifugation (10 min., $7000 \mathrm{rpm}, 4^{\circ} \mathrm{C}$ ) wurde der Überstand für 30 min bei $37^{\circ} \mathrm{C}$ mit RNaseA und DNase (Endkonzentrationen jeweils $1 \mu \mathrm{g} / \mathrm{ml}$ ) unter Schütteln inkubiert. Danach wurde der Überstand mit einem Volumen 20\% Polyethylenglycol-6000/ $2 \mathrm{M} \mathrm{NaCl}$ für $1 \mathrm{~h}$ auf Eis präzipitiert. Die Phagen wurden pelletiert (20 min, $7000 \mathrm{rpm}, 4^{\circ} \mathrm{C}$ ) in $0,5 \mathrm{ml} \mathrm{SM}$ gelöst und einmal nachgewaschen. Nach 15 minütiger Inkubation bei $68^{\circ} \mathrm{C}$ in $10 \%$ SDS und $0,5 \mathrm{M}$ EDTA folgte eine Phe-Extraktion, eine Phe/ Chl-Extraktion und eine Chl-Extraktion. Die Phagen-DNA wurde gefällt, gewaschen und schließlich für eine Stunde bei $60^{\circ} \mathrm{C}$ in $0,1 \times$ TE gelöst.

\section{Genotypisieren}

Präparation genomischer Maus DNA

Das Gewebe, etwa 0,5-1 cm Schwanzspitze oder ES-Zellen, wurde in $500 \mu \mathrm{l}$ Lysepuffer mit $20 \mu \mathrm{l}$ Proteinase K $(10 \mathrm{mg} / \mathrm{ml})$ gegeben und schüttelnd ü.N. bei $56^{\circ} \mathrm{C}$ inkubiert. Die unverdauten Knochen und Haare wurden am nächsten Tag abzentrifugiert und der Überstand über Phe/ Chl-Extraktion gereinigt. Die DNA wurde gefällt, einmal mit 70\% EtOH gewaschen und in $200 \mu 10,1 \times$ TE für $1-2 \mathrm{~h}$ bei $60^{\circ}$ Cgelöst. 
Lysepuffer:

$200 \mathrm{mM} \mathrm{NaCl}$

$100 \mathrm{mM}$ Tris-Cl, $\mathrm{pH} 8,5$

5 mM EDTA

$0,2 \%$ SDS

\section{$\underline{\text { Polymerase-Kettenreaktion (PCR) }}$}

Alle PCR-Reaktionen fanden in einem "PTC-200, Peltier Thermal Cycler" statt. Für eine PCR-Analyse wurde von nach obigem Protokoll isolierter DNA 0,5 $\mu 1$ eingesetzt. Zum Genotypisieren der Pippin-knock-out Mäuse wurden die Oligonucleotide FK12, 13 und FK 14 eingesetzt. Dabei diente FK12 zur Detektion der Neomycin-Resistenz, FK13 erkannte den Bereich der 3'-Homologie des Pippin-knock-out Konstrukts und FK14 den Deletionsbereich.

Beispiel für einen Reaktionsansatz: Gesamtvolumen $30 \mu \mathrm{l}$

$3 \mu \mathrm{l}$ 10x Reaktionspuffer (Genecraft)

$1,2 \mu \mathrm{l} \mathrm{MgCl}_{2}$ (50 mM, Genecraft)

$0,3 \mu \mathrm{l}$ dNTP Mix (je $20 \mathrm{mM}$, Genecraft)

$0,075 \mu \mathrm{l}$ Primer $(0,1 \mathrm{nmol} / \mu \mathrm{l})$

$0,5 \mu$ DNA-Matrize

$0,15 \mu \mathrm{l}$ Taq-Polymerase (5U/ $\mu \mathrm{l}$, Genecraft)

$\mathrm{x} \mu \mathrm{l}$ Wasser

10x Reaktionspuffer:

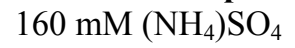

$670 \mathrm{mM}$ Tris-HCl, $\mathrm{pH} \mathrm{8,8}$

$0,1 \%$ Tween 20

Reaktionsbedingungen:

1. Schritt: $\quad 95^{\circ} \mathrm{C} \quad 4^{\prime}$

2. Schritt $\quad 95^{\circ} \mathrm{C} \quad 30^{\prime \prime}$

3. Schritt $65^{\circ} \mathrm{C} \quad 30^{\prime \prime}$

4.Schritt $72^{\circ} \mathrm{C} \quad 40^{\prime \prime}$

5. Schritt: Schritte 2-4 29 mal wiederholen

6. Schritt: $\quad 4^{\circ} \mathrm{C}$ Temperatur halten

\section{$\underline{\text { Southern Blot }}$}

Die mit Restriktionsenzymen geschnittene DNA wurde im Agarosegel aufgetrennt, gefärbt und mit einem Lineal fotografiert. Das Gel wurde dann für $15 \min$ in 0,25 M $\mathrm{HCl}$ gewaschen, kurz mit MQ-Wasser gespült und anschließend für 40 min in 1,5 M $\mathrm{NaCl} / 0,5 \mathrm{M} \mathrm{NaOH}$ denaturiert. Nach kurzem Spülen folgte die Neutralisierung für 40 min in $1 \mathrm{M}$ Tris-HCl/ 1,5 M NaCl. Zum Blotten wurde der Aufbau nach Southern verwendet. Als Transferpuffer diente 20xSSC, transferriert wurde für zwei Tage. Anschließend wurde die DNA durch Bestrahlung mit langwelligem UV-Licht (312 $\mathrm{nm} ; 0,3 \mathrm{~J} / \mathrm{cm}^{2}$ ) und zweistündigem Backen bei $80^{\circ} \mathrm{C}$ auf der Membran ("Qiabrane", Qiagen) kovalent fixiert. 


\section{Radioaktive Markierung von DNA-Sonden}

Die radioaktive Markierung von DNA-Fragmenten erfolgte nach dem "rediprime II, random prime labelling system" (Amersham Pharmacia Biotech) nach Herstellerangaben. Nicht inkorporierte Nuceotide wurden über G-50-Mikrosäulen (Sephadex G-50 Probe Quant, Pharmacia) nach Anleitung entfernt. Um die Qualität der Sonde zu messen, wurde $1 \mu \mathrm{l}$ vom Säulendurchfluß für eine Szintillationszählung eingesetzt. $1 \mu 1$ sollte ein Signal von 400 000-700 $000 \mathrm{cpm}$ liefern.

\section{$\underline{\text { Hybridisierung der Membranen }}$}

Alle Schritte erfolgten in Hybridisierungsflaschen, die bei $65^{\circ} \mathrm{C}$ kontinuierlich gedreht wurden. Zunächst wurden die Membranen für $1 \mathrm{~h}$ in $2 \mathrm{xSSC} / 0,5 \% \mathrm{SDS}$, dann für 1-2 h in Hybridisierungslösung prähybridisiert. Die markierte Sonde und $100 \mu \mathrm{g} /$ ml Heringsspermium-DNA wurden für $5 \mathrm{~min}$. bei $95^{\circ} \mathrm{C}$ denaturiert, $5 \mathrm{~min}$ auf Eis inkubiert und mit der Hybridisierungslösung auf die Membran gegeben. Es wurde ü.N. hybridisiert. Am nächsten Tag wurde zweimal für 30 min. mit 2xSSC/ 0,5\% SDS und einmal 30 min. mit 0,2xSSC/ 0,5\% SDS gewaschen. Die Exposition erfolgte für ein bis drei Tage mit einem Biomax-Film bei $-70^{\circ} \mathrm{C}$.

Hybridisierungslösung:

6xSSC

0,01 M EDTA

$5 x$ Denhardt Lösung

$0,5 \% \mathrm{SDS}$

\subsection{RNA}

Bei allen Arbeiten mit RNA wurden Handschuhe getragen, das Wasser für alle Lösungen wurde mit 0,1\% DEPC versetzt und alle Lösungen wurden zusätzlich autoklaviert. Die Arbeitsfläche wurde mit Ethanol gereinigt, Elektrophoresezubehör wurde in $0,5 \%$ SDS eingeweicht und anschließend mit DEPC-Wasser gespült. Frisch präpariertes Gewebe wurde in flüssigem Stickstoff eingefroren und bei $-70^{\circ} \mathrm{C}$ aufbewahrt. 


\section{Isolierung von Gesamt-RNA mit TRIzol}

Das Gewebe wurde in TRIzol (LIFE TECHNOLOGIES) homogenisiert, wobei für 50-100 mg Gewebe $1 \mathrm{ml}$ TRIzol eingesetzt wurde. Das Homogenat wurde zentrifugiert (10 min., $12000 \mathrm{rpm}, 4^{\circ} \mathrm{C}$ ), der Überstand wurde abgenommen und für 5 min. bei RT inkubiert. Nach Zugabe von 0,2 $\mathrm{ml}$ Chloroform pro $\mathrm{ml}$ TRIzol wurde das Röhrchen kurz geschüttelt, 2-3 min. bei RT inkubiert und schließlich zur Phasentrennung zentrifugiert (15 min., $12000 \mathrm{rpm}, 4^{\circ} \mathrm{C}$ ). Der Überstand wurde abgenommen und die RNA mit Isopropanol gefällt. Nachdem die RNA einmal gewaschen wurde, wurde das Pellet getrocknet und in DEPC-Wasser für $10 \mathrm{~min}$. bei $60^{\circ} \mathrm{C}$ gelöst.

\section{Isolierung von Gesamt-RNA mit RNeasy Total RNA Isolation Kit (Qiagen)}

Hierfür wurde das Protokoll für Tiergewebe nach den Angaben des Herstellers durchgeführt.

\section{Aufreinigung von poly $\mathrm{A}^{+}$RNA aus Gesamt-RNA (Oligotex Kit, Qiagen)}

Die Isolierung von poly $\mathrm{A}^{+} \mathrm{RNA}$ erfolgte nach Herstellerangaben.

\section{Northern Blot}

Die RNA (etwa 4-6 $\mu$ g poly $\mathrm{A}^{+}$oder $10 \mu \mathrm{g}$ total RNA/ Geltasche) wurde in einem 1,2\%-igen denaturierenden Agarose/ Formaldehydgel aufgetrennt. Als Laufpuffer wurde 1x MOPS-Puffer verwendet. Für die Probendenaturierung wurden pro Probe $5 \mu \mathrm{l}$ 10x MOPS-Puffer, 8,75 $\mu 1$ 37\% Formaldehyd, $25 \mu$ l Formamid und 11,25 $\mu 1$ RNA (+ evtl. DEPC-Wasser) gemischt und für 5 min. bei $60^{\circ} \mathrm{C}$ inkubiert. Nach Zugabe von $10 \mu \mathrm{l}$ Ladepuffer wurde das Gel beladen und mit $75 \mathrm{~V}$ für 3-4 h laufen gelassen bis die Bromphenolblau-Bande 2/ 3 des Gels durchlaufen hatte. Danach wurde der Bereich des Gels, der den Längenstandard enthielt, abgetrennt, mit EtBr gefärbt und mit einem Lineal fotografiert.

Der Aufbau des Northern Blots entspricht dem des Southern Blots. Die RNA wurde ebenfalls über zwei Tage auf eine Membran transferriert. Es folgte der Blotabbau, das 
Markieren der Geltaschen auf der Membran und zweistündiges Backen bei $80^{\circ} \mathrm{C}$, um die RNA auf der Membran kovalent zuf ixieren.

Prähybridisierung, Hybridisierung und Waschschritte wurden in rotierenden Hybridisierungsflaschen in Wärmeschränken entsprechend der Hybridisierung von DNA-Blots durchgeführt.

Prähybridisierung: $60^{\circ} \mathrm{C}$

30 min., $2 x \mathrm{SSC} / 0,5 \%$ SDS

1-2 h Hybridisierungspuffer

Hybridisierung: $42^{\circ} \mathrm{C}$, ü.N.

aufgekochte, radioaktiv markierte Sonde mit aufgekochter Heringsspermium-DNA (Endkonz. $50 \mu \mathrm{g} /$ $\mathrm{ml}$ )

Waschen: $60^{\circ} \mathrm{C}$

zweimal 30 min. $2 x \mathrm{SSC} / 0,5 \% \mathrm{SDS}$

einmal $30 \mathrm{~min} .0,1 \mathrm{xSSC} / 0,5 \% \mathrm{SDS}$

Als Filmmaterial wurden auch hier Biomax-Filme benutzt, die Exposition erfolgte bei $-70^{\circ} \mathrm{C}$.

10x MOPS-Puffer:

$0,2 \mathrm{M}$ MOPS

$0,5 \mathrm{M}$ Natriumacetat

0,01 M EDTA

Ladepuffer:

1 mM EDTA

$0,25 \%$ Bromphenolblau

$0,25 \%$ Xylencyanol

$50 \%$ Glycerin

Northern Blot Hybridisierungslösung:

$25 \mathrm{mM} \mathrm{KPO}_{4}, \mathrm{pH} 7,4$

$5 \mathrm{xSSC}$

5x Denhardt Lösung

$50 \%$ Formamid

mRNA in situ-Hybridisierung auf Cryoschnitten mit Digoxigenin (DIG)-markierten RNA-Sonden

Herstellung von linearisierter DNA als Matrize für die in vitro Transkription

Restriktionsansatz: Gesamtvolumen $100 \mu \mathrm{l}$

25-30 $\mu \mathrm{g}$ DNA

20 U Enzym

$10 \mu l$ Restriktionspuffer

$\mathrm{x} \mu \mathrm{l} 0,1 \mathrm{x}$ TE

Nach 2-3 h Inkubation bei $37^{\circ} \mathrm{C}$ wurde der Verdau im Gel auf Vollständigkeit mit unverdauter DNA als Kontrolle kontrolliert. Bei unvollständiger Linearisierung 
wurden erneut 10 U Enzym zugefügt. Nach vollständiger Linearisierung des Plasmids erfolgte eine Phe/ Chl-Extraktion und die Präzipitation der DNA. Das Pellet wurde je nach Größe in 10-20 $\mu$ 1 DEPC-Wasser aufgenommen.

$\underline{\text { In vitro Transkriptionsreaktion zur Synthese von RNA-Sonden }}$

Reaktionsansatz: Gesamtvolumen $20 \mu \mathrm{l}$

$1 \mu \mathrm{g}$ DNA-Matrize

$2 \mu \mathrm{l}$ 10x Transkriptionpuffer (Roche)

$2 \mu 1$ 10x DIG RNA Markierungsmix (Roche)

$0,5 \mu \mathrm{l}$ Rasin (40 U/ $\mu$ l, Promega)

$1 \mu \mathrm{l}$ T3, T7 oder Sp6 RNA Polymerase (Roche, $20 \mathrm{U} / \mu \mathrm{l}$ ), je nach Plasmid

$\mathrm{x} \mu \mathrm{l}$ Wasser

10x Transkriptionspuffer:

0,4 M Tris- $\mathrm{HCl}, \mathrm{pH} 8,0$

$60 \mathrm{mM} \mathrm{MgCl} 2$

$100 \mathrm{mM}$ DTT

$20 \mathrm{mM}$ Spermidin

Der Transkriptionsansatz wurde für $2 \mathrm{~h}$ Stunden bei $37^{\circ} \mathrm{C}$ inkubiert gefolgt von einem 15 minütigen DNase-Verdau bei $37^{\circ} \mathrm{C}$ (Zugabe von $20 \mathrm{U} / \mu 1$, Promega). Danach wurde die RNA durch Zugabe von $100 \mu \mathrm{TE}(\mathrm{pH}$ 8), $10 \mu \mathrm{l} 4 \mathrm{M} \mathrm{LiCl}$ und $300 \mu 1$ absolutem Ethanol für $2 \mathrm{~h}$ bei $-20^{\circ} \mathrm{C}$ gefällt. Nach einmaligem Waschen wurde die RNA in $100 \mu 1$ TE gelöst und im Agarosegel auf ihre Integrität hin überprüft.

\section{Behandlung der Schnitte}

Zunächst wurden die $18 \mu \mathrm{m}$ dicken Schnitte (zur Erstellung s. 2.4 Histologie) auf RT gebracht. Nach der Umrandung mit einem hitzebeständigen Stift ("ImmEdge Pen", Vector) durchliefen sie die folgenden Schritte:

\section{Tag:}

15 min. Fixierung in $4 \%$ PFA in PBS

$2 \mathrm{x} 5 \mathrm{~min}$. PBS

4-5 min. Proteinase $\mathrm{K}(20 \mu \mathrm{g} / \mathrm{ml})$ in $50 \mathrm{mM}$ Tri- $\mathrm{HCl}$, pH8 und $5 \mathrm{mM}$ EDTA, $37^{\circ} \mathrm{C}$

5 min. $0,2 \%$ Glycin in PBS

$2 \mathrm{x} 5 \mathrm{~min}$. PBS

20 min. Postfixierung in 4\% PFA / PBS und 0,2\% Glutaraldehyd

$2 \mathrm{x} 5 \mathrm{~min}$. PBS

$2 \mathrm{~h}$ Prähybridisierung in Hybridisationsmix, $70^{\circ} \mathrm{C}$

3 min. Denaturieren der RNA-Sonde bei $80^{\circ} \mathrm{C}$, Zugabe zum Hybridisationsmix

Hybridisierung ü.N bei $70^{\circ} \mathrm{C}$ in einer feuchten Kammer mit Formamid/ SSC/ Wasser

Hybridisationsmix:

$50 \%$ Formamid

$5 \mathrm{x}$ SSC

$1 \%$ Boehringer Block 
5 mM EDTA

$0,1 \%$ Tween 20

$0,1 \%$ CHAPS

$0,1 \mathrm{mg} / \mathrm{ml}$ Heparin

$1 \mathrm{mg} / \mathrm{ml}$ tRNA

2. Tag:

5 min. $2 x$ SSC, $\mathrm{pH} 4,5$

$3 \times 30$ min. 2 x SSC/ $50 \%$ Formamid, $65^{\circ} \mathrm{C}$

2x 10 min. KTBT

$2 \mathrm{~h}$ Blocken in Blocklösung

Inkubation ü.N mit anti-DIG-alkalischer Phosphatase, Fab-Fragmenten (Roche, 1:2000) in Blocklösung, $4^{\circ} \mathrm{C}$

\section{KTBT:}

$50 \mathrm{mM}$ Tris- $\mathrm{HCl}, \mathrm{pH} 7,5$

$150 \mathrm{mM} \mathrm{NaCl}$

$10 \mathrm{mM} \mathrm{KCl}$

$1 \%$ Triton X-100

\section{Blocklösung:}

$20 \%$ Schafserum in KTBT

\section{Tag:}

3x 5 min KTBT

$3 \times 30 \mathrm{~min}$. KTBT

$3 \times 5$ min. NTMT

Färben mit NBT / BCIP (1:50, Roche) in NTMT bei RT für mehrere Stunden, evtl. ü.N

3x 5 min. PBT

Eindeckeln mit Mowiol 4-88 (Kuraray Specialities Europe)

\section{NTMT:}

$100 \mathrm{mM}$ Tris-HCl, pH 9,5

$100 \mathrm{mM} \mathrm{NaCl}$

$50 \mathrm{mM} \mathrm{MgCl} 2$

$0,05 \%$ Tween 20

PBT: PBS mit $0,1 \%$ Triton X-100

\subsection{DNA Microarray Screen}

\section{Gewebepräparation}

Zum Embryonaltag E16.5 wurde von mehreren Würfen aus folgenden cerebralen

Cortexregionen Gewebe präpariert:

- frontalem Cortex (Anlage des motorischen Cortex)

- occipitalen Cortex (Anlage des visuellen Cortex)

- parietalem Cortex (Anlage des somatosensorischen Cortex)

- rostro-medialem Cortex (Anlage des Cingulums)

- caudo-medialem Cortex (Anlage des Hippocampus) 
Als Kontrolle wurden Körper von E16.5 Embryonen verwendet, denen das Gehirn,

Rückenmark und die Genitalleiste entfernt wurde (= Restkörper). Es ist bekannt, daß

Nervensystem und Geschlechtsorgane überlappende Gene besitzen. Um im

Microarray Screen nicht diese Gene zu verlieren, wurde die Genitalleiste entfernt.

Das Gewebe wurde in kaltem, autoklaviertem DEPC-PBS präpariert, gepoolt und in "RNAlater" (Ambion) bei $-20^{\circ} \mathrm{C}$ gelagert.

\section{RNA-Präparation}

Zur Isolierung von Gesamt-RNA aus den präparierten Gehirngeweben wurde der "Total RNA Isolation kit" (Qiagen) verwendet.

\section{cDNA Synthese (SuperScript Choice System, GibcoBRL)}

\section{1) Erststrangsynthese}

Primerhybridisierung:

$8 \mu \mathrm{g}$ total RNA in $10 \mu \mathrm{l}$ DEPC-Wasser

$1 \mu \mathrm{l}$ RNasin

$1 \mu \mathrm{l}(100 \mathrm{pmol}) \mathrm{T} 7-(\mathrm{dT})_{24}$-Primer

Der Ansatz wurde $10 \mathrm{~min}$. bei $70^{\circ} \mathrm{C}$ inkubiert, kurz anzentrifugiert und $1 \mathrm{~min}$. auf Eis gelagert.

Temperaturangleichung:

$4 \mu \mathrm{l}$ 5x Erststrang cDNA Puffer

$2 \mu \mathrm{l} 0,1 \mathrm{M}$ DTT

$1 \mu \mathrm{l} 10 \mathrm{mM}$ dNTP Mix

2 min. Inkubation bei $42^{\circ} \mathrm{C}$

Einzelstrangsynthese:

$2 \mu \mathrm{l}$ Superscript II Reverse Transcriptase $(200 \mathrm{U} / \mu \mathrm{l})$

Mischen und eine Stunde bei $42^{\circ} \mathrm{C}$ inkubieren

\section{2) Zweitstrangsynthese}

Zugabe von:

$91 \mu$ DEPC-Wasser

$30 \mu \mathrm{l}$ 5x Zweitstrang Reaktionspuffer

$3 \mu 110 \mathrm{mM}$ dNTP

$1 \mu 110 \mathrm{U} / \mu 1$ DNA Ligase

$4 \mu \mathrm{l} 10 \mathrm{U} / \mu \mathrm{l}$ DNA Polymerase I

$1 \mu \mathrm{l} 2 \mathrm{U} / \mu \mathrm{l}$ RNase H

Den Ansatz mischen und für zwei Stunden bei $16^{\circ} \mathrm{C}$ inkubieren.

$+2 \mu 110$ U T4 DNA Polymerase

Erneutes Inkubieren für 5 Minuten bei $16^{\circ} \mathrm{C}$.

$+10 \mu \mathrm{l} 0,5 \mathrm{M}$ EDTA 
Die doppelsträngige cDNA wurde mit Hilfe von "Phase Lock Gels" (Eppendorf) über Phe/ Chl-Extraktion aufgereinigt und schließlich mit Ethanol präzipitiert. Nach zweimaligem Waschen mit 80\%-igem Ethanol wurde das Pellet getrocknet und in 12 $\mu 1$ DEPC-Wasser aufgenommen.

\section{Synthese der biotin-markierten cRNA (BioArray High Yield RNA Transcript Labeling Kit, Enzo)}

Ansatz der in vitro Transkriptionsreaktion: Gesamtvolumen $40 \mu \mathrm{l}$

$12 \mu \mathrm{l}$ cDNA (Einsatz der gesamten cDNA-Ausbeute)

$4 \mu \mathrm{l}$ 10x RNase Inhibitor Mix

$4 \mu$ 10x HY Reaktionspuffer

$4 \mu \mathrm{l}$ 10x biotin-markierte Ribonucleotide

$4 \mu \mathrm{l}$ 10x DTT

$2 \mu 1$ 20x T7 RNA Polymerase

Die Reaktion wurde für $5 \mathrm{~h}$ bei $37^{\circ} \mathrm{C}$ inkubiert, wobei der Ansatz alle $45 \mathrm{~min}$. vorsichtig gemischt wurde. Anschließend wurden die in vitro Transkriptionsprodukte mit RNeasy Säulen (Qiagen) nach Herstelleranleitung aufgereinigt und durch Zugabe von 2,5 Volumen absolutem Ethanol und 0,5 Volumen 7,5 $\mathrm{M} \mathrm{NH}_{4} \mathrm{Ac}$ präzipitiert. Das Pellet wurde nach dem Waschen je nach Größe in 10-20 $\mu$ l DEPC-Wasser für 5 min. bei $70^{\circ} \mathrm{C}$ unter Schütteln gelöst. Danach wurde über die Messung der OD die cRNAAusbeute quantifiziert. Zur Berechnung der tatsächlichen cRNA-Ausbeute wurde die eingesetzte Menge total RNA von der Menge cRNA nach in vitro Transkription abgezogen.

\section{Fragmentierung der cRNA}

Es wurden pro Gewebe $16 \mu \mathrm{g}$ cRNA zur Fragmentierung eingesetzt.

Fragmentierungsansatz: Gesamtvolumen $40 \mu \mathrm{l}$

$16 \mu \mathrm{g}$ cRNA

$8 \mu \mathrm{l} 5 \mathrm{x}$ Fragmentierungspuffer

$\mathrm{x} \mu \mathrm{l}$ DEPC-Wasser

5x RNA Fragmentierungs Puffer:

$200 \mathrm{mM}$ Tris-acetat, $\mathrm{pH} 8,1$

$500 \mathrm{mM} \mathrm{KOAc}$

$150 \mathrm{mM} \mathrm{MgOAc}$

Der Puffer wurde mit DEPC-Wasser hergestellt und steril filtriert

Der Ansatz wurde 35 min. bei $94^{\circ} \mathrm{C}$ inkubiert und bis zur Hybridisierung bei $-20^{\circ} \mathrm{C}$ gelagert. $1 \mu \mathrm{g}$ fragmentierter cRNA wurde auf einem 1\%-igem Agarosegel auf erfolgreiche Fragmentierung hin getestet. 


\section{Hybridisierung}

Herstellen des Hybridisierungscocktails für einen Standard Microchip: Gesamtvolumen $300 \mu 1$ $16 \mu \mathrm{g}$ fragmentierte cRNA

$3 \mu$ K Kontroll-Oligonucleotide B2 (5 nM)

$3 \mu \mathrm{l}$ Kontroll-cRNA Cocktail (nach Affymetrix-Angaben erstellt)

$3 \mu$ l Heringssperma-DNA $(10 \mathrm{mg} / \mathrm{ml})$

$3 \mu \mathrm{l}$ acetyliertes BSA ( $50 \mathrm{mg} / \mathrm{ml}$, Gibco BRL Life Technologies)

$150 \mu \mathrm{l} 2 \mathrm{x}$ MES Hybridization Buffer

$\mathrm{x} \mu \mathrm{l}$ DEPC-Wasser

12x MES Stammlösung

$1,22 \mathrm{M}$ MES

$0,89 \mathrm{M}\left[\mathrm{Na}^{+}\right]$

2x MES Hybridisierungspuffer:

$8,3 \mathrm{ml} 12 \mathrm{x}$ MES Stammlösung

$17,7 \mathrm{ml} 5 \mathrm{M} \mathrm{NaCl}$

4,0 $\mathrm{ml} \mathrm{0,5} \mathrm{M}$ EDTA

$0,1 \mathrm{ml} 10 \%$ Tween 20

$19,9 \mathrm{ml}$ Wasser

Der Hybridisierungscocktail wurde in einem Thermocycler für $5 \mathrm{~min}$. bei $99^{\circ} \mathrm{C}$ und anschließend für 5 min. bei $45^{\circ} \mathrm{C}$ inkubiert. Nach kurzem Anzentrifugieren wurde der Cocktail in die äquilibrierten Microchips (Affymetrix Testchip Test 3 Array bzw.

MGU 74, Version 1, Chip A und B) eingefüllt. Die Hybridisierung erfolgte rotierend ü.N in einem Hybridisierungsofen ("GeneChip Hybridization Oven 640", Affymetrix) bei $45^{\circ} \mathrm{C}$ und $60 \mathrm{rpm}$.

Zum Äquilibrieren wurden die Microchips mit $100 \mu 1$ xMES für $10 \mathrm{~min}$. bei $45^{\circ} \mathrm{C}$ und $60 \mathrm{rpm}$ im Hybridisierungsofen rotiert.

\section{Waschen, Färben und Scannen der Microchips}

Die Wasch- und Färbeprozedur wurde in der "GeneChip Fluidics Station 400" nach folgendem Protokoll vollzogen:

Posthybridisieren:

- 10 Zyklen Waschpuffer A, $25^{\circ} \mathrm{C}$

- 4 Zyklen Waschpuffer B, $50^{\circ} \mathrm{C}$

Färben:

- 10 min. SAPE-Lösung, $25^{\circ} \mathrm{C}$

- 10 Zyklen Waschpuffer A, $25^{\circ} \mathrm{C}$

- 10 min. Antikörper-Lösung, $25^{\circ} \mathrm{C}$

- 10 min. SAPE-Lösung, $25^{\circ} \mathrm{C}$

- 15 Zyklen Waschpuffer A, $30^{\circ} \mathrm{C}$ 
Waschpuffer A (nicht stringenter Waschpuffer):

6x SSPE

$0,01 \%$ Tween 20

$0,005 \%$ Antifoam

Waschpuffer B (stringenter Waschpuffer)

$100 \mathrm{mM}$ MES

$0,1 \mathrm{M}\left[\mathrm{Na}^{+}\right]$

$0,001 \%$ Tween 20

Streptavidin Phycoerythrin (SAPE)-Lösung:

2x Färbelösung

$2 \mathrm{mg} / \mathrm{ml}$ acetyliertes BSA

$10 \mu \mathrm{g} / \mathrm{ml}$ R-Phycoerythrin Streptavidin (Molecular Probes)

2x Färbelösung:

$200 \mathrm{mM}$ MES

$2 \mathrm{M}\left[\mathrm{Na}^{+}\right]$

$0.1 \%$ Tween 20

$0,01 \%$ Antifoam

\section{Antikörper-Lösung:}

2x Färbelösung

$2 \mathrm{mg} / \mathrm{ml}$ acetyliertes BSA

$0,1 \mathrm{mg} / \mathrm{ml} \mathrm{IgG}$ aus der Ziege (Sigma)

$3 \mu \mathrm{g} / \mathrm{ml}$ biotinylierter anti-Streptavidin-Antikörper, Ziege (Vector Laboratories)

Danach wurden die Microchips in einem "Agilent GeneArray Scanner" mit einer Laserwellenlänge von $570 \mathrm{~nm}$ gescannt.

\section{Auswertung}

Die Analyse der Daten erfolgte mit der Affymetrix Software "Microarray Suite, Version 4.0". Wegen eines Produktionsfehlers der Microchips wurden durch Maskierung Daten aus der Analyse entfernt. Die Qualität der cRNA-Proben wurde zunächst mit einem Testchip ermittelt. Dieser Testchip enthält murine Haushaltsgene wie z.B. GAPDH und $\beta$-Actin. Bei guten Hybridisierungs-Proben sollten die Hybridisierungssignale nicht einen höheren Wert als 3 besitzen. Bei höheren Werten muß eine Degradierung der RNA vermutet werden.

Um zwei Microchips miteinander vergleichen zu können, wurde der Algorhythmus "Scaling" (Skalierung) angewandt. Als Targetintensität wurde 500 ausgewählt. Es wurden Dateien des Typs ".chp" erstellt und paarweise miteinander verglichen. Mit den entstandenen Daten für "Fold Change" (FC,Verhältnis der Genexpression zwischen einem Basiswert und einer Probe) und "Difference Call" (DC, Unterschied in der Expression) wurden Listen von Genen angefertigt, deren Expression in einer 
der fünf Cortexregionen erhöht war. Zur Aufnahme in eine Liste mußte ein Gen folgende Kriterien erfüllen:

1. Der "Difference Call" muß im Vergleich zu den anderen Cortexregionen und der Kontrolle (Restkörper) "marginal increased" (geringfügig erhöht) oder "increased" (erhöht) betragen.

2. Die Expression ist im Vergleich zu allen anderen vier Cortexregionen um einen "Fold Change" von mindestens 2 erhöht.

3. Die Expression ist im Vergleich zu mindestens einer Cortexregion um einen "Fold Change" von $\geq 3$ erhöht.

\subsection{Protein}

\section{Western Blot}

Aufbereitung des Gewebes

Das Gewebe wurde in RIPA-Puffer, versetzt mit Protease Inhibitor (Protease Inhibitor Cocktail Set III, Calbiochem), homogenisiert. Dabei entsprach das Volumen an Puffer in $\mu \mathrm{ldem}$ Gewicht des Gewebes in mg multipliziert mit 10. Das Homogenat wurde 15 min. bei $13000 \mathrm{rpm}$ zentrifugiert und anschließend mit dem Überstand weitergearbeitet. Bis zum Gebrauch wurde er bei $-20^{\circ} \mathrm{C}$ gelagert.

\section{RIPA-Puffer:}

für $500 \mathrm{ml}$

$2,5 \mathrm{ml} 10 \% \mathrm{SDS}$

$15 \mathrm{ml} 5 \mathrm{M} \mathrm{NaCl}$

$5 \mathrm{ml} 10 \% \mathrm{NP}-40$

$25 \mathrm{ml} \mathrm{10 \%} \mathrm{Na-Desoxycholat}$

$1 \mathrm{ml} 0,5 \mathrm{M}$ EDTA

$25 \mathrm{ml} 1 \mathrm{M}$ Tris- $\mathrm{HCl}$

Wasser

Für den Nachweis des Histons $\mathrm{H}^{\circ}{ }^{\circ}$ wurde das Gewebe nach einer speziellen Histonpräparation aufbereitet (Seyedin und Kistler, 1980). Hierbei wurde das Gewebe unter flüssigem Stickstoff zermörsert und in $15 \mathrm{ml}$ Perchlorsäure $1 \mathrm{~h}$ auf Eis gerührt. Nach einer halbstündigen Zentrifugation bei $5000 \mathrm{rpm}$ wurde der Überstand aufbewahrt und das Pellet erneut mit Perchlorsäure resuspendiert und auf Eis gerührt. Der durch erneute Zentrifugation gewonnene Überstand wurde mit dem ersten 
vereinigt. Durch Zugabe von 100\%-iger Trichloressigsäure (TCA) bis zu einer Endkonzentration von 20\% wurden für 10 min auf Eis die Proteine gefällt. Es folgte eine Zentrifugation für $20 \mathrm{~min}$ bei $9000 \mathrm{rpm}$ und ein anschließendes Waschen des Pellets mit Ethanol/ Ether (1:1). Das Pellet wurde getrocknet und in $500 \mu \mathrm{l}$ Wasser gelöst. Nach Zugabe von $500 \mu \mathrm{l}$ 0,4 M Schwefelsäure wurde der Ansatz eine Stunde auf Eis gerührt. Die nicht-H1-Proteine wurden mit 100\%-iger TCA bis zu einer Endkonzentration von 3\% für 10 min auf Eis gefällt. Nach Zentrifugation wurde der Überstand, der die H1-Proteine enthält, mit 100\%-iger TCA bis zu einer Endkonzentration von $9,5 \%$ versetzt, um die H1-Proteine zu fällen. Nach Zentrifugation wurde das Präzipitat ü.N in $0,1 \mathrm{M} \mathrm{HCl}$ rotierend bei $4^{\circ} \mathrm{C}$ gelöst.

\section{Bradford-Assay}

Zur Bestimmung des Proteingehalts einer Probe wurden $800 \mu \mathrm{l}$ PBS und $200 \mu \mathrm{l}$ BIORAD- Farbreagenz mit $1 \mu 1$ Probe gut durchmischt. Als Kontrollwert diente PBS mit Farbreagenz ohne Probe. Nach Vermessen des Ansatzes im Photometer bei 595 nm wurde der Proteingehalt mit Hilfe einer BSA/ PBS Eichkurve ermittelt.

\section{SDS-Polyacrylamid-Gelelektrophorese}

Die Proben wurden in einem denaturierenden Proteingel nach Laemmli aufgetrennt (Laemmli, 1970). Dazu wurde in einer BIORAD Gießapparatur ein 12\%-iges Trenngel gegossen und mit Wasser überschichtet. Nach dem Polymerisieren des Gels wurde das Wasser aufgesaugt, ein 4\%-iges Sammelgel hinzugegossen und ein Kamm zum Formen der Taschen eingeschoben. Nach dem Auspolymerisieren des Sammelgels wurde der Kamm herausgezogen und das Gel in eine vertikale Gelkammer (BIORAD) eingespannt. Als Laufpuffer wurde Laemmli-Puffer verwendet. Die Proben wurden mit 3x Ladepuffer versetzt und für $3 \mathrm{~min}$. bei $95^{\circ} \mathrm{C}$ denaturiert. Nach kurzer Inkubation auf Eis wurden die Proben und ein Proteinmarker (Precision Plus Protein Standard, BIORAD) geladen und für 3-4 h bei $60 \mathrm{~V}$ aufgetrennt bis die Lauffront den unteren Rand des Gels erreicht hatte. 
Trenngel (12\%):

$10 \mathrm{ml} \mathrm{30 \%}$ Acrylamid / 0,8\% Bisacrylamid (BIORAD)

$6,25 \mathrm{ml}$ 1,5 M Tris-HCl, $\mathrm{pH} \mathrm{8,8}$

$0,25 \mathrm{ml} 10 \%$ SDS

$0,25 \mathrm{ml} \mathrm{10 \%} \mathrm{Ammoniumpersulfat}$

$25 \mu 1$ TEMED

$8,5 \mathrm{ml}$ Wasser

\section{Sammelgel (4\%):}

1,3 ml 30\% Acrylamid / 0,8\% Bisacrylamid (BIORAD)

2,5 ml 0,5 M Tris-HCl, pH 6,8

$0,1 \mathrm{ml} \mathrm{10 \%}$ SDS

$0,1 \mathrm{ml} \mathrm{10 \%} \mathrm{Ammoniumpersulfat}$

$20 \mu \mathrm{T}$ TEMED

$6 \mathrm{ml}$ Wasser

Laemmli-Puffer:

$25 \mathrm{mM}$ Tris-HCl, pH7,5

$250 \mathrm{mM}$ Glycin

$0,1 \%$ SDS

3x Ladepuffer:

3,6 ml 0,5 M Tris-HCl, pH 6,8

$1,5 \mathrm{ml} \beta$-Mercaptoethanol

$0,6 \mathrm{~g}$ SDS

$3 \mathrm{ml}$ Glycerin

0,25\% Bromphenolblau

$1,5 \mathrm{ml}$ Wasser

$\underline{\text { Transfer von Proteinen auf eine Nitrocellulosemembran }}$

Das Elektroblotten wurde hier nach der "semi-dry"-Methode durchgeführt.

Nach dem Auftrennen der Proteine im SDS-Gel mußten Gel und Membran zunächst äqulibriert werden. Dazu wurde das Gel 15 min. in kaltemTransferpuffer geschwenkt. Die Membran (Immobilon-P, Millipore) wurde für $15 \mathrm{~s}$ in kaltem Methanol, $2 \mathrm{~min}$. in Wasser und für $5 \mathrm{~min}$. in kaltem Transferpuffer inkubiert.

In Transferpuffer getränkt wurde dann der Blot aufgebaut:

Anode $(+)$

drei feuchte Filterpapiere

Membran

Polyacrylamid-Gel

drei feuchte Filterpapiere

Kathode (-)

Zum Blotten wurde die "Trans-Blot Semi-Dry Electrophoretic Transfer Cell" von BIORAD verwendet. Der Transfer wurde für $30 \mathrm{~min}$. bei $15 \mathrm{~V}$ durchgeführt. Anschließend wurde die Membran reversibel mit Ponceau S gefärbt, um den Erfolg des Transfers zu überprüfen. 
Transferpuffer:

14,4 g Glycin

$3 \mathrm{~g}$ Tris- $\mathrm{HCl}$

$20 \%$ Methanol

auf 11 auffüllen

Ponceau S-Färbelösung:

$0,5 \mathrm{~g}$ Ponceau $\mathrm{S}$ in $1 \%$ Essigsäure lösen

$\underline{\text { Immunodetektion von Proteinen auf einer Nitrocellulosemembran }}$

Nach Abwaschen der Ponceau S-Färbung mit Wasser wurde die Membran für $1 \mathrm{~h}$ geblockt. Danach erfolgte schüttelnd die Primär-Antikörper-Inkubation bei $4^{\circ} \mathrm{C}$ ü.N, der Antikörper wurde in 1\% Blocklösung verdünnt. Am nächsten Tag wurde nicht gebundener Antikörper bei RT weggewaschen: 1x 5 min. mit Waschpuffer/ 0,1\% Tween-20 und 3x 5 min. mit Waschpuffer. Der HRP (horseradish peroxidase)gekoppelte Sekundärantikörper (DIANOVA) wurde 1:10 000 in Waschpuffer verdünnt und für $1 \mathrm{~h}$ bei RT inkubiert. Nach erneuter obiger Waschprozedur wurde der Blot 5 min. mit Chemilumineszenz-Substrat (SuperSignal West Pico Chemiluminescent Substrate) entwickelt. Eingeschlagen in Folie wurde der Blot auf Röntgenfilmen exponiert. Die Belichtungszeit betrug $5 \mathrm{~min}$. bis $1 \mathrm{~h}$.

TBS:

$50 \mathrm{mM}$ Tris-HCl, $\mathrm{pH} 8,0$

$150 \mathrm{mM} \mathrm{NaCl}$

Blocklösung:

$5 \%$ Milchpulver in TBS

Waschpuffer:

1:20 Verdünnung der Blocklösung

\section{Coomassie-Blau-Färbung}

Um die Integrität der Gewebeproben zu überprüfen, wurden die Proteinbanden nach der gelelektrophoretischen Auftrennung ü.N. mit 1x Coomassie-Blau angefärbt. Überschüssiger Farbstoff wurde mit saurer Entfärbelösung weggewaschen.

Coomassie-Blau-Färbelösung:

$0,025 \%$ Coomassie-Blau-G250 (Serva)

$10 \%$ Essigsäure

$1 \mathrm{~h}$ Stunde mit Wasser mischen und filtern 


\section{Entfärbelösung:}

$7 \%$ Essigsäure

$5 \%$ Methanol

$88 \%$ Wasser

\section{Präparation von Acetonpuder}

Das Gewebe wurde in 0,9\% $\mathrm{NaCl}$ homogenisiert (1 ml Lösung/ g Gewebe). Nach 5 minütiger Inkubation auf Eis wurden $8 \mathrm{ml}$ eiskaltes Aceton hinzugefügt und alles gut durchmischt. Es folgte eine halbstündige Inkubation auf Eis mit gelegentlichem Mischen, danach wurde der Ansatz für $10 \mathrm{~min}$. bei $10000 \mathrm{rpm}$ zentrifugiert. Der Überstand wurde verworfen, das Pellet erneut mit eiskaltem Aceton resuspendiert und für 10 min. auf Eis stehen gelassen. Nach Zentrifugation wurde das Pellet auf ein sauberes Filterpapier gebracht und zum Trocknen darauf verteilt. Bis zum Gebrauch wurde das Acetonpuder in einem luftdichten Röhrchen bei $-80^{\circ} \mathrm{C}$ gelagert.

\section{Präadsorption des Ratte-anti-PPPin-Antikörpers}

Eine 1:100 Verdünnung des Antikörpers wurde zusammen mit dem Acetonpuder für $30 \mathrm{~min}$. rotierend bei $4^{\circ} \mathrm{C}$ inkubiert. Nach einer 10 minütigen Zentrifugation bei 10 $000 \mathrm{rpm}$ wurde der Überstand abgenommen und in einer 1:1000 Endverdünnung auf den Western Blot gegeben.

\subsection{Histologie}

\section{Herstellung von Gefrierschnitten}

Nach dem Präparieren wurden die Gehirne je nach Größe in 4\% PFA/ PBS für 1-3 h Stunden bzw. ü.N (bei adulten Gehirnen) fixiert. Auf zwei Waschschritte in PBS folgte das Überführen der Hirne in $25 \%$ Sucrose in PBS (ü.N). Am nächsten Tag wurden die Gehirne in Einbettmedium (Tissue Freezing Medium, Jung) geschwenkt und in Plastikförmchen (Leica) auf Trockeneis eingefroren. Die eingebetteten Gehirne wurden bei $-20^{\circ} \mathrm{C}$ gelagert und mit einem Cryostaten der Firma Leica (CM 3050S) geschn itten. 


\section{Herstellung von Paraffinschnitten}

Für diese Schneidetechnik erfolgte das Fixieren der Gehirne ü.N. in 4\% PFA/ PBS. Nach gründlichem Waschen in PBS durchliefen die Gehirne folgende Bäder im Karussell (Citadel 1000, Shandon):

Dehydrieren: je $1 \mathrm{~h}$

PBS

$0,86 \% \mathrm{NaCl}$

$50 \% \mathrm{EtOH}$

$70 \% \mathrm{EtOH}$

$80 \% \mathrm{EtOH}$

$90 \% \mathrm{EtOH}$

$100 \% \mathrm{EtOH}$

Infiltrieren:

Isopropanol

Toluol

2x Paraplast

Adulte Gehirne wurden für 2 Nächte fixiert und verblieben zum Dehydrieren und Infiltrieren jeweils für einen Tag in der entsprechenden Lösung.

Nachdem noch einmal das Paraplast gewechselt wurde, wurden die Gehirne an der Einbettstation (Leica EG 1160) in Paraplast eingebettet. Es wurden je nach Anwendung 6-10 $\mu \mathrm{m}$ dicke Schnitte angefertigt (Leica Microtom, RM 2165).

\section{Hämatoxylin-Eosin-Färbung (HE-Färbung)}

Hierfür wurden $10 \mu \mathrm{m}$ dicke Paraffinschnitte erstellt, die im "Jung Auto Stainer XL" (Leica) wie folgt behandelt wurden:

$\begin{array}{lll}\text { Schritt } & \text { Reagenz } & \text { Zeit } \\ 1 & \text { Xylolersatz } & 5 \mathrm{~min} . \\ 2 & \text { Xylolersatz } & 5 \mathrm{~min} . \\ 3 & \text { Xylolersatz } & 3 \mathrm{~min} . \\ 4 & 100 \% \text { EtOH } & 4 \mathrm{~min} . \\ 5 & 90 \% \mathrm{EtOH} & 4 \mathrm{~min} . \\ 6 & 70 \% \mathrm{EtOH} & 4 \mathrm{~min} . \\ 7 & 50 \% \text { EtOH } & 4 \mathrm{~min} . \\ 8 & \text { Wasser } & 2 \mathrm{~min} . \\ 9 & \text { Hämatoxylin } & 5-8 \mathrm{~min} . \text { (je nach Gewebe) } \\ 10 & \text { Wasser } & 3 \mathrm{~min} . \\ 11 & \text { Wasser } & 3 \mathrm{~min} . \\ 12 & \text { Wasser } & 2 \mathrm{~min} . \\ 13 & \text { HCl-Alkohol } & 12 \mathrm{sec} . \\ 14 & \text { Wasser } & 1 \mathrm{~min} . \\ 15 & \text { Wasser } & 1 \mathrm{~min} . \\ 16 & \text { Eosin } & 30 \mathrm{sec} . \\ & & \end{array}$




$\begin{array}{lll}17 & 50 \% \text { EtOH } & 55 \mathrm{sec} . \\ 18 & 70 \% \mathrm{EtOH} & 1 \mathrm{~min} . \\ 19 & 90 \% \mathrm{EtOH} & 2 \mathrm{~min} . \\ 20 & 100 \% \mathrm{EtOH} & 2 \mathrm{~min} . \\ 21 & 100 \% \text { EtOH } & 2 \mathrm{~min} . \\ 22 & \text { Xylolersatz } & 3 \mathrm{~min} . \\ 23 & \text { Xylolersatz } & 3 \mathrm{~min} .\end{array}$

Hämatoxylin: nach Harris (Sigma), wurde vor Gebrauch filtriert Eosin G: 1\%-igeStammlösung (Merck) in Wasser, vor Gebrauch filtriert Gebrauchslösung (0,1\%): $50 \mathrm{ml}$ Stammlösung, $450 \mathrm{ml} \mathrm{MQ}, 150 \mu$ l Essigsäure HCl-Alkohol: $500 \mathrm{ml} 70 \% \mathrm{EtOH}, 5 \mathrm{ml}$ rauchende $\mathrm{HCl}$

Im Anschluß wurden die Schnitte mit "Eukitt"-Einbettmedium (O. Kindler GmbH) eingedeckelt und getrocknet.

\section{$\beta$-Galactosidase-Färbung}

Die Cryoschnitte wurden $30 \mathrm{~min}$. schüttelnd auf Eis in Fixierlösung inkubiert. Anschließend wurden sie 2x 20 min. in PBS bei RT gewaschen. Die Färbung erfolgte unter Lichtausschluß bei $30^{\circ} \mathrm{C}$ ü.N..

Fixierlösung: für $50 \mathrm{ml}$

$1,35 \mathrm{ml} \mathrm{37 \%}$ Formaldehyd

$0,2 \mathrm{ml} 50 \%$ Glutaraldehyd

$0,1 \mathrm{ml} 10 \% \mathrm{NP}-40$

$2,5 \mathrm{ml} 20 \mathrm{x}$ PBS

$45,85 \mathrm{ml} \mathrm{MQ}$

X-Gal Färbelösung: für $25 \mathrm{ml}$ 23,37 $\mathrm{ml} 1 \mathrm{x}$ PBS

0,625 $\mathrm{ml} \mathrm{X-Gal} \mathrm{(40} \mathrm{mg} \mathrm{/} \mathrm{ml}$ in Dimethylformamid, Gibco BRL)

$0,625 \mathrm{ml} \mathrm{K}_{3} \mathrm{Fe}(\mathrm{CN})_{6}(200 \mathrm{mM})$

$0,625 \mathrm{ml} \mathrm{K}_{4} \mathrm{Fe}(\mathrm{CN})_{6}(200 \mathrm{mM})$

$0,5 \mathrm{ml} \mathrm{MgCl}(100 \mathrm{mM})$

Am nächsten Tag wurden die Schnitte 2x mit PBS gewaschen und in 0,02\% Na-Azid/ PBS bei $4^{\circ} \mathrm{C}$ gelagert.

\section{BrdU (5-Bromo-2'-deoxyuridin)-Aufnahmestudien}

Es wurden $0,014 \mathrm{~g} / \mathrm{ml}$ BrdU eingewogen und in PBS bei $37^{\circ} \mathrm{C}$ schüttelnd gelöst. Die

Maus wurde gewogen und $100 \mu \mathrm{l} / 10 \mathrm{~g}$ Körpergewicht injiziert. Nach 30-40 min. Inkorporationszeit wurden die Embryonen entnommen und die Gehirne schnell in kaltem PBS präpariert. Sie wurden ü.N. in 4\% PFA/ PBS fixiert und in Paraffin 
eingebettet (s.o.). Für die anti-BrdU-Färbung betrug die Dicke der Schnitte $6 \mu \mathrm{m}$. Sie durchliefen diese Behandlung:

$\begin{array}{ll}\begin{array}{l}\text { Entparaffinierung: } \\ \text { Xylolersatz }\end{array} & \\ \text { Xylolersatz } & 5 \mathrm{~min} . \\ 100 \% \mathrm{EtOH} & 5 \mathrm{~min} . \\ 96 \% \mathrm{EtOH} & 2 \mathrm{~min} . \\ 90 \% \mathrm{EtOH} & 2 \mathrm{~min} . \\ 70 \% \mathrm{EtOH} & 2 \mathrm{~min} . \\ 50 \% \mathrm{EtOH} & 2 \mathrm{~min} . \\ \mathrm{MQ} & 2 \mathrm{~min} . \\ 1 \mathrm{X} \mathrm{PBS} & 5 \mathrm{~min} . \\ & 5 \mathrm{~min} .\end{array}$

DNA-Vorbehandlung:

$2 \mathrm{~N} \mathrm{HCl} \quad 30 \mathrm{~min}$.

$0,1 \mathrm{M} \mathrm{Na}$-Borat $10 \mathrm{~min}$.

$0,1 \mathrm{M} \mathrm{Na}$-Borat $10 \mathrm{~min}$.

1x PBS $5 \mathrm{~min}$.

1x PBS $5 \mathrm{~min}$.

Proteinase K $7 \mathrm{~min}$.

$(20 \mu \mathrm{g} / \mathrm{ml}$ in $20 \mathrm{mM}$ Tris-HCl, $1 \mathrm{mM}$ EDTA $)$

1x PBS $5 \mathrm{~min}$.

1x PBS 5 min.

Blocken in PBSTG $1-2 \mathrm{~h}$

1x PBS $5 \mathrm{~min}$.

anti-BrdU-Fluorescein (1:10 in PBS, Roche) ü.N bei $4^{\circ} \mathrm{C}$

$1 x$ PBS $5 \mathrm{~min}$.

PBSTG $\quad 5$ min.

1x PBS $5 \mathrm{~min}$.

Gegenfärbung mit Propidiumiodid (1:3000 in PBS, Molecular Probes) für 1 min. im Dunkeln 4x Waschen mit 1x PBS für 3 min.

PBSTG: $0,2 \%$ Gelatine, $0,2 \%$ Tween 20 in PBS

$\mathbf{0 , 1} \mathbf{M ~ N a}_{2} \mathbf{B}_{4} \mathbf{O}_{7}$ : mit $1 \mathrm{M}$ Borsäure auf $\mathrm{pH} 8,5$ eingestellt

Die Schnitte wurden in Vectashield (Vector) eingedeckelt.

Aus dem Verhältnis der BrdU inkorporierenden Zellen und den Propidiumiodid gefärbten Zellen wurde der mitotische Index ermittelt. 


\section{6 in vitro Elektroporation embryonaler Gehirne und organotypische Kultur}

\section{Zubereitung der Plasmid-DNA}

Plasmid-DNA wurde mit dem Qiagen Plasmid Maxi Kit präpariert und nach Phe/ Chl- und Chl-Extraktion in 0,01\% Fast green (Sigma) in sterilem PBS gelöst. Die DNA-Konzentration wurde auf 2,0 $\mu \mathrm{g} / \mu \mathrm{l}$ (Osumi und Inoue, 2001) eingestellt, zusätzlich wurden 0,8 $\mu \mathrm{g} / \mu 1$ des Plasmids CMV-EGFP (Luo et al., 2004) zugefügt.

\section{Herstellung der Mikrokapillaren}

Mikrokapillaren (Clark Electromedical Instruments) wurden mit einem vertikalen Kapillarenzieher (Modell 720, David Kopf Instruments) gezogen (Solenoid $=0$, Heater $=18,5)$.

\section{Elektroporation und organotypische Kultur}

Diese Methode wurde von S. Mühlfriedel (noch nicht publiziert) etabliert und ist nach bereits publizierten Elektroporationen (Stuhmer et al., 2002; Alifragis et al., 2004) modifiziert worden.

Nach Präparation in kaltem Earle's balanced salts (EBSS, Gibco BRL) wurden die embryonalen Gehirne (E14.5) auf einem Elektroporationstisch elektroporiert. Dazu wurden $100 \mu \mathrm{l}$ kaltes, steriles PBS zur Benetzung beider Elektroden in die Vertiefung gegeben. Das zu elektroporierende Gehirn wurde im PBS mit dem Zielareal zur Anode hin orientiert. Mit Mikrokapillaren wurden 2-3 $\mu$ l Plasmid-Lösung in das zur Anode gerichtete laterale Ventrikel injiziert (2650 hPa, Microinjector 5242, Eppendorf) und fünf elektrische Pulse verabreicht (Pulsdauer $=50 \mathrm{~ms}$, Spannung $=70$ $\mathrm{V}$, Pause $=1 \mathrm{~s}$; Rechteckspannungsgenerator ECM 830, BTX). Elektroporierte Gehirne wurden in kaltem Gewebe-Kulturmedium gelagert und schließlich in 2\% niedrigschmelzender Agarose (Gibco, BRL) in EBSS eingebettet. Von den eingebetteten Gehirnen wurden in kaltem PBS $300 \mu \mathrm{m}$ dicke, coronale Schnitte 
erstellt (manuelles Vibratom, TSE-Systems). Die Schnitte wurden zur Gewebekultur auf Kultur-Einsätzen (Durchmesser $25 \mathrm{~mm}$, Porendurchmesser 0,4 $\mu \mathrm{m}$, Nunc) in 6well-Platten (Greiner) mit je 1,5 ml Kulturmedium gegeben. Sie wurden so ü.N. bei $37^{\circ} \mathrm{C}$ in einem Inkubator (BBD 6220, Heraeus) in feuchter $\mathrm{CO}_{2}$-Atmosphäre $(5 \%)$ kultiviert (Luftfeuchte $=95 \%)$. Am folgenden Tag wurden die Gewebeschnitte fixiert und gefärbt (s. Protokoll zur $\beta$-Galctosidase-Färbung).

Zusammensetzung des Gewebe-Kulturmediums:

Neurobasal A-Medium (ohne Glutamin, Gibco BRL)

$86 \mathrm{ml}$

Fetales Kälberserum (Pan Biotech GmbH)

$10 \mathrm{ml}$

Streptomycin (10 mg/ ml, Gibco BRL)

$0,5 \mathrm{ml}$

Penicillin (10 000 Units/ ml, Gibco BRL)

$0,5 \mathrm{ml}$

Glutamin (200 mM, Gibco BRL)

B27-Supplement (50x, Gibco BRL)

$1 \mathrm{ml}$

$2 \mathrm{ml}$ 


\section{Ergebnisse}

\section{Microarray-Expressionsanalyse von verschiedenen Regionen des cerebralen Cortex zum Embryonaltag 16,5}

Ausgangspunkt dieser Arbeit war das Ziel, neue Gene zu identifizieren, die im cerebralen Cortex der Maus zum Embryonaltag 16,5, eine regionenspezifische Expression aufweisen. Es wurden dafür fünf Cortexregionen des Stadiums E16,5 präpariert (s. Abb.3):

- der frontale Cortex (Anlage des motorischen Cortex)

- der rostro-mediale Cortex (Anlage des Cingulums)

- der parietale Cortex (Anlage des somatosensorischen Cortex)

- der caudo-mediale Cortex (Anlage des Hippocampus)

- und der occipitale Cortex (Anlage des visuellen Cortex)

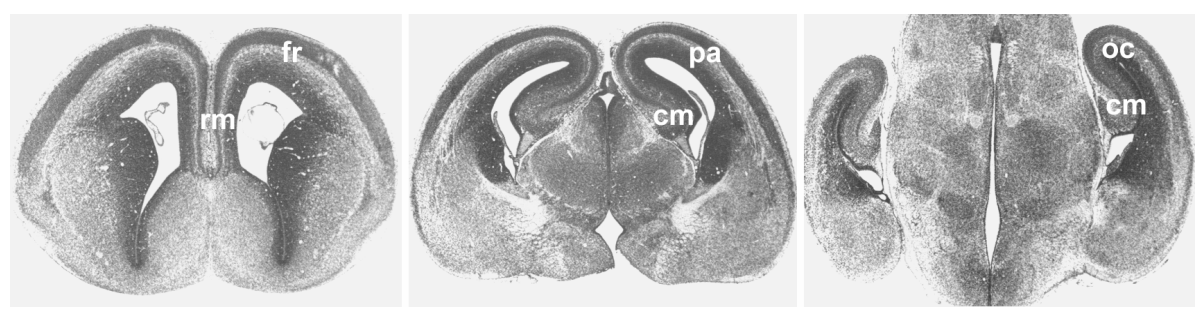

Abb.3: Regionen des cerebralen Cortex der Maus zum Embryonaltag E16,5 (Schambra et al., 1992)

Die Bilder zeigen coronale Schnitte und gehen von links nach rechts von anterior nach posterior.

cm, caudo-medialer Cortex; fr, frontaler Cortex; oc, occipitaler Cortex; pa, parietaler Cortex; rm, rostro-medialer Cortex

Um vornehmlich nervensystemspezifische Gene zu erhalten, wurde als Kontrolle der Körper von E16,5 Embryonen gewählt, denen Gehirn, Rückenmark und die Genitalleiste entfernt wurden.

Nach Synthese von biotin-markierten RNA-Proben, Hybridisieren, Färben und Scannen der Microchips wurden die produzierten Daten mit Hilfe der Affymetrix Software "Microarray Suite, Version 4.0" ausgewertet (s. Kap.II, 2.3). Dazu wurden Listen von Genen erstellt, deren Expression in einer der fünf Cortexregionen erhöht war. Um in eine Liste aufgenommen zu werden, mußte ein Gen drei Kriterien erfüllen: 
1. Der "Difference Call" (Expressionsunterschied) sollte im Vergleich zu den anderen Cortexregionen und der Kontrolle "marginal increased" (geringfügig erhöht) oder "increased" (erhöht) betragen.

2. Die Expression ist im Vergleich zu allen anderen vier Cortexregionen um einen "Fold Change" von mindestens 2 erhöht.

3. Die Expression ist im Vergleich zu mindestens einer Cortexregion um einen "Fold Change" von $\geq 3$ erhöht.

Mit Hilfe dieser Filterkriterien wurden 96 Sequenzen selektiert, die laut MicroarrayAnalyse spezifisch in einer bestimmten Cortexregion zum Entwicklungszeitpunkt E16,5 exprimiert werden (Tab.1). Zwei Gene waren doppelt auf den Microchips vertreten (Nef3 und Zfp288). Die Aufteilung dieser ausgewählten Sequenzen auf die verschiedenen Cortexregionen ist in Abb.4 dargestellt. Es entfielen auf den frontalen Cortex 55 Gene (58\%), auf den rostro-medialen Cortex 12 (13\%), auf den caudomedialen Cortex 10 (10\%), auf den parietalen Cortex 7 (7\%) und auf den occipitalen Cortex 12 Gene (12\%). Mit Hilfe der CELERA Datenbank wurden die ausgewählten Gene annotiert, wobei für 37 Gene zu diesem Zeitpunkt keine Annotation möglich war.

Alle bekannten Gene (57) wurden basierend auf dem "Gene Ontology Mining Tool" (Ashburner et al., 2000) nach ihrer Funktion klassifiziert, was in Abb.5 dargestellt ist. Es überwogen dabei die Funktionen als Transkriptionsfaktoren (15 Gene, 25\%), Rezeptoren (8 Gene, 14\%), Funktionen in der Signaltransduktion (8 Gene, 14\%) und als Enzyme (9 Gene, 16\%). Auf die anderen Gruppierungen wie z.B. Hormone (2\%), Cytoskelett (7\%) und Ionenkanäle (4\%) entfielen weniger Gene. 10 Gene (18\%) fallen in die Kategorie "Andere" (wie z.B. Smyd5), der keine der klassischen Funktionen zuzuordnen ist. 


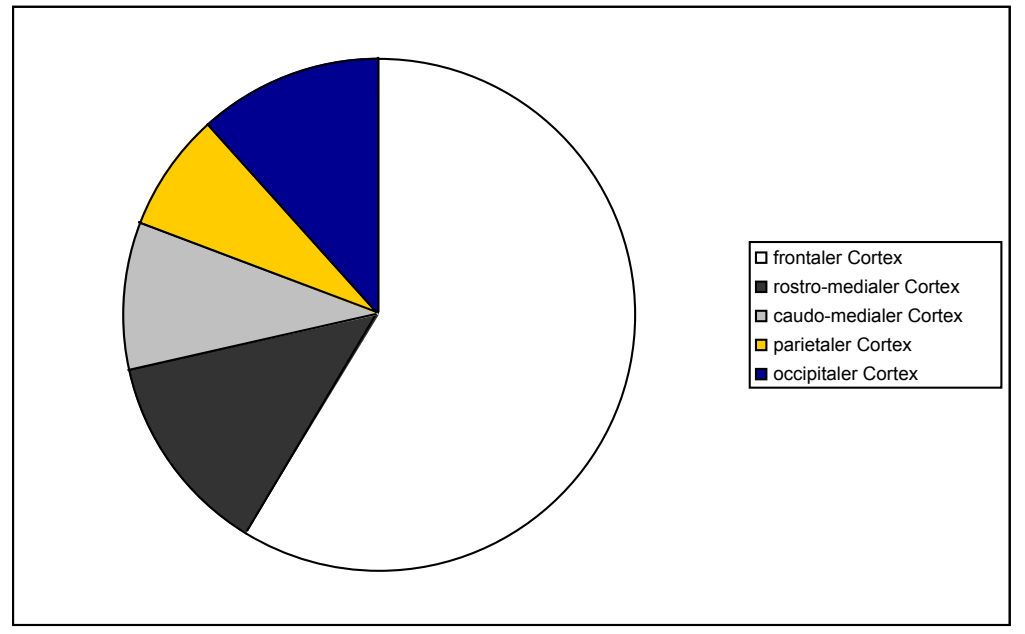

Abb.4: Aufteilung der 96 ausgewählten Gene in die Cortexregionen, in denen sie laut MicroarrayAnalyse zum Embryonaltag 16,5 exprimiert werden

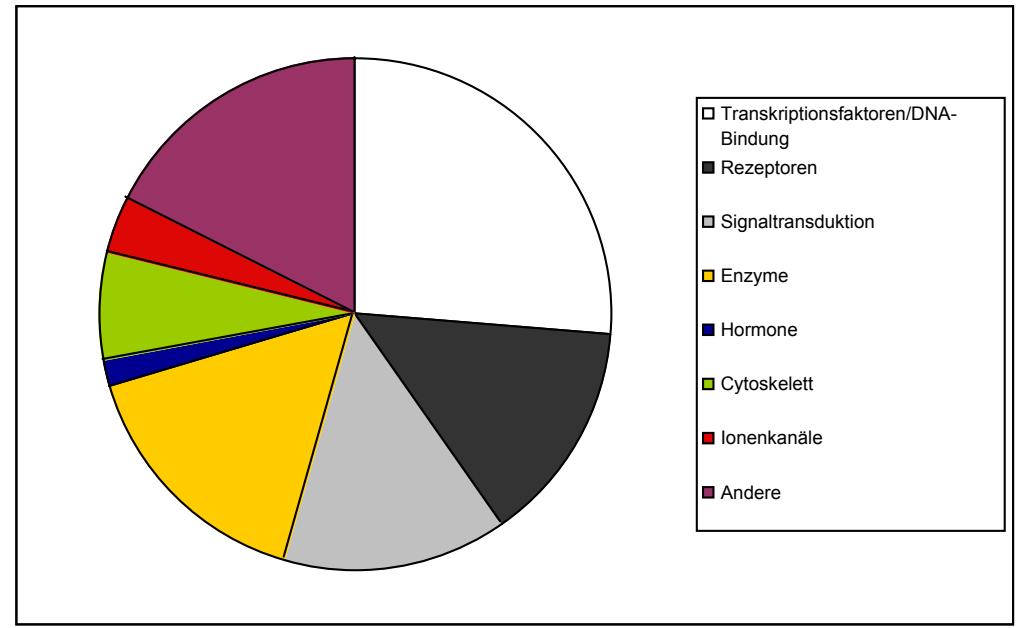

\section{Abb.5: Klassifizierung der bekannten Gene nach ihrer Funktion}

Die meisten Gene lassen sich den Gruppen Transkriptionsfaktoren, Rezeptoren und Signaltransduktion zuordnen. Die Zuordnung erfolgte nach dem "Gene Ontology Mining Tool". 
Tab.1:

In den folgenden Tabellen sind die Gene aufgeführt, die alle beschriebenen Filterkriterien erfüllten. Der "Difference call" (DC) beschreibt den Unterschied in der Expression im Vergleich zu einer Basislinie während der "Fold change" (FC) das Verhältnis der Genexpression zwischen einem Basiswert und einer Probe darstellt.

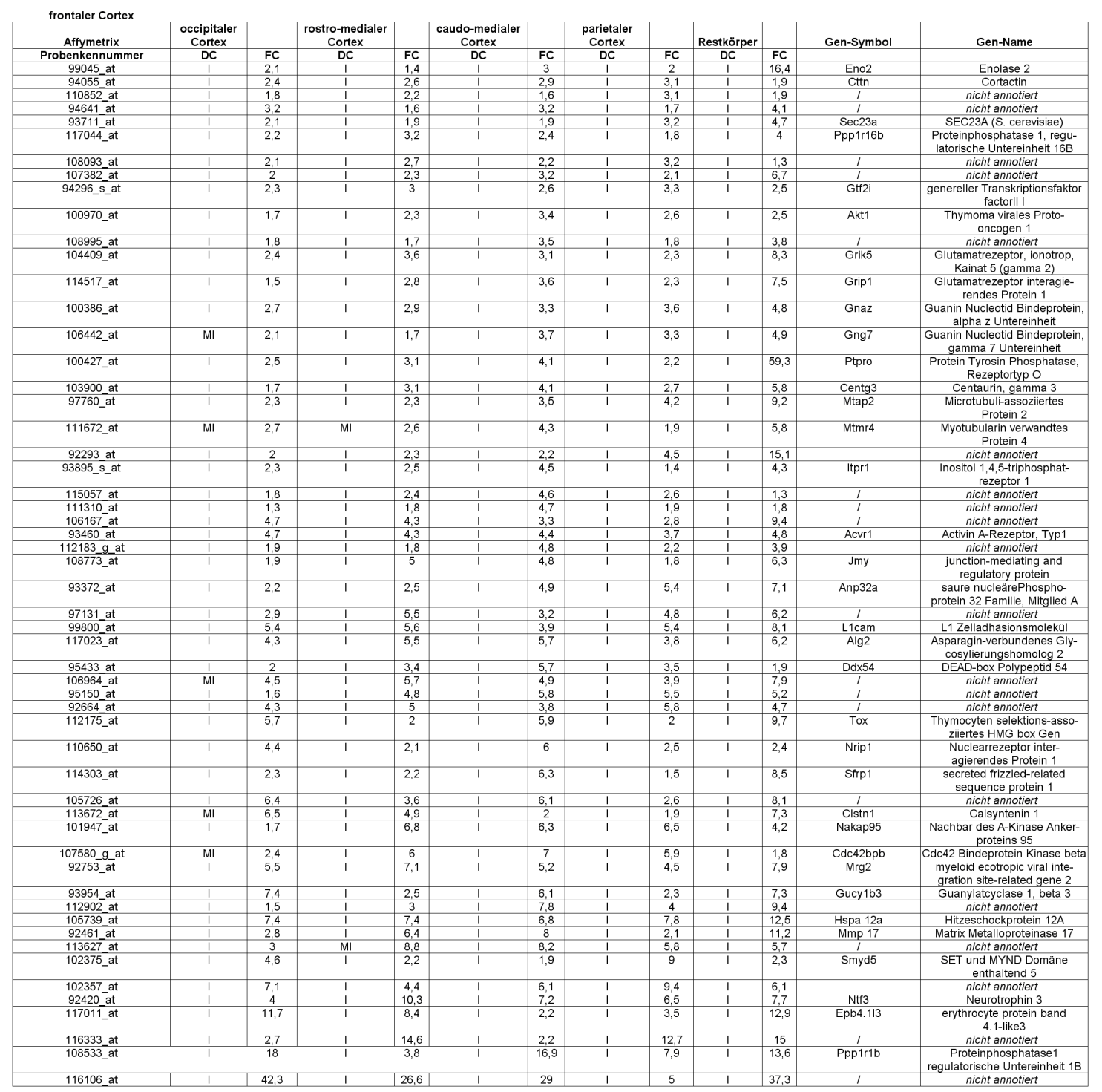




\begin{tabular}{|c|c|c|c|c|c|c|c|c|c|c|c|c|}
\hline Affymetrix & $\begin{array}{c}\text { occipitaler } \\
\text { Cortex }\end{array}$ & & $\begin{array}{c}\text { frontaler } \\
\text { Cortex }\end{array}$ & & $\begin{array}{l}\text { caudo- } \\
\text { medialer } \\
\text { Cortex }\end{array}$ & & $\begin{array}{c}\text { parietaler } \\
\text { Cortex }\end{array}$ & & Restkörper & & $\begin{array}{c}\text { Gen- } \\
\text { Symbol }\end{array}$ & Gen-Name \\
\hline Probenkennummer & DC & FC & DC & FC & DC & $\mathrm{FC}$ & DC & FC & DC & FC & & \\
\hline 94100_s_at & 1 & 2,5 & I & 3,3 & 1 & 2,3 & 1 & 1,4 & 1 & 9,8 & Trpc4 & $\begin{array}{c}\text { transient receptor potential } \\
\text { cation channel, Subfamilie } C_{i} \\
\text { Mitglied } 4\end{array}$ \\
\hline 96672_at & 1 & 3,6 & I & 3,4 & 1 & 1,9 & 1 & 2,8 & 1 & 3,5 & 1 & nicht annotiert \\
\hline 102900_at & I & 3,3 & 1 & 2,6 & 1 & 2,7 & I & 3,7 & 1 & 3,5 & Six3 & $\begin{array}{c}\text { sine oculis-verwandtes Homeo- } \\
\text { box Homolog (Drosophila) }\end{array}$ \\
\hline 92930_at & 1 & 2 & 1 & 4 & 1 & 1,7 & 1 & 3,3 & 1 & 3,6 & Dlx5 & distal-less Homeobox 5 \\
\hline 103061_at & 1 & 1,6 & $\mathrm{I}$ & 2,4 & 1 & 1,8 & 1 & 4,6 & 1 & 26,6 & Gad1 & glutamic acid decarboxylase 1 \\
\hline 94123_at & 1 & 5,1 & 1 & 3,4 & $\mathrm{I}$ & 1,8 & 1 & 3,9 & 1 & 10 & Neurod4 & neurogene Differenzierung 4 \\
\hline 97721_at & 1 & 3,7 & 1 & 5,4 & 1 & 3 & 1 & 3,3 & 1 & 4,2 & Fgf15 & Fibroblastenwachstumsfaktor 15 \\
\hline 98330_at & 1 & 9,2 & 1 & 7,2 & 1 & 6,1 & 1 & 6 & 1 & 14 & Zic3 & $\begin{array}{c}\text { Zink-Fingerprotein des } \\
\text { Cerebellums } 3\end{array}$ \\
\hline 116403_at & 1 & 6,7 & 1 & 7,7 & 1 & 1,8 & I & 10,4 & 1 & & Zic5 & $\begin{array}{l}\text { Zink-Fingerprotein des } \\
\text { Cerebellums } 5\end{array}$ \\
\hline 98843_at & 1 & 10 & 1 & 11,2 & 1 & 2 & 1 & 7,8 & 1 & 10,6 & Zic2 & $\begin{array}{l}\text { Zink-Fingerprotein des } \\
\text { Cerebellums2 }\end{array}$ \\
\hline 103597_at & 1 & 33,9 & 1 & 3 & 1 & 23,2 & 1 & 27,2 & 1 & 30,6 & Det & Dopachrom Tautomerase \\
\hline 104169_at & 1 & 54,9 & 1 & 11,3 & 1 & 5 & 1 & 26,5 & 1 & 102,6 & Zic1 & $\begin{array}{l}\text { Zink-Fingerprotein des } \\
\text { Cerebellums } 1\end{array}$ \\
\hline
\end{tabular}

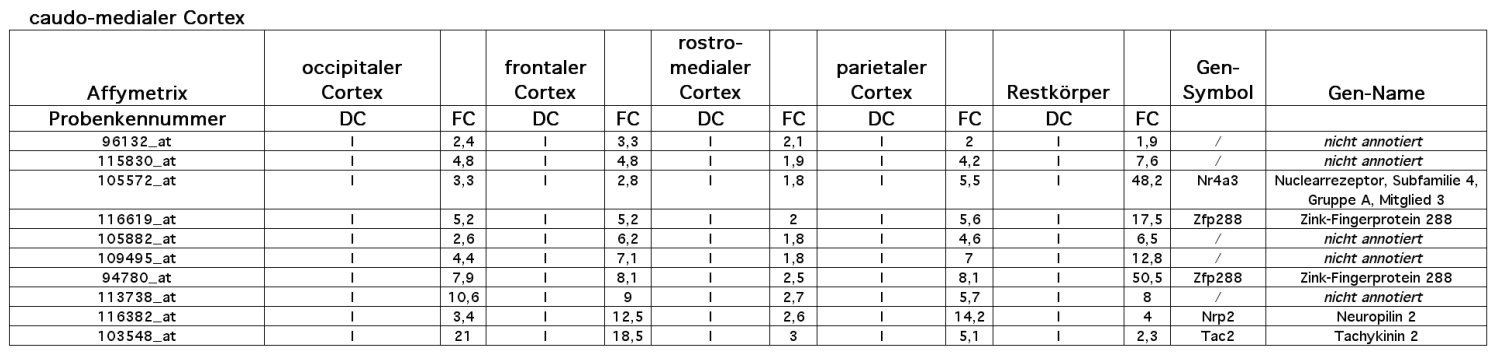

\begin{tabular}{|c|c|c|c|c|c|c|c|c|c|c|c|c|}
\hline Affymetrix & $\begin{array}{l}\text { occipitaler } \\
\text { Cortex }\end{array}$ & & $\begin{array}{c}\text { frontaler } \\
\text { Cortex }\end{array}$ & & $\begin{array}{c}\text { rostro- } \\
\text { medialer } \\
\text { Cortex }\end{array}$ & & $\begin{array}{c}\text { caudo- } \\
\text { medialer } \\
\text { Cortex }\end{array}$ & & Restkörper & & $\begin{array}{c}\text { Gen- } \\
\text { Symbol }\end{array}$ & Gen-Name \\
\hline Probenkennummer & DC & $\mathrm{FC}$ & DC & FC & DC & FC & DC & FC & DC & FC & 1 & nicht annotiert \\
\hline 99362_at & 1 & 3 & 1 & 3,3 & 1 & 2,7 & 1 & 2.5 & 1 & 3,1 & 1 & nicht annotiert \\
\hline 102091_fat & MI & 2,4 & $\mathrm{Ml}$ & 3,6 & MI & 2,6 & 1 & 2.6 & 1 & 2,4 & 1 & nicht annotiert \\
\hline 94028 f at & 1 & 3 & $\mathrm{I}$ & 3,7 & 1 & 3,2 & I & 3 & I & 3,1 & 1 & nicht annotiert \\
\hline 100344_at & 1 & 2,2 & $\mathrm{Ml}$ & 2,8 & 1 & 2,6 & 1 & 3.9 & 1 & 2,1 & 1 & nicht annotiert \\
\hline 99527_at & I & 2,2 & 1 & 1,4 & 1 & 3,8 & I & 5.4 & I & 5,4 & Nfe2/3 & $\begin{array}{l}\text { nuclear factor, erythroid } \\
\text { derived } 2 \text {, like } 3\end{array}$ \\
\hline 95184_f_at & 1 & 3,5 & 1 & 8,3 & $\mathrm{I}$ & 8,3 & 1 & 3.2 & $\mathrm{I}$ & 2,3 & 1 & nicht annotiert \\
\hline 98577_f_at & 1 & 4,2 & 1 & 15,2 & 1 & 6,6 & 1 & 9.1 & 1 & 3 & 1 & nicht annotiert \\
\hline
\end{tabular}

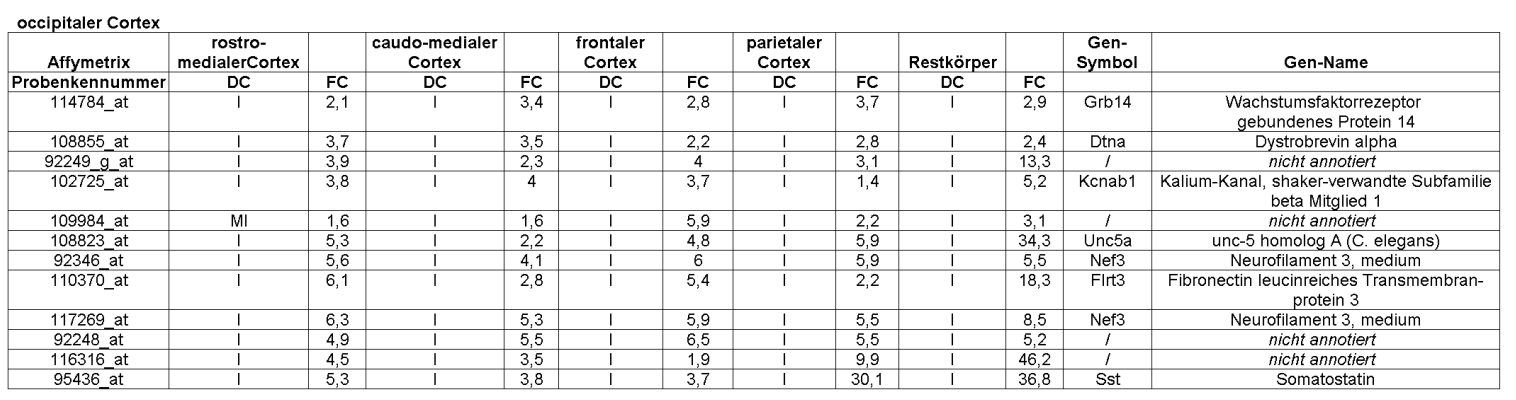




\section{RNA-in situ-Hybridisierung ausgewählter Gene aus der Microarray-Expressionsanalyse}

Zur Überprüfung, ob die nach den Filterkriterien selektierten Gene aus der Microarray-Analyse tatsächlich in der entsprechenden Cortexregion exprimiert werden, wurde ein zweiter Screen mittels der RNA-in situ-Hybridisierung an E16,5Gehirnschnitten durchgeführt. Dafür wurden nur die Gene berücksichtigt, die zum Zeitpunkt der Analyse laut Affymetrix noch nicht annotiert waren. Um an die DNA der ausgewählten Gene zu gelangen, wurden Klone des IMAGE Konsortiums bestellt, die vor Gebrauch in der in situ Hybridisierung zunächst ansequenziert wurden. Im Folgenden werden 10 Gene mit ihrem Expressionsmuster näher vorgestellt.

Abb.6 zeigt drei Gene, die nach der Microarray-Expressionsanalyse die stärkste Expression im frontalen Cortex aufweisen sollten.

Thymocyten selektions-assoziiertes HMG (high mobility group) box Gen (Tox) (Abb.6 A-D)

Das Verhältnis der Expression zwischen einem Basiswert (in diesem Fall der frontale Cortex) und einer anderen Probe (die anderen Cortexgewebe) wird durch den "Fold Change" angegeben. Für das Gen Tox betragen diese Werte für den parietalen und rostro-medialen Cortex 2. Im Vergleich zum caudo-medialen Cortex beträgt der Wert 5,9 und zum occipitalen Cortex 5,7.

Tox zeigt eine Expression in den postmitotischen Zellen der tieferen Corticalplatte des frontoorbitalen Cortex (A), in der Anlage des Cingulums und im frontalen Cortex (B). Weiterhin findet es sich in der Subventrikulärzone des Septums (Pfeil in B). Die Genexpression liegt in einem Gradienten vor, der sich von rostro-medial (hoch) nach caudo-lateral (niedrig) bewegt. 


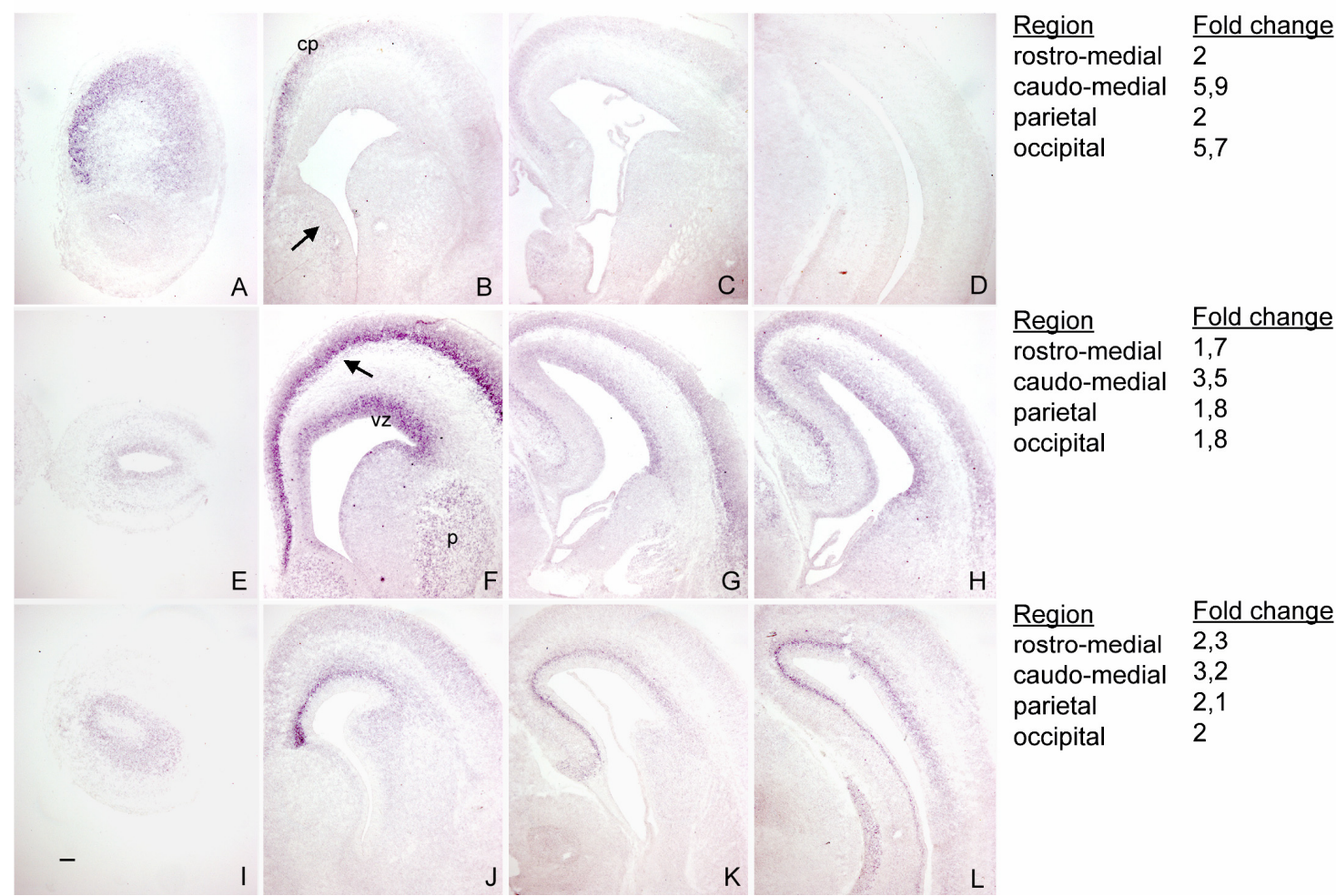

Abb.6: RNA-in situ-Hybridisierung von Genen, die laut Microarray-Expressionsanalyse im frontalen Cortex exprimiert werden.

Die Bilder zeigen coronale Gefrierschnitte des Embryonalstadiums E16,5 (links rostral, rechts caudal). Das Expressionsverhältnis zwischen dem frontalen Cortex und den anderen Cortexregionen ist als Fold Change in den Tabellen wiedergegeben.

A-D: Thymocyten selektions-assoziiertes HMG (high mobility group) box Gen (Tox) mit starker Expression im frontalen Bereich des Gehirns.

E-H: Ein neues Gen, das in einem Gradienten von rostro-medial (hoch) nach caudo-lateral (niedrig) exprimiert wird.

I-L: Bei diesem neuen Gen ist eine Expression in der Subventrikulärzone und in der tieferen Corticalplatte des frontalen und rostro-medialen Cortex zu beobachten.

$\mathrm{cp}$, Corticalplatte; $\mathrm{p}$, Putamen; vz, Ventrikulärzone

Der Pfeil in B zeigt auf die Subventrikulärzone des Septums, in F auf die Subplatte des Cortex.

Maßstab: $100 \mu \mathrm{m}$ 
Ein neues Gen mit der Affymetrix Probenkennummer 108995 at (Abb.6 E-F)

Die Fold Change-Werte gegenüber den anderen Cortexregionen sind: parietal und occipital 1,8; rostro-medial 1,7 und caudo-medial 3,5.

Die Expression dieses Gens erstreckt sich über die postmitotischen Zellen der tieferen Corticalplatte und der Subplatte (Pfeil in F) der Anlage des motorischen Cortex, des Cingulums und des primären und sekundären somatosensorischen Feldes (F). Weiterhin kommt es in der proliferativen Schicht des Cortex vor: in der Ventrikulärzone des dorsalen und ventralen Palliums. Im Putamen ist dieses Gen ebenfalls exprimiert (F). Auch hier ist ein Gradient in der Expression zu beobachten: rostro-lateral (hoch) und caudo-medial (niedrig).

$\underline{\text { Expression eines neues Gens mit der Affymetrix Probenkennummer } 107382 \text { at }}$ (Abb.6 I-L)

Die Microarray-Expressionsanalyse ergab die folgenden Fold Change-Werte für dieses Gen: rostro-medial 2,3; caudo-medial 3,2; parietal 2,1 und occipital 2.

Für dieses Gen ist eine Expression in der tieferen Corticalplatte und in der Subventrikulärzone zu beobachten. Die Expression erstreckt sich von rostral nach caudal und liegt in einem medial (hoch) und lateral (niedrig)-Gradienten vor.

In Abb.7 sind drei Gene dargestellt, die laut Microarray-Expressionsanalyse regionalisiert im caudo-medialen Cortex auftreten sollten.

Zink-Fingerprotein 288 (Abb.7 A-D)

Dieses Gen war mit den Sequenzen 94780_at und 116619_at zweimal vertreten. Die Fold Change-Werte sind rostro-medial 2 und 2,5; frontal 5,2 und 8,1; parietal 5,6 und 8,1 und occipital 5,2 und 7,9 . 


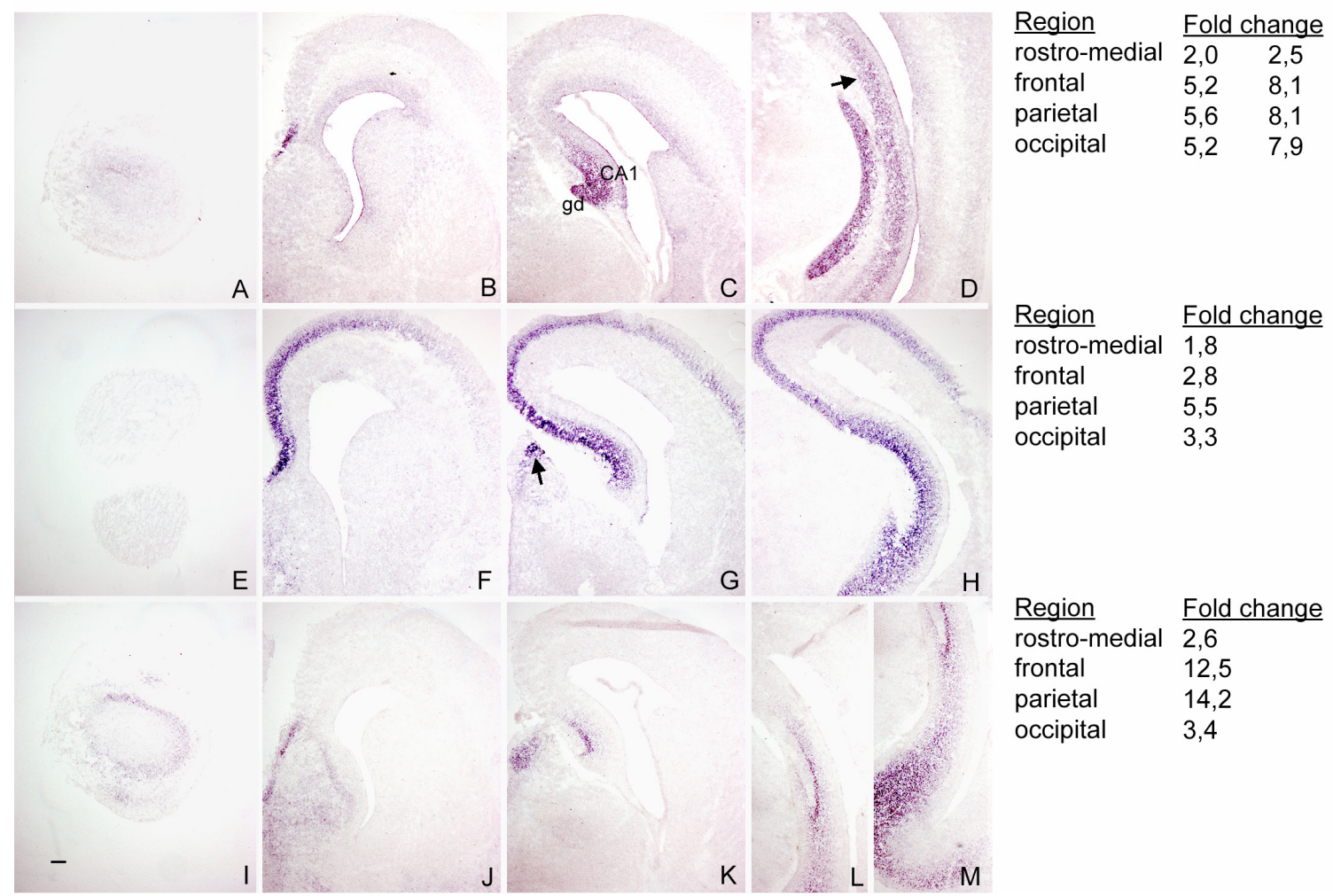

Abb.7: Expressionsmuster von Kandidaten, die nach den Filterkriterien für den caudo-medialen Cortex ausgewählt wurden

RNA-in situ-Hybridisierung mit antisense-Sonden auf E16,5 coronalen Gefrierschnitten (links rostral, rechts caudal), die Tabellen geben das Expressionsverhältnis zwischen dem caudo-medialen Cortex und den anderen für die Microarray-Expressionsanalyse verwendeten Geweben wieder.

A-D: Zink-Fingerprotein 288 zeigt Expression im Gyrus dentatus und in dem Feld CA1.

E-H: Hier ist die Expression eines neuen Gens zu sehen mit starkem Signal in der tieferen Corticalplatte. Die Expression verläuft graduell von medial (hoch) nach lateral (niedrig).

I-M: Neuropilin2 liefert starke Signale im Hippocampus und im Subiculum.

gd, Gyrus dentatus; CA1, Feld CA1

Die Pfeile deuten in D auf das Subiculum, in G auf den Epithalamus.

Maßstab: $100 \mu \mathrm{m}$ 
Das Zink-Fingerprotein 288 kommt in der Anlage des Hippocampus (B, C, D) vor: im Gyrus dentatus und in dem Feld CA1 (C). Weiterhin ist eine Expression im Übergangsgebiet zwischen Hippocampus und der angrenzenden entorhinalen Rinde, dem Subiculum (Pfeil in D), zu verzeichnen sowie ein schwaches Expressionssignal in der Ventrikulärzone des Cortex.

Nuclear-Rezeptor Subfamilie 4, Gruppe A, Mitglied 3 (Nr4a3 (Abb.7 E-H))

Im Vergleich zum rostro-medialen Cortex liegt ein Fold Change von 1,8 vor, zum frontalen Cortex 2,8; zum parietalen 5,5 und zum occipitalen Cortex 3,3.

Die Expression dieses Gens verläuft graduell in der tieferen Corticalplatte von medial (hoch) nach lateral (niedrig). Die in situ Hybridisierung lieferte starke Signale in der Anlage des Hippocampus, des Cingulums, des motorischen und somatosensorischen Cortex. Weiterhin wird das Gen in den postmitotischen Zellen des Epithalamus exprimiert (s. Pfeil in G).

\section{Neuropilin2 (Abb.7 I-M)}

Die Fold Change-Werte gegenüber den anderen Cortexregionen betragen: rostromedial 2,6; frontal 12,5; parietal 14,2 und occipital 3,4.

Eine Neuropilin2-Expression ist im Feld CA1 (K) des Hippocampus, in der Subventrikulärzone des Epithalamus (J) und im Subiculum (L, M) zu beobachten.

In Abb.8 A-D und 8 E-H sind zwei Beispiele zu betrachten, die in der MicroarrayAnalyse die stärkste Expression im occipitalen Cortex zeigten.

Neurofilament3, medium (Abb.8 A-D)

Dieses Gen war mit zwei Sequenzen auf dem Microarray vertreten: 117269_at und 92346_at. Die Fold Change-Werte im Vergleich zu den anderen Geweben sehen wie folgt aus: rostro-medial 6,3 und 5,6; caudo-medial 5,3 und 4,1; frontal 5,9 und 6 und parietal 5,5 und 5,9.

Abb.8 B zeigt eine Expression des Neurofilaments in der Subventrikulärzone der Basalganglien. Darüberhinaus kommt es im ventralen Thalamus (C), im caudalen Bereich in der oberen Corticalplatte des occipitalen und auditorischen Cortex (D) vor. Es liegt eine stärkere Expression caudal als rostral vor. 
Ein neues Gen mit der Probennummer 116316 at (Abb.8 E-H)

Mit Hilfe der Microarray-Expressionsanalyse wurden diese Fold Change-Werte ermittelt: rostro-medial 4,5; caudo-medial 3,5; frontal 1,9 und parietal 9,9.

Dieses Gen wird in der Lamina glomerulosa des Bulbus olfactorius (E), in der Anlage des Hippocampus(F) und im Piriformcortex $(\mathrm{H})$ exprimiert. Außerdem ist ein in situ Hybridisierungssignal in der Ventrikulärzone der Basalganglien, des lateralen und ventralen Palliums (F) und des occipitalen Cortex $(\mathrm{H})$ zu vermerken.

Das Zink-Fingerprotein 5 des Cerebellums (Zic5) (Abb.8 I-L) ist ein Beispiel für ein Gen, das in der Microarray-Analyse das stärkste Signal in der Anlage des Cingulums (rostro-medialer Cortex) lieferte. Der Fold Change zum caudo-medialen Cortex beträgt 1,8; zum frontalen Cortex 7,7; zum parietalen Cortex 10,4 und zum occipitalen Cortex 6,7.

Zic5-Expression ist in der Mantelschicht des Septums (J), des Epithalamus und dorsalen Thalamus $(\mathrm{K})$ zu beobachten. 


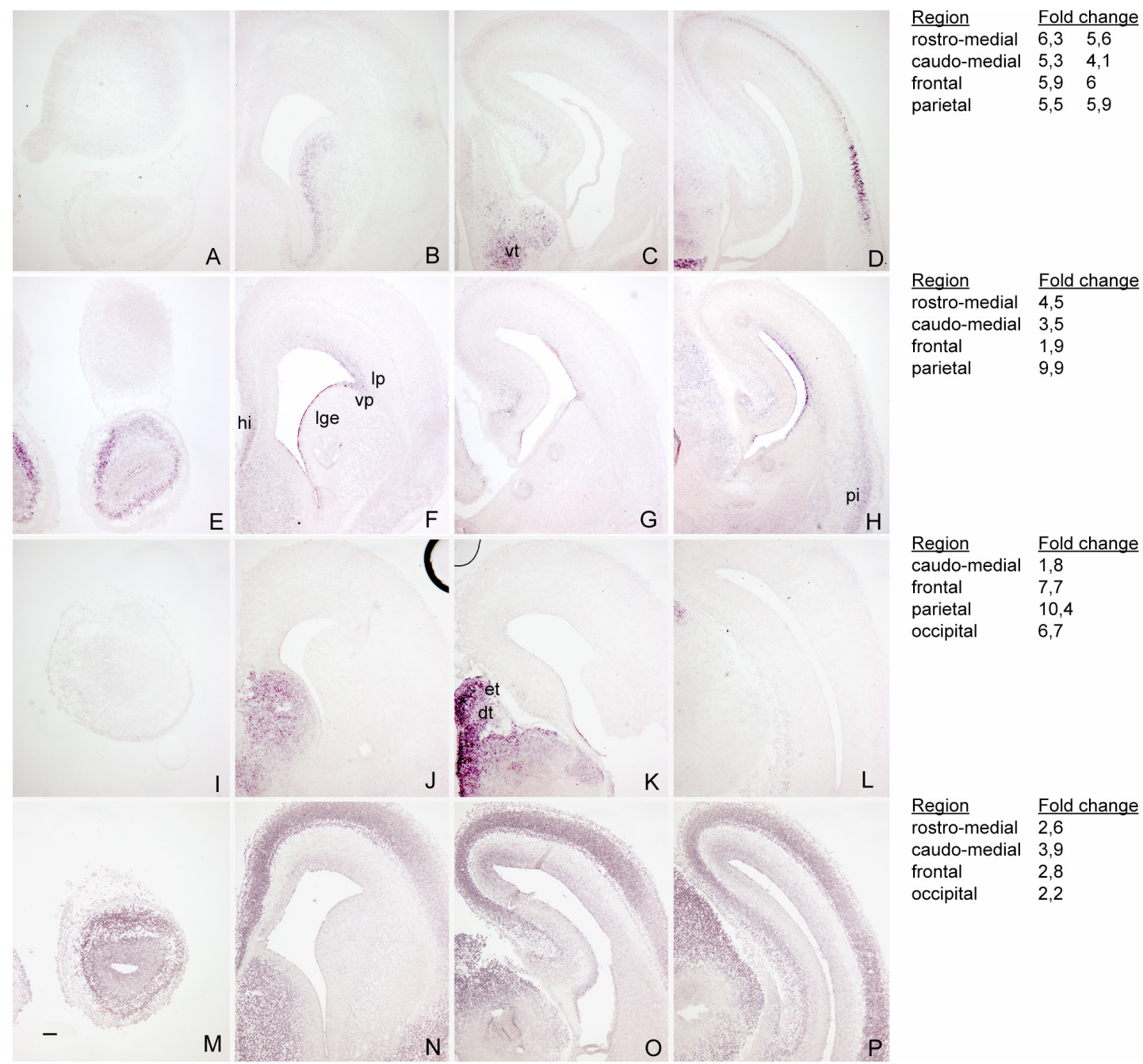

Abb.8: Gene, die nach der Microarray-Expressionsanalyse eine regionalisierte Expression im cerebralen Cortex zum Embryonaltag E16,5 aufweisen.

Dargestellt sind RNA-in situ-Hybridisierungen auf E16,5 coronalen Gefrierschnitten, in den Tabellen sind die Fold Change-Werte zu den anderen Regionen angegeben.

A-D: Das Neurofilament3, medium mit Expressionsgradienten von rostral (niedrig) nach caudal (hoch)

E-H: Dieses neue Gen lieferte hauptsächlich ein Expressionssignal in der Ventrikulärzone des Cortex. I-L: Das Expressionsmuster des Zink-Fingerprotein 5 des Cerebellums (Zic5) ist charakterisiert durch ein starkes Signal im Septum, Epithalamus und dorsalen Thalamus.

M-P: Ein weiteres neues Gen mit einer breit angelegten Expression im cerebralen Cortex.

dt, dorsaler Thalamus; et, Epithalamus; hi, Hippocampus; lge, laterale ganglionäre Eminenz; lp, laterales Pallium; vp, ventrales Pallium; vt, ventraler Thalamus; pi. Piriformcortex;

Maßstab: $100 \mu \mathrm{m}$ 
Zum Abschluß folgt ein neues Gen (Affymetrix Probenkennummer 100344 at, Abb.8 $\underline{\mathrm{M}-\mathrm{P})}$ als Beispiel für einen Kandidaten, der im Microarray-Experiment das stärkste Signal im parietalen Cortex erbrachte. Die Fold Change-Werte zu den anderen Geweben betragen: rostro-medial 2,6; caudo-medial 3,9; frontal 2,8 und occipital 2,2. Hier fällt eine besonders breit gestreute Expression des Gens auf. Es kommt in der Lamina mitralis des Bulbus olfactorius (M), in den postmitotischen Zellen des Septums $(\mathrm{N})$ und in der tieferen Corticalplatte des rostro-medialen, frontalen $(\mathrm{N})$, caudo-medialen, parietalen $(\mathrm{O})$ und occipitalen $(\mathrm{P})$ Cortex vor. Daneben ist auch Expression im Epithalamus und dorsalen Thalamus zu sehen.

\section{Auswahl des Gens Maus-PIPPin zur weiteren}

\section{Charakterisierung}

Nach der Verifizierung der Microarray-Daten durch die RNA-in situ-Hybridisierung rief die Sequenz 116316_at (Abb.8 E-H), die im Microarray-Experiment die stärkste Expression im occipitalen Cortex aufwies, besonderes Interesse zur weiteren Bearbeitung hervor. Das Gen wurde Maus-PIPPin benannt, in Anlehnung an das bereits klonierte Ratten-PIPPin (Castiglia et al., 1996). Der Name "PIPPin" entstand durch die Aminosäuresequenz P I P P im Protein (s. Abb.13). 


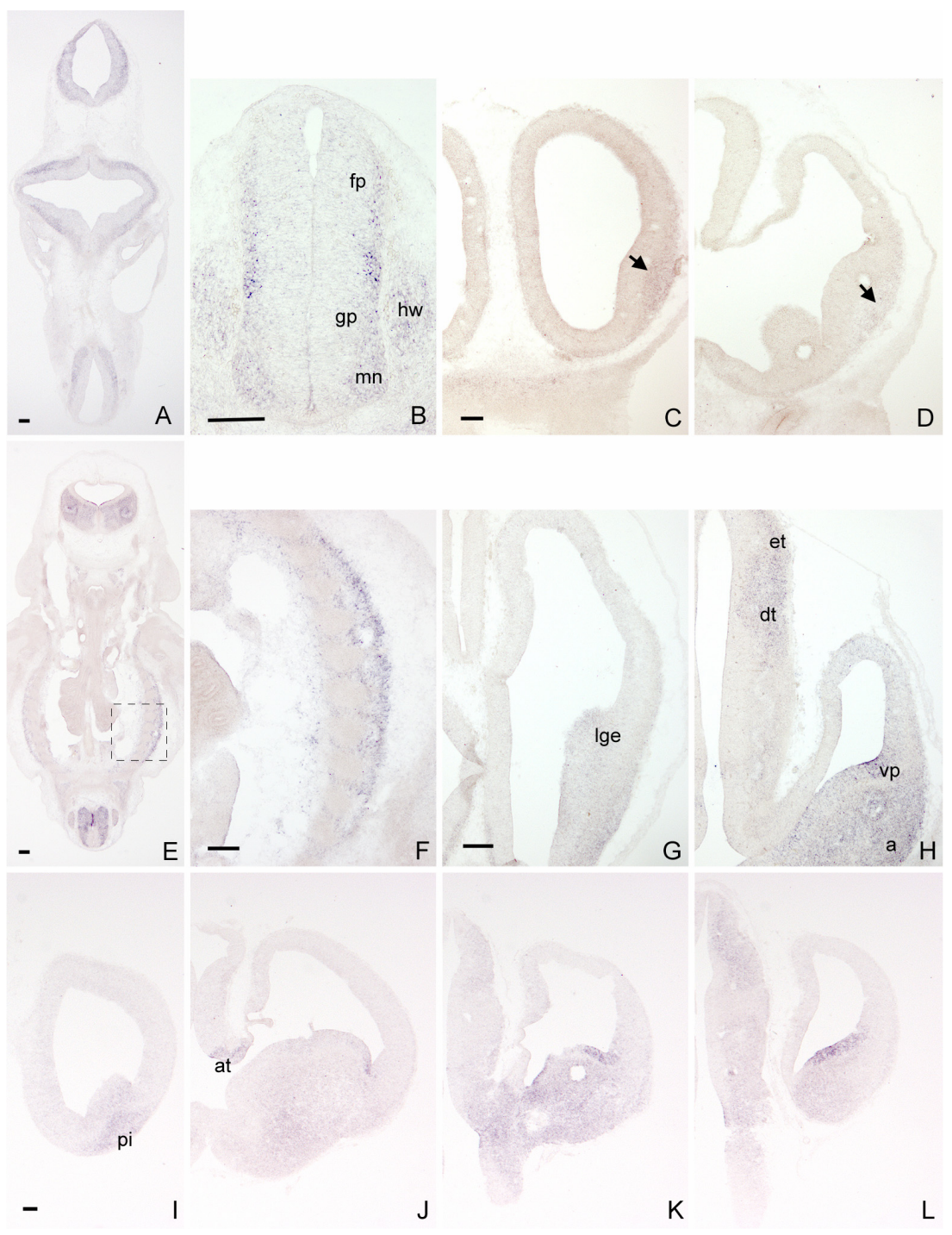

Abb.9: Die PIPPin-Expression im cerebralen Cortex der Maus verstärkt sich zwischen E11,5 und E12,5.

Maus-PIPPin-in situ-Hybridisierung auf Gefrierschnitten:

A-D: E11,5 coronale Embryo- und Gehirnschnitte

Die Pfeile zeigen auf die schwache PIPPin-Expression im Cortex.

E-H: E12,5 coronale Embryo- und Gehirnschnitte zeigen beginnende PIPPin-Expression in der Ventrikulärzone der ganglionären Eminenzen und des ventralen Palliums.

I-L: E14,5 coronale Gehirnschnitte

a, Amygdala; at, anteriorer Thalamus; dt, dorsaler Thalamus; et, Epithalamus; fp, Flügelplatte; gp, Grundplatte; hw, Hinterwurzelganglion; lge, laterale ganglionäre Eminenz; mn, Motorneuron; pi, Piriformcortex

Maßstab: $100 \mu \mathrm{m}$ (F, G: $500 \mu \mathrm{m})$ 


\subsection{Expressionsstudie von Maus-PIPPin}

Analyse der Maus-PIPPin-Expression mit Hilfe der RNA-in situ-Hybridisierung

Embryonaltag 11,5 (Abb.9A-D)

PIPPin wird hier in der Marginalzone von Mes-, Met-, und Myelencephalon exprimiert (A). Im Rückenmark ist Expression in Marginal- und Mantelzone der Flügel- und Grundplatte (B) festzustellen, dagegen ist der Bereich von Boden- und Deckplatte frei von PIPPin-Expression. Weiterhin sind Hinterwurzelganglion und Motoneuron angefärbt. Im Cortex ist die PIPPin-Expression an E11,5 äußerst schwach. In $\mathrm{C}$ und $\mathrm{D}$ sind geringe Signale im Bereich der Intermediärzone der ganglionären Eminenzen zu sehen (s. Pfeile).

\section{Embryonaltag 12,5 (Abb.9 E-H)}

Die PIPPin-Expression ist im Cortex nun deutlich stärker $(\mathrm{G}, \mathrm{H})$. Jetzt ist auch ein Signal in der Ventrikulärzone der lateralen ganglionären Eminenz und des ventralen Palliums zu beobachten. Außerdem tritt PIPPin im Epithalamus, dorsalen Thalamus und in der Amygdala auf. Bei der Färbung im E12,5-Körper (E, F) könnte es sich um Knorpelvorläufer handeln.

\section{Embryonaltag 14,5 (Abb.9 I-L)}

Die PIPPin-Expression in der Ventrikulärzone des ventralen Palliums und der ganglionären Eminenzen setzt sich auch an E14,5 fort (J, K, L). Zusätzlich sind Signale im Piriformcortex, anterioren Thalamus und in der Amygdala zu verzeichnen $(\mathrm{I}, \mathrm{J}, \mathrm{K})$ 


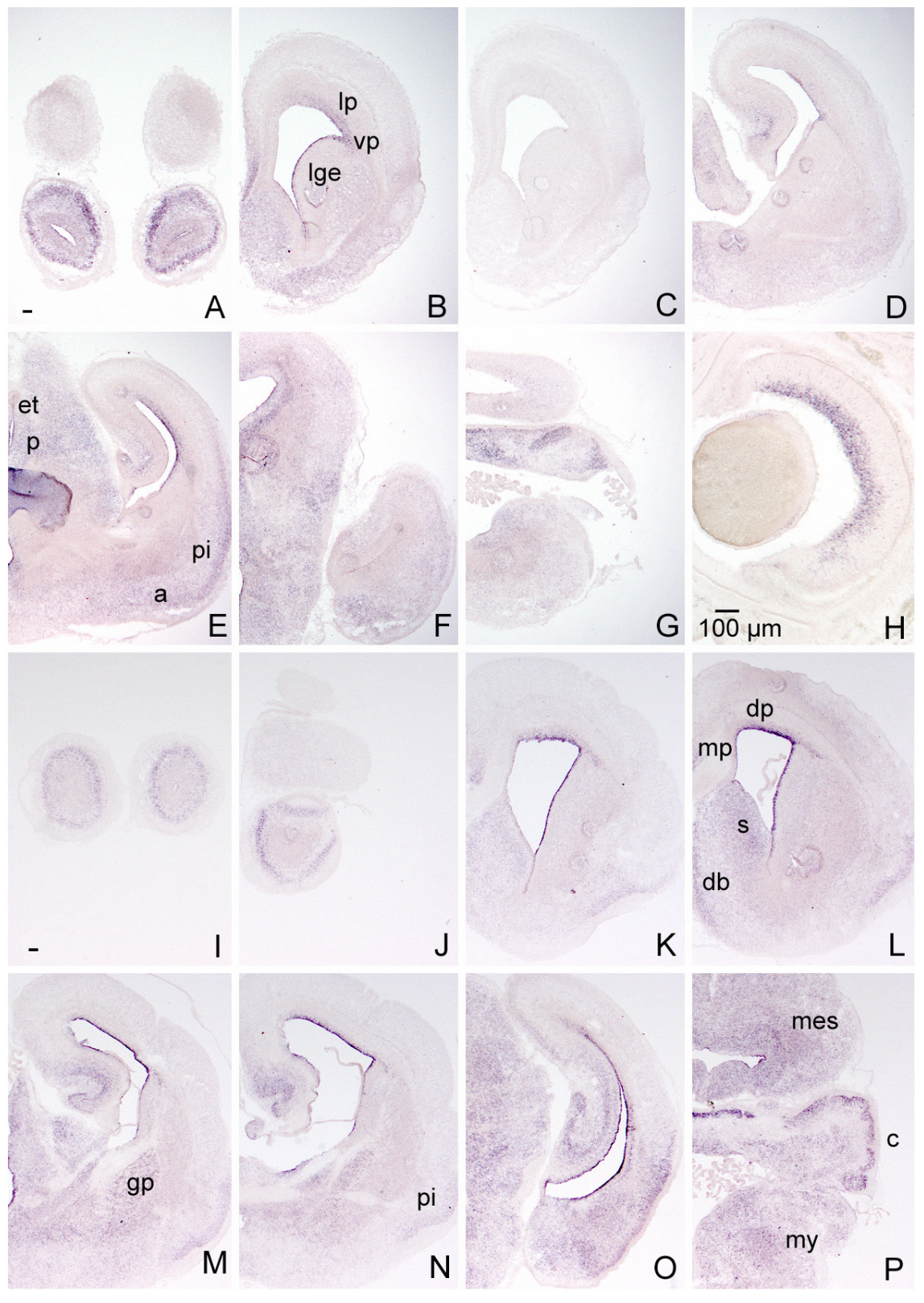

\footnotetext{
Abb.10: Expressionsstudie des Maus-PIPPin Gens zum Entwicklungszeitpunkt E16,5 und E18,5 basierend auf RNA-in situ-Hybridisierung: Maus-PIPPin ist neben dem Cortex auch im Auge, Mesencephalon und Cerebellum exprimiert.

A-H: coronale Gefrierschnitte eines E16,5-Gehirns bzw. Embryos (H) hybridisiert mit einer PIPPinspezifischen Sonde (C mit sense Sonde als Negativkontrolle)

I-P: Hier ist die PIPPin-in situ-Hybridisierung auf E18,5-Gehirnen zu betrachten.

a, Amygdala; c, Cerebellum; db, diagonales Band von Broca; et, Epithalamus; dp, dorsales Pallium; gp, Globus pallidus; lge, laterale ganglionäre Eminenz,; lp, laterales Pallium; mes, Mesencephalon; mp, mediales Pallium; my, Myelencephalon; p, Prätectum; pi, Piriformcortex; s, Septum; vp, ventrales Pallium;

Maßstab: $100 \mu \mathrm{m}$
} 
Embryonaltag 16,5 (Abb.10 A-H)

Maus-PIPPin wird zu diesem Zeitpunkt in der Lamina glomerulosa des Bulbus olfactorius exprimiert (A). Im Cortex liegt eine graduelle Expression vor, die sich von lateral (hoch) nach medial (niedrig) bewegt (B, D, E). Hier kommt Maus-PIPPin in den Zellen der Ventrikulärzone vor, nämlich im Bereich der lateralen ganglionären Eminenz, des lateralen und ventralen Palliums (B, D, E) und des occipitalen Cortex (E). In $\mathrm{C}$ ist eine Hybridisierung mit der sense Sonde als Negativkontrolle zu sehen. Damit wird deutlich, daß es sich bei dem Signal in der Ventrikulärzone um ein spezifisches Signal handelt. Weiterhin ist eine Expression in der Anlage des Hippocampus (B), im Piriformcortex, in der Amygdala, im Epithalamus und Prätectum zu beobachten (E). Auf der Ebene des Mesencephalons und des Cerebellums ist Maus-PIPPin in den postmitotischen Zellen $\mathrm{zu}$ finden (F, G). Das Auge weist eine Maus-PIPPin-Expression in der inneren Schicht des Neuroepithels der Retina auf $(\mathrm{H})$.

Embryonaltag 18,5 (Abb.10 I-P)

Das zum Zeitpunkt E16,5 beobachtete Expressionsmuster setzt sich an E18,5 fort. Noch deutlicher tritt nun der von lateral nach medial verlaufende Gradient in der Ventrikulärzone zu Tage. Jetzt reicht die Maus-PIPPin-Expression bis in das dorsale und mediale Pallium hinein (L). Zusätzlich treten Färbungen im Septum, im diagonalen Band von Broca (L) und im Globus pallidus (M) auf. Im Mes- und Myelencephalon exprimieren postmitotische Zellen Maus-PIPPin während im Cerebellum die Zellen der Ventrikulärzone Maus-PIPPin besitzen (P).

Postnataltag 6 (Abb.11 A-H)

Im Bulbus olfactorius ist zu diesem Zeitpunkt in der Lamina mitralis die stärkste Maus-PIPPin-Expression zu beobachten (A, B). Eine schwache PIPPin-Expression ist in einigen Schichten des Cortex zu sehen, vornehmlich in Schicht V, IV und II/ III (D). Weitere Orte mit PIPPin-Expression sind zu diesem Zeitpunkt der Hippocampus, 


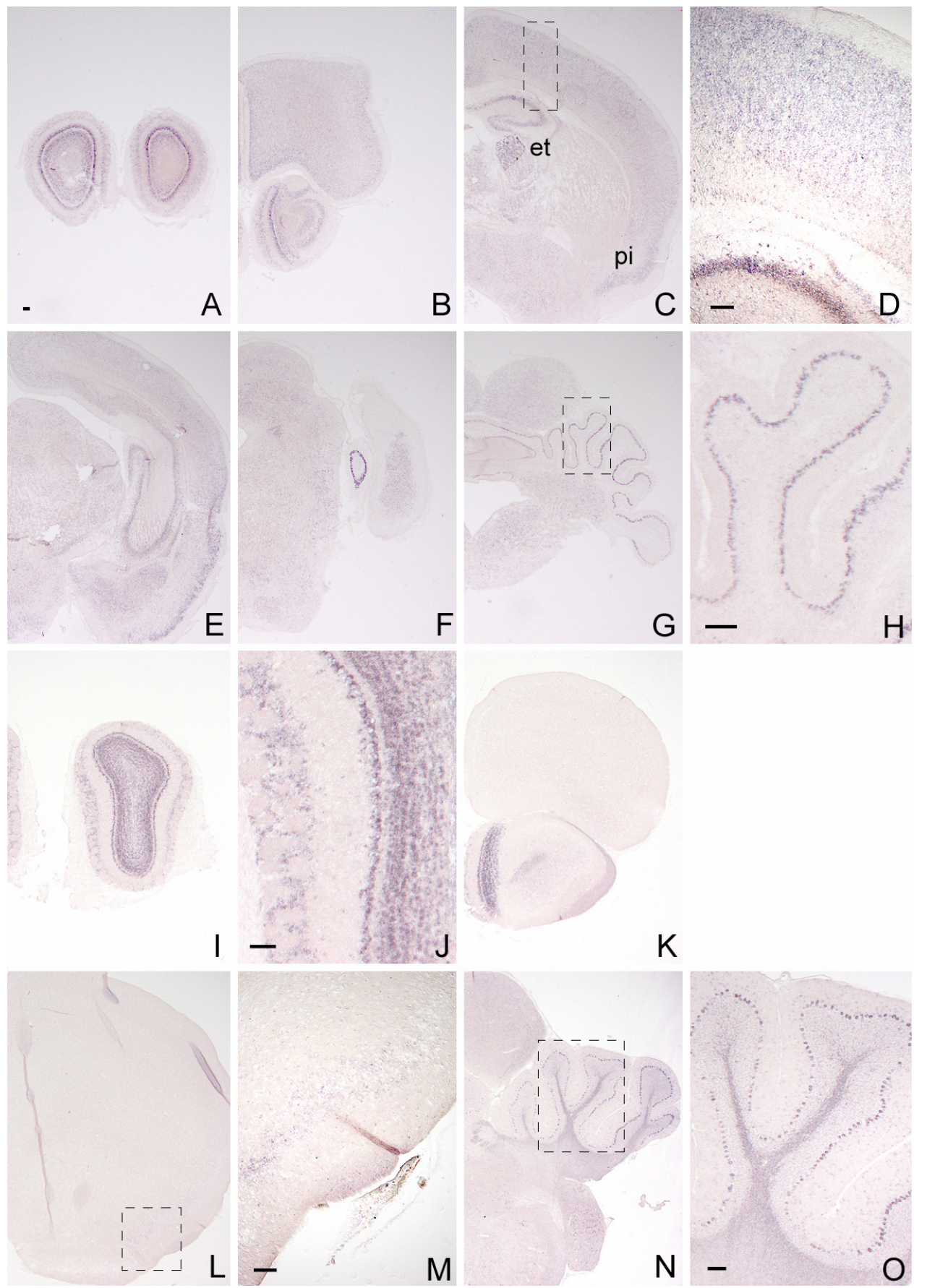

Abb.11: PIPPin-RNA-in situ-Hybridisierung mit Gehirnen des Postnataltags 6 und des adulten Stadiums zeigt Expression in der Purkinje-Zellschicht des Cerebellums

A-H: Überblick der PIPPin-Expression an Tag 6 postnatal

I-O: Maus-PIPPin-RNA in situ-Hybridisierung ausgeführt an adulten Gehirnen zeigt starke Expression in den drei Schichten des Riechkolbens und in der Purkinje-Zellschicht des Cerebellums. et, Epithalmus; pi, Piriformcortex

Maßstab: $100 \mu \mathrm{m}$ 
der Epithalamus und der Piriformcortex (C, E). Im Cerebellum ist nun spezifisch die Purkinje-Zellschicht angefärbt $(\mathrm{G}, \mathrm{H})$.

Adultstadium (Abb.11 I-O)

Alle drei Schichten des Bulbus olfactorius, die Lamina glomerulosa, mitralis und granularis exprimieren nun Maus-PIPPin (I, J). Die Expression im Cortex ist zu diesem Zeitpunkt sehr gering, es sind nur einzeln schwach gefärbte Zellen im Piriformcortex zu beobachten (L, M). Deutlich PIPPin-positiv sind auch hier die Purkinje-Zellen des Cerebellums (N, O).

Analyse der Maus-PIPPin-Expression mittels eines Northern Blots zum Embryonaltag $\underline{16,5}$

Um die Expression von Maus-PIPPin in verschiedenen Geweben zum Zeitpunkt E16,5 zu vergleichen, wurden Rückenmark, Telencephalon, Resthirn (ohne Telencephalon), Lunge, Leber und Herz zu diesem Zeitpunkt präpariert und in einem Northern Blot verarbeitet. Abb.12 zeigt, daß Maus-PIPPin zu diesem Zeitpunkt stark im zentralen Nervensystem vorkommt und keine PIPPin-Expression in Lunge, Leber oder Herz zu detektieren ist. Die Größe des Maus-PIPPin-Transkripts beträgt 2,4kb.

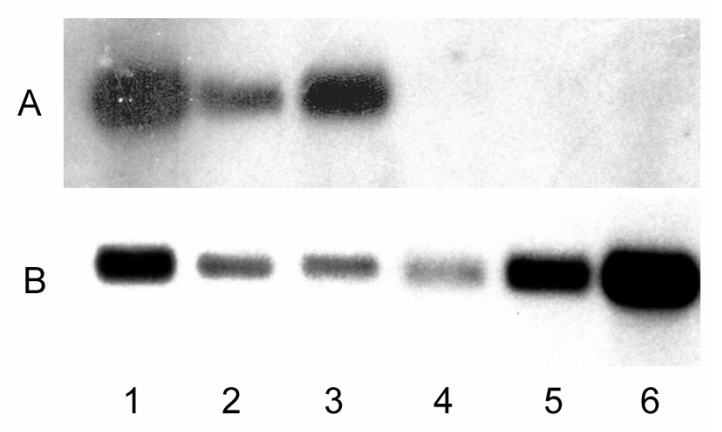

Abb.12: Northern Blot mit verschiedenen Geweben des Embryonaltags 16,5 zeigt Maus-PIPPinExpression im zentralen Nervensystem.

A: Hier wurde der Northern Blot mit der Maus-PIPPin spezifischen Sonde 108 hybridisiert.

B: Hybridisierung des Northern Blots mit einer Sonde für das Haushaltsgen GAPDH, um die aufgetragenen Mengen poly $\mathrm{A}^{+} \mathrm{RNA}$ abzuschätzen.

Die Größe des Maus-PIPPin-Transkripts beträgt 2,4 kb.

1: Rückenmark, 2: Telencephalon, 3: Resthirn, 4: Lunge, 5: Leber, 6: Herz 


\subsection{Klonierung des Gens Maus-PIPPin und Sequenzanalyse der cDNA}

Durchmustern einer cDNA-Bibliothek zum Erhalt der Maus-PIPPin-Sequenz

Nach Informationen der CELERA-Datenbank beträgt die Größe des Maus-PIPPinTranskripts (mCT9223) 2478 bp. Dies wurde im Northern Blot bestätigt (Abb.12). Um die Maus-PIPPin-cDNA-Sequenz zu erhalten, wurde eine Mausembryo-cDNABibliothek (E10,5) mit einer PIPPin spezifischen Sonde durchgemustert. Als Sonde diente der IMAGE-Klon 404613 5'(NCBI W82945) mit der internen Bezeichnung 116 (Sonde 116). Es wurden zwei positive Klone isoliert und zur näheren Analyse in pBluescript II KS+ subkloniert. Dazu wurden die Inserts mit EcoRI aus dem Phagen herausgeschnitten. Nach dem Sequenzieren der subklonierten Fragmente wurde die Lage der beiden Klone zueinander bestimmt (Abb.14). Dabei deckt Klon 116.1 mit einer Länge von 867 bp den 5'-Bereich des Transkripts ab, während Klon 116.2 mit einer Länge von 2119 bp weit bis in den 3' nicht translatierten Bereich hineinreicht. Die beiden Klone überlappen in einem Bereich von 659 bp. Der codierende Bereich (das offene Leseraster oder "open reading frame") ist in beiden Klonen repräsentiert und ist 465 bp lang. Der Translationsstart (ATG) des Maus-PIPPin-Transkripts liegt bei 347 bp. Das Ende der Translation (STOP) findet sich bei 809 bp. Nach Voraussagen aus der CELERA-Datenbank besitzt Maus-PIPPin eine Proteindomäne, eine sog. "cold-shock"-Domäne, welche in Abb.14 als schwarze Box dargestellt ist. Nähere Erklärungen zu dieser Proteindomäne folgen in 3.3. Die Nucleotid- wie auch die Aminosäuresequenz von Maus-PIPPin ist in Abb.13 abgedruckt. 
CACACACACACACACACACACACACACACGCCACGGAGAGTGCATTATCCAGACGTGACCCCTGCGAGCCAGCTCCACAGTCCAGA GAGATCGGGTGCTGCCCACTACAGGAGACAGTGCCTGGACCCAGCTGCCACGGCGAGACGGAGTCCATAGCTGGCGAGGCCGGTGA GCAGGGCGAGGCCAGGCCCTGCCCGAAAGGACCCCAGAGTCCTTCACCGGCCCCCGAGCTCCAGAGCCCATCAGGCTCTCCTGCTG GCTCCACC ATG ACA TCA GAG TCT ACA TTA CCG CCA GTG GTG CCA CCC

$\begin{array}{llllllllllllllllll}1 & & M & \text { T } & \text { S } & \text { E } & \text { S } & \text { T } & \text { L } & \text { P } & \text { P } & \text { V } & \text { V } & \text { P } & \text { P } & 14\end{array}$

CTC CAC TCC CCC AAA TCC CCC GTC TGG CCC ACG TTC CCC TTC CAC AGg GAG GGC AGT AgG $\begin{array}{llllllllllllllllllllllllllllll}\mathrm{L} & \mathrm{H} & \mathrm{S} & \mathrm{P} & \mathrm{K} & \mathrm{S} & \mathrm{P} & \mathrm{V} & \mathrm{W} & \mathrm{P} & \mathrm{T} & \mathrm{F} & \mathrm{P} & \mathrm{F} & \mathrm{H} & \mathrm{R} & \mathrm{E} & \mathrm{G} & \mathrm{S} & \mathrm{R} & 33\end{array}$ ATC TGG GAA CGT GGT GGT GGC ATT GCT CCT CGG GAC CTG CCC AGC CCT CTG CCT ACC AAg $\begin{array}{lllllllllllllllllllllllllll}I & W & E & R & G & G & G & I & A & P & R & D & L & P & S & P & L & P & T & K & 53\end{array}$ CGG ACC AGg ACA TAC TCA GCG ACA GCT CGA GCC TCG GCC GGC CCC GTG TTC AAG GGC GTC $\begin{array}{llllllllllllllllllllllllllllll}R & T & R & T & Y & S & A & T & A & R & A & S & A & G & P & V & F & K & G & V & 73\end{array}$ TGT AAG CAG TTC TCC CGC TCC CAG GGC CAC GGC TTC ATC ACG CCT GAg AAT GGC TCC GAg $\begin{array}{lllllllllllllllllllllllllllllll}C & K & \& & F & S & R & S & \& & G & H & G & F & I & T & P & E & N & G & S & E & 93\end{array}$ GAC ATC TTC GTG CAT GTT TCT GAC ATC GAg GGG GAG TAC GTG CCT GTG GAA GGA GAC GAG $\begin{array}{llllllllllllllllllllllllllll}D & I & F & V & H & \text { V } & \text { S } & \text { D } & \text { I } & \text { E } & G & \text { E } & \text { Y } & \text { V } & \text { P } & \text { V } & \text { E } & G & \text { D } & \text { E113 }\end{array}$ GTG ACC TAC AAg ATT TGT CCC ATC CCC CCC AAg AAC CAg AAg TTT CAg GCT GTG GAg GTG $\begin{array}{llllllllllllllllllllllllllllllllll}V & T & Y & K & I & C & P & I & P & P & K & N & Q & K & F & Q & A & V & E & V 133\end{array}$ GTG CTC ACC CAG TTG GCT CCC CAC ACC CCC CAC GAG ACA TGG TCT GGC CAG GTT GTG GGA $\begin{array}{llllllllllllllllllll}V & \text { L } & \text { T } & \text { Q } & \text { L } & \text { A } & \text { P } & \text { H } & \text { T } & \text { P } & \text { H } & \text { E } & \text { T } & \text { W } & \text { S } & \text { G } & \text { Q } & \text { V } & \text { V } & \text { G153 }\end{array}$ TCC TAG 731

$\mathrm{S} * 154$

732GCAGGTGGGGGTATCCCCACGAGGAGGCAGGCAGCAGCCAGTCTGTGCCCCCACTGTGCTGCTGACCCAGCCCTTGGGTGTGC TTGTTTGTCCGCCTGTCTGTCTGTGCTTGTAGCTGTGAATGTGTGCTTCCACCTGTGACCCGTGACTTGTATGATCCGGCCTAGGG TTGGACGGAGTGCAGCTACCAAGGCGTGTTTCTCCTTCCTCCCAACTCTGCCACGTACACACACCTTCTCGCCCTCTTGCCCACTA TCTATACACTGAGTCTCTGTGGGTCTGTGTCATGTTCTTGAGAACCCAGGGGGACCCCTCTCCTGTGAGCCTGTTCCTTACTGCTG TCTCCGGTACCCAGGCCTGTCTGCTTGTGTTCCTGTCTCCTGTGCTGGACCTGGGTTATGTACCACAGCCTGGGCCCTTCCTCTCA CAAGCCAGGCCTCTGAGTACTTTGTAGGGGTCTCCTTTAGGGAGGAAGAGGGCAAAACGTGGAGGTTCCTGGCCAATCCCTGCCAT AACCTGCCCAGTTCATCTTCCTGTCCCGCCTGTTTGGTGCCCTGAGAACATGGCTGCAAGCAGGAGGGAACTTTAGCACTCCTGTT ATGTAGGCCAGTCCTCTCTCCTCAGCTGTCAGATGATCTTTGAACCCCACAGAGCTGAGGAAGCCAAGCTCACTCACTCCCTGAGG TGAGGCGGGGATAGGGTTTCCTTCCAGCTTGCTCTTCTACCCGGGATGCTCAAACCTCACGAATGCTCTGGCCCATTGCTGGCCAT GACAGCAGCTGAGGATGCAGCAATGACTGACATGTCACCTCAGGCAAGGCCAGGTCCAGGCACCCAAAGGATCGGTCCTCAGCCAG GGAGACCACTGGCTTTGCCCCTCCCACCCCCCATGAGATCCTCTTCCCAGAGCTATGCAATGGCTCTCATAAGCCCCTGACAGGTC AGCAGCTGAGGTGGCTCTTATCTCTCTTGTCCCCAAGTGTGACTGTCCCTCTTCCCTGGAGTCCCTTTGGAGCTGTGTCCCTTCTA GAGAGCCAGTTACTTAACCAGAGGATAAGTGAGGTCACAGGCTCAGGAAGGGCCTGGCACAATAGTGACCTTTATGAGACCCAGCC CAGAAGTAAAATGTGAGCACAGATAGCCAGGGTGAAGGGGTCAGTGGTTGCGAGGTAGCCTTGTAGGCATTCCAGGACCACAGGGT AGTCATTTGGGGCATTTGCACCCCAACTTGTCCTAGTACCCTTTGCACATGACCCAGCAGCCTAGAGCTGCTAACAAGTGCTGGCC AGTCCTCCATCCTGGGAAGGACCTGTCTGATACCCCACTGTGAGCTAGGCTTCTCCAGCAAAGCCTATCCCTGGAGACCAGTCCTC AGCAACCTTGAGGACCAGAGTTCAAATCTCCAGCAAGCCTGTAACCCAGAACTGTGTTAATAAAGACACAGGCGGATCCTTTGACA AGGAACCCCAGGGCCATCAGCCCTCTGTTGTGAGCAGGTCCTTAGCAGTCATCACCTTGAGGCTCCCCGAGTGATAGGGACAACAG ACCTCCTCCCTACTCTTGGGCCCTGCAGCGCCAAGTCAGAAACTTCCCCACTCAGACCCCAGCCACGGATTCCCCATCCCTCCTGA CACTGGCAATAAACTCAACTGTGACCCCCCTTGCCCCTGAAAAAAAAAAAAAAA 2478

\author{
Abb.13: Die Nucleotid- und Aminosäuresequenz von Maus-PIPPin \\ grün: Startcodon \\ rot: die "cold-shock"-Protein-Domäne (die rot unterstrichenen Aminosäuren P I P P gaben dem Protein \\ den Namen) \\ violett: Stopcodon
}




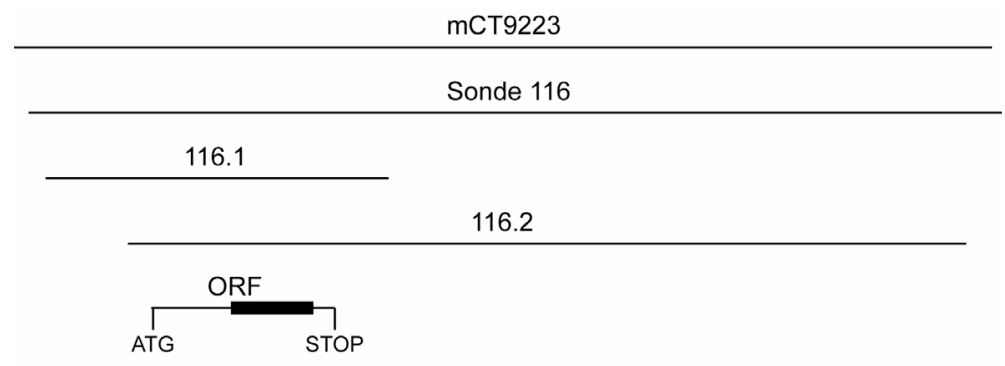

\begin{abstract}
Abb.14: Das Durchmustern einer E10,5 cDNA-Bibliothek ergab zwei Klone, die beide die codierende Sequenz von Maus-PIPPin enthalten.

Hier ist die Lage der beiden cDNA-Klone 116.1 und 116.2 zueinander dargestellt. mCT9223 stellt das Transkript nach der CELERA-Datenbank dar, mit der Sonde 116 wurde das Durchmustern der Bibliothek durchgeführt.

ATG: Startcodon

STOP: Ende der Translation

ORF: das offene Leseraster oder "open reading frame

Die schwarze Box stellt die Proteindomäne von Maus-PIPPin dar, die "cold-shock"-Domäne.
\end{abstract}

\title{
3.3 Die Proteindomäne von Maus-PIPPin
}

Nach Vorhersagen der Datenbanken CELERA und InterPro besitzt das Protein PIPPin (154 Aminosäuren) eine sog. cold-shock-Domäne von etwa 70 Aminosäuren Länge. Diese Domäne ist hoch konserviert und tritt in pro- und eukaroytischen DNA- und RNA-bindenden Proteinen auf (Matsumoto et al., 1998). In Abb.15 ist ein Vergleich der PIPPin-Proteinsequenz von Ratte, Maus und Mensch dargestellt. Die cold-shockDomäne (CSD) ist in rot zu sehen und unterscheidet sich bei der Maus in nur einer Aminosäure im Vergleich zu Ratte und Mensch (an Position 118 besitzt die Maussequenz ein Isoleucin anstatt Methionin bei Ratte und Mensch).

Ein CSD-enthaltendes Maus-PIPPin-Homolog

Die Suche mit der Maus-PIPPin-Proteinsequenz in der CELERA-Datenbank nach anderen CSD-enthaltenden Proteinen der Maus ergab einen erfolgreichen Treffer. Es 


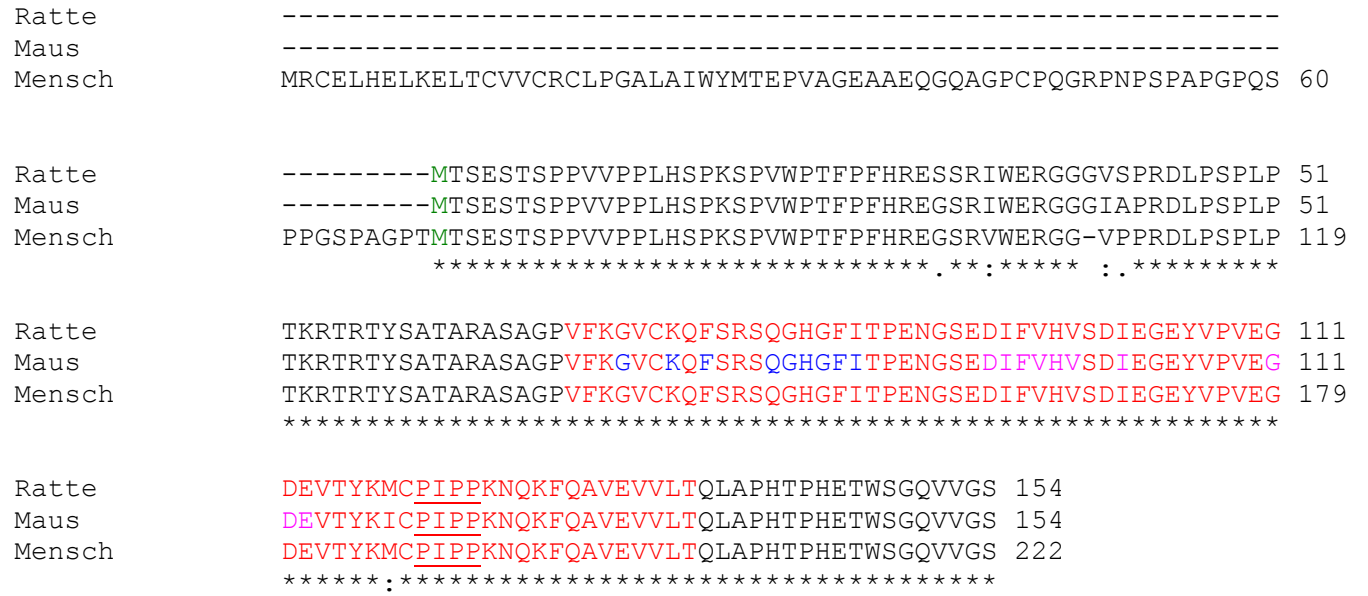

Abb.15: Ein Vergleich der PIPPin-Proteinsequenz zwischen Ratte, Maus und Mensch zeigt die starke Konservierung der cold-shock-Domäne.

rot: die "cold-shock"-Protein-Domäne (die unterstrichenen Aminosäuren P I P P gaben dem Protein den Namen), die beiden RNA-bindenden Sequenzmotive RNP1 (blau) und RNP2 (pink) sind ein Teil dieser Domäne

grün: Start-Methionin

Dieser Sequenzvergleich wurde mit Hilfe der Software ClustalW erstellt.

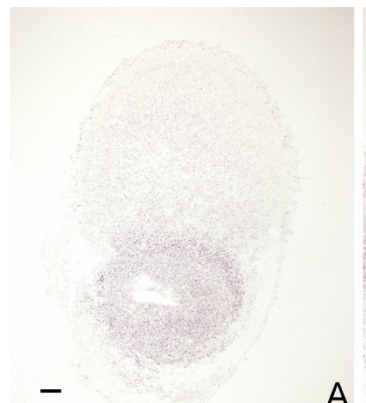

A

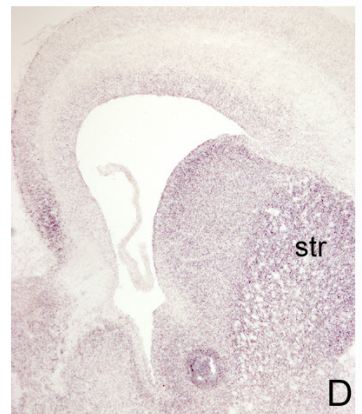

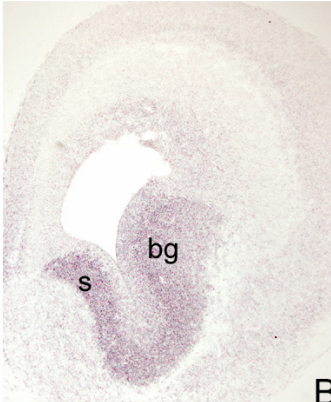

B
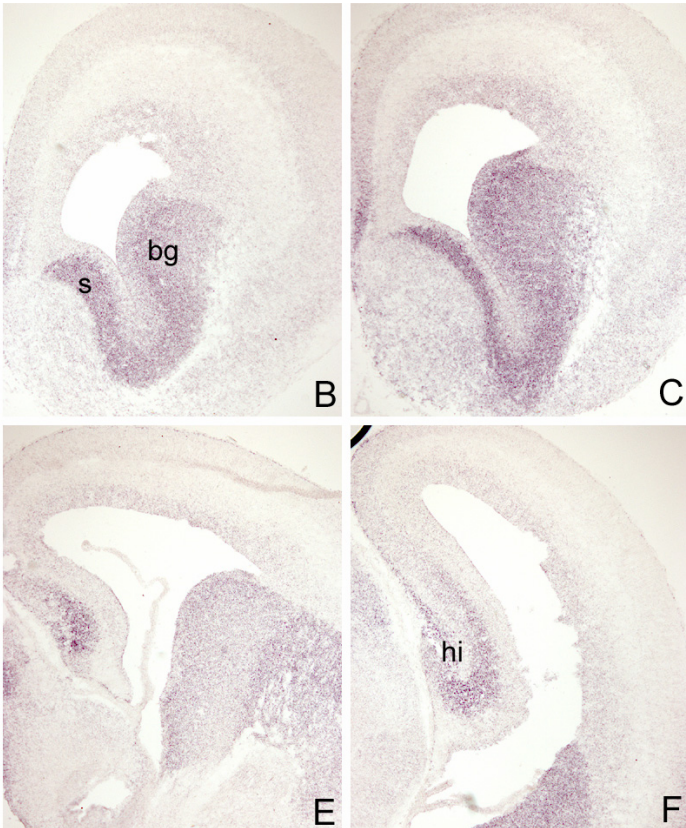

C

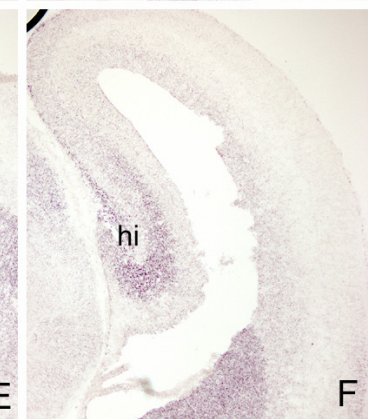

Abb.16: Ein unbekanntes CSD-enthaltendes Mausprotein zeigt ein zu Maus-PIPPin komplementäres Expressionsmuster.

RNA-in situ-Hybridisierung auf E16,5 coronalen Gefrierschnitten

bg, Basalganglien; hi, Hippocampus; s, Septum; str, Striatum

Maßstab $100 \mu \mathrm{m}$ 
handelt sich um ein namenloses Proteinprodukt mit der NCBI-Nummer BAB 22408 und wird nach Informationen der CELERA-Datenbank aus 148 Aminosäuren gebildet. Die Nucleotidsequenz soll aus 710 Nucleotiden und einem Exon bestehen (Lage auf Chromosom 3). In Abb.16 ist das Expressionsmuster für dieses unbekannte Gen auf coronalen E16.5-Gehirnschnitten zu sehen. Es wurde dafür der IMAGE-Klon 5346967 5' (NCBI BI691226) verwendet. Auch dieses CSD-enthaltende MausPIPPin-Homolog wird im Gehirn exprimiert. Die Expression ist im Bulbus olfactorius (A), in der Subventrikulärzone von Septum und Basalganglien (B, C), im Striatum (D) und im Hippocampus (E, F) zu bemerken. Die für diesen Zeitpunkt typische Maus-PIPPin-Expression in der Ventrikulärzone von ventralem und lateralem Pallium tritt nicht auf, was auf mögliche unterschiedliche Funktionen dieser beiden Proteine schließen läßt. Ein Vergleich der Proteinsequenzen von Maus-PIPPin und dem neuen CSD-enthaltenden Protein ist in Abb.17 dargestellt.

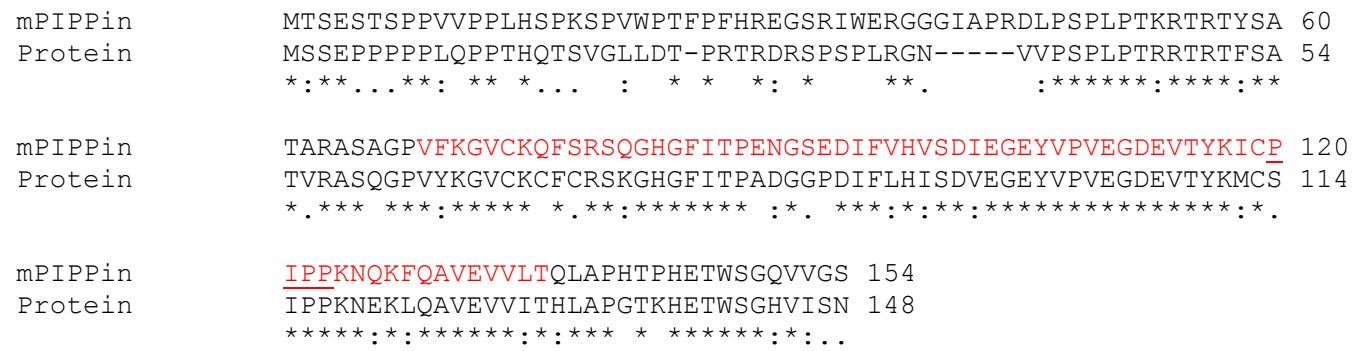

Abb.17: Alignment der Proteinsequenz von Maus-PIPPin und dem homologen CSDenthaltenden Protein zeigt Übereinstimmungen (durch Sterne symbolisiert).

mPIPPin: Maus-PIPPin

Protein: ein neues CSD-enthaltendes Protein

Die CSD ist rot hervorgehoben.

\subsection{Genomische Organisation des Maus-PIPPin-Gens}

Um die Lage und Größe der Introns und Exons des Maus-PIPPin-Locus zu charakterisieren, wurde eine genomische Bibliothek durchgemustert. Als Sonde wurde der IMAGE-Klon 368539 5' (NCBI W61690) benutzt (interne Bezeichnung: 108, Abb.18). Es wurden sieben positive Klone identifiziert, wovon drei kartiert wurden. Die Lage der genomischen Klone 108.1, 108.3, und 108.7 zueinander ist in Abb.18 dargestellt. Mit Hilfe des Computerprogramms BLAST (NCBI) wurden die Sequenzen der genomischen Klone mit denen der cDNA-Klone abgeglichen ("pairwise blast"). Auf diese Weise wurde die Exon-Intron-Struktur des Maus-PIPPin- 
Genlocus ermittelt (Abb.19). Dieser erstreckt sich über $15 \mathrm{~kb}$ und besteht aus vier Exons, wobei sich das Startcodon im zweiten und das Stopcodon im vierten Exon befindet. Die sog. "cold-shock"-Domäne (CSD) ist in Exon drei und vier lokalisiert (hellgraue Boxen in Abb.19). Die codierende Sequenz wird durch drei Introns unterschiedlicher Länge unterbrochen. Nach Angaben der CELERA-Datenbank befindet sich der Maus-PIPPin-Genlocus auf dem Chromosom 15.

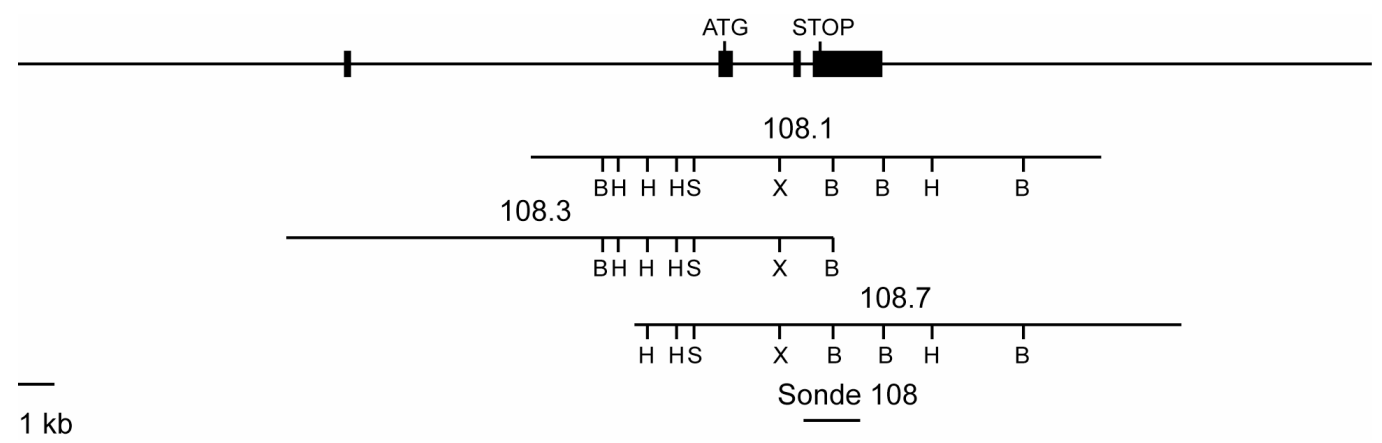

Abb.18: Das Durchmustern einer genomischen Bibliothek mit einer Maus-PIPPin spezifischen Sonde ergab drei Klone, deren Lage zueinander hier dargestellt ist.

108.1, 108.3, 108.7: Die genomischen Klone, die mit der Maus-PIPPin-spezifischen Sonde 108 identifiziert wurden. Zum Ausschneiden der genomischen Klone aus den $\lambda$-Phagen wurde NotI verwendet.

charakteristische Enzymschnittstellen:

B: Bam HI, H: Hind III, S: Spe I, X: Xho I 


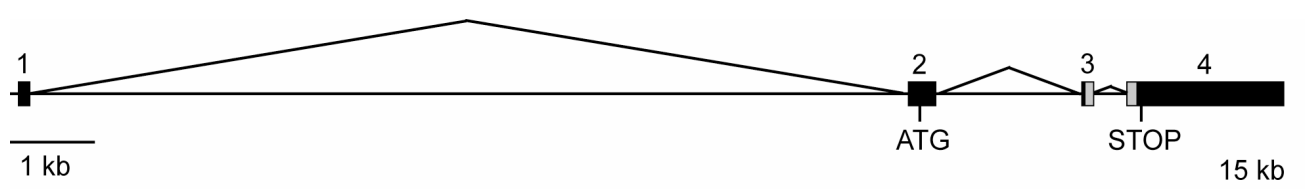

Abb.19: Der Maus-PIPPin-Genlocus besteht aus vier Exons und erstreckt sich über einen Bereich von $15 \mathrm{~kb}$.

1, 2, 3, 4: Exon 1-4 mit dem Startcodon in Exon 2 und Translationsstop in Exon 4

Die cold-shock-Domäne befindet sich in Exon 3 und 4 (hellgraue Boxen). Das Herausschneiden der Introns (Spleißen) ist durch Striche symbolisiert.

\subsection{Herstellen eines Rekombinationskonstruktes für die homologe Rekombination in ES-Zellen}

Um die Funktion des Maus-PIPPin-Gens zu analysieren, wurde es mittels homologer Rekombination inaktiviert (es wurde eine "PIPPin-Knock-out-Maus" erstellt.). Die Inaktivierung durch homologe Rekombination geschah dabei durch die Insertion eines Reportergens (hier $\beta$-Galactosidase) in den codierenden Bereich des Gens.

Für die Erstellung des Rekombinationskonstruktes wurde der genomische Klon 108.1 ausgewählt. Dieser enthält den codierenden Bereich und bietet außerdem die Möglichkeit, auf 5'- und 3'-Seite ausreichend große Homologiebereiche zu wählen. Die Größe des Homologiebereichs ist für die Effizienz des Rekombinationsereignisses wichtig (Thomas und Capecchi, 1987) und sollte etwa 10 $\mathrm{kb}$ betragen. Als Vektor für das Rekombinationskonstrukt wurde der Vektor pKC414 benutzt. Dieser basiert auf pBluescriptIIKS+ (Stratagene) und enthält zusätzlich eine lacZpolyA-pGKNeopolyA-Kassette. Das lacZ-Gen ermöglicht die $\beta$-GalactosidaseExpression und dient als Reportergen. Die Neomycin-Resistenz ermöglicht eine positive Selektion der ES-Zellen nach der Elektroporation. In Abb.20 B ist das Konstrukt für die homologe Rekombination abgebildet. 


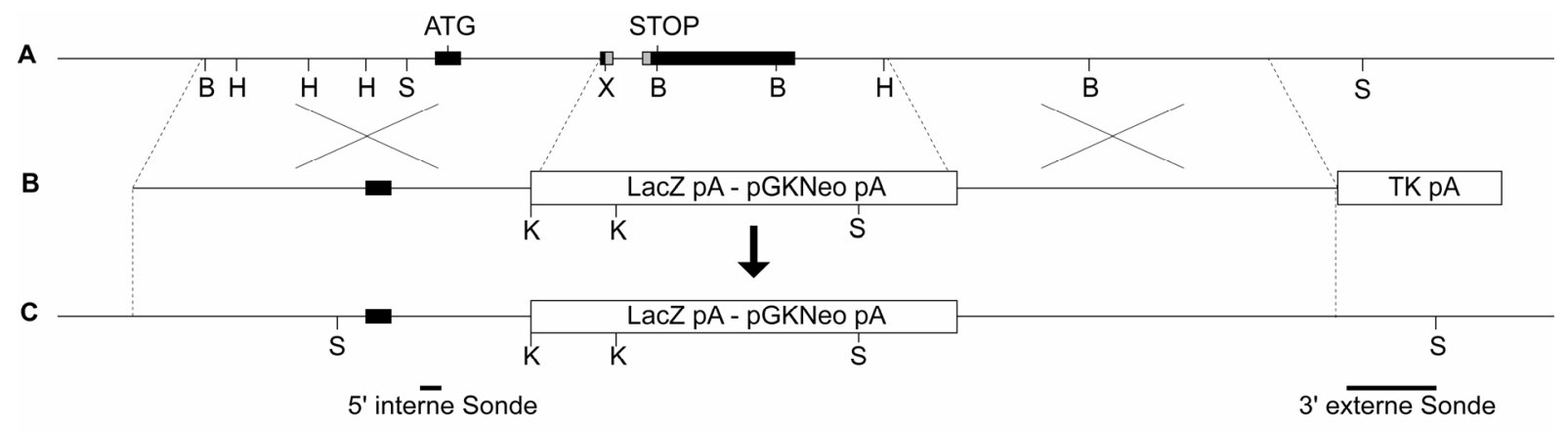

Abb.20: Darstellung des Konstruktes für die homologe Rekombination in den Maus-PIPPinGenlocus und des Maus-PIPPin-Genlocus vor und nach homologer Rekombination

A: Maus-PIPPin-Genlocus

B: Konstrukt zur homologen Rekombination

C: Maus-PIPPin-Genlocus nach homologer Rekombination

In $\mathrm{C}$ ist außerdem die Lage der 3' externen und 5' internen Sonde für den folgenden ES-Zell-Screen zu sehen.

charakteristische Enzymschnittstellen:

B: Bam HI, H: Hind III, K: Kpn I, S: Spe I, X: Xho I

Eine weitere Kpn I-Schnittstelle befindet sich 9,5 kb in 5'-Richtung vor Beginn der LacZpA-pGKNeo pA-Kassette.

\section{Klonierung der 3'-Homologie und Thymidinkinase}

Als 3'-Homologie diente das 4,6 kb große HindIII-NotI-Fragment aus Klon 108.1, welches zunächst in pBluescriptII KS+ subkloniert wurde. Es folgte eine "blunt end"Ligierung mit einem $2 \mathrm{~kb}$ großen RsrII-Thymidinkinase-Fragment. Dabei wurde nur mit der Klonierung weitergearbeitet, wo sich das Thymidinkinase-Fragment auf 3'Seite der 3'-Homologie befand. Bei dieser NotI-RsrII-"blunt end"-Ligierung enstand eine zusätzliche SacII-Schnittstelle. Die Thymidinkinase (TK) wirkt als negativer Selektionsmarker und stammt aus dem pKO Scrambler NTK Vektor (Stratagene).

Das Fragment 3'-Homologie-TK wurde mit HindIII und SacII ausgeschnitten. (Dafür mußte vorher durch SacII-Partialverdau der Klon identifiziert werden, der nicht eine zusätzliche SacII-Schnittstelle im 3'-Homologie-TK-Fragment besaß.) Nach einer T4 DNA-Polymerase-Reaktion zum Erhalt glatter Enden wurde das 3'-Homologie-TKFragment mit pKC414-XhoI "blunt" ligiert. Für die spätere Ligation mit der 5'Homologie wurde das gesamte Fragment mit SmaI linearisiert. 


\section{$\underline{\text { Klonierung der 5'-Homologie }}$}

Bei diesem Klonierungsschritt mußte darauf geachtet werden, daß der Übergang von der 5'-Homologie in die lacZpolyA-pGKNeopolyA-Kassette sich im Leseraster befindet, da sonst die $\beta$-Galactosidase nicht korrekt exprimiert werden kann.

Als 5'-Homologie wurde das 4,8 kb große BamHI-XhoI-Fragment ausgewählt. Dieses wurde blunt mit dem mit SmaI linearisierten pKC414-3'-Homologie-TK-Fragment ligiert. Dabei wurde das Leseraster eingehalten. Als Kontrolle dafür diente eine zusätzliche XhoI-Schnittstelle, die bei einer XhoI blunt-SmaI-Ligierung entsteht.

Für die Elektroporation wurden $100 \mu \mathrm{g}$ des Konstrukts mit NotI linearisiert und nach Aufreinigung in sterilem 0,1xTE aufgenommen.

Die Gesamtgröße des Konstruktes beträgt 19,6 kb. Nach erfolgreicher homologer Rekombination (Abb.20 C) sollte ein Bereich von 3,5 kb deletiert werden, der die funktionelle Domäne, die "cold-shock"-Domäne, enthält.

In Abb.21 ist ein Kontrollgel gezeigt, das die korrekte Klonierung des Rekombinationskonstruktes bestätigt. Spur 1 zeigt das unverdaute Konstrukt, während in Spur 2 das mit NotI linearisierte Fragment $\mathrm{zu}$ sehen ist. Ein Restriktionsverdau mit NotI und XhoI sollte die lacZpolyA-pGKNeopolyA-Kassette, die 3'-Homologie und TK herausschneiden. Dies sollte ein Fragment von 11,8 kb und ein Restfragment von 8,2 kb ergeben, was in Spur $3 \mathrm{zu}$ beobachten ist. Drei Fragmente entstehen erwartungsgemäß bei einem Restriktionsverdau mit BamHI (Spur 4). Das 3,5 kb-Fragment entsteht durch zwei BamHI-Schnittstellen in pKC414, nämlich im polylinker und in der lacZpolyA-pGKNeopolyA-Kassette. Das zweite 4,2 kb große Fragment ist durch eine weitere BamHI-Schnittstelle in der 3'-Homologie zu erklären (s. Abb.20). Die dritte Bande wird durch das Restfragment gebildet. 


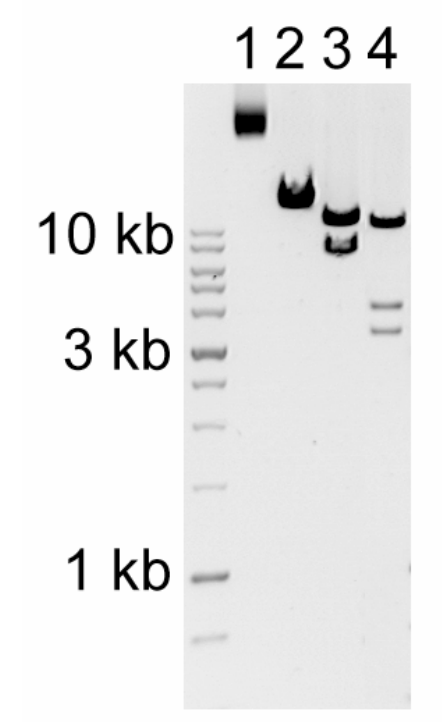

Abb.21: Ein Kontrollgel zeigt die korrekte Klonierung des Rekombinationskonstruktes.

Spur 1: unverdauter Vektor

Spur 2: Ein Verdau mit Not I liefert das linearisierte Plasmid.

Spur 3: Verdau mit Not I / Xho I

Spur 4: Ein BamHI-Verdau ergibt erwartungsgemäß drei Fragmente.

\subsection{Gentransfer in ES-Zellen/ Der ES Zell-Screen}

Embryonale Stammzellen (ES-Zellen) werden aus der inneren Zellmasse der Mausblastocyste gewonnen und können in Kultur gehalten werden. Sie behalten ihre Pluripotenz, wenn sie in Anwesenheit des "Leukemia Inhibiting Factor" kultiviert werden, der die Differenzierung der embryonalen Stammzellen hemmt.

Die folgenden Zellkulturarbeiten wurden nach Beschreibung von A. Mansouri von S. Mahsur durchgeführt (Mansouri, 2001).

Das Rekombinationskonstrukt wurde in die MPI II-ES-Zellinie (Mausstamm 129/Sv) (Doetschman et al., 1985) elektroporiert und auf das homologe Rekombinationsereignis selektiert. Es fand eine Doppelselektion statt, wobei das Antibiotikum G418 oder Geneticin (verwandt mit Neomycin) der positiven und Gancyclovir der negativen Selektion diente. Nach dieser Selektion wurden insgesamt 272 Klone isoliert.

Zur Identifizierung des homologen Rekombinationsereignisses wurde genomische DNA aus den ES-Zellen gewonnen. Für die Southern-Blot-Analyse wurden die Klone zunächst mit einer 3'-externen Sonde untersucht (s. Abb.20 C). Die 3'-externe Sonde war ein PCR-Produkt, das mit den Oligonucleotiden FK4 und 6 aus dem genomischen Klon 108.7 gewonnen wurde. Zur Southern-Blot-Analyse wurde die genomische 
DNA mit SpeI verdaut und ergab eine 14,1 kb-Bande für das Wildtyp-Allel und eine zusätzliche 9,5 kb-Bande für das homolog rekombinierte Allel (Abb.22 A). Auf diese Weise wurden 20 positive Klone identifiziert.

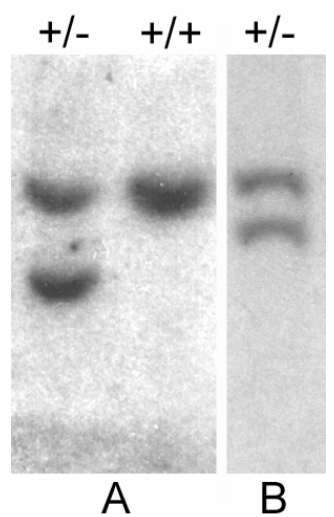

\footnotetext{
Abb.22: Southern-Blot-Analyse der elektroporierten ES-Zellen mit $3^{\prime}$ externer (A) und 5' interner (B) Sonde.

Die obere Bande zeigt in beiden Fällen die Wildtyp-Situation während die untere Bande die Situation nach homologer Rekombination widerspiegelt.

$+/+$ : Wildtyp-Allel

+/-: homolog rekombiniertes Allel
}

Diese positiven Klone wurden weiter mit einer 5'-internen Sonde analysiert, welche mit Hilfe der Oligonucleotide FK 10 und 11 aus der subklonierten 5'-Homologie kloniert wurde. Nach dem Verdau mit KpnI wurde das Wildtyp-Allel mit einer 10,4 $\mathrm{kb}$ - und das homolog rekombinierte Allel mit einer 9,4 kb-Bande nachgewiesen (Abb.22 B). Nach dieser Hybridisierung waren noch 17 Klone positiv, was einer Rekombinations-Frequenz von 1:16 entspricht.

\subsection{Morula-Aggregation von ES-Zellen (Wood et al., 1993) und Keimbahntransfer}

Um chimäre Mäuse zu erhalten, wurden vier positive ES-Zell-Klone (Mausstamm 129/Sv mit schwarzen Augen) mit Morulae aggregiert, die aus dem NMRIMausstamm gewonnen wurden. Dazu mußte den Morulae die Zona pelucida entfernt werden. Das Aggregat wurde $24 \mathrm{~h}$ bei $37^{\circ} \mathrm{C}$ inkubiert. Am nächsten Tag wurden die Embryonen in scheinschwangere (Schwangerschaftstag 2) Ammenmütter transferiert. Es wurden dafür diejenigen Embryonen ausgewählt, die bis zum BlastocystenStadium entwickelt waren. Sollten die Embroynen 17 Tage nach dem Retransfer nicht geboren werden, wurde per Kaiserschnitt entbunden. Viele Jungtiere starben danach, 
da sie trotz Wärmplatte und leichter Massage nicht begonnen, selbständig zu atmen oder von der Mutter gefressen wurden.

Nach erfolgreicher Geburt durch Kaiserschnitt und Aufzucht waren noch folgende Tiere zur weiteren Verpaarung vorhanden:

\begin{tabular}{cc} 
ES-Zell-Klon & Anzahl der Chimären \\
\hline FK-169 & 4 \\
FK-194 & 4 \\
FK-216 & 3 \\
FK-256 & 4
\end{tabular}

Der Grad des Chimärismus ist an der Fellfarbe erkennbar. Je höher der Anteil an dunkler Fellfarbe ist, desto höher ist die Wahrscheinlichkeit, daß die chimäre Maus die transgene Information in ihren Keimzellen trägt und somit diese Information an ihre Nachkommen weitergibt.

Nach sechs Wochen wurden die Chimären mit NMRI-Wildtypmäusen verpaart. Ein Keimbahntransfer konnte bei den Nachkommen anhand der Augenfarbe erkannt werden. Mäuse mit schwarzen Augen entstammten der Keimbahn der transgenen ESZellen (Stamm: 129/Sv), wogegen Mäuse mit roten Augen von den nicht-transgenen ES-Zellen (Stamm: NMRI) abstammten.

Verpaarungen mit einem chimären Männchen (ca. 40\% chimär) der Linie FK-194 brachte ein bis zwei schwarzäugige Nachkommen pro Wurf. Von 33 schwarzäugigen analysierten Tieren war allerdings keins heterozygot. Dagegen lieferte ein nur gering chimäres Männchen (ca. 15\%) der Linie FK-216 100\% schwarzäugige Nachkommen. Heterozygote Tiere dieser Generation (F1) wurden miteinander verpaart, um homozygote Tiere zur Phänotyp-Analyse zu erhalten (genetischer Mischhintergrund). Für spätere Verhaltensexperimente wurde begonnen auf den Inzuchtstamm C57 BL/6 zu züchten, der für neuronale Fragestellungen als besonders geeignet gilt.

\subsection{Bestätigung der homologen Rekombination in den Maus- PIPPin Genlocus}

Bestätigung des Maus-PIPPin-Knock-outs auf RNA-Ebene

Eine RNA-in situ-Hybridisierung auf E16,5 Gehirnen von Wildtyp- und homozygoten Mäusen zeigt, daß die Inaktivierung des PIPPin-Gens erfolgreich war (Abb.23I). Die Hybridisierung mit der Maus-PIPPin-spezifischen Sonde, die Sequenzen des 
deletierten Bereichs erkennt, ergibt das bekannte PIPPin-Expressionsmuster im Wildtyp (A-C), aber nicht in einer homozygoten PIPPin-defizienten Maus (D-F).

Ähnliches gibt auch der Northern Blot mit E16,5 Hirnhomogenat in Abb.23II wieder.

Die Verwendung der für den Deletionsbereich spezifischen Maus-PIPPin-Sonde liefert eine starke Bande bei dem Wildtypgewebe (1). Ein positives Signal auf homozygotem Hirnhomogenat ist nur mit einer Sonde, die gegen das Gen der Neomycin-Resistenz gerichtet ist, zu erlangen (2).

I.

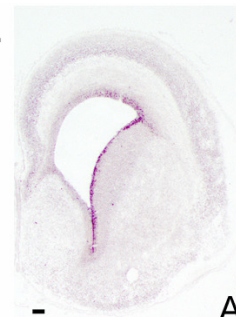

A

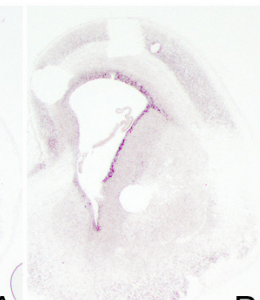

B

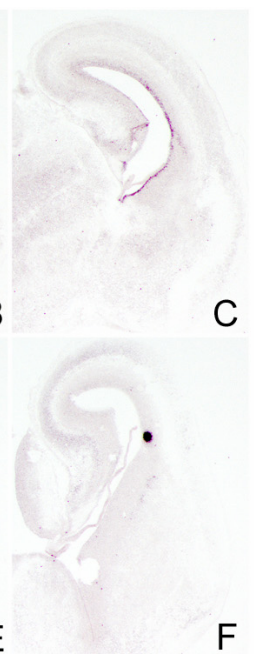

$\mathrm{D}$

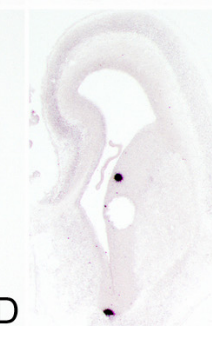

E

$\mathrm{F}$
II.

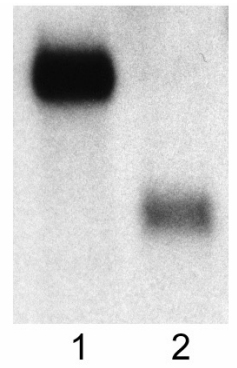

\begin{abstract}
Abb.23: In situ-Hybridisierung und Northern Blot mit Wildtyp und PIPPin -/- Gewebe zeigen, daß die homologe Rekombination in den Maus-PIPPin-Genlocus erfolgt ist.

I. RNA-in situ-Hybridisierung mit einer PIPPin-spezifischen Sonde, die die Sequenz des deletierten Bereichs erkennt. A-C: Wildtyp; D-F: homozygotes Gehirn

II. Northern Blot mit E16,5 Hirnhomogenat aus Wildtyp- (1) bzw. homozygoten Mäusen (2) zeigt eine starke Bande mit einer PIPPin-Sonde für den Deletionsbereich im Wildtyp (1). Eine Sonde, die gegen das Gen der Neomycin-Resistenz gerichtet ist, bringt ein Signal bei dem Hirnhomogenat homozygoter Mäuse (2).
\end{abstract}

\title{
Bestätigung des Maus-PIPPin-Knock-outs auf Protein-Ebene
}

Um zu zeigen, daß in den homozygoten Mäusen auch kein PIPPin-Protein gebildet wird, wurden Homogenate von Wildtyp- und Mutanten-Telencephali unter denaturierenden Bedingungen im Proteingel aufgetrennt. Der Western-Blot wurde mit einer 1:1000-Verdünnung des anti-Ratte-PIPPin-Antikörpers inkubiert (Nastasi et al., 1999), als Positivkontrolle für den Rattenantikörper wurde Homogenat aus RattenCerebellum (P14) mit aufgetragen. In Abb.24 ist das Ergebnis des Western-Blots dargestellt. Die Positivkontrolle (Spur 3) liefert wie bereits in Nastasi et al., 1999 eine Hauptbande bei etwa $30 \mathrm{kD}$ und eine schwache darunterliegende Bande. Auf dem Mausgewebe verursacht dieser Antikörper sowohl mit Wildtypgewebe (Spur 1) als 
auch mit homozygotem Gewebe (Spur 2) die gleiche Doppelbande und eine weitere Bande bei etwa $75 \mathrm{kD}$.

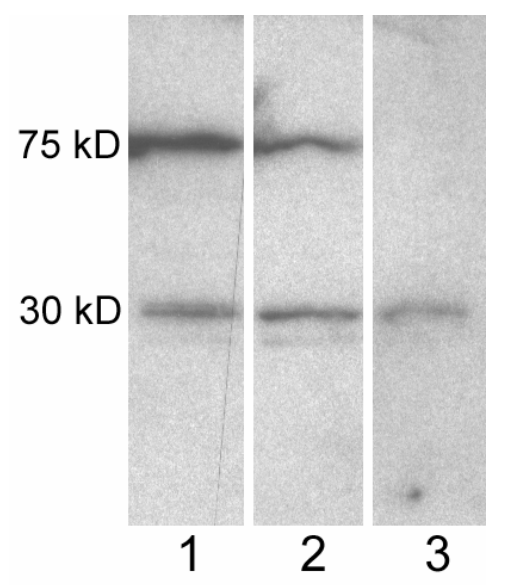

\footnotetext{
Abb.24: Western-Blot mit anti-Ratte-PIPPin-Antikörper deutet auf Unspezifität des Antikörpers.

Spur 1: Homogenat ausWildtyp-Telencephali (E16,5)

Spur 2: Homogenat aus Homozygoten-Telencephali (E16,5)

Spur 3: Positivkontrolle (Homogenat aus Ratten-Cerebellum, P14)

Der Blot wurde 30 min. belichtet. Antikörper-Verdünnung: 1 : 1000
}

Nach diesem Ergebnis traten Zweifel an der Spezifität des anti-Ratte-PIPPinAntikörpers auf. Zur Überprüfung der Spezifität dieses Antikörpers wurde er vor Inkubation auf dem Western-Blot mit Acetonpuder präadsorbiert, das aus homozygoten PIPPin-defizienten-P8-Gehirnen gewonnen wurde. Nach der Präadsorption, die alle unspezifischen Anteile des polyklonalen Serums beseitigen und somit möglichen Hintergrund reduzieren sollte, erfolgte die Inkubation mit dem Western-Blot. Da für die Herstellung des Acetonpuders Gewebe aus PIPPindefizienten-Mäusen verwendet wurde, sollten die Anteile des Serums, die PIPPin erkennen, erhalten bleiben. In Abb.25 ist das Ergebnis vor (Spur1 und 2) und nach der Präadsorption (Spur 3 und 4) zu sehen. Erneut wurden auf dem Proteingel E16,5 Telencephali aufgetragen. Nach der Präadsorption des PIPPin-Antikörpers ist die Doppelbande deutlich reduziert, was auf eine Unspezifität dieses Antikörpers schließen läßt. Möglicherweise sind die vier Unterschiede in der Aminosäuresequenz zwischen Ratte und Maus (s. Abb.15) wichtig für die Epitoperkennung des polyklonalen Antikörpers. Damit ist dieser Antikörper, der gegen das PIPPin-Protein der Ratte gerichtet ist, für weitere Experimente in der Maus unbrauchbar. 


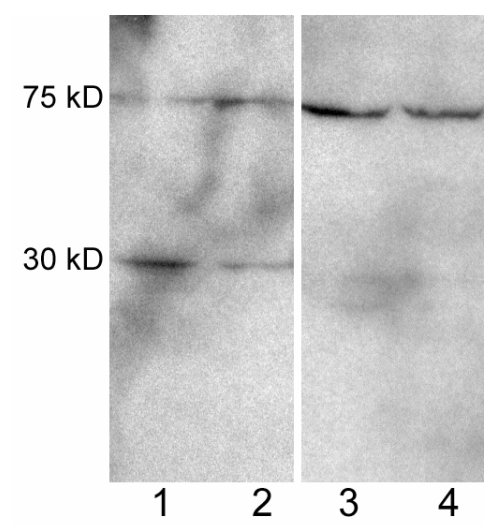

\author{
Abb.25: Nach Präadsorption des polyklonalen anti-Ratte-PIPPin-Antikörpers mit Acetonpuder \\ aus PIPPin-defizienten Gehirnen bestätigt sich die Unspezifität dieses Antikörpers in der Maus. \\ vor Präadsorption: \\ Spur 1: Homogenat ausWildtyp-Telencephali (E16,5) \\ Spur 2: Homogenat aus Homozygoten-Telencephali (E16,5) \\ nach Präadsorption: \\ Spur 3: Homogenat ausWildtyp-Telencephali (E16,5) \\ Spur 4: Homogenat aus Homozygoten-Telencephali (E16,5) \\ Das gleiche Ergebnis wurde mit einem Blot erzielt, bei dem Homogenat aus P8-Gehirnen aufgetragen \\ wurde. Der Blot wurde 5 min. belichtet. Antikörper-Verdünnung: $1: 1000$
}

Die Abwesenheit des PIPPin-Proteins nach homologer Rekombination in den MausPIPPin-Genlocus konnte somit nicht gezeigt werden.

\title{
3.9 Fortpflanzungsstatistik der heterozygoten PIPPin-Mäuse
}

Heterozygote Tiere der PIPPin-defizienten Mauslinie pflanzen sich nach dem 2. Mendelschen Gesetz monohybrider Erbgänge fort (1:2:1) (Wehner und Gehring, 1995). Von 144 geborenen Tieren waren 37 Tiere Wildtypen, 71Tiere heterozygot und 36 Tiere homozygot. Bei 307 während der Embryonalentwicklung präparierten Tieren spalteten sich die Genotypen wie folgt auf: 76 (Wildtyp) : 156 (heterozygot) : 75 (homozygot). Somit kann ausgeschlossen werden, daß PIPPin-defiziente Mäuse bereits vor der Geburt sterben. Die homozygoten PIPPin-defizienten Mäuse sind lebensfähig.

\subsection{Analyse des Gehirns PIPPin-defizienter Mäuse}

Für die Phänotyp-Analyse der PIPPin-Knock-out-Maus wurden verschiedene Hinweise verfolgt, die sich aus dem Expressionsmuster von Maus-PIPPin und aus den bereits bekannten Daten über das Ratten-PIPPin (Castiglia et al., 1996; Nastasi et al., 1999; Nastasi et al., 2000; Raimondi et al., 2003) ergaben. Dabei wurde mit den meisten Untersuchungen zum Embryonaltag 16,5 begonnen. Dies ist das Stadium, an 
dem Maus-PIPPin in der Microarray-Expressionsanalyse entdeckt wurde und gilt seitdem als Referenzstadium.

Zunächst wurde die Histologie der Gehirne von Wildtyp und PIPPin-defizienten Mäusen verglichen.

Vergleich der Histologie von Wildtyp und PIPPin -/- Gehirnen mittels HämatoxylinEosin-Färbung

\section{$\underline{\mathrm{E} 16,5}$}

Abb.26 zeigt repräsentative Bereiche von E16,5 Wildtyp (A-D) und homozygoten (EH) Gehirnen. Es konnte im Hinblick auf Anzahl der Zellen, Dicke und Form einzelner Schichten kein Unterschied zwischen Wildtyp und Mutante festgestellt werden. Die Struktur des Bulbus olfactorius sieht in der Mutante (E) nicht auffällig aus, ebenso gleicht die Anatomie der Mutante auf der Ebene der Basalganglien, des ventralen und lateralen Palliums (F) der des Wildtyps (B). Weitere Expressionsorte von MausPIPPin, wie der Hippocampus und der Bereich des occipitalen Cortex $(G, H)$ ergeben ebenfalls keine signifikanten Auffälligkeiten.

adulte Gehirne

In Abb.27 sind erneut repräsentative Bereiche des Gehirns dargestellt, in denen MausPIPPin in der Wildtypsituation vorzufinden ist. Der Bulbus olfactorius sieht beim Vergleich zwischen Wildtyp (A) und Mutante (E) normal ausgebildet aus. Alle drei Schichten, die Lamina glomerulosa, mitralis und granularis sind vorhanden. Auch in 

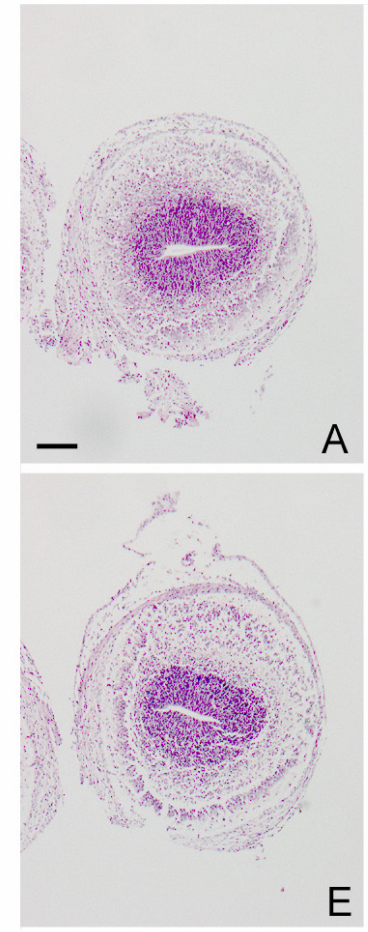

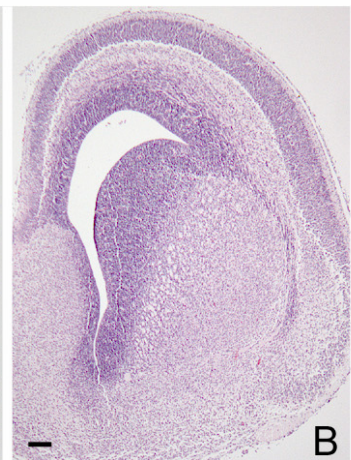

B

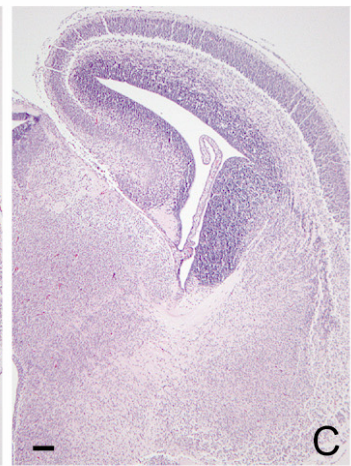

C

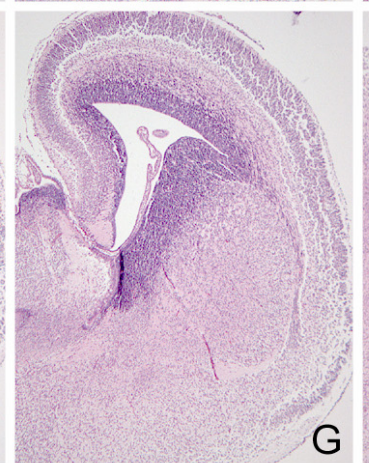

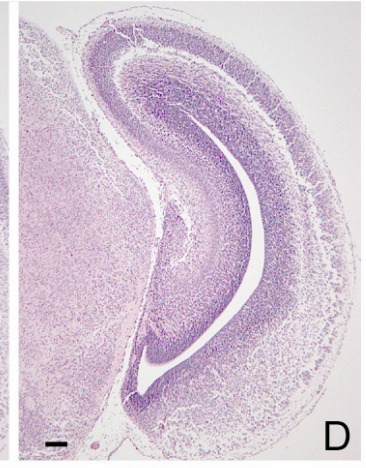

G

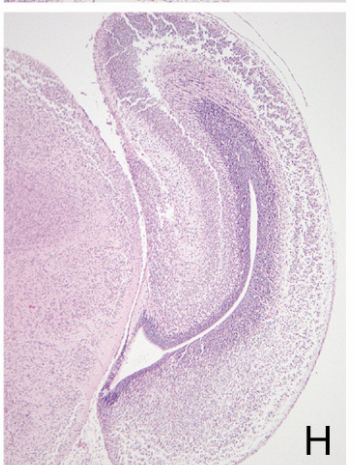

$\mathrm{H}$

\author{
Abb.26: Hämatoxylin-Eosin-Färbung von E16,5 Wildtyp und PIPPin-defizienten Gehirnen zeigt \\ keinen offensichtlichen Phänotyp. \\ Es wurden $10 \mu \mathrm{m}$ dicke Paraffinschnitte gefärbt. \\ A-D: Wildtyp-Gehirne \\ E-H: Maus-PIPPin -/- Gehirne \\ A / E: Bulbus olfactorius; B / F: Ebene der Basalganglien und des ventralen Palliums \\ C / G: Ebene des caudo-medialen Cortex; D / H: Ebene des occipitalen Cortex \\ $\mathrm{n}($ Wildtyp $)=1 ; \mathrm{n}$ (Mutante) $=2$; Maßstab: $100 \mu \mathrm{m}$
}




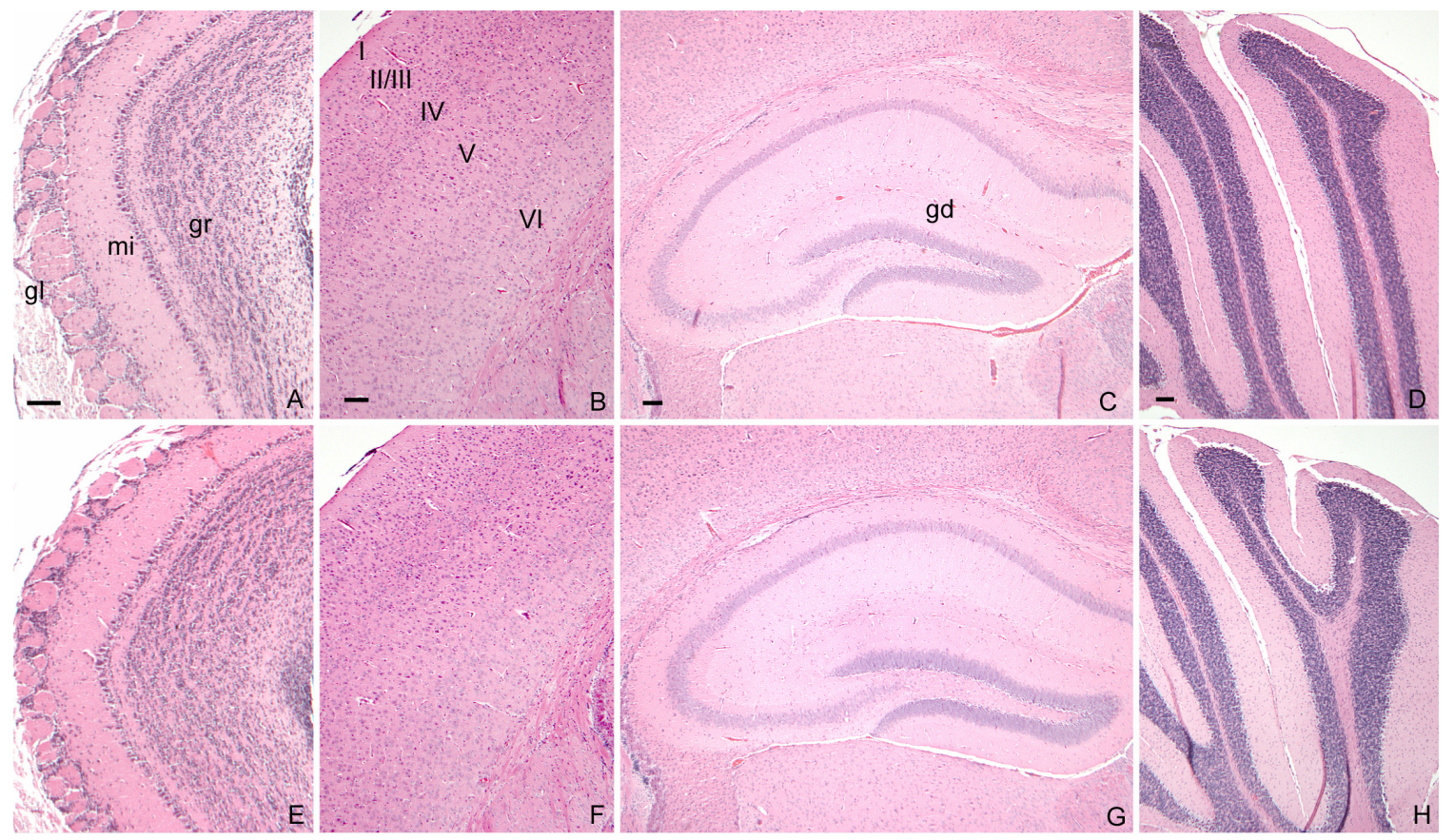

Abb.27: Adulte Wildtyp und homozygote Gehirne ergeben in der HE-Färbung keinen signifikanten Unterschied.

A-D: Wildtyp-Gehirne

E-H: Maus-PIPPin -/- -Gehirne

gd, Gyrus dentatus;, gl, Lamina glomerulosa; gr, Lamina granularis; mi, Lamina mitralis; I-VI: Schichten I-VI des cerebralen Cortex

A / E: Bulbus olfactorius; B / F: Cortexschichten; C / G: Hippocampus; D, H: Cerebellum Es wurden $10 \mu \mathrm{m}$ dicke Paraffinschnitte gefärbt.

$\mathrm{n}($ Wildtyp $)=1 ; \mathrm{n}($ Mutante $)=2 ;$ Maßstab $100 \mu \mathrm{m}$ 
der 6-schichtigen Struktur des cerebralen Cortex (B, F) ist kein offensichtlicher Phänotyp zu detektieren. Der Hippocampus ist mit dem Gyrus dentatus und den Feldern CA1-3 im homozygoten Gehirn in Größe oder Form nicht auffällig (G). Auch auf der Ebene des Cerebellums ist kein deutlicher Phänotyp auszumachen (D, H).

In der Expressionsanalyse in 3.1 wurde gezeigt, daß Maus-PIPPin zu mehreren Zeitpunkten der Entwicklung in der proliferativen Schicht des cerebralen Cortex, in der Ventrikulärzone, vorkommt. Aus diesem Befund wurde geschlossen, daß in den PIPPin-defizienten Gehirnen im Vergleich zum Wildtyp ein Unterschied in der Rate der DNA-Replikation vorliegen könnte. Um diesen Aspekt zu untersuchen, wurden BrdU-Markierungen durchgeführt. BrdU ist ein Thymidin-Analog und wird während der S-Phase selektiv in die DNA inkorporiert. Die BrdU-Inkorporation wurde mit einem Flourescein-gekoppelten Antikörper sichtbar gemacht (grüne Zellen). Als Gegenfärbung wurde Propidiumiodid benutzt (rote Zellen). Zur Auswertung wurde zunächst in repräsentativen Bereichen die gesamte Zellzahl ermittelt. Nach dem Auszählen der BrdU-positiven Zellen in diesen Bereichen wurde der mitotische Index ermittelt, der aus dem Quotienten der Anzahl der BrdU-positiven Zellen und der Gesamtzahl aller Zellen gebildet wird.

\section{BrdU-Aufnahmestudien in Wildtyp und PIPPin-defiziente Cortices}

\section{$\underline{\mathrm{E} 16,5}$}

Zur Auswertung wurden drei Ebenen ausgewählt, in denen PIPPin exprimiert ist und daher einen Effekt auf die DNA-Replikation ausüben könnte: der Bulbus olfactorius (Ebene 1, Abb.28 A, B, G, H), das ventrale Pallium (Ebene 2: C, D, I, J) und der occipitale Cortex (Ebene 3: E, F, K, L). In A, C und E sind die Flächen angedeutet, die ausgezählt wurden. Dabei wurden pro Ebene fünf Flächen ausgezählt. Die Anzahl der gesamten Zellen betrug in Wildtyp und Knock-out 0,018 Zellen/ $\mu \mathrm{m}^{2}$. Bei der Berechnung des mitotischen Index' trat kein signifikanter Unterschied zwischen Wildtyp und PIPPin-Knock-out-Maus auf. 

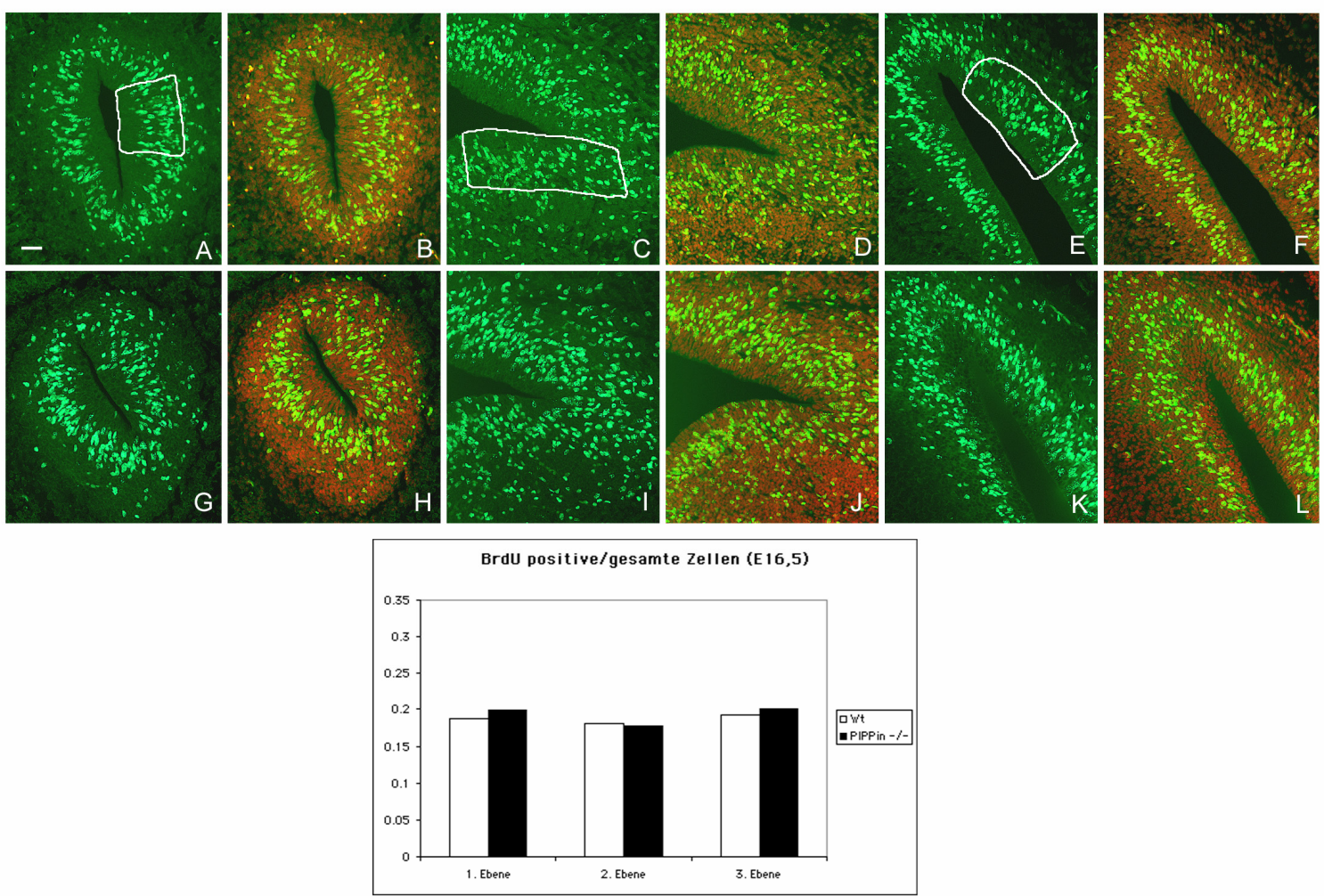

Abb. 28: BrdU-Aufnahmestudien in E16,5 +/+ und PIPPin -/- -Gehirnen zeigen keinen signifikanten Unterschied in der Rate der DNA-Replikation.

Die Färbung wurde an $6 \mu \mathrm{m}$ dicken Schnitten durchgeführt.

1. Ebene: A-B (+/+), G-H (-/-)

2. Ebene: C-D (+/+), I-J (-/-)

3. Ebene: E-F $(+/+)$, K-L (-/-)

grün: BrdU markierte Zellen, rot: Propidiumiodid gefärbte Zellen

B, H, D, J, F und L zeigen die Überlagerung des grünen und roten Kanals.

$\mathrm{n}($ Wildtyp $)=2 ; \mathrm{n}$ (Mutante) $=2 ;$ Maßstab $100 \mu \mathrm{m}$

\section{$\underline{\mathrm{E} 13,5}$}

Als zweites Stadium wurde für die Untersuchung des Aspekts der mitotischen Aktivität in Wildtyp und Knock-out E13,5 ausgewählt, um auch ein früheres Stadium mit proliferativer Aktivität zu untersuchen. Die Auswertung wurde hier genauso durchgeführt wie zu E16,5 beschrieben. Die Anzahl der gesamten Zellen wurde für Wildtyp und Mutante mit 0,017 Zellen/ $\mu \mathrm{m}^{2}$ berechnet. Auf der Ebene des Riechkolbens (Abb.29 A, E), des ventralen Palliums (C, G) und des occipitalen Cortex (D, H) wurde ebenso keine signifikante Differenz im mitotischen Index zwischen Wildtyp und PIPPin-defizienten Gehirnen ausgemacht. 

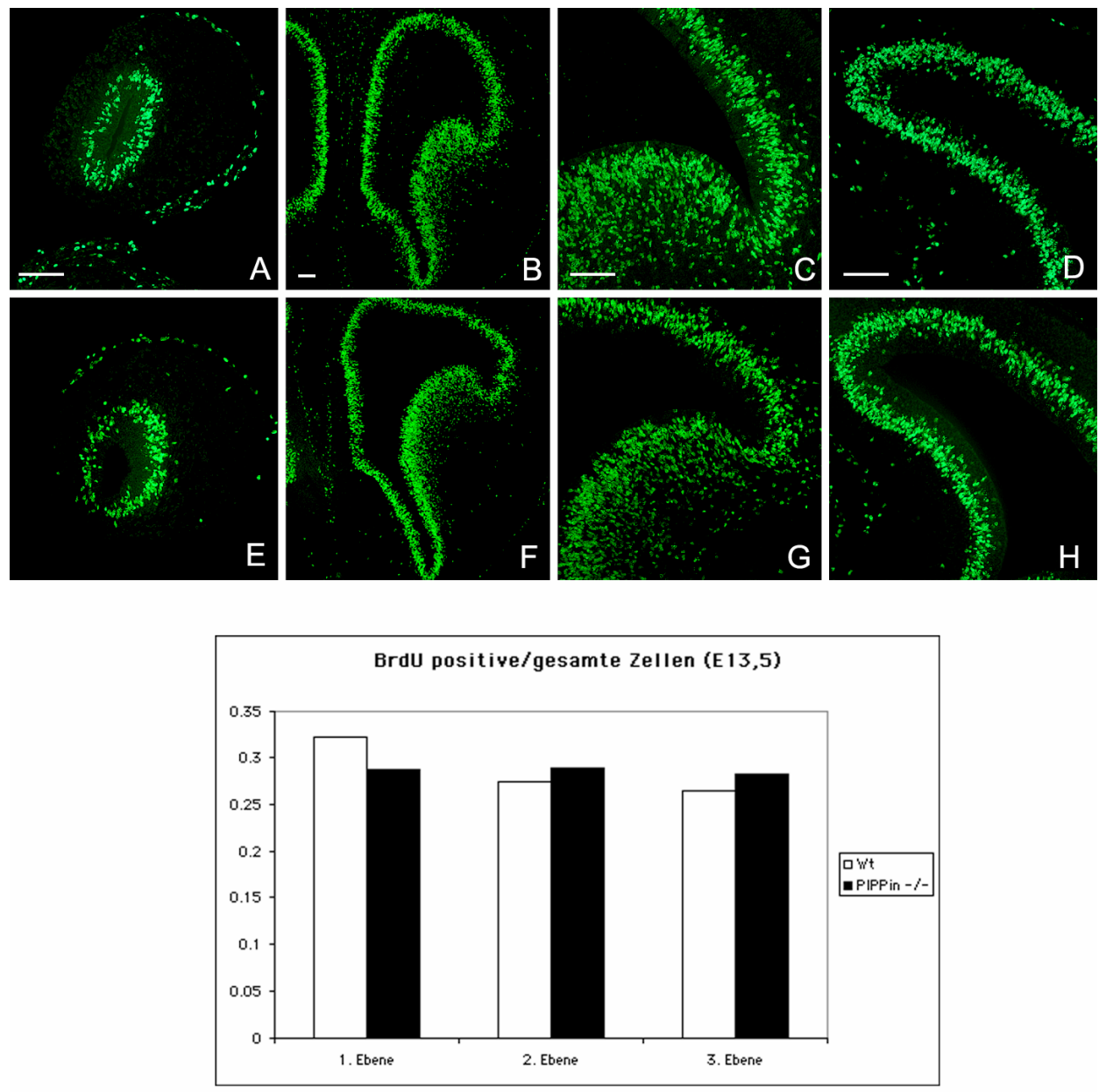

Abb.29: BrdU-Markierung mitotischer Zellen an E13,5 ergibt keinen offensichtlichen Phänotyp in PIPPin-defizienten Mäusen.

1. Ebene: A $(+/+)$, E $(-/-)$

2. Ebene: $\mathrm{C}(+/+), \mathrm{G}(-/-)$

3. Ebene: D (+/+), $\mathrm{H}(-/-)$

$\mathrm{B}(+/+)$ und $\mathrm{F}(-/-)$ zeigen Übersichten.

$\mathrm{n}($ Wildtyp $)=1 ; \mathrm{n}($ Mutante $)=2 ;$ Maßstab $100 \mu \mathrm{m}$

In der Maus-PIPPin-Expressionsstudie wurde an mehreren Stadien eine Region häufig als Ort von PIPPin-Expression erwähnt: das ventrale Pallium. Diese Region wird auch "Intermediärzone" (Fernandez et al., 1998) oder "anti-hem" (lateral im Cortex) genannt, da sie gegenüber von der sog. "cortical hem" (embryonale Fimbria, medial) liegt (Assimacopoulos et al., 2003). Das ventrale Pallium ist charakterisiert durch die Expression vieler Signalmoleküle z. B. Mitglieder der EGF-Familie wie Tgfo, Neuregulin1 und 3. Weiterhin finden sich im ventralen Pallium Signalmoleküle wie Fgf7, Sfrp2 und die Transkriptionsfaktoren Pax6 und ER81. Mit Hilfe von RNA-in situ-Hybridisierungen wurde untersucht, ob zwischen Wildtyp und PIPPin-defizienten Mäusen zum Zeitpunkt E16,5 Unterschiede in der Expression dieser Marker bestehen. 
Vergleich der Expression von Markergenen für das ventrale Pallium in Wildtyp- und PIPPin-defizienten Mäusen

In Abb.30 ist eine Zusammenfassung dieser Markeranalyse zu sehen, es wurden jeweils repräsentative Schnitte ausgewählt.

Sfrp2 (Abb. A, B)

Die Expression dieses Wnt-Antagonisten verläuft im PIPPin -/- -Gehirn (B) nicht anders als im Wt-Gehirn (A).

Neuregulin1 (C, D)

Die Sonde für diesen Marker des ventralen Palliums lieferte nur ein sehr schwaches Signal im Bereich der Ventrikulärzone des ventralen und lateralen Palliums (s. Pfeile). Zwischen Nrg1-Expression in Wildtyp (C) und Mutante (D) konnte kein eindeutiger Unterschied festgestellt werden.

\section{$\underline{\operatorname{Pax} 6(\mathrm{E}, \mathrm{F})}$}

Der Transkriptionsfaktor Pax6 wird sowohl im Wildtyp (E) als auch in der Mutante (F) in Zellen der Ventrikulärzone des ventralen und lateralen Palliums exprimiert. $\underline{\operatorname{ER} 81(\mathrm{G}, \mathrm{H})}$

Ebenso konnte in der Expression des Transkriptionsfaktors ER81 kein offensichtlicher Phänotyp detektiert werden (G: Wildtyp, H: PIPPin -/-).

Die Sonde für Neuregulin3 erbrachte ein ubiquitäres Signal, wogegen die Fgf7-Sonde kein Signal ergab (ohne Abb.). Die in situ-Hybridisierung mit der Sonde für Tgfo lieferte Signale im Hippocampus und Striatum, jedoch zu diesem Zeitpunkt weder beim Wildtyp noch bei der Mutante ein Signal im ventralen Pallium (ohne Abb.).

Bei Arbeiten am PIPPin-Protein der Ratte wurde herausgefunden, daß es sich bei PIPPin um ein RNA-bindendes Protein handelt, welches spezifisch u.a. an Histon $\mathrm{H} 1^{\circ}$-mRNAs bindet (Nastasi et al., 1999). Basierend auf in vitro Experimenten wird vermutet, daß Ratten-PIPPin sogar die Expression von Histonvarianten herunterreguliert (Nastasi et al., 2000). Sollte dies auch in vivo der Fall sein, könnte der Gehalt an $\mathrm{H}^{\circ}{ }^{\circ}$ im PIPPin-Knock-out höher sein. Dies wurde auf RNA-Ebene durch eine $\mathrm{H} 1^{\circ}$-in situ-Hybridisierung untersucht.

$\underline{\mathrm{H} 1^{\circ}(\mathrm{I}, \mathrm{J})}$

Es konnte im Wildtyp (I) und in PIPPin-defizienten Gehirnen (J) H1 ${ }^{\circ}$ detektiert werden. Der Eindruck der breiteren $\mathrm{H}^{\circ}{ }^{\circ}$-Expression in der Mutante $(\mathrm{J})$ im Bereich der 
Basalganglien kann durch die nicht ganz identische Schnittebene wie beim Wildtyp erklärt werden.

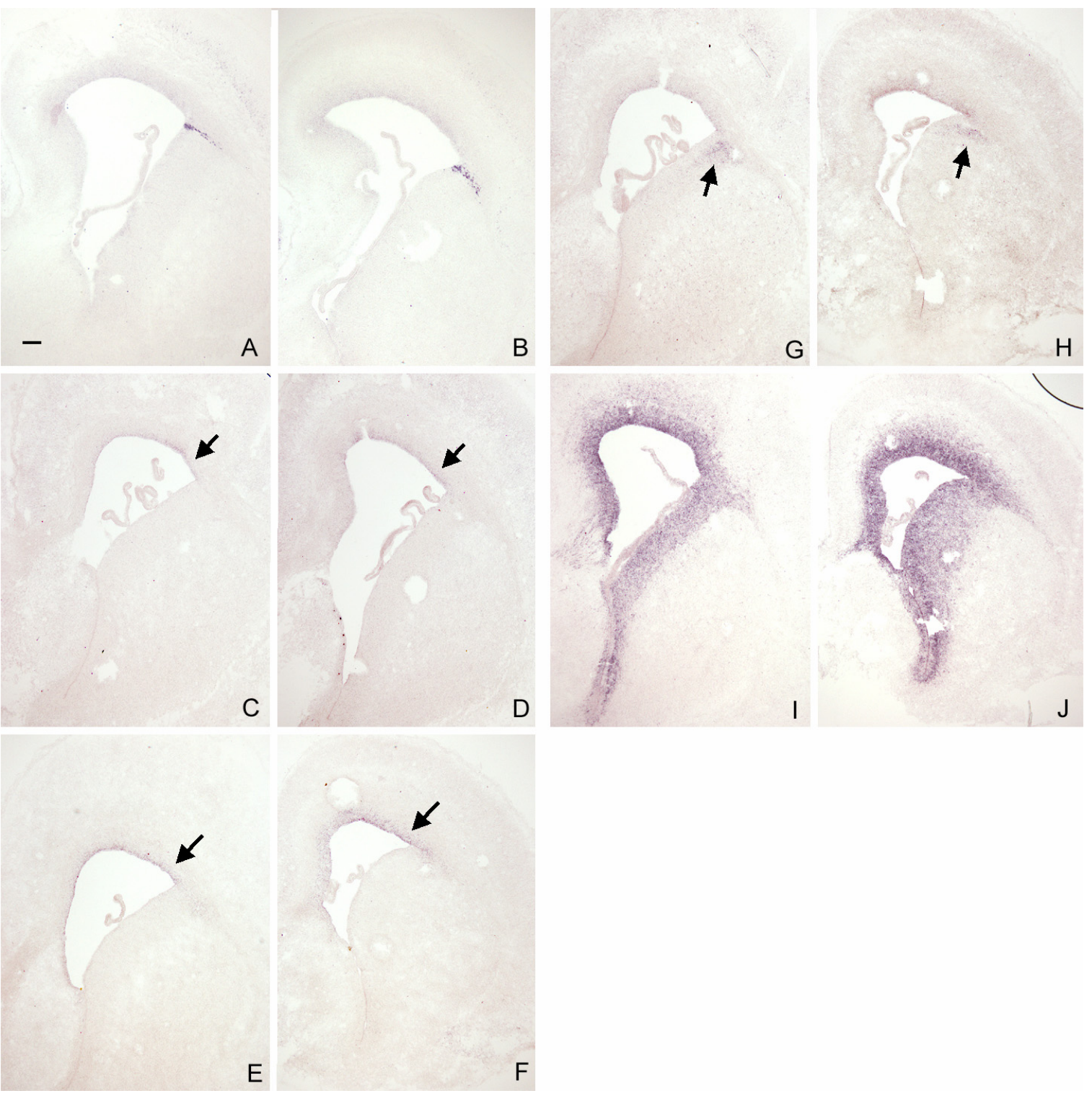

Abb.30: Vergleich der Expression verschiedener Markergene des ventralen Palliums zum Zeitpunkt E16,5 offenbart keinen offensichtlichen Phänotyp.

Sfrp2: A (Wt), B (homozygot); Nrg1 C (Wt), D (homozygot)

Pax6: E (Wt), F (homozygot); ER81: G (Wt), H (homozygot)

$\mathrm{H} 1^{\circ}$ : I (Wt), J (homozygot)

Maßstab $100 \mu \mathrm{m}$ 
Analyse des Gehalts von Histon $\mathrm{H} 1^{\circ}$-Protein in adulten Wildtyp- und MutantenGehirnen

Der Gehalt an $\mathrm{H}^{\circ}$ in Wildtyp und PIPPin-defizienten Gehirnen wurde auch mittels eines $\mathrm{H} 1^{\circ}$-Antikörpers auf Proteinbasis untersucht. Dafür wurde eine Histonpräparation aus P50 +/+ und -/- -Gehirnen durchgeführt. Der Zeitpunkt P50 wurde ausgewählt, um ausreichende Mengen Protein $\mathrm{zu}$ erlangen. Auch vom physiologischen Standpunkt erschien dieser Zeitpunkt angebracht, da das Histon $\mathrm{H}^{\circ}$ zu den replikationsunabhängigen Genen gehört (Zlatanova und Doenecke, 1994) und das Protein um den Zeitpunkt der Geburt und im Adultstadium sein höchstes Vorkommen erreicht (Doenecke et al., 1997). Für beide Genotypen lagen die H1Proteine in einer Konzentration von $1 \mu \mathrm{g} / \mathrm{ml}$ vor. Die H1-Proteine wurden im Proteingel aufgetrennt, es wurden $20 \mu \mathrm{l}$ aufgetragen. In Abb.31 ist eine CoomassieFärbung zu sehen, die zeigt, daß sowohl für Wildtyp (Spur 1) als auch für die Probe der Mutante (Spur 2) vergleichbare Mengen aufgetragen wurden. Das Ergebnis der $\mathrm{H} 1^{\circ}$-Immunodetektion wird in Abb.32 gezeigt. Die $\mathrm{H} 1^{\circ}$-Bande befindet sich auf der Höhe von etwa 25 kD und besitzt in Wildtyp (Spur 1) und PIPPin-Knock-out (Spur 2) die gleiche Intensität. Die kleineren Banden bei 15 und $17 \mathrm{kD}$ könnten sich durch Abbauprodukte des $\mathrm{H}^{\circ}{ }^{\circ}$-Proteins erklären lassen. Die These, daß PIPPin ein negativer Regulator der $\mathrm{H}^{\circ}{ }^{-}$-Translation sei, konnte in vivo zu dem Zeitpunkt P50 mit Hilfe des Western-Blots nicht bestätigt werden.
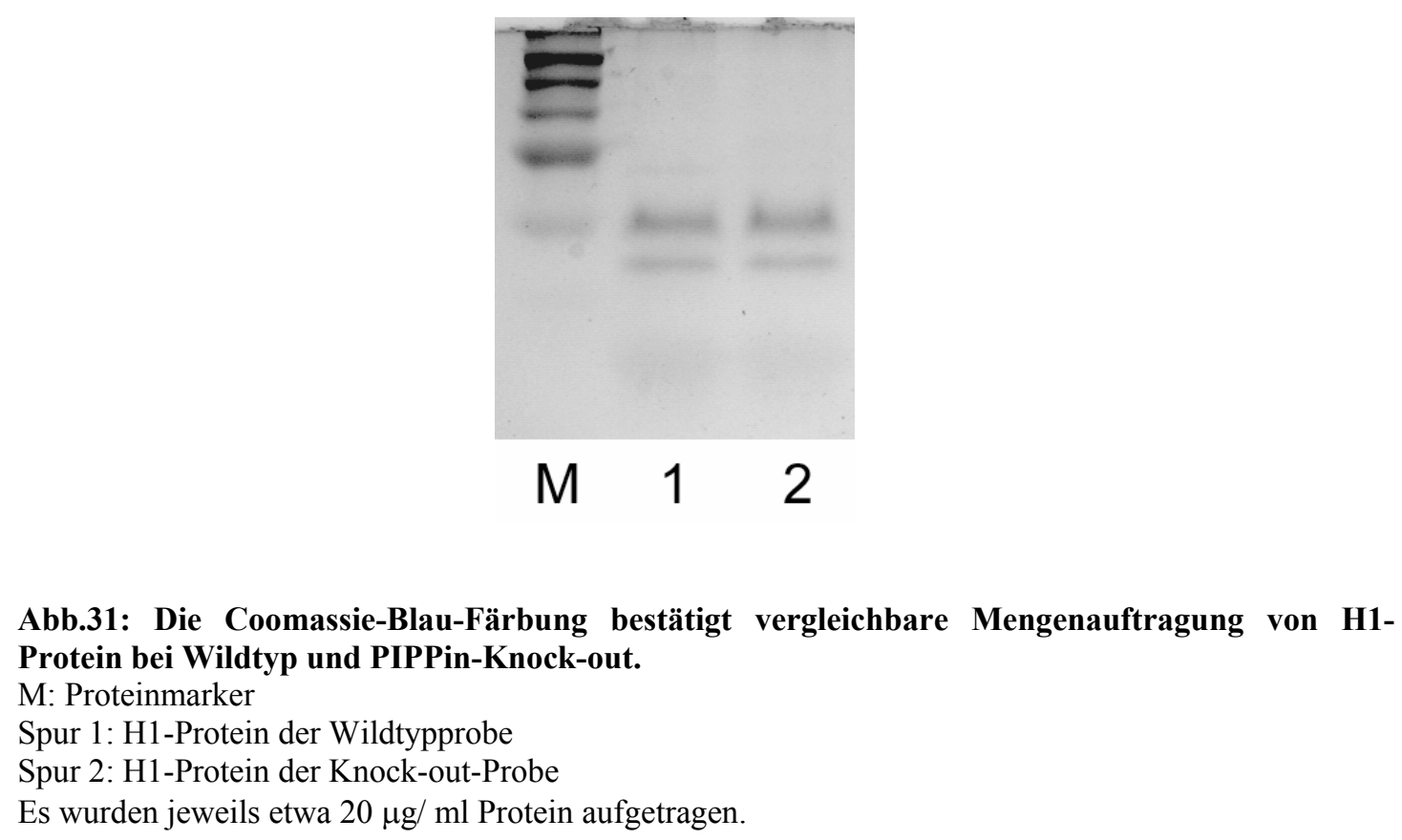


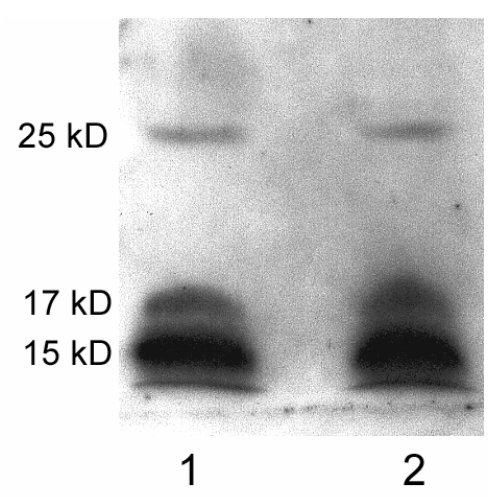

Abb.32: Der Nachweis von $\mathrm{H1}^{\circ}$-Protein in Wildtyp und PIPPin-defizienten P50-Gehirnen zeigt keinen Unterschied im $\mathrm{H1}^{\circ}$-Proteingehalt.

Spur 1: $\mathrm{H} 1^{\circ}$-Protein im P50 Gehirn

Spur 2: $\mathrm{H}^{\circ}{ }^{\circ}$-Protein im P50 Knock-out-Gehirn

Der $\mathrm{H} 1^{\circ}$-Antikörper wurde in einer 1:400-Verdünnung eingesetzt. Der Blot wurde für eine Stunde entwickelt.

Analyse des Purkinje-Zellmarkers Calbindin D-28K in Wildtyp und PIPPin-Knock-

out

Bei der Analyse der PIPPin-Knock-out Maus wurde auch der Aspekt der PIPPinExpression in der Purkinje-Zellschicht des Cerebellums berücksichtigt. Als ein Marker der Purkinje-Zellen wurde das Vorkommen des Calcium-bindenden Proteins Calbindin D-28K (Barski et al., 2003) im Cerebellum von Wildtyp- und MutantenGehirnen des Stadiums P51 untersucht (Abb.33). In Abb.33 A ist die Calbindin D28K-Immunfärbung in einer Übersicht im Wildtyp zu sehen. Beim Vergleich mit der Färbung von PIPPin-defizienten Cerebella (C, D, E) sind keine Auffälligkeiten in der Mutante zu beobachten. Auch hier zeigen die Purkinje-Zellen ihre strenge geometrische Anordnung. Sie bilden in relativ regelmäßigen Abständen eine Reihe zwischen der Körner- (Stratum granulare) und Molekularschicht (Stratum moleculare) der Cerebellumrinde. In Größe und Form der Purkinje-Zellkörper sind keine Unterschiede in der Mutante auffällig. Die Betrachtung der Purkinje-Zellen im Detail ist in B (Wildtyp) und F (Knock-out) zu sehen. Bei beiden Genotypen zweigen am oberen Pol der Zellen primäre Dendritenstämme ab, die sich wieder in feine Verästelungen aufzweigen. 

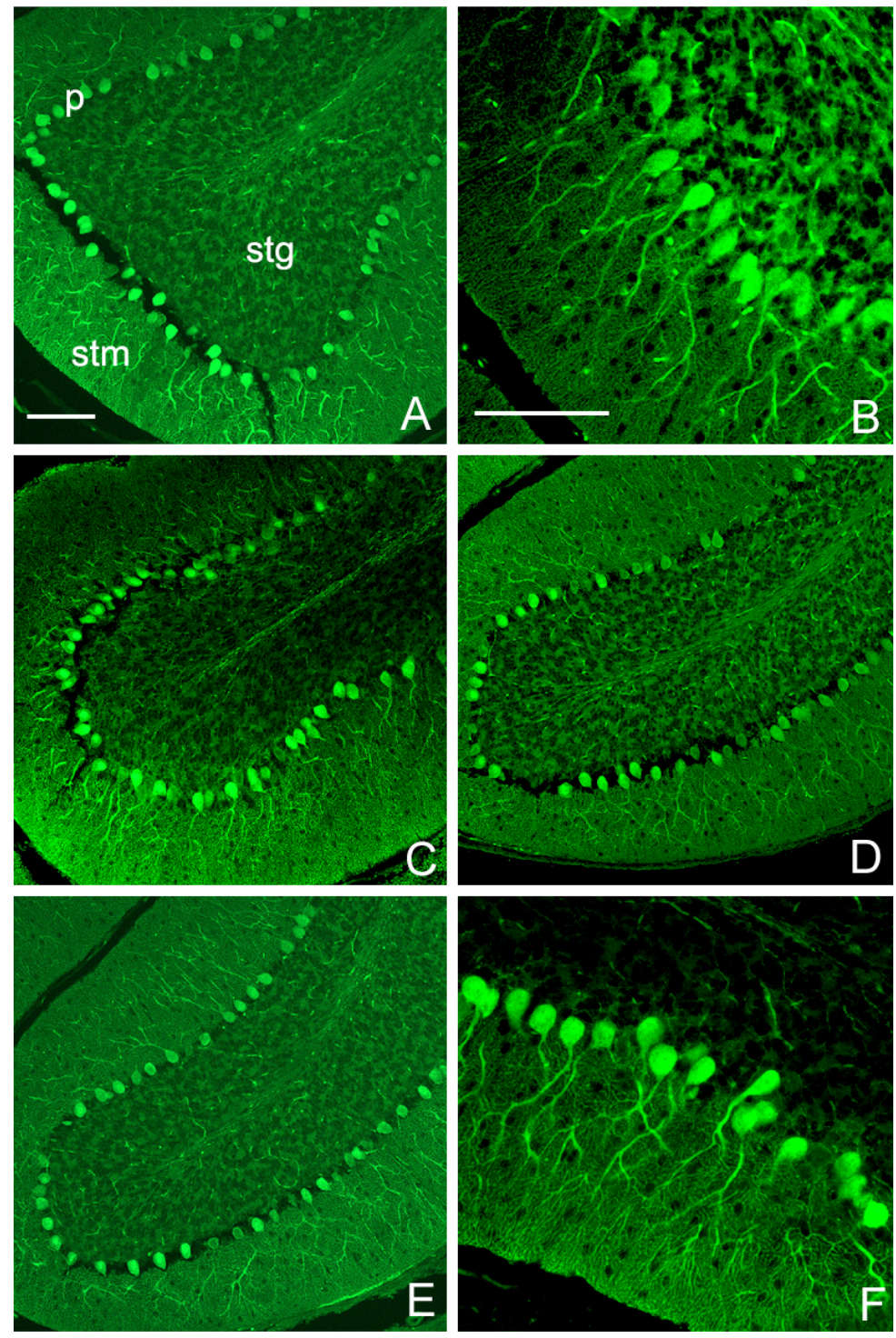

Abb.33: Die Immunfärbung mit Antikörper gegen den Purkinje-Zellmarker Calbindin D-28K liefert keine Unterschiede zwischen Wildtyp und PIPPindefizienten P51 Cerebella

A: Übersicht Wildtyp

B: Detailaufnahme von Purkinje-Zellen, Wildtyp

C, D, E: Übersicht Mutante

F: Detailaufnahme von Purkinje-Zellen, Mutante

Die Färbung wurde an $8 \mu \mathrm{m}$ dicken Paraffinschnitten durchgeführt, der Primärantikörper wurde bei $4^{\circ} \mathrm{C}$ für zwei Tage in einer 1:500-Verdünnung inkubiert.

stg, stratum granulare; stm, stratum moleculare; $p$, Purkinje-Zellschicht

Maßstab $100 \mu \mathrm{m}$ 


\subsection{Identifikation und Analyse von regulatorischen}

\section{Sequenzelementen des Maus-PIPPin-Genlocus}

Problem der negativen $\beta$-Galactosidase-Färbung von Geweben des PIPPin-Knock$\underline{\text { outs }}$

Wie in Abschnitt 3.5 beschrieben, enthielt das Konstrukt zur homologen Rekombination in den Maus-PIPPin-Genlocus u.a. das Reportergen $\beta$-Galactosidase. Dieser Umstand sollte für $\beta$-Galactosidase-Färbungen PIPPin-defizienter E11Embryonen genutzt werden, um die zu diesem Zeitpunkt schwache PIPPinExpression im Cortex besser beschreiben zu können. Doch war in Testfärbungen von E12,5-Embryonen (PIPPin -/-) und E16,5-Gehirnen (PIPPin -/-) nahezu keine Blaufärbung zu detektieren (Abb.34 A: E12,5; B: E16,5). Einzig im Bereich des ventralen Palliums, wo PIPPin im Wildtyp prominent in der Ventrikulärzone exprimiert wird, ist in B eine leichte Blaufärbung zu beobachten (s. Pfeil). Allerdings sollte die $\beta$-Galactosidase-Färbung homozygoter Gewebe das Expressionsmuster der PIPPin-RNA-in situ-Hybridisierung im Wildtyp wiedergeben. Als Ursache für diese Diskrepanz wurden verschiedene Erklärungsmöglichkeiten bedacht:

- $\quad$ Die Klonierung des Gens $\beta$-Galactosidase erfolgte nicht im Leseraster, so daß dieses Gen nicht korrekt exprimiert werden kann.

Die korrekte Klonierung der $\beta$-Galactosidase wurde auf zwei Weisen überprüft. Zum einen wurde der Übergang der 5'-Homologie in das Gen $\beta$-Galactosidase mit einem speziellen Oligonucleotid (FK7) sequenziert. Zum anderen sollte bei diesem Klonierungsschritt eine zusätzlich XhoI-Schnittstelle entstehen (s. S.77), die auch vorhanden ist (s. Abb.21). Diese Erkärungsmöglichkeit für die negative $\beta$ Galactosidase-Färbung ist somit nicht zutreffend.

- $\quad$ Die negative $\beta$-Galactosidase-Färbung ist abhängig von dem ES-Zellklon, der für die Morula-Aggregation verwendet wurde.

Um diesen Einwand zu überprüfen, wurden aus einem weiteren positiven ES-Zellklon (FK-178) PIPPin-Knock-out-Mäuse erstellt. Die $\beta$-Galactosidase-Färbung eines E18,5-Gehirns dieser Linie ist in Abb.34 C dargestellt. Auch hier ist nur ein leichter Blauschimmer im Bereich des ventralen Palliums zu sehen (s. Pfeil). Die nahezu negative Färbung ist somit nicht von dem verwendeten ES-Zellklon abhängig. 


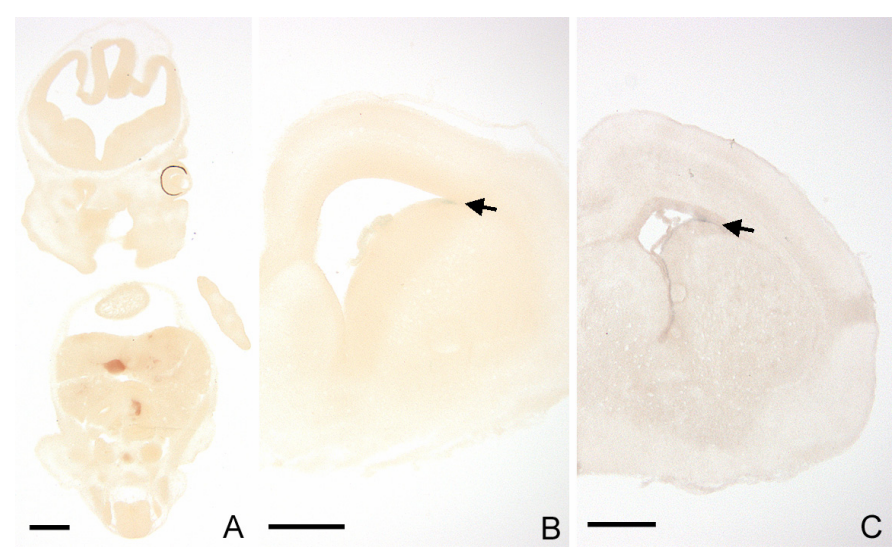

Abb.34: Bei einer $\beta$-Galactosidase-Färbung von PIPPin-defizientem Gewebe ist ein nur sehr schwaches Signal im Bereich des ventralen Palliums zu erkennen.

A: E12,5-Embryo der Linie FK-216

B: E16,5-Gehirn der Linie FK-216

C: E18,5-Gehirn der Linie FK-178

Die Färbung erfolgte an $30 \mu \mathrm{m}$ dicken Gefrierschnitten, eine Positivkontrolle wurde mitgeführt (ohne Abb.). Maßstab $500 \mu \mathrm{m}$

- $\quad$ Die Inaktivierung des Maus-PIPPin-Gens durch die Insertion der lacZpolyApGKNeopolyA-Kassette deletierte regulatorische Elemente des PIPPin-Gens.

Der deletierte Bereich von 3,5 $\mathrm{kb}$ wurde zur Untersuchung dieser Erklärungsmöglichkeit in ein Reporterkonstrukt subkloniert (s. Kap.II, S.22) und in der in vitro Elektroporation getestet. 
Der im PIPPin-Knock-out durch homologe Rekombination deletierte 3,5 kb-Bereich $\underline{\text { ist in der Lage, die Aktivität eines Reportergens anzutreiben }}$

In Abb.35 ist das Ergebnis der in vitro Elektroporation (E14,5) des im Knock-out deletierten Bereichs (pFK35) dargestellt. An der Fluoreszenz des GFP sind diejenigen Bereiche zu erkennen, in die das Plasmid pFK35 gelangt ist (A-C). In denselben Bereichen tritt in der $\beta$-Galactosidase-Färbung eine deutliche Blaufärbung auf $\left(\mathrm{A}^{\prime}-\mathrm{C}^{\prime}\right)$. Die Elektroporation der Negativkontrolle (nur der leere Vektor, D) ergibt keine Blaufärbung (D'), was die Spezifität des Signals bestätigt. Aus diesem Experiment kann geschlossen werden, daß die 3,5 kb-Sequenz, die durch homologe Rekombination deletiert wurde, die Transkription verstärkende, regulatorische Elemente ("Enhancer") enthält. Dieser Enhancer ist in der Lage, die Transkription des Reportergens $\beta$-Galactosidase im Bereich der Ventrikulärzone des ventralen und lateralen Palliums anzutreiben. Da dieses regulatorische Element in PIPPindefizientem Gewebe fehlt, wird dort die Transkription der $\beta$-Galactosidase nicht verstärkt. Die geringe Blaufärbung in den PIPPin-defizienten Gewebeschnitten in Abb.34 läßt sich durch eine kleine Restaktivität des Enhancers oder durch weitere regulatorische Elemente in anderen Bereichen des PIPPin-Genlocus erklären.

Das Signal der $\beta$-Galactosidase-Färbung im Bereich der Ventrikulärzone des ventralen und lateralen Palliums ist spezifisch

In Abb.35 A ist zu beobachten, daß außer in dem Bereich des ventralen und lateralen Palliums auch noch DNA in die mediale Region des Cortex gelangt ist. Da dort kein $\beta$-Galactosidase-Signal zu beobachten ist (A'), handelt es sich bei dem Enhancer um ein Maus-PIPPin-spezifisches Element, das nur in der Region wirkt, in der auch Maus-PIPPin natürlicherweise exprimiert wird (nämlich im Bereich der Ventrikulärzone des ventralen und lateralen Palliums). 

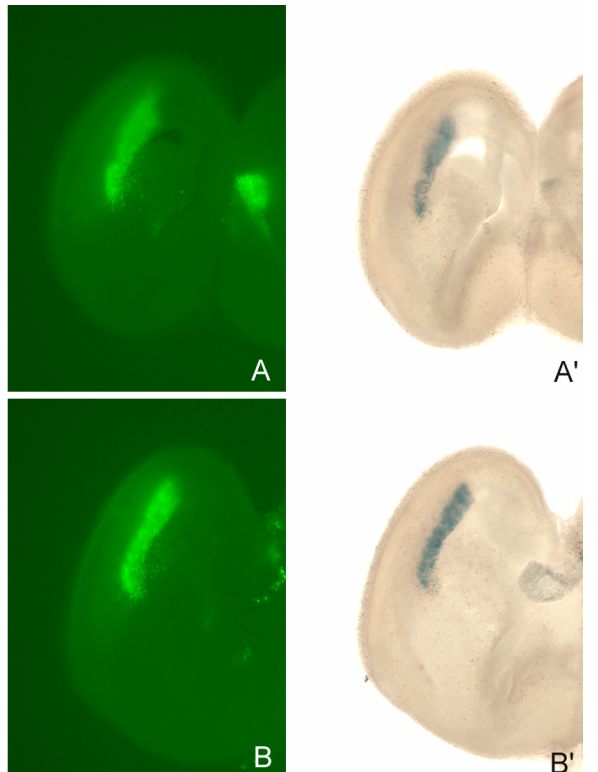

$A^{\prime}$
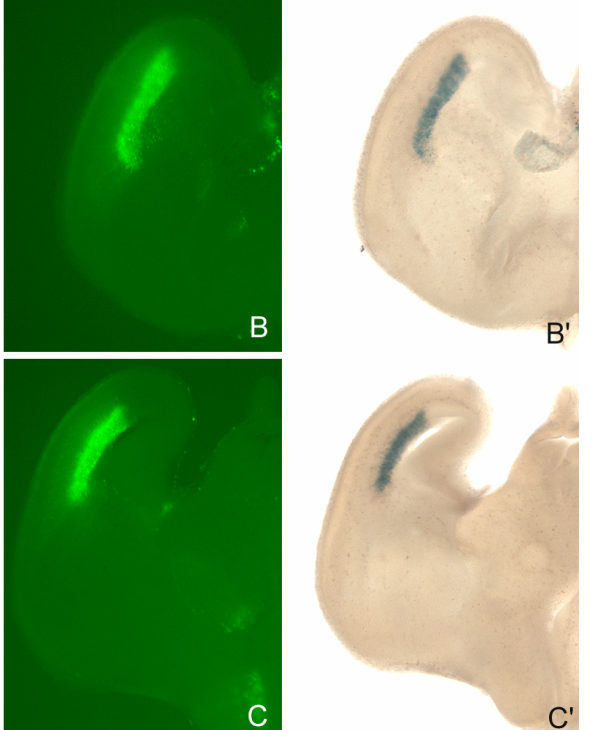

$B^{\prime}$
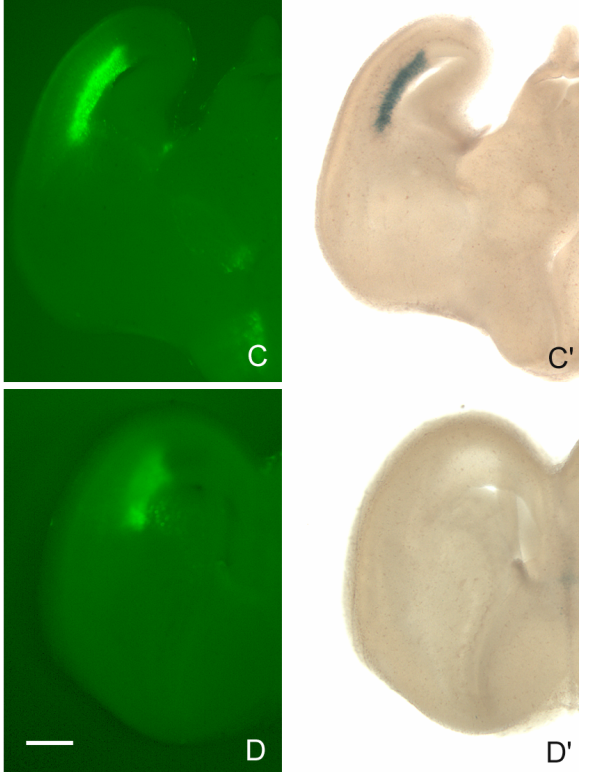

Abb.35: Der Deletionsbereich der PIPPin-Knock-out-Maus enthält Enhancer-Elemente und ist daher in der Lage, spezifisch die Expression der $\beta$-Galactosidase im Bereich des Neuroepithels des ventralen und lateralen Palliums anzuschalten.

Fehlt dieses Element, wie es in PIPPin-defizienten-Mäusen der Fall ist, so ist die $\beta$-GalactosidaseFärbung negativ.

In vitro Elektroporation des Konstrukts pFK35 in E14,5-Gehirne.

A-D: GFP, A'-D': $\beta$-Galactosidase

Maßstab: $500 \mu \mathrm{m}$ 
$\underline{\text { In vitro Elektroporation weiterer Deletionskonstrukte zur Eingrenzung des Enhancer- }}$ Elements

Um herauszufinden, welcher Bereich des 3,5 kb-Fragments den Enhancer enthält, wurden verschiedene Deletionskonstrukte kloniert. Eine Zusammenfassung dieser Experimente ist in Abb.37 dargestellt. Das 1,7 kb große Fragment pFK36 ist in sense und antisense-Richtung positiv (A, B). Dies deutet tatsächlich auf einen Enhancer hin, der im Gegensatz zu Promotoren, richtungsungebunden wirkt (Sassone-Corsi et al., 1984). Die Elektroporation der nächsten beiden Konstrukte pFK37 und 38 ergab nur eine positive $\beta$-Galactosidase-Färbung bei pFK37 (C). Somit konnte das EnhancerElement bis zum jetztigen Zeitpunkt bis auf einen Bereich von etwa 700 bp eingegrenzt werden. Diese 700 bp befinden sich im 3' nicht translatierten Bereich des Maus-PIPPin-Genlocus (s. Abb.36).

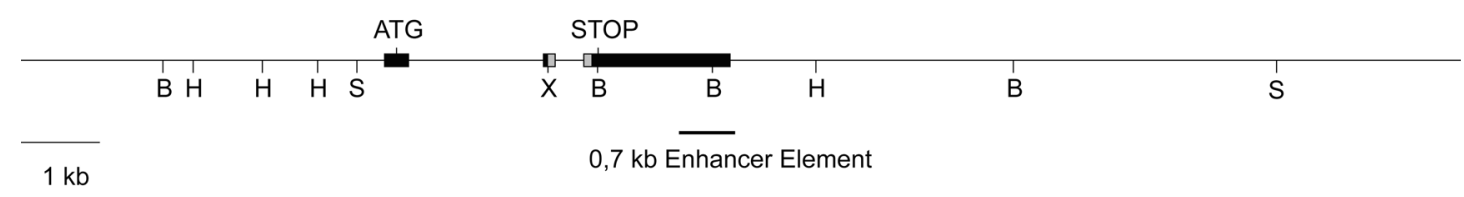

\footnotetext{
Abb.36: Das 3,5 kb große Enhancer-enthaltende Fragment konnte durch Deletionskonstrukte auf einen postiven Bereich von 700 bp eingegrenzt werden.

Dieser Bereich befindet sich im 3' nicht translatierten Bereich des Maus-PIPPin-Genlocus.

Die schwarzen Boxen symbolisieren Exon 2, 3 und 4 des PIPPin-Gens, die hellgrauen Boxen stellen die CSD-Domäne dar.

ATG: Startcodon, STOP: Ende der Translation

B: Bam HI, H: Hind III, S: Spe I, X: Xho I
} 
I.
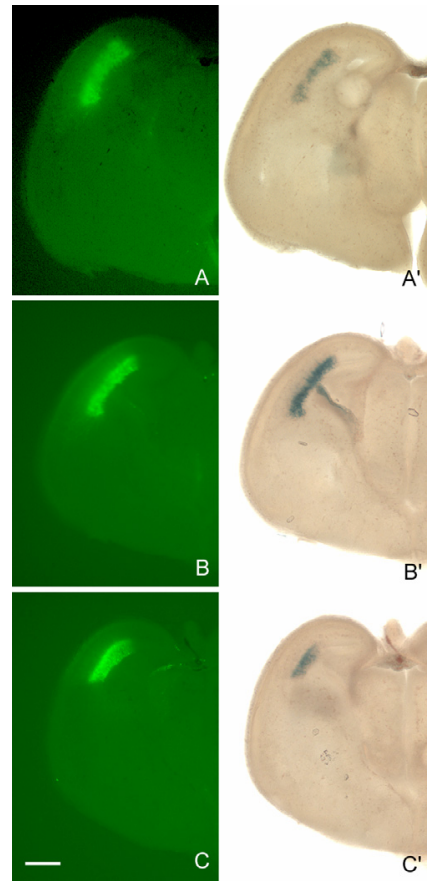

II.

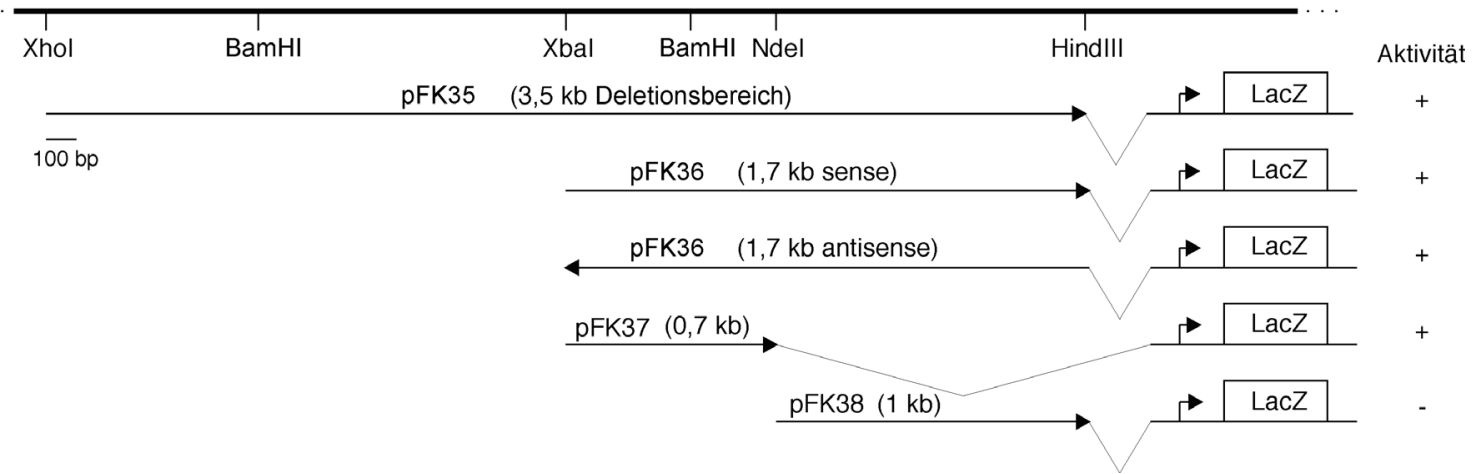

Abb.37: In vitro Elektroporation von Deletionskonstrukten zur Eingrenzung des 3,5 kb Enhancerenthaltenden Elements führt zu einem positiven Bereich von 700 bp.

I. Das Experiment wurde wiederum an E14,5 durchgeführt.

A-C: GFP, A'-C': $\beta$-Galactosidase

A, A': pFK36 sense; B, B': pFK36 antisense; $\mathrm{C}, \mathrm{C}^{\prime}$ : pFK37

Maßstab: $500 \mu \mathrm{m}$

II. Darstellung der Deletionskonstrukte in ihrer Lage zueinander. 
Analyse des Enhancer-enthaltenden 700 bp großen Fragments im Hinblick auf Bindestellen für Transkriptionsfaktoren

Das Enhancer-enthaltende Element pFK37 wurde auf konservierte Bereiche hin durch Sequenz-Vergleich mit dem humanen Genom untersucht. Dabei wurden fünf Bereiche von 21-47 Nucleotiden identifiziert, die Übereinstimmungen von 89-100\% mit dem humanen Genom aufwiesen. Die Nucleotidsequenz des 700 bp großen Fragments und die Übereinstimmungen mit dem humanen Genom sind in Abb.38 und 39 dargestellt. Der erste Treffer (Abb.39), der bei der Suche nach konservierten Bereichen ausgegeben wurde, stimmt mit dem fettgedruckten Bereich (Abb.38) zu 89\% überein. Der blau gedruckte Bereich der Nucleotidsequenz besitzt zu 100\% (2. Treffer) einen entsprechenden Bereich im Humangenom. Als dritter Treffer wurde der kursiv gedruckte Bereich genannt, als vierter der rot gedruckte, die beide ebenfalls eine vollständige Entsprechung im humanen Genom besitzen. Als letzter Treffer wurde eine komplette Übereinstimmung mit der Humansequenz im Bereich der grün eingefärbten Sequenz des Enhancer-Elements ermittelt.

Diese konservierten Bereiche wurden mit Hilfe des Programms MatInspector auf Transkriptionsfaktor-Bindestellen hin untersucht. Bei der Angabe der Suchergebnisse des MatInspectors sind zwei Werte von Bedeutung:

- Die "core similarity" gibt die Übereinstimmung mit der "core sequence" an, die aus den vier höchst konservierten, aufeinanderfolgenden Nucleotiden der Bindestelle besteht. Die "core similarity" sollte bei kompletter Übereinstimmung den Wert 1,0 betragen.

- Die Übereinstimmung mit der Umgebung der Bindestellen wird durch die "matrix similarity" angedeutet und sollte bei guter Übereinstimmung einen Wert um eins besitzen. 
Ets-1

CTAGAGAGCCAGTTACTTAACCAGAGGATAAGTGAGGTCACAGGCTCAGG Pax6

AAGGGCCTGGCACAATAGTGACCTTTATGAGACCCAGCCCAGAAGTAAAA TGTGAGCACAGATAGCCAGGGTGAAGGGGTCAGTGGTTGCGAGGTAGCCT TGTAGGCATTCCAGGACCACAGGGTAGTCATTTGGGGCATTTGCACCCCA ACTTGTCCTAGTACCCTTTGCACACGGCCCAGCAGCCTAGAGCTGCTAAC AAGTGCTGGCCAGTCCTCCATCCTGGGAAGGACCTGTCTGATACCCCACT GTGAGCTAGGCTTCTCCAGCAAAGCCTATCCCTGGAGACCAGTCCTCAGC AACCTTGAGGACCAGAGTTCAAATCTCCAGCAAGCCTGTAACCCAGAACT GTGTTAATAAAGACACAGGCGGATCCTTTGACAAGGAACCCCAGGGCCAT CAGCCCTCTGTTGTGAGCAGGTCCTTAGCAGTCATCACCTTGAGGCTCCCC GAATGATAGGGACAACAGACCTCCTCCCTACTCTTGGGCCCTGCAGCGCC AAGTCAGAAACTTCCCCACTCAGACCCCAGCCA

Östrogen-Rezeptor

CGGATTCCCCATCCCTCCTGACACTGGCAATAAACTCAACTGTGACCC АССCTGCCCCTGAGCTGCCTGTCTTGAGTGTTCTTGTGGAAGGGGCTGAGG AAGGACACAACAT

Abb.38: Nucleotidsequenz des 700 bp Enhancer-enthaltenden Elements Die mit dem humanen Genom übereinstimmenden Bereich sind farbig bzw. fett und kursiv hervorgehoben. Die unterstrichenen Bereiche deuten auf Bindestellen für Transkriptionsfaktoren (Angabe der "core sequence") hin. 
1. Treffer: 42 von 47 Nucleotiden stimmen mit dem Humangenom überein (89\%)

Query: 591 ccccatccctcctgacactggcaataa--ctcaactgtgacccacc 635

|| |||| | |||| || |||||||||||| ||||||||||||||||||

Sbjct: 45246 ccccattcttcctaacactggcaataaaccctcaactgtgacccacc 45292

2. Treffer: Vollständige Übereinstimmung mit dem humanen Genom

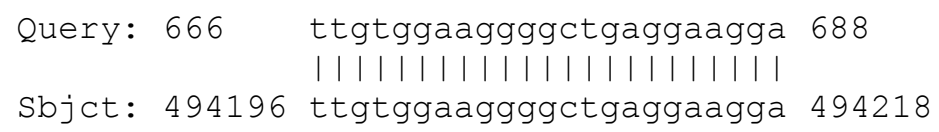

3. Treffer: $100 \%$-ige Identität mit dem humanen Genom

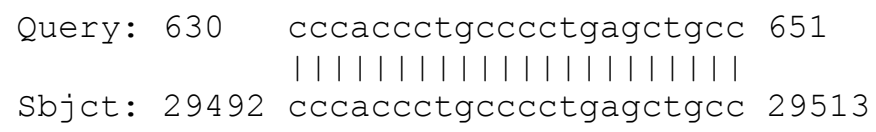

4. Treffer: Komplette Übereinstimmung mit dem humanen Genom

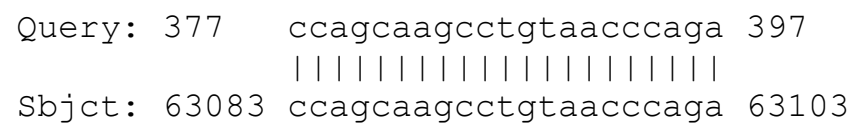

5. Treffer: Vollständige Übereinstimmung mit dem humanen Genom

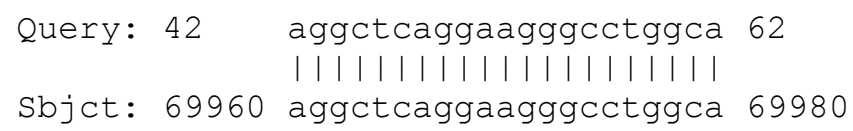

\begin{abstract}
Abb.39: Blast des 700 bp Enhancer-enthaltenden Elements mit der Sequenz des Humangenoms in der CELERA-Datenbank ergibt fünf konservierte Bereiche.

Treffer 1 findet sich in der Nucleotidsequenz als Fettdruck, Treffer 2 als Druck in blau wieder. Der 3. Treffer der Suche nach Übereinstimmungen mit dem humanen Genom ist kursiv geschrieben, Treffer 4 wurde rot und Treffer 5 grün eingefärbt.
\end{abstract}


Die Treffer 2, 3 und 4 lieferten keine Suchergebnisse. Treffer 1 ergab vier Suchergebnisse, wovon nur ein Ergebnis eine akzeptable "core similarity" von 1,0 aufwies. Es handelt sich dabei um eine Bindestelle für einen Östrogen-Rezeptor (s. Abb.38).

Die fünfte mit dem Humangenom übereinstimmende Sequenz ergab im MatInspector eine Bindestelle für den Transkriptionsfaktor Ets-1 ("core similarity": 1,0) (Abb.38).

Abgesehen von der Analyse der mit dem Humangenom übereinstimmenden Bereiche wurde auch die gesamte Enhancer-enthaltende Sequenz von 700 bp Länge auf Bindestellen für Transkriptionsfaktoren untersucht. Dabei stieß vor allem ein Ergebnis mit guten Werten für die "core similarity" $(1,0)$ und "matrix similarity" $(0,893)$ auf besonderes Interesse: die Enhancer-enthaltende Sequenz besitzt eine Bindestelle für den Transkriptionsfaktor Pax6 (Abb.38). In diesem Zusammenhang soll als Abschluß des Ergebniskapitels folgendes Ergebnis genannt werden.

\section{Die PIPPin-Expression ist in homozygoten Small eye-Mäusen reduziert}

Die Small eye (Sey)-Mutation wird durch eine Punktmutation im Pax6-Gen verursacht und resultiert damit in der Produktion eines nicht funktionalen Proteins (Hill et al., 1991).

In Abb.40 ist eine PIPPin-in situ-Hybridisierung auf E14,5 (A-F Wildtyp, G-L homozygot) und E16,5 (M-R Wildtyp, S-X homozygot) Sey-Gehirnschnitten gezeigt. Bei beiden Entwicklungsstadien ist eine starke Reduktion der PIPPin-Expression in homozygoten Sey-Mäusen zu verzeichnen. Besonders auffällig ist dieser Effekt im Bereich der Ventrikulärzone der Basalganglien, des ventralen und lateralen Palliums (H-K, S-W). Auch die an E16,5 prominente Färbung des Piriformcortex im Wildtyp $(\mathrm{O}, \mathrm{P})$ ist im homozygoten Gewebe deutlich reduziert $(\mathrm{U}, \mathrm{V})$. Erhalten bleibt die PIPPin-Expression dagegen im Bereich des Mes- und Metencephalons an E14,5 (F, L) und an E16,5 auf der Ebene des Cerebellums (R, X). 


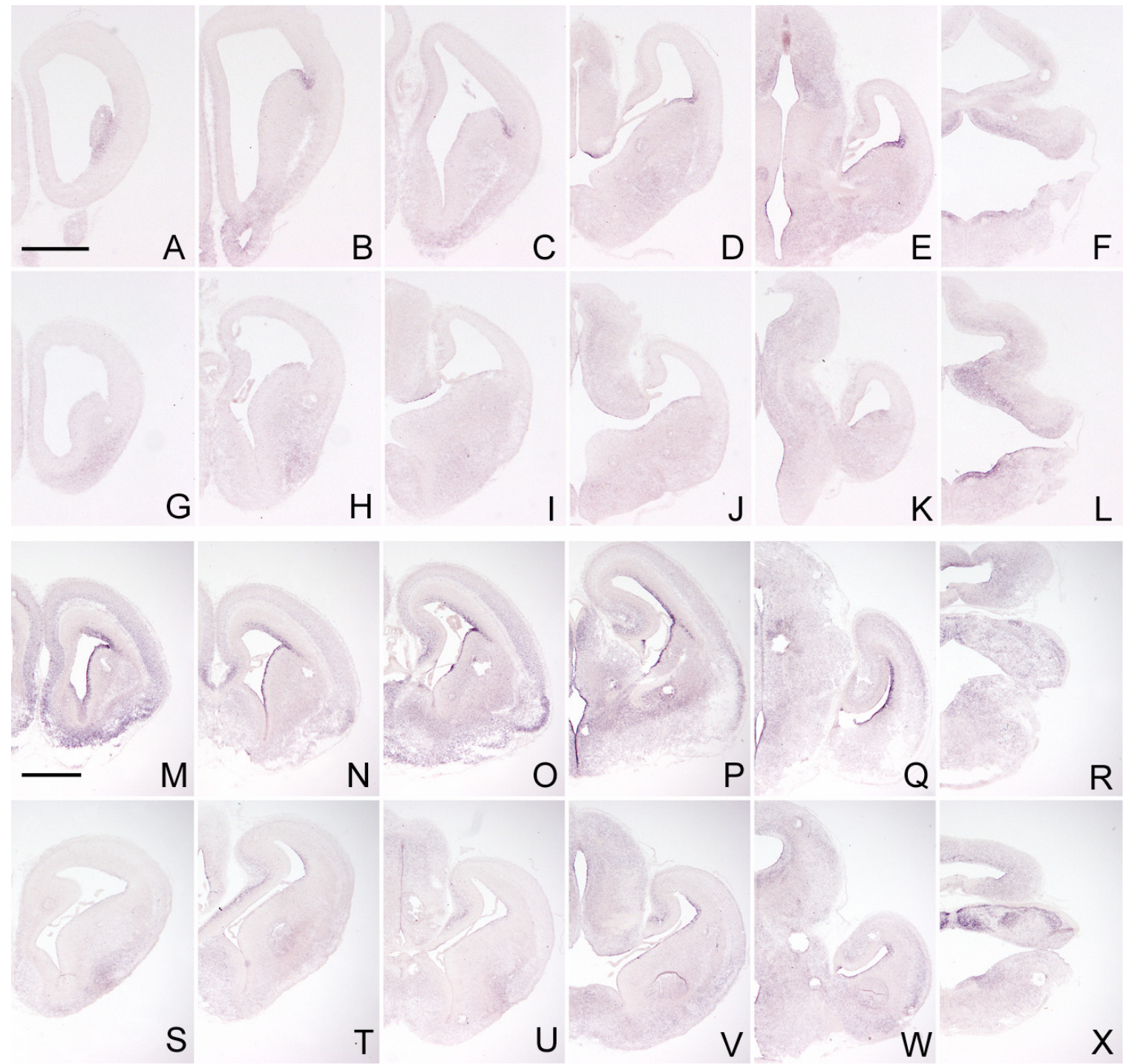

Abb.40: Die PIPPin-Expression ist in homozygoten Sey (Small eye)-Gehirnen der Stadien E14,5 und E16,5 im Bereich der Ventrikulärzone des ventralen und lateralen Palliums, der Basalganglien und des Piriformcortex stark reduziert.

PIPPin-in situ-Hybridisierung auf homozygoten Sey coronalen Gehirnschnitten E14,5: A-F (Wildtyp), G-L (homozygot); E16,5: M-R (Wildtyp), S-X homozygot Maßstab $500 \mu \mathrm{m}$ 


\section{Diskussion}

\section{Microarray-Expressionsanalyse identifizierte Gene mit regionen- und schichtspezifischer Expression im cerebralen Cortex des Embryonaltags 16,5}

Zur Identifikation von Genen mit regionenspezifischer Expression an E16,5 wurde von fünf Cortexregionen dieses Stadiums eine Microarray-Expressionsanalyse durchgeführt. Nach Anwendung bestimmter Filterkriterien (s. Kap. II, 2.3) zur Auswertung der Daten wurden 96 Sequenzen selektiert, die zum Zeitpunkt E16,5 spezifisch in einer der Cortexregionen exprimiert werden sollten. Dabei fiel auf, daß über die Hälfte dieser Gene (58\%) in der Anlage des motorischen Cortex (frontal) exprimiert werden sollte (Abb.4). Auf den posterior gelegenen parietalen Cortex entfielen dagegen nur 7\% der selektierten Gene. Dieses Verhältnis könnte den longitudinalen neurogenetischen Entwicklungsgradienten widerspiegeln. Auf der Basis von $\left[{ }^{3} \mathrm{H}\right]$ Thymidin-Markierungen verschiedener Cortexschichten wurde ein signifikant früherer Ursprungszeitpunkt anteriorer Zellen im Vergleich zu posterioren Bereichen festgestellt (Bayer und Altman, 1991). Dies würde somit auch eine erhöhte Genaktivität in der anterior gelegenen Anlage des motorischen Cortex bedeuten. Ein weiterer neurogenetischer Entwicklungsgradient, der sich von lateral nach medial bewegt (der transverse Gradient) läßt sich an Hand der Aufteilung der selektierten Gene nach den Cortexregionen nicht ablesen.

Die Einteilung der bekannten Gene (aus den 96 ausgewählten Sequenzen) in ihre Funktion ergab (Abb.5), daß 53\% dieser Gene im Zusammenhang mit Transkriptionsfaktor-, Rezeptor- und Signaltransduktionsaktivität stehen, was auf Entwicklungs- und Differenzierungsprozesse hindeuten könnte. 


\section{Bestätigung der meisten ausgewählten Gene in der}

\section{RNA-in situ-Hybridisierung, Kommentar der Microarray- Technologie}

Nach der Auswertung der Chipdaten wurden die durch die Anwendung der Filterkriterien erhaltenen Gene in der in situ-Hybridisierung auf ihre Expression hin überprüft. Dabei bestätigten viele Kandidaten die Chipdaten, andere dagegen zeigten widersprüchliche Expressionsmuster. In der in situ-Hybridisierungs-Analyse ergaben sich verschiedene Mustergruppen, es gab sowohl Gene mit regionenspezifischer als auch schichtspezifischer Expression. Die im Ergebnisteil gezeigten Beispiele sollen einen repräsentativen Überblick über die Microarray- und in situ-HybridisierungsAnalyse geben und werden nun näher kommentiert.

Thymocyten selektions-assoziiertes HMG (high mobility group) box Gen (Tox) (Abb.6 A-D)

Dieses Gen galt nach Analyse der Chipdaten als ein Kandidat für regionenspezifische Expression im frontalen Cortex, was sich in der in situ-Hybridisierung bestätigte.

Tox codiert für ein nucleäres Protein der HMG-Familie, die viele Proteine beinhaltet und deren Miglieder alle ein DNA-Bindemotiv besitzen. In die Familie der HMG-Box Proteine gehören z. B Transkriptionsfaktoren wie SRY (sex-determining region Y protein) (Sinclair et al., 1990), damit verwandte SOX Proteine (SRY box-containing proteins) (Soullier et al., 1999), TCF1 (T cell factor 1) (van de Wetering et al., 1991) und LEF1 (lymphoid enhancer factor 1) (Travis et al., 1991). Mitglieder dieser Proteinfamilie sind auch im Nervensystem von Bedeutung, z. B. agieren LEF1 und TCF als "downstream" Mediatoren des Wnt-Signalwegs, der ja im Zusammenhang mit dem Signalzentrum "cortical hem" steht (s. Kap. I). Bezüglich der Funktion von Tox im Nervensystem wurde noch nichts publiziert. Seine Expression im embryonalen Vorderhirn wurde in der vorgelegten Arbeit erstmals betrachtet. Auf der Ebene des Immunsystems ist Tox in die Regulation der Thymocyten-Selektion involviert (Wilkinson et al., 2002).

Ein neues Gen mit der Affymetrix Probenkennummer 108995 at (Abb.6 E-F)

Die in situ Hybridisierung bestätigt die Aussage des Microarrays, daß es sich hierbei um ein Gen handelt, das in der Anlage des motorischen Cortex exprimiert wird. Nach Aussagen der NCBI Datenbank besitzt das dazugehörige Protein eine 
Sulfotransferase- und eine WSC-Domäne, die als putative Kohlehydrat-Bindedomäne gilt. In der Literatur sind einige Sulfotransferasen im Nervensystem bekannt, z. B. HNK-1. Aus Beobachtungen an HNK-1-defizienten Mäusen wird eine Funktion dieser Sulfotransferase in dem Erhalt der synaptischen Plastizität des Hippocampus vermutet (Senn et al., 2002). Die Expression der in dieser Arbeit neu entdeckten Sulfotransferase in der Ventrikulärzone, der Sub- und Corticalplatte könnte auf eine Beteiligung an Differenzierungsprozessen deuten.

Expression eines neues Gens mit der Affymetrix Probenkennummer 107382 at $\underline{(\mathrm{Abb} .6 \mathrm{I}-\mathrm{L})}$

Auch für dieses Gen bestätigt das Muster der in situ Hybridisierung die Chipdaten, nach denen es im frontalen Cortex exprimiert sein soll. Nach Datenbankeninformationen besitzt das Gen Ähnlichkeit mit dem humanen transkriptionellen Repressor "scratch". Dieser gehört zur Familie der "snail"Zinkfinger (C2H2 Typ)-Transkriptionsfaktoren, von denen eine Rolle in der Neurogenese bei Invertebraten (Drosophila und Caenorhabditis elegans) bekannt ist (Manzanares et al., 2001). In der NCBI-Datenbank werden zwei humane "scratch"Homologe geführt, bei der Maus dagegen bisher nur eines. Daraus läßt sich vermuten, daß es sich bei diesem Gen um das zweite Maus-"scratch"-Homolog handelt. Als Funktion von "scratch" im Säuger wird an eine Modulation der Aktivität von "basic helix-loop-helix" Transkriptionsfaktoren gedacht, die wichtig in neuronalen Differenzierungsprozessen sind (Nakakura et al., 2001).

\section{Zink-Fingerprotein 288 (Abb.7 A-D)}

Das Expressionsmuster und die Chipdaten stimmen überein: das Zink-Fingerprotein 288 (Zfp288) wird in der Anlage des Hippocampus exprimiert. Es gehört zur Familie der nucleären DNA-bindenden BTB/POZ-(broad complex tramtrack bric-a-brac/ poxvirus and zinc finger) Zink-Finger, die transkriptionelle Repression vermitteln und in der Chromatinorganisation involviert sind (Deweindt et al., 1995). Weiterhin wirkt die POZ-Domäne als spezifische Protein-Protein-Interaktions-Domäne (Bardwell und Treisman, 1994). In der Literatur ist Zfp288 auch unter dem Namen "HOF" bekannt. Aus BrdU-Markierungen wurde auf eine Funktion von HOF in der Neurogenese des Hippocampus geschlossen, da es in differenzierten Zellen herunterreguliert wird (Mitchelmore et al., 2002). Das hier gezeigte Expressionsmuster zum Zeitpunkt E16,5 
unterstützt die Vermutung, daß Zfp288 an der Neurogenese des Hippocampus beteiligt sein könnte.

Nuclear-Rezeptor Subfamilie 4, Gruppe A, Miglied 3 (Nr4a3) (Abb.7 E-H)

Laut den Daten aus der Microarray-Expressionsanalyse sollte Nr4a3 im Hippocampus vorkommen, das bestätigte sich in der in situ Hybridisierung. Nr4a3 ist auch als Nor1, MINOR, CHN und TEC (translocated in extraskeletal chondrosarcoma) bekannt und gehört zur Familie der durch Liganden induzierbaren Transkriptionsfaktoren. Die Liganden für Nr4a3 sind unbekannt, weswegen dieser Rezeptor auch zur Gruppe der "orphan" (Waise) Nuclear-Rezeptoren gezählt wird. Nr4a3 wird hauptsächlich im Nervensystem exprimiert, eine konkrete Funktion konnte für dieses Gen noch nicht gezeigt werden. Seine Beteiligung an der Kontrolle von Zellproliferation und Apoptose (Maltais und Labelle, 2000) könnte auf Prozesse der Carcinogenese hinweisen. Die Expression außerhalb des corticalen Neuroepithels läßt auf eine Funktion in postmitotischen Zellen schließen. Da dieses Gen in einem medial (hoch)/ lateral (niedrig)-Gradienten exprimiert wird, hat es evtl. im medialen Cortex eine gewichtigere Funktion als lateral.

Neuropilin2 (Abb.7 I-M)

Der Hippocampus bestätigte sich als Expressionsort dieses Gens. Im frontalen und occipitalen Cortex wird Neuropilin2 nicht exprimiert, wodurch die hohen Fold Change-Werte zu erklären sind.

Neuropilin2 besitzt als Transmembran-Rezeptor eine wichtige Funktion in der Axonlenkung indem er die repulsive Wirkung der Semaphorine vermittelt. Studien an Mäusen mit einer Deletion im Neuropilin2-Locus führten zu dem Schluß, daß Neuropilin2 für die Organisation und Faszikulation vieler Cranial- und Spinalnerven benötigt wird. Zusätzlich sind in den Gehirnen adulter Mutanten einige Hauptfasertrakte desorganisiert oder fehlen (Giger et al., 2000). Andere Untersuchungen deuten auf eine Beteilung von Neuropilin2 in der Ausbildung kleiner lymphatischer Gefäße und Kapillaren (Yuan et al., 2002). Die embryonale und stark regionalisierte Neuropilin2-Expression im Hippocampus könnte auf ein Mitwirken bei Differenzierungsprozessen des Hippocampus verweisen. Dafür spricht auch die starke hippocampale Expression von SemaE und SemaIV, an die Neuropilin2 mit hoher Affinität bindet (Chen et al., 1997). 
Neurofilament 3, medium (Nef3) (s. Abb.8 A-D)

Nach Auswertung der Microarray-Daten sollte dieses Gen in der Anlage des visuellen Cortex (occipital) exprimiert werden. Trotz der geringen Nef3-Expression in diesem Bereich, wurde dieses Gen durch die Microarray-Analyse erfaßt, was die hohe Sensitivität dieser Methode zeigt.

Neurofilamente (NF) sind die bedeutendsten Intermediärfilamente von Neuronen des zentralen und peripheren Nervensystems. Sie bilden aus den Untereinheiten "high" (NF-H), "middle" oder medium (NF-M = Nef3) und "low" (NF-L) Heteropolymere und stellen so die Komponenten großer, myelinisierter Axone bereit. Es wird vermutet, daß die NF-M-Untereinheit den Gehalt an NF-L reguliert und daß ihre Anwesenheit notwendig ist, um maximale Axondurchmesser in allen Größenklassen myelinisierter Axone zu erhalten. Tiere mit einer Nullmutation in NF-M zeigen keine offensichtlichen Verhaltensauffälligkeiten oder strukturelle Defekte im Nervensystem (Elder et al., 1998). Ein Zusammenhang zwischen Nef3 und der Corticogenese wurde bisher in der Literatur noch nicht hergestellt.

Ein neues Gen mit der Probennummer 116316 at (Abb.8 E-H)

Dieses Gen galt als ein Kandidat für regionenspezifische Expression im occipitalen Cortex. Die in situ Hybridisierung ergab in dieser Region ein Signal, das auf die Ventrikulärzone beschränkt ist und in einem Gradienten von lateral (hoch) nach medial (niedrig) verläuft. Dennoch wurde dieses Gen in der Microarray-Analyse erfaßt und zeigt, daß diese Methode auch Gradienten detektiert.

Es handelt sich bei diesem Gen um "Maus-PIPPin", das im Verlauf der Promotion weiter charakterisiert wurde und an dieser Stelle nicht weiter behandelt werden soll.

\section{Zink-Fingerprotein 5 des Cerebellums (Zic5) (Abb.8 I-L)}

Zic5 ergab in der Microarray-Analyse das stärkste Signal im rostro-medialen Cortex, was in der in situ-Hybridisierung nicht bestätigt werden konnte. Dort zeigte Zic5 Expressionssignale im Diencephalon (Epithalamus und dorsaler Thalamus), im Telencephalon fand sich eine Färbung in der Mantelschicht des Septums.

Ein neues Gen (Affymetrix Probenkennummer 100344 at, Abb.8 M-P)

Die Angabe der Microarray-Analyse, es handele sich hierbei um einen Kandidaten mit regionenspezifischer Expression im parietalen Cortex, konnte nicht bestätigt werden. Dieser Kandidat zeigt keine regionenspezifische Expression, sondern ein ubiquitäres Vorkommen. 
Beurteilung der Methode der Microarray-Expressionsanalyse

Die vorgestellten Beispiele bestätigen, daß es mit Hilfe dieser Methode möglich ist, Gene zu identifizieren, die eine regionenspezifische Expression im Cortex aufweisen. Die Methode ist so sensitiv, daß mit ihr sogar Gene erfaßt werden, die in nur einer Schicht des Cortex exprimiert werden oder in Gradienten vorkommen. Die Ergebnisse einer Microarray-Analyse sollten jedoch immer noch mit einer zweiten Methode, wie z. B. der in situ-Hybridisierung, überprüft werden. Bei den letzten beiden Beispielen erwiesen sich die Ergebnisse des Chips in dieser Überprüfung als falsch. Auch erhält man mit diesem zweiten Screen einen besseren Überblick über die Genexpression in anderen Bereichen des Gehirns.

\section{Auswahl des Gens Maus-PIPPin zur weiteren \\ Charakterisierung basierend auf Microarray-Expressions- und RNA-in situ-Hybridisierung-Analyse}

3.1 Analyse der Expression von Maus-PIPPin während der Embryonalentwicklung

Obwohl PIPPin bereits in der Ratte kloniert wurde (Castiglia et al., 1996), so liegt bisher keine detaillierte Expressionsstudie dieses Gens vor. Die Charakteristika der Expression von Maus-PIPPin lassen sich in drei Aussagen zusammenfassen:

- Maus-PIPPin wird im zentralen Nervensystem exprimiert. Es kommt in allen fünf Hauptabschnitten des Gehirns (Tel-, Di-, Mes-, Met- und Myelencephalon), im Rückenmark und im Auge vor.

- $\quad$ PIPPin ist sowohl in mitotischen Zellen als auch in postmitotischen Zellen zu finden.

- Verschiedene Neuronentypen exprimieren PIPPin.

$\underline{\text { Regionen, in denen Maus-PIPPin exprimiert wird und damit in Zusammenhang }}$ stehende Funktionen

Die beiden Untereinheiten des embryonalen Telencephalons, Pallium und Subpallium, sind PIPPin-positiv. Es kommt von E12,5 an in der Ventrikulärzone des ventralen Palliums vor, später dann auch im lateralen (E16,5), dorsalen und medialen 
Pallium $(E 18,5)$. Die PIPPin-Expression in der Ventrikulärzone der lateralen ganglionären Eminenz (Subpallium) beginnt schwach an E12,5 und setzt sich bis E18,5 fort. Die Region des ventralen Palliums wird als Grenzregion zwischen Pallium und Subpallium betrachtet (s. Kap.I, 3.). Diese Grenze wird von einigen Transkriptionsfaktoren eingehalten, was $\mathrm{zu}$ der Vermutung führte, daß ihre biologische Funktion in der Regionalisierung des Telencephalons und in der Modulation der dorso-ventralen Musterbildung des Cortex liegt (Stoykova et al., 2000). Das ventrale Pallium wurde auch unter dem Begriff "anti-hem" als eine Quelle von Migliedern der EGF-Familie identifiziert. Die "anti-hem" gilt als ein laterales, corticales Signalzentrum, das durch Faktoren wie TGF $\alpha$, Neuregulin1 und 3, Fgf7 und Sfrp2 (Assimacopoulos et al., 2003) Einfluß auf die Musterbildung im Cortex ausübt. Maus-PIPPin ist ein neuer, weiterer Marker für diese Region und könnte somit ebenfalls an diesem Prozeß beteiligt sein.

Weitere PIPPin-positive telencephale Strukturen sind der Bulbus olfactorius, der piriforme oder olfaktorische Cortex, der Hippocampus, das Septum, das diagonale Band Brocas und die Amygdala (Mandelkern). Die vier zuletzt genannten Regionen werden dem limbischen System zugerechnet. Es handelt sich dabei nicht um ein geschlossenes, topisch geordnetes Bahnensystem, sondern um eine Zusammenfassung funktionell eng verknüpfter Kerne und Rindenbezirke. Man hat das System auch als "viszerales" oder als "emotionales" Gehirn bezeichnet, womit seine funktionelle Bedeutung gekennzeichnet werden soll. Das limbische System spielt eine wichtige Rolle bei der Regulation grundlegender vitaler Vorgänge wie Nahrungsaufnahme, Verdauung und Fortpflanzung. Auch das emotionale Geschehen wird auf das limbische System bezogen. Die Teile des limbischen Systems sind untereinander und mit anderen Bereichen über verschiedene Bahnen verknüpft. Die aus mehreren Kernen bestehende Amygdala ist z. B. reziprok mit dem Hypothalamus, Hippocampus, Neocortex und Thalamus verbunden. In der Amygdala enden auch wichtige Faserbündel aus dem olfaktorischen System, allerdings ist die Amygdala nicht essentiell für die olfaktorische Wahrnehmung. Neue Studien beschäftigen sich mit der Entstehung der verschiedenen Nuclei der Amygdala (Medina et al., 2004). Aufgrund der Analyse der Expressionsmuster verschiedener regulatorischer Gene wie z. B. Neurogenin2, Cadherin8 und Semaphorin5A wird vermutet, daß bestimmte Nuclei der Amygdala Derivate des ventralen und lateralen Palliums sind. Da PIPPin 
im ventralen und lateralen Pallium und in der Amygdala zu finden ist, könnte es an diesen Entwicklungsprozessen beteiligt sein.

Auf der Ebene des Diencephalons exprimieren der Globus pallidus, der Epithalamus, der dorsale und anteriore Thalamus und das Prätectum Maus-PIPPin. Der Globus pallidus enthält Kerne des extrapyramidal-motorischen Systems, das bei unbewußten Bewegungsabläufen wirkt. Ein Schaltsystem mit afferenten und efferenten Bahnen enthält der Epithalamus. Dort werden olfaktorische Impulse zu Kernen des Hirnstammes übermittelt. Auf diesem Weg soll der Einfluß der Riechempfindung auf die Nahrungsaufnahme zustande kommen. Zwei große Kernkomplexe bilden den dorsalen Thalamus. Er ist die Endigungsstätte von sensiblen und sensorischen Bahnen und durch efferente und afferente Fasersysteme mit dem Cortex verbunden. Der Bereich des anterioren Thalamus wird auch dem limbischen System zugeteilt und ist ein Bestandteil des von Papez postulierten Neuronenkreises. In diesem Neuronenkreis werden reziproke Verbindungen zwischen Hypothalamus und corticalen Zentren zur Wahrnehmung und Verarbeitung von Gefühlen zusammengefaßt. Das Prätectum ist wichtig im Zusammenhang mit Reflexen der Pupille zu erwähnen, da es Projektionen der Retina empfängt.

Die PIPPin-Expression im Mesencephalon ist eher als diffus $\mathrm{zu}$ beschreiben und ist auf postmitotische Zellen beschränkt.

Der dorsale Teil des Metencephalons wird von dem Cerebellum gebildet. Dort wird PIPPin an E18,5 in der Ventrikulärzone ("external germinal layer") exprimiert, später dann (P6 und adult) in der Purkinje-Zellschicht. Das Cerebellum gilt als Integrationsorgan für die Koordination und Feinabstimmung der Körperbewegungen und für die Regulierung des Muskeltonus. Die größte und charakteristischste Zelle des Cerebellums ist die Purkinje-Zelle, die das efferente Element der Kleinhirnrinde bildet.

Die Maus-PIPPin-Expression im Rückenmark (s. E11,5) ist sowohl im dorsalen (Flügelplatte) als auch im ventralen (Grundplatte) Bereich $\mathrm{zu}$ beobachten. Im Rückenmark sind zwei funktionale Systeme beherbergt, die auch anantomisch aufgeteilt sind. So finden sich Neurone zur Weiterleitung von sensorischem Input dorsal, wogegen in Proprioception und motorische Kontrolle involvierte Neurone ventral auftreten. 
$\underline{\text { Ist Maus-PIPPin an der Entscheidung der neuronalen Vorläufer den Zellzyklus }}$ zuverlassen beteiligt?

Bei der Beobachtung der PIPPin-Expression zu verschiedenen Zeitpunkten der Entwicklung fällt auf, daß dieses Gen in mitotischen und postmitotischen Zellen exprimiert wird. Bereiche, in denen mitotische Zellen der Ventrikulärzone PIPPin exprimieren sind:

- das Telencephalon:

das Pallium (von E12,5 an beginnend im ventralen Pallium, bis E18,5 auch im lateralen, dorsalen und medialen Pallium), die laterale ganglionäre Eminenz (zum Subpallium gehörend)

- das Auge:

die innere Schicht des Neuroepithels der Retina (s. E16,5)

- das Cerebellum:

die externe Keimschicht ("external germinal layer") des Cerebellums (s. E18,5).

Die Bildung der Neurone im cerebralen Cortex der Maus geschieht zwischen E11 und E17 (Levers et al., 2001). Proliferierende neuronale Vorläuferzellen sind auf das Neuroepithel oder die Ventrikulärzone beschränkt, die sich direkt an den cerebralen Ventrikel anschließt. Nach der letzten mitotischen Teilung migrieren die neuronalen Vorläufer radial nach außen in die Corticalplatte und differenzieren dort aus. Auf diese Weise bilden sich die Schichten des Cortex nach dem "inside-first outside-last"Muster. Die früh entstandenen Neurone bilden die tiefen Schichten während die jüngeren Neurone die Schichten an der Oberfläche des Cortex bilden. Die radiale Migration im Telencephalon wird als primärer Mechanismus betrachtet, durch den sich entwickelnde Neurone an ihre finale Position gelangen. Nach Untersuchungen des Ursprungs von Zellpopulationen in Nager- und Hühnergehirnen entstammen diese radial migrierenden Neurone der Ventrikulärzone des Palliums und bilden glutamerge Pyramidalneurone (Marin und Rubenstein, 2001). Es trägt nach diesen Untersuchungen noch eine weitere neuronale Population zu der Bildung des Cortex bei, was aufgrund der Verteilung des Transkriptionsfaktors Dlx2 geschlossen wurde. Diese zweite Zellpopulation besteht aus tangential migrierenden Neuronen, die aus der Ventrikulärzone des Subpalliums stammen und sich zu den GABA ( $\gamma$ Aminobuttersäure) produzierenden Neuronen entwickeln. Es wurden drei Hauptpfade der tangentialen Migration (vom Subpallium ausgehend) identifiziert: latero-caudal 
zum Cortex, medio-rostral zum Bulbus olfactorius und latero-caudal zum Striatum. Da Maus-PIPPin von E12,5 an in der Ventrikulärzone des ventralen Palliums und später $(E 16,5)$ auch in der Ventrikulärzone des Subpalliums exprimiert wird, könnte es in die Entscheidung, zu welchem Zeitpunkt ein neuronaler Voläufer den Zellzyklus verläßt, zur finalen Position migriert und dort ausdifferenziert, involviert sein. PIPPin würde somit auf die Neurogenese verschiedener Zellpopulationen Einfluß ausüben. Es ist eine Beteiligung PIPPins an der Entstehung und Differenzierung radial migrierender neuronaler Vorläufer aus dem Pallium denkbar, was auch die PIPPinExpression in einigen Cortexschichten an P6 vermuten läßt. Durch seine Expression im Subpallium könnte PIPPin ebenso an der Entstehung und Differenzierung tangential migrierender Neurone involviert sein, worauf z. B. die PIPPin-Expression im Bulbus olfactorius (medio-rostrale Migration) hindeutet.

Auch bei der Ausbildung des Auges wirken dieselben Prinzipien wie im Cortex: Bildung von Vorläuferzellen in einer proliferativen Zone, Migration und Differenzierung. Die visuelle Wahrnehmung der Umwelt ist von der korrekten Positionierung von sieben Zelltypen in die Retina abhängig. Während der Retinogenense entstehen diese Zelltypen aus einer gemeinsamen Population multipotenter retinaler Vorläuferzellen, die sich in der inneren Schicht des Augenbechers befinden (Marquardt und Gruss, 2002). Die retinale Zelldifferenzierung geschieht in einer stark konservierten Ordnung, wobei zunächst retinale Ganglien- und Horizontalzellen differenzieren gefolgt von Zapfen- und amakrinen Zellen. Danach bilden sich Stäbchen-, Bipolar- und Müllergliazellen. An der Retinogenese sind viele Transkriptionsfaktoren beteiligt. So werden z. B. zum Zeitpunkt der PIPPin-Detektion in der inneren Schicht des Neuroepithels der Retina an E16,5 dort auch Pax6, Six3, Rx1, Chx10 und Hes1 exprimiert. PIPPin besitzt mit seiner vorhergesagten Proteindomäne, der "cold shock-Domäne" (s. dazu Absatz 3.2), die Fähigkeit RNA und DNA zu binden. Somit könnte es auch durch Beeinflussen transkriptioneller und translationaler Prozesse an der Retinogenese beteiligt sein.

Die PIPPin-Expression in einer Proliferationszone des Cerebellums (s. E18,5), die "external germinal layer" (externe Keimschicht), könnte auch hier eine Beteiligung von PIPPin an Differenzierungsprozessen andeuten. In der externen Keimschicht findet die Proliferation der Körnerzellenvorläufer statt. Diese Proliferation steht unter der Kontrolle der Purkinje-Zellen, die diffusible Faktoren wie z. B. sonic hedghog ausschütten (Wang und Zoghbi, 2001). Erreichen die Vorläufer der Körnerzellen den 
postmitotischen Status, migrieren sie nach innen, um dann ihre Position unter der Purkinje-Zellschicht einzunehmen (Hatten und Heintz, 1995).

Dieser spezifischen PIPPin-Expression in proliferierenden Schichten des zentralen Nervensystems steht die Expression dieses Gens in postmitotischen Zellen gegenüber (z. B im Rückenmark und Mesencephalon). Denkbar ist in diesen Regionen eine Beteiligung PIPPins an dem Erhalt eines postmitotischen, ausdifferenzierten Status wie z. B. der Status eines Motoneurons im Rückenmark.

\section{PIPPin wird in verschiedenen Typen von Neuronen exprimiert}

Die Expression des Maus PIPPin-Gens ist an vielen Orten zu beobachten, an denen sich Pyramidenzellen befinden. Darunter fallen der Hippocampus, der Epithalamus, der Piriformcortex und der cerebrale Cortex. Die Frage, ob PIPPin in allen Pyramidenzellen zu finden ist oder nur in einer bestimmten Subgruppe, kann nicht beantwortet werden. In Schichten V, IV und II/ III des cerebralen Cortex ist PIPPin erst postnatal $\mathrm{zu}$ detektieren (P6). Die Schichten V und II/ III enthalten Pyramidenzellen, wobei Schicht $\mathrm{V}$ die größten Pyramidenzellen besitzt. Pyramidenzellen sind die wichtigsten "output"- oder Projektionsneurone und befördern Information über lange Axone aus corticalen Bereichen in andere weiter entfernte Regionen des zentralen Nervensystems. Als Transmitter nutzen die exzitatorischen Pyramidenzellen Glutamat.

In den Purkinje-Zellen des Cerebellums ist PIPPin deutlich an P6 und im Adultstadium $\mathrm{zu}$ detektieren. Über verschiedene Fasersysteme (Kletter- und Moosfasern) werden ihnen Erregungen zugeleitet. Mit ihren langen Axonen in die weiße Substanz bilden die Purkinje-Zellen den einzigen "output" des Cerebellums. Alle Purkinje-Neurone sind inhibitorisch und nutzen GABA als Neurotransmitter.

Die Expression von PIPPin Pyramiden- und Purkinje-Zellen wurde auch schon in der Ratte beobachtet (Nastasi et al., 2000). Eine interessante Gemeinsamkeit dieser beiden Neuronentypen ist, daß sie beide als Projektionsneuron wirken und Information aus dem Cortex oder Cerebellum in entlegene Bereiche des zentralen Nervensystems leiten.

Die sensorischen Neurone des Hinterwurzelganglions im Rückenmark sind ein weiterer PIPPin-positiver Neuronentyp. Im ventralen Bereich des Rückenmarks zeigen motorische Neurone PIPPin-Expression (s. E11,5), sie senden Fasern zur Muskulatur. Weiterhin sind im ventralen Rückenmark im Bereich der V0- und V1- 
Säule PIPPin-positive Zellen zu beobachten, es handelt sich dabei um Interneurone mit kurzen Axonen. Die Spezifikation der ventralen Zellen des Rückenmark ist von Konzentration an sonic hedgehog abhängig, das vom Bereich der Bodenplatte (floor plate) ausgeschüttet wird (Jessell, 2000).

\subsection{Die "cold-shock"-Domäne und ihre verschiedenen Funktionen in Zellproliferation und Entwicklung}

Die Klonierung des Ges Maus-PIPPin und die folgende Sequenzanalyse ergaben, daß das Protein eine putative "cold-shock"-Domäne (CSD) besitzt, die sich auf Exon drei und vier des Maus-PIPPin Genlocus zurückführen läßt (Abb.19). CSD-enthaltende Proteine, auch Y-Box Proteine genannt, sind DNA- und RNA-bindende Proteine, die die spezifische Genexpression auf transkriptionaler und translationaler Ebene kontrollieren. Die CSD gilt als die am stärksten konservierte Nucleinsäure-bindende Sequenz, da sie etwa 40\% Identität und 60\% Ähnlichkeit zwischen Bakterien und Vertebraten besitzt (Sommerville, 1999). In prokaryotischen "cold-shock"-Proteinen wirkt die CSD als "RNA-Chaperon", indem sie RNA Sekundärstrukturen destabilisiert und dadurch bei niedrigen Temperaturen die Translation kontrolliert (Jones und Inouye, 1994). Somit wird auch bei Temperaturen unterhalb des Wachstumsoptimums die Expression der Gene erhalten, die für das Zellwachstum notwendig sind. In der frühen Embryogenese scheint das Y-Box Protein lin-28 in C. elegans wichtige regulatorische Funktion durch die Kontrolle Stadium-spezifischer Gene zu übernehmen (Moss et al., 1997). Mutationen in lin-28 verursachen die frühreife Entwicklung. Die Funktionen von Y-Box Proteinen in Vertebraten sind sehr unterschiedlich und können sowohl aktivierende als auch repressive Wirkung hervorrufen. Das Keimzell-spezifische Y-Box Protein FRGY2 in Oocyten von Xenopus laevis bindet spezifisch mRNAs, die somit "maskiert" und für die Translation unzugänglich sind (Matsumoto et al., 1996). Ebenso wurde für das CSDenthaltende Protein MSY-1 der Maus eine Suppressorwirkung herausgefunden. Durch die Ausbildung spezifischer Protein-DNA-Komplexe im 5'-Bereich des codierenden Stranges des TSH (Thyroidea-stimulating-hormone)-Rezeptor-Gens wird dort die Transkription gehemmt (Ohmori et al., 1996). Als Beispiel für die aktivierende Wirkung der Y-Box Proteine ist das Protein p50 der Ratte zu nennen, das an der Initiation der Translation beteiligt zu sein scheint (Evdokimova et al., 1998). Das 
humane Y-Box Protein YB-1 wird in der Literatur als ein Aktivator der Transkription genannt (Zou und Chien, 1995).

Eukaryotische Y-Box Proteine erkennen doppel- und einzelsträngige DNA und zeigen auch sequenzspezifische und nichtspezifische Interaktionen mit RNA. Sie besitzen keine offensichtlichen nucleäre Lokalisationssequenzen und sind sowohl im Cytoplasma als auch im Kern zu finden. Die CSD, eine Oligonucleotid-bindende Struktur, besteht aus einem fünfsträngigem $\beta$-Faltblatt, das zwei RNA-bindende Sequenzmotive RNP1 und RNP2 (ribonucleoprotein particle, s. Abb.15) beinhaltet (Graumann und Marahiel, 1998). Von der Initiation der Transkription an tritt mRNA niemals nackt auf, sondern wird in Ribonucleoprotein-Partikel verpackt. Das RNPMotiv ist dafür das am weitesten verbreitete RNA-bindende Motiv und stellt das Gegenstück zu den Zink-Finger- oder Homeobox-Motiven für DNA-Bindung dar (Varani und Nagai, 1998). Die korrekte Zusammenfügung eines RNA-bindenden Proteins mit der entsprechenden Ziel-RNA ist entscheidend für alle folgenden Prozesse wie z. B. das Herausschneiden von Introns, das Prozessieren des 3'-Endes der prä-mRNA, der Export der mRNA aus dem Nucleus ins Cytoplasma und die Translation (Nagai et al., 1995).

\section{PIPPin als Beispiel für ein CSD-enthaltendes RNA-bindendes Protein}

Bei der Suche nach RNA-bindenden Faktoren in der Ratte wurde PIPPin von einer italienischen Gruppe identifiziert (Castiglia et al., 1996). Aus KompetitionsExperimenten wurde auf eine präferentielle Bindung PIPPins an mRNAs der Histonvarianten $\mathrm{H}^{\circ}{ }^{\circ}$ und H3.3 geschlossen. Die Bindung des Proteins soll an die 3' nicht translatierte Region der mRNA erfolgen, die auch das Polyadenylierungssignal enthält. Ratten-PIPPin tritt im Nucleus und Zellkern auf, wobei die Fähigkeit RNA zu binden auf den Nucleus beschränkt zu sein scheint und auf post-translationale Modifizierung des Proteins hindeutet (Nastasi et al., 1999). In einem in vitro System wurde ein inhibierender Effekt des Ratten-PIPPins auf die $\mathrm{H} 1^{\circ}$ - und H3.3-Translation festgestellt und daher eine negative Regulatorfunktion PIPPins in der Synthese dieser Histonvarianten vermutet (Nastasi et al., 2000). Die Histontypen $\mathrm{H} 1^{\circ}$ und $\mathrm{H} 3.3$ scheinen in Prozesse der Zelldifferenzierung involviert zu sein. Sie gehören in die Gruppe der sog. "replacement" (Ersatz)-Histone, da sie auch unabhängig von DNAReplikation in nicht proliferierenden Zellen synthetisiert werden können. Ihre graduelle Akkumulation geschieht parallel zu der Abnahme der Histone des Haupttyps (Doenecke et al., 1997). Die Akkumulation von $\mathrm{H} 1^{\circ}$ und $\mathrm{H} 3.3$ im Laufe 
der Embryonalentwicklung wurde im Gehirn der Ratte gezeigt (Castiglia et al., 1994). Eine Funktion dieser beiden Histontypen in der Gehirnentwicklung ist vorstellbar, da die Migration der postmitotischen Neurone aus der Ventrikulärzone zu ihrer finalen Position mit großen Umstrukturierungen des neuronalen Chromatins verbunden ist.

Für Chromatin-Modifikationen in postmitotischen Neuronen sind daher die Expression proliferationsunabhängiger Histone Voraussetzung. Ebenso bedarf es einer Feinregulierung der Expression dieser Histonvarianten, die über RNA-bindende Proteine geschehen kann.

\subsection{Entwurf für eine mögliche allgemeine Funktion PIPPins in der}

\section{Entwicklung des Nervensystems der Maus}

Aus dem Expressionsmuster von Maus-PIPPin, den Informationen über die CSD und das bereits bekannte Ratten-PIPPin soll nun ein Bild der generellen Funktion von PIPPin im Nervensystem der Maus skizziert werden:

Da PIPPin in mitotischen und postmitotischen Zellen exprimiert wird, ist eine Funktion im Zusammenhang mit Proliferation und Zelldifferenzierung möglich. Durch die Fähigkeit PIPPins mRNA im Zellkern zu binden, ist eine Rolle als Transporter für mRNA aus dem Nucleus in das Cytoplasma zur Translationsmaschinerie denkbar. Durch die Bindung an mRNA könnte PIPPin auch

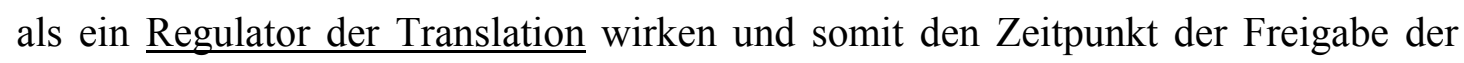
mRNA zur Translation beeinflussen. Als Ziel-RNA PIPPins käme z. B. die $\mathrm{H} 1^{\circ}$ mRNA in Frage. Die Translation des Histons $\mathrm{H} 1^{\circ}$ könnte durch die Bindung PIPPins an die $\mathrm{H} 1^{\circ}$-mRNA feinreguliert werden. Als zweite generelle Aufgabe PIPPins ist eine Beteiligung an der Bildung und Aufrechterhaltung von Grenzen oder funktionellen Einheiten im Cortex vorstellbar. Dies läßt sich aus der PIPPinExpression im ventralen Pallium schließen, das als ein Signalzentrum der corticalen Musterbildung gilt.

Zur Analyse der Funktion von PIPPin wurde der "loss of function"-Ansatz gewählt, bei dem die Funktion eines Gens gezielt ausgeschaltet wird. Basierend auf dem Prinzip der homologen Rekombination in den Maus-PIPPin-Genlocus wurde erfolgreich ein Bereich von 3,5 kb deletiert, der die CSD enthält. Die daraus resultierenden PIPPin-defizienten Mäuse sind lebensfähig und pflanzen sich nach dem 
2. Mendelschen Gesetz (1:2:1) fort. Daher kann die Lethalität dieser Mäuse bereits vor der Geburt ausgeschlossen werden.

\subsection{Analyse des Gehirns der PIPPin-knock-out-Maus ergibt keinen offensichtlichen Phänotyp}

Die Histologie homozygoter und Wildtyp-Gehirne wurde $\mathrm{zu}$ E16,5 und im Adultstadium im Rahmen von Hämotoxylin-Eosin-Färbungen verglichen. Mit Hilfe von BrdU-Aufnahmestudien wurde $\mathrm{zu}$ E13,5 und E16,5 die Rate der DNAReplikation im Cortex von +/+ - und -/- -Tieren ermittelt. Weiterhin wurden zur Phänotyp-Analyse verschiedene Marker des ventralen Palliums hinzugezogen $\left(\right.$ E16,5). Es wurde in einem Western-Blot der Gehalt von $\mathrm{H} 1^{\circ}$-Protein im Gehirn adulter Wildtyp- und PIPPin defizienter Mäuse (P50) untersucht. Nach möglichen Defekten des Cerebellums wurde mit einer $\alpha$-Calbindin D-28K-Immunfärbung (P51) gesucht. Mit keiner der durchgeführten Experimente konnte ein signifikanter Phänotyp der PIPPin-knock-out-Maus detektiert werden.

Auf diesen Befund könnte die Aussage folgen, Maus-PIPPin besitze in keinem der diskutierten Punkte eine Funktion. Gegen diese Aussage spricht allerdings das weit verbreitete Vorkommen PIPPins in Vertebraten wie Ratte, Maus, Mensch, Frosch und Huhn. Auch die Identifikation eines weiteren PIPPin-Homologs im Gehirn der Maus (s. Abb.16) deutet auf eine Bedeutung dieser beiden Proteine im Gehirn hin. Die Proteindomäne von PIPPin, die CSD mit den beiden RNA-bindenden Sequenzmotiven RNP1 und 2, ist die am stärksten konservierte Nucleinsäurebindende Sequenz und zieht sich durch Organismen der Pro- und Eukaryoten. Diese potentielle Aktivität eines Transkriptionsfaktors und die überaus starke evolutionäre Konservierung der CSD unterstreichen die Vermutung, daß Maus-PIPPin im Gehirn eine Funktion ausübt.

Die zweite Vermutung aus obigem Befund ist, daß Maus-PIPPin zwar eine Funktion besitzt, daß aber dieses Gen für die normale Gehirnentwicklung entbehrlich ist und sein Fehlen durch andere Faktoren kompensiert werden kann. Für diese Annahme spricht die Expression zahlreicher Gene im Bereich des ventralen Palliums wie z. B. Pax6, Sfrp2 und Tgf $\alpha$. Diese Gene könnten mögliche Aufgaben PIPPins in der Etablierung von Grenzen in diesem Bereich übernehmen. Ebenso kommen im 
Neuroepithel der Retina einige Transkriptionsfaktoren (z. B. Pax6, Six3 und Rx1) vor, die sich an der Regulation von Proliferation und Differenzierung der retinalen Vorläuferzellen beteiligen und somit das Fehlen von PIPPin im Knock-out ausgleichen könnten. Das Gleiche trifft für die weitere mögliche Funktion PIPPins als Ribonucleoprotein-Partikel, Regulator der Translation und "RNA-Shuttle" zwischen Nucleus und Kern zu. Diese Tätigkeit könnte durch andere CSD-enthaltende oder andere RNA-bindende Faktoren übernommen werden. Zudem wurde ein inhibierender Effekt von Ratten-PIPPin auf die H1 ${ }^{\circ}$ - und H3.3-Translation bisher nur in einem in vitro System gezeigt (Nastasi et al., 2000). Ob die Translation dieser Histonvarianten auch in vivo durch PIPPin reguliert wird oder ob an dieser Stelle andere Regulationsmechanismen greifen, ist ungewiß.

Als dritte Möglichkeit wäre zu bedenken, daß das Fehlen PIPPins zwar milde Defekte hervorruft, diese aber mit den genutzten Methoden und ausgewählten Zeitpunkten nicht festzustellen sind. Hinzu kommt die Expression von Maus-PIPPin in vielen Bereichen, bei denen sich Defekte erst durch Verhaltensexperimente aufdecken lassen. Darunter fällt z. B. die Expression in Komponenten des limbischen Systems (Amygdala, anteriorer Thalamus, Hippocampus, Septum), die das emotionale Geschehen beeinflussen. PIPPin kommt ebenso in Bereichen der Riechempfindung (Bulbus olfactorius, Epithalamus) vor. Fehlentwicklungen in diesen Bereichen müßten mit entsprechenden Geruchstests erfaßt werden. Ebenso ist es denkbar, daß gewisse Phänotypen erst mit höherem Alter der Tiere auftreten, dies könnte z. B. für Defekte im Zusammenhang mit der Feinabstimmung von Körperbewegungen durch das Cerebellum zutreffen.

Für die Durchführung von Verhaltensexperimenten ist ein reiner genetischer Hintergrund erforderlich, für den die Tiere idealerweise 10x rückgekreuzt werden sollten. Die Rückkreuzung der PIPPin-knock-out-Maus von einem 129/Sv /CD1Mischhintergrund auf den für neuronale Fragen geeigneten Stamm C57 BL/6 ist begonnen worden.

Die Frage des genetischen Hintergrundes ist bei einer Phänotyp-Analyse zu bedenken, da das Auftreten, die Penetranz und auch das Ausmaß eines Phänotyps abhängig von dem genetischen Hintergrund sind. So treten z. B. die Auffälligkeiten im Aufzuchtverhalten homozygoter Fkh5 (ein Transkriptionsfaktor der "fork head"Familie)-Mütter im C57 BL/6-Hintergrund auf (Wehr et al., 1997). Homozygote Fkh5-Tiere in 129/Sv-Hintergrund haben dagegen aufgrund geringer 
Paarungsaktivität keine Nachkommen. Als ein weiteres Beispiel für die Beeinflussung des Phänotyps durch den genetischen Hintergrund ist die L1 (ein Zelladhäsionsmolekül der Immunoglobulin-Familie)- knock-out-Maus zu nennen, die je nach genetischem Hintergrund verschiedene Mißbildungen der Niere unterschiedlicher Penetranz und unterschiedlichen Ausmasses zeigt (Debiec et al., 2002).

\subsection{Identifikation eines Maus-PIPPin spezifischen Enhancers mit Bindestellen für Transkriptionsfaktoren}

Der durch die homologe Rekombination deletierte Bereich des Maus-PIPPin Genlocus stellte sich in der in vitro Elektroporation als Enhancer-enthaltendes Element heraus. Dieser Enhancer ist ein Maus-PIPPin spezifisches Element, da es bei Elektroporation nur in den Bereichen wirkt, in denen Maus-PIPPin exprimiert wird. Zur Bestätigung dieses Enhancers in vivo wird zur Zeit eine transgene Mauslinie mit dem Konstrukt pFK35 etabliert.

Der positive Enhancer-Bereich von 3,5 kb konnte im Rahmen dieser Doktorarbeit durch Deletionskonstrukte auf einen positiven Bereich von etwa 700 bp eingegrenzt werden. In diesem 700 bp-Fragment sind fünf mit dem Humangenom übereinstimmende Bereiche von ca. 20-45 Nucleotiden Länge enthalten. Die Untersuchung dieser homologen Bereiche im Hinblick auf TranskriptionsfaktorBindestellen ergab mit Bindestellen für einen Östrogen-Rezeptor und Ets-1 zwei signifikante Treffer. Die Bedeutung dieser beiden Faktoren im Zusammenhang mit dem Nervensystems soll im Folgenden diskutiert werden.

Neuroprotektive Wirkung der Östrogen-Rezeptor Subtypen $\alpha$ und $\beta$

Der Östrogen-Rezeptor (ER, estrogen receptor) ist ein Ligand-aktiviertes Enhancerprotein, das zur Superfamilie der Steroid-Nuclear-Rezeptoren gehört. Zwei Gene codieren den ER der Säuger: ER $\alpha$ und ER $\beta$ (Klinge, 2001). Der ER bindet mit hoher Affinität an spezifische DNA-Sequenzen und transaktiviert Genexpression als Antwort auf Östradiol. Beide ER-Subtypen zeigen verschiedene Verteilungsmuster in unterschiedlichen Geweben. Im Gehirn sind beide Rezeptoren stark exprimiert, wobei bei der Maus ER $\alpha$ vornehmlich im Hippocampus vorkommt (Mitra et al., 2003) und ER $\beta$ höhere Expressionslevel im Cortex besitzt (Couse et al., 1997). Neue Daten belegen eine Beteiligung von ER $\alpha$ und ER $\beta$ in der Aktivierung von Neuroprotektion 
in Neuronen des Hippocampus. Dieser Effekt korreliert mit einer Hochregulierung des anti-apoptotischen Proteins Bcl-2 (Zhao et al., 2004). Da Maus-PIPPin auch im Hippocampus zu finden ist, könnte es mit seiner ER-Bindestelle zu diesen Prozessen beitragen.

\section{Die Expression des Transkriptionsfaktors Ets-1 ist breit gestreut}

Die Ets-Familie enthält eine Reihe von Transkriptionsfaktoren, die spezifisch mit der Ets-DNA-Bindedomäne interagieren und auf diese Weise Genexpression regulieren. Das Ets-1-Gen wurde aufgrund seiner Sequenzhomologie zu dem v-ets Onkogen des Avian Erythroblastosis Virus E26 identifiziert (Maroulakou et al., 1994). Während der Embryogenese ist Ets-1 weit verbreitet und kommt in lymphoiden Geweben, im Gehirn und in der Lunge vor (Kola et al., 1993). Andere Beobachtungen identifizierten Ets-1 auch in Endothelzellen während der Angiogenese im Embryo (Lelievre et al., 2001). In diesem Fall ist es schwierig, einen Zusammenhang zwischen PIPPin- und Ets-1-Expression und der Ets-1-Bindestelle im PIPPinEnhancer herzustellen.

Ist Maus-PIPPin ein "downstream-target" von Pax 6 ?

Die Untersuchung der 700 bp-Enhancersequenz nach Bindestellen ergab u.a. mit einer Bindestelle für den Transkriptionsfaktor Pax6 ein interessantes, signifikantes Ergebnis. Hinzu kommt in diesem Zusammenhang der Befund, daß in homozygoten Sey-Mäusen die PIPPin-Expression in der Ventrikulärzone des Palliums und Subpalliums deutlich reduziert ist (s. Abb.40). Wie eingangs erwähnt (s. Kap.I, 4.) fallen Pax6 entscheidende Funktionen während der Entwicklung des zentralen Nervensystems zu. Im embryonalen Telencephalon ist Pax6 an der dorso-ventralRegionalisierung des Neuroepithels beteiligt, was auf Grund der veränderten Expression verschiedener Markergene in homozygoten Sey-Mäusen gefolgert wurde (Stoykova et al., 2000). Die beiden Grenzregionen des Telencephalons, die PalliumSubpallium- und die MGE-LGE-Grenze sind in homozygoten Sey-Mäusen gestört. Es ist in diesen Bereichen eine Ventralisierung $\mathrm{zu}$ beobachten, d.h. typischerweise ventral auftretende Transkriptionsfaktoren wie z. B. Dlx1, werden über das ventrale Pallium hinaus auch in dorsalen Bereichen exprimiert. Die Tatsache der reduzierten PIPPin-Expression in Pax6-defizienten Mäusen könnte durch den Defekt im Bereich der Pallium-Subpallium- und MGE-LGE-Grenze zu erklären sein und somit den Phänotyp der Pax6-defizienten Mäuse widerspiegeln. Eine weitere Interpretationsmöglichkeit dieses Befundes wäre, daß Pax6 zur PIPPin-Expression in 
der Ventrikulärzone des Palliums und Subpalliums notwendig ist und Maus-PIPPin somit im Gehirn ein neues "downstream-target" von Pax6 wäre. Die Frage der Interaktionspartner von Pax6 konnte mit Hilfe eines konditionalen Pax6-Knock-outs für das Auge untersucht werden (Ashery-Padan et al., 2000). Auf der Ebene des Gehirns wurden ebenso einige "downstream-targets" von Pax6 identifiziert wie z. B. Neurogenin2 (Scardigli et al., 2003) und AldolaseC (Skala-Rubinson et al., 2002), dennoch bleibt hier das Bild fragmentär.

Für die Bestimmung der Relevanz der hier aufgeführten TranskriptionsfaktorBindestellen ist es zunächst notwendig, den Bereich des Enhancers durch zusätzliche Deletionskonstrukte weiter einzugrenzen. Die Bedeutung einer Bindestelle kann dann durch eine gezielte Punktmutation, durch ein DNAse "foot print"-Experiment oder mit Hilfe eines "gel-mobility shift"-Assays untersucht werden.

Die Lage des Enhancers im 3' nicht translatierten Bereich des Maus-PIPPin-Genlocus (s. Abb.36) ist nicht ungewöhnlich. So besitzt z. B. das humane $\beta$-Globin-Gen viele regulatorische Regionen, wobei ein Enhancer im 3'-Bereich des Gens zu finden ist (Antoniou et al., 1988). Die Deletion dieses 3'-Enhancers in "yeast artificial chromosome" (YAC) transgenen Mäusen verursacht eine Reduktion der $\beta$-GlobinExpression (Pasceri et al., 1998). In in vitro Experimenten wurde die Bindung eines Erythrocyten-spezifischen Nuclearfaktors im Bereich des 3'-Enhancers des $\beta$-GlobinGens gezeigt (Wall et al., 1988). Ebenso wird die Expression der beiden "basic helixloop-helix" Transkriptionsfaktoren Neurogenin1 und 2 durch Enhancer-Sequenzen im 3'-Bereich reguliert (Scardigli et al., 2001; Nakada et al., 2004).

\subsection{Ausblick}

Phänotyp-Analyse der PIPPin-knock-out-Maus

Ein besonderes Augenmerk soll noch auf die Entstehung der Amygdala gerichtet werden. Wie bereits erwähnt, sind verschiedene Nuclei der Amygdala Derivate des ventralen und lateralen Palliums, was mit Hilfe der Marker Dbx1, Ngn2 und Sema5A für das ventrale Pallium und Cadherin8 und Emx1 für das laterale Pallium untersucht wurde (Medina et al., 2004). Wegen seiner Expression in der Ventrikulärzone des Palliums und Subpalliums und in der Amygdala könnte PIPPin an der Entstehung 
bestimmter Nuclei der Amygdala beteiligt sein. Zur Untersuchung dieses Aspekts sind RNA-in situ-Hybridisierungen mit o.g. Markern auf Wildtyp und PIPPindefizienten Gehirnschnitten in Vorbereitung.

Weiterhin sind Verhaltensexperimente in einem reinen C57 BL/6-Hintergrund geplant, um mögliche Defekte in der Riechempfindung oder Defekte, die im Zusammenhang mit dem limbischen System stehen, zu untersuchen.

Enhancer-Analyse des Maus-PIPPin-Genlocus

Im Vordergrund steht hier zunächst die in vivo-Bestätigung des Enhancer-Elements. Die dafür benötigte transgene Mauslinie basierend auf dem Konstrukt pFK35 ist in Vorbereitung. Es sollen dann weitere Deletionskonstrukte folgen, um das Enhancerenthaltende 700 bp-Fragment näher einzugrenzen und im Hinblick auf Transkriptionsfaktor-Bindestellen zu charakterisieren. 


\section{Zusammenfassung}

Zur Identifikation neuer Gene mit regionenspezifischer Expression im cerebralen Cortex der Maus des Stadiums E16,5 wurde eine Microarray-Expressionsanalyse mit fünf verschiedenen Cortexregionen durchgeführt. Die nach der Analyse der Daten 96 erhaltenen Gene wurden mittels der RNA-in situ-Hybridisierung auf ihre Expression hin überprüft.

Basierend auf diesen beiden Screens wurde zur weiteren Analyse das neue Mausgen PIPPin ausgewählt. Die Expressionsanalyse ergab, daß PIPPin in der mitotisch aktiven Ventrikulärzone des Palliums (ventral, lateral, dorsal und medial) und des Subpalliums (in der lateralen ganglionären Eminenz) zu finden ist. Das ventrale Pallium gilt als ein corticales Signalzentrum zur Musterbildung und als Quelle verschiedener Signalproteine u.a. aus der EGF-Familie und der Wnt-Anatagonist Sfrp2. Maus-PIPPin ist ein neuer, weiterer Marker dieser Signalregion. Mit dem Neuroepithel der Retina und der externen Keimschicht des Cerebellums wird PIPPin in weiteren proliferativen Schichten exprimiert. Darüber hinaus kommt Maus-PIPPin in postmitotischen Zellen vor u.a. im Bulbus olfactorius, in den corticalen Schichten V, IV und II/ III, im Hippocampus, im Piriformcortex, in der Amygdala, im Epithalamus, im dorsalen und anterioren Thalamus und in der Purkinje-Zellschicht des Cerebellums.

PIPPin besitzt mit der stark konservierten putativen "cold-shock"-Domäne die Fähigkeit, mit DNA und RNA $\mathrm{zu}$ interagieren und somit potentielle Transkriptionsfaktor-Aktivität.

Zur Funktionsanalyse von Maus-PIPPin in der Corticogenese wurde das Gen kloniert und mittels homologer Rekombination inaktiviert. Ein Phänotyp konnte mit den hier angewendeten Methoden und ausgewählten Entwicklungsstadien nicht detektiert werden. Ursache dafür könnte funktionelle Redundanz sein, da im Rahmen dieser Arbeit ein PIPPin-Homolog identifiziert wurde, das ebenso im Gehirn exprimiert wird. 
Mit Hilfe der in vitro Elektroporation wurde eine Enhancer-enthaltende Sequenz im 3'-Bereich des Maus-PIPPin-Gens identifiziert. Dieser Bereich wurde von 3,5 kb auf $700 \mathrm{bp}$ eingegrenzt und auf potentielle Transkriptionsfaktor-Bindestellen untersucht. Dabei wurden Bindestellen für einen Östrogen-Rezeptor und für die Transkriptionsfaktoren Ets-1 und Pax6 identifiziert. In der vorliegenden Arbeit wurde eine verringerte Expression von PIPPin in der homozygoten Pax6-Mutante "Sey" beobachtet. Weiterführende Deletionsanalysen des PIPPin-Enhancers werden zeigen, inwiefern ein direkter Zusammenhang zwischen diesem Element und dem Transkriptionsfaktor Pax6 besteht. 


\section{Abkürzungen}

\begin{tabular}{|c|c|}
\hline bp & Basenpaar \\
\hline BrdU & 5-Bromo-2'-deoxyuridin \\
\hline cDNA & copy-DNA \\
\hline cpm & counts per million \\
\hline DEPC & Diethylpyrocarbonat \\
\hline DIG & Digoxigenin \\
\hline DNA & desoxyribonucleic acid \\
\hline dNTP & desoxy-Nucleotidtriphosphat \\
\hline $\mathrm{E}$ & Embryonaltag \\
\hline EGF & epidermal growth factor \\
\hline EtBr & Ethidiumbromid \\
\hline FGF & fibroblast growth factor \\
\hline \multirow[t]{2}{*}{ GAPDH } & Glycerin-Aldehyd-Phosphat \\
\hline & Dehydrogenase \\
\hline GFP & green fluorescent protein \\
\hline $\mathrm{kb}$ & kilo Basenpaar \\
\hline LGE & laterale ganglionäre Eminenz \\
\hline MGE & mediale ganglionäre Eminenz \\
\hline $\min$. & Minute \\
\hline MQ & MilliQ \\
\hline ng & Nanogramm \\
\hline OD & optische Dichte \\
\hline $\mathrm{P}$ & Postnataltag \\
\hline PBS & phosohate buffered saline \\
\hline PCR & polymerase chain reaction \\
\hline pfu & plaque forming units \\
\hline PFA & Paraformaldehyd \\
\hline Phe/ Chl & Phenol/ Chloroform \\
\hline RNA & ribonucleic acid \\
\hline
\end{tabular}


rpm

RT

SM

STI

TGF

$\mathrm{U}$

ü.N.
Umdrehungen pro Minute (rounds per

minute)

Raumtemperatur

Suspensionsmedium

Standard I-Nährbouillon

transforming growth factor

unit

über Nacht 


\section{Literaturverzeichnis}

Alifragis P, Liapi A, Parnavelas JG (2004) Lhx6 regulates the migration of cortical interneurons from the ventral telencephalon but does not specify their GABA phenotype. J Neurosci 24:5643-5648.

Altschul SF, Madden TL, Schaffer AA, Zhang J, Zhang Z, Miller W, Lipman DJ (1997) Gapped BLAST and PSI-BLAST: a new generation of protein database search programs. Nucleic Acids Res 25:3389-3402.

Antoniou M, deBoer E, Habets G, Grosveld F (1988) The human beta-globin gene contains multiple regulatory regions: identification of one promoter and two downstream enhancers. Embo J 7:377-384.

Apweiler R, Attwood TK, Bairoch A, Bateman A, Birney E, Biswas M, Bucher P, Cerutti L, Corpet F, Croning MD, Durbin R, Falquet L, Fleischmann W, Gouzy J, Hermjakob H, Hulo N, Jonassen I, Kahn D, Kanapin A, Karavidopoulou Y, Lopez R, Marx B, Mulder NJ, Oinn TM, Pagni M, Servant F, Sigrist CJ, Zdobnov EM (2000) InterPro--an integrated documentation resource for protein families, domains and functional sites. Bioinformatics 16:1145-1150.

Arimatsu Y (1994) Latexin: a molecular marker for regional specification in the neocortex. Neurosci Res 20:131-135.

Ashburner M, Ball CA, Blake JA, Botstein D, Butler H, Cherry JM, Davis AP, Dolinski K, Dwight SS, Eppig JT, Harris MA, Hill DP, Issel-Tarver L, Kasarskis A, Lewis S, Matese JC, Richardson JE, Ringwald M, Rubin GM, Sherlock G (2000) Gene ontology: tool for the unification of biology. The Gene Ontology Consortium. Nat Genet 25:25-29. 
Ashery-Padan R, Marquardt T, Zhou X, Gruss P (2000) Pax6 activity in the lens primordium is required for lens formation and for correct placement of a single retina in the eye. Genes Dev 14:2701-2711.

Assimacopoulos S, Grove EA, Ragsdale CW (2003) Identification of a Pax6dependent epidermal growth factor family signaling source at the lateral edge of the embryonic cerebral cortex. J Neurosci 23:6399-6403.

Bardwell VJ, Treisman R (1994) The POZ domain: a conserved protein-protein interaction motif. Genes Dev 8:1664-1677.

Barski JJ, Hartmann J, Rose CR, Hoebeek F, Morl K, Noll-Hussong M, De Zeeuw CI, Konnerth A, Meyer M (2003) Calbindin in cerebellar Purkinje cells is a critical determinant of the precision of motor coordination. J Neurosci 23:3469-3477.

Bayer SA, Altman J (1991) Neocortical Development, Raven Press

Birnboim HC, Doly J (1979) A rapid alkaline extraction procedure for screening recombinant plasmid DNA. Nucleic Acids Res 7:1513-1523.

Bishop KM, Goudreau G, O'Leary DD (2000) Regulation of area identity in the mammalian neocortex by Emx2 and Pax6. Science 288:344-349.

Bishop KM, Rubenstein JL, O'Leary DD (2002) Distinct actions of Emx1, Emx2, and Pax6 in regulating the specification of areas in the developing neocortex. $J$ Neurosci 22:7627-7638.

Brox A, Puelles L, Ferreiro B, Medina L (2004) Expression of the genes Emx1, Tbr1, and Eomes (Tbr2) in the telencephalon of Xenopus laevis confirms the existence of a ventral pallial division in all tetrapods. J Comp Neurol 474:562577. 
Castiglia D, Cestelli A, Scaturro M, Nastasi T, Di Liegro I (1994) H1(0) and H3.3B mRNA levels in developing rat brain. Neurochem Res 19:1531-1537.

Castiglia D, Scaturro M, Nastasi T, Cestelli A, Di Liegro I (1996) PIPPin, a putative RNA-binding protein specifically expressed in the rat brain. Biochem Biophys Res Commun 218:390-394.

Chen H, Chedotal A, He Z, Goodman CS, Tessier-Lavigne M (1997) Neuropilin-2, a novel member of the neuropilin family, is a high affinity receptor for the semaphorins Sema E and Sema IV but not Sema III. Neuron 19:547-559.

Chiang C, Litingtung Y, Lee E, Young KE, Corden JL, Westphal H, Beachy PA (1996) Cyclopia and defective axial patterning in mice lacking Sonic hedgehog gene function. Nature 383:407-413.

Couse JF, Lindzey J, Grandien K, Gustafsson JA, Korach KS (1997) Tissue distribution and quantitative analysis of estrogen receptor-alpha (ERalpha) and estrogen receptor-beta (ERbeta) messenger ribonucleic acid in the wild-type and ERalpha-knockout mouse. Endocrinology 138:4613-4621.

Debiec H, Kutsche M, Schachner M, Ronco P (2002) Abnormal renal phenotype in L1 knockout mice: a novel cause of CAKUT. Nephrol Dial Transplant 17:4244.

Deweindt C, Albagli O, Bernardin F, Dhordain P, Quief S, Lantoine D, Kerckaert JP, Leprince D (1995) The LAZ3/BCL6 oncogene encodes a sequence-specific transcriptional inhibitor: a novel function for the $\mathrm{BTB} / \mathrm{POZ}$ domain as an autonomous repressing domain. Cell Growth Differ 6:1495-1503.

Doenecke D, Albig W, Bode C, Drabent B, Franke K, Gavenis K, Witt O (1997) Histones: genetic diversity and tissue-specific gene expression. Histochem Cell Biol 107:1-10. 
Doetschman TC, Eistetter H, Katz M, Schmidt W, Kemler R (1985) The in vitro development of blastocyst-derived embryonic stem cell lines: formation of visceral yolk sac, blood islands and myocardium. J Embryol Exp Morphol $87: 27-45$.

Eckart WU. (1994) Geschichte der Medizin, Springer

Elder GA, Friedrich VL, Jr., Bosco P, Kang C, Gourov A, Tu PH, Lee VM, Lazzarini RA (1998) Absence of the mid-sized neurofilament subunit decreases axonal calibers, levels of light neurofilament (NF-L), and neurofilament content. J Cell Biol 141:727-739.

Evdokimova VM, Kovrigina EA, Nashchekin DV, Davydova EK, Hershey JW, Ovchinnikov LP (1998) The major core protein of messenger ribonucleoprotein particles (p50) promotes initiation of protein biosynthesis in vitro. J Biol Chem 273:3574-3581.

Fernandez AS, Pieau C, Reperant J, Boncinelli E, Wassef M (1998) Expression of the Emx-1 and Dlx-1 homeobox genes define three molecularly distinct domains in the telencephalon of mouse, chick, turtle and frog embryos: implications for the evolution of telencephalic subdivisions in amniotes. Development 125:2099-2111.

Ferri RT, Levitt P (1995) Regulation of regional differences in the differentiation of cerebral cortical neurons by EGF family-matrix interactions. Development 121:1151-1160.

Finger S. (1994) Origins of Neuroscience, Oxford University Press

Fukuchi-Shimogori T, Grove EA (2001) Neocortex patterning by the secreted signaling molecule FGF8. Science 294:1071-1074. Epub 2001 Sep 1020.

Fukuchi-Shimogori T, Grove EA (2003) Emx2 patterns the neocortex by regulating FGF positional signaling. Nat Neurosci 6:825-831. 
Galceran J, Miyashita-Lin EM, Devaney E, Rubenstein JL, Grosschedl R (2000) Hippocampus development and generation of dentate gyrus granule cells is regulated by LEF1. Development 127:469-482.

Garel S, Huffman KJ, Rubenstein JL (2003) Molecular regionalization of the neocortex is disrupted in Fgf8 hypomorphic mutants. Development 130:19031914.

Giger RJ, Cloutier JF, Sahay A, Prinjha RK, Levengood DV, Moore SE, Pickering S, Simmons D, Rastan S, Walsh FS, Kolodkin AL, Ginty DD, Geppert M (2000) Neuropilin-2 is required in vivo for selective axon guidance responses to secreted semaphorins. Neuron 25:29-41.

Gitton Y, Cohen-Tannoudji M, Wassef M (1999) Role of thalamic axons in the expression of H-2Z1, a mouse somatosensory cortex specific marker. Cereb Cortex 9:611-620.

Golembo M, Yarnitzky T, Volk T, Shilo BZ (1999) Vein expression is induced by the EGF receptor pathway to provide a positive feedback loop in patterning the Drosophila embryonic ventral ectoderm. Genes Dev 13:158-162.

Graumann PL, Marahiel MA (1998) A superfamily of proteins that contain the coldshock domain. Trends Biochem Sci 23:286-290.

Grove EA, Fukuchi-Shimogori T (2003) Generating the cerebral cortical area map. Annu Rev Neurosci 26:355-380.

Gulisano M, Broccoli V, Pardini C, Boncinelli E (1996) Emx1 and Emx2 show different patterns of expression during proliferation and differentiation of the developing cerebral cortex in the mouse. Eur J Neurosci 8:1037-1050.

Hatten ME, Heintz N (1995) Mechanisms of neural patterning and specification in the developing cerebellum. Annu Rev Neurosci 18:385-408. 
Hebert JM, Mishina Y, McConnell SK (2002) BMP signaling is required locally to pattern the dorsal telencephalic midline. Neuron 35:1029-1041.

Hill RE, Favor J, Hogan BL, Ton CC, Saunders GF, Hanson IM, Prosser J, Jordan T, Hastie ND, van Heyningen V (1991) Mouse small eye results from mutations in a paired-like homeobox-containing gene. Nature 354:522-525.

Jessell TM (2000) Neuronal specification in the spinal cord: inductive signals and transcriptional codes. Nat Rev Genet 1:20-29.

Jones PG, Inouye M (1994) The cold-shock response--a hot topic. Mol Microbiol 11:811-818.

Klinge CM (2001) Estrogen receptor interaction with estrogen response elements. Nucleic Acids Res 29:2905-2919.

Kola I, Brookes S, Green AR, Garber R, Tymms M, Papas TS, Seth A (1993) The Ets1 transcription factor is widely expressed during murine embryo development and is associated with mesodermal cells involved in morphogenetic processes such as organ formation. Proc Natl Acad Sci U S A 90:7588-7592.

Laemmli UK (1970) Cleavage of structural proteins during the assembly of the head of bacteriophage T4. Nature 227:680-685.

Landsman D (1992) RNP-1, an RNA-binding motif is conserved in the DNA-binding cold shock domain. Nucleic Acids Res 20:2861-2864.

Lathe R, Vilotte JL, Clark AJ (1987) Plasmid and bacteriophage vectors for excision of intact inserts. Gene 57:193-201.

Lee SM, Tole S, Grove E, McMahon AP (2000) A local Wnt-3a signal is required for development of the mammalian hippocampus. Development 127:457-467. 
Lelievre E, Lionneton F, Soncin F, Vandenbunder B (2001) The Ets family contains transcriptional activators and repressors involved in angiogenesis. Int $\mathrm{J}$ Biochem Cell Biol 33:391-407.

Levers TE, Edgar JM, Price DJ (2001) The fates of cells generated at the end of neurogenesis in developing mouse cortex. J Neurobiol 48:265-277.

Levitt P, Barbe MF, Eagleson KL (1997) Patterning and specification of the cerebral cortex. Annu Rev Neurosci 20:1-24.

Liu Q, Dwyer ND, O'Leary DD (2000) Differential expression of COUP-TFI, CHL1, and two novel genes in developing neocortex identified by differential display PCR. J Neurosci 20:7682-7690.

Luo L, Yang X, Takihara Y, Knoetgen H, Kessel M (2004) The cell-cycle regulator geminin inhibits Hox function through direct and polycomb-mediated interactions. Nature 427:749-753.

Mallamaci A, Iannone R, Briata P, Pintonello L, Mercurio S, Boncinelli E, Corte G (1998) EMX2 protein in the developing mouse brain and olfactory area. Mech Dev 77:165-172.

Maltais A, Labelle Y (2000) Structure and expression of the mouse gene encoding the orphan nuclear receptor TEC. DNA Cell Biol 19:121-130.

Mansouri A (2001) Determination of gene function by homologous recombination using embryonic stem cells and knockout mice. Methods Mol Biol 175:397413.

Manzanares M, Locascio A, Nieto MA (2001) The increasing complexity of the Snail gene superfamily in metazoan evolution. Trends Genet 17:178-181. 
Marin O, Rubenstein JL (2001) A long, remarkable journey: tangential migration in the telencephalon. Nat Rev Neurosci 2:780-790.

Maroulakou IG, Papas TS, Green JE (1994) Differential expression of ets-1 and ets-2 proto-oncogenes during murine embryogenesis. Oncogene 9:1551-1565.

Marquardt T, Gruss P (2002) Generating neuronal diversity in the retina: one for nearly all. Trends Neurosci 25:32-38.

Matsumoto K, Meric F, Wolffe AP (1996) Translational repression dependent on the interaction of the Xenopus Y-box protein FRGY2 with mRNA. Role of the cold shock domain, tail domain, and selective RNA sequence recognition. $\mathrm{J}$ Biol Chem 271:22706-22712.

Matsumoto K, Wolffe AP, Graumann PL, Marahiel MA, Landsman D (1998) Gene regulation by Y-box proteins: coupling control of transcription and translation A superfamily of proteins that contain the cold-shock domain RNP-1, an RNA-binding motif is conserved in the DNA-binding cold shock domain. Trends Cell Biol 8:318-323.

Medina L, Legaz I, Gonzalez G, De Castro F, Rubenstein JL, Puelles L (2004) Expression of Dbx1, Neurogenin 2, Semaphorin 5A, Cadherin 8, and Emx1 distinguish ventral and lateral pallial histogenetic divisions in the developing mouse claustroamygdaloid complex. J Comp Neurol 474:504-523.

Mitchelmore C, Kjaerulff KM, Pedersen HC, Nielsen JV, Rasmussen TE, Fisker MF, Finsen B, Pedersen KM, Jensen NA (2002) Characterization of two novel nuclear BTB/POZ domain zinc finger isoforms. Association with differentiation of hippocampal neurons, cerebellar granule cells, and macroglia. J Biol Chem 277:7598-7609. Epub 2001 Dec 7513. 
Mitra SW, Hoskin E, Yudkovitz J, Pear L, Wilkinson HA, Hayashi S, Pfaff DW, Ogawa S, Rohrer SP, Schaeffer JM, McEwen BS, Alves SE (2003) Immunolocalization of estrogen receptor beta in the mouse brain: comparison with estrogen receptor alpha. Endocrinology 144:2055-2067.

Miyashita-Lin EM, Hevner R, Wassarman KM, Martinez S, Rubenstein JL (1999) Early neocortical regionalization in the absence of thalamic innervation. Science 285:906-909.

Monuki ES, Porter FD, Walsh CA (2001) Patterning of the dorsal telencephalon and cerebral cortex by a roof plate-Lhx2 pathway. Neuron 32:591-604.

Moss EG, Lee RC, Ambros V (1997) The cold shock domain protein LIN-28 controls developmental timing in C. elegans and is regulated by the lin-4 RNA. Cell 88:637-646.

Muzio L, DiBenedetto B, Stoykova A, Boncinelli E, Gruss P, Mallamaci A (2002) Emx2 and Pax6 control regionalization of the pre-neuronogenic cortical primordium. Cereb Cortex 12:129-139.

Nagai K, Oubridge C, Ito N, Avis J, Evans P (1995) The RNP domain: a sequencespecific RNA-binding domain involved in processing and transport of RNA. Trends Biochem Sci 20:235-240.

Nakada Y, Parab P, Simmons A, Omer-Abdalla A, Johnson JE (2004) Separable enhancer sequences regulate the expression of the neural bHLH transcription factor neurogenin 1. Dev Biol 271:479-487.

Nakagawa Y, Johnson JE, O'Leary DD (1999) Graded and areal expression patterns of regulatory genes and cadherins in embryonic neocortex independent of thalamocortical input. J Neurosci 19:10877-10885. 
Nakakura EK, Watkins DN, Schuebel KE, Sriuranpong V, Borges MW, Nelkin BD, Ball DW (2001) Mammalian Scratch: a neural-specific Snail family transcriptional repressor. Proc Natl Acad Sci U S A 98:4010-4015. Epub 2001 Mar 4013.

Nastasi T, Scaturro M, Bellafiore M, Raimondi L, Beccari S, Cestelli A, di Liegro I (1999) PIPPin is a brain-specific protein that contains a cold-shock domain and binds specifically to $\mathrm{H} 1$ degrees and H3.3 mRNAs. J Biol Chem 274:24087-24093.

Nastasi T, Muzi P, Beccari S, Bellafiore M, Dolo V, Bologna M, Cestelli A, Di Liegro I (2000) Specific neurons of brain cortex and cerebellum are PIPPin positive. Neuroreport 11:2233-2236.

O'Leary DD (1989) Do cortical areas emerge from a protocortex? Trends Neurosci 12:400-406.

Ohmori M, Shimura H, Shimura Y, Kohn LD (1996) A Y-box protein is a suppressor factor that decreases thyrotropin receptor gene expression. Mol Endocrinol 10:76-89.

Osumi N, Inoue T (2001) Gene transfer into cultured mammalian embryos by electroporation. Methods 24:35-42.

Pasceri P, Pannell D, Wu X, Ellis J (1998) Full activity from human beta-globin locus control region transgenes requires 5'HS1, distal beta-globin promoter, and 3' beta-globin sequences. Blood 92:653-663.

Pellegrini M, Mansouri A, Simeone A, Boncinelli E, Gruss P (1996) Dentate gyrus formation requires Emx2. Development 122:3893-3898.

Pfeffer PL, Bouchard M, Busslinger M (2000) Pax2 and homeodomain proteins cooperatively regulate a $435 \mathrm{bp}$ enhancer of the mouse Pax5 gene at the midbrain-hindbrain boundary. Development 127:1017-1028. 
Puelles L, Kuwana E, Puelles E, Bulfone A, Shimamura K, Keleher J, Smiga S, Rubenstein JL (2000) Pallial and subpallial derivatives in the embryonic chick and mouse telencephalon, traced by the expression of the genes Dlx-2, Emx-1, Nkx-2.1, Pax-6, and Tbr-1. J Comp Neurol 424:409-438.

Quandt K, Frech K, Karas H, Wingender E, Werner T (1995) MatInd and MatInspector: new fast and versatile tools for detection of consensus matches in nucleotide sequence data. Nucleic Acids Res 23:4878-4884.

Ragsdale CW, Grove EA (2001) Patterning the mammalian cerebral cortex. Curr Opin Neurobiol 11:50-58.

Raimondi L, D'Asaro M, Proia P, Nastasi T, Di Liegro I (2003) RNA-binding ability of PIPPin requires the entire protein. J Cell Mol Med 7:35-42.

Rakic P (1988) Specification of cerebral cortical areas. Science 241:170-176.

Sassone-Corsi P, Dougherty JP, Wasylyk B, Chambon P (1984) Stimulation of in vitro transcription from heterologous promoters by the simian virus 40 enhancer. Proc Natl Acad Sci U S A 81:308-312.

Scardigli R, Schuurmans C, Gradwohl G, Guillemot F (2001) Crossregulation between Neurogenin2 and pathways specifying neuronal identity in the spinal cord. Neuron 31:203-217.

Scardigli R, Baumer N, Gruss P, Guillemot F, Le Roux I (2003) Direct and concentration-dependent regulation of the proneural gene Neurogenin2 by Pax6. Development 130:3269-3281.

Schambra U., Lauder J., Silver J. (1992) Atlas of the prenatal mouse brain, Academic press, Inc. 
Schindehütte, J. (1998) Prä- und postnatale Expression von H1-Histongenen in der Leber der Maus, Dissertation

Senn C, Kutsche M, Saghatelyan A, Bosl MR, Lohler J, Bartsch U, Morellini F, Schachner M (2002) Mice deficient for the HNK-1 sulfotransferase show alterations in synaptic efficacy and spatial learning and memory. Mol Cell Neurosci 20:712-729.

Seyedin SM, Kistler WS (1980) Isolation and characterization of rat testis H1t. An H1 histone variant associated with spermatogenesis. J Biol Chem 255:5949-5954.

Sinclair AH, Berta P, Palmer MS, Hawkins JR, Griffiths BL, Smith MJ, Foster JW, Frischauf AM, Lovell-Badge R, Goodfellow PN (1990) A gene from the human sex-determining region encodes a protein with homology to a conserved DNA-binding motif. Nature 346:240-244.

Skala-Rubinson H, Vinh J, Labas V, Kahn A, Phan DT (2002) Novel target sequences for Pax-6 in the brain-specific activating regions of the rat aldolase $\mathrm{C}$ gene. $\mathrm{J}$ Biol Chem 277:47190-47196. Epub 42002 Oct 47194.

Sommerville J (1999) Activities of cold-shock domain proteins in translation control. Bioessays 21:319-325.

Soullier S, Jay P, Poulat F, Vanacker JM, Berta P, Laudet V (1999) Diversification pattern of the HMG and SOX family members during evolution. J Mol Evol 48:517-527.

Stoykova A, Gruss P (1994) Roles of Pax-genes in developing and adult brain as suggested by expression patterns. J Neurosci 14:1395-1412.

Stoykova A, Treichel D, Hallonet M, Gruss P (2000) Pax6 modulates the dorsoventral patterning of the mammalian telencephalon. J Neurosci 20:8042-8050. 
Stuhmer T, Anderson SA, Ekker M, Rubenstein JL (2002) Ectopic expression of the Dlx genes induces glutamic acid decarboxylase and Dlx expression. Development 129:245-252.

Thomas KR, Capecchi MR (1987) Site-directed mutagenesis by gene targeting in mouse embryo-derived stem cells. Cell 51:503-512.

Thompson JD, Higgins DG, Gibson TJ (1994) CLUSTAL W: improving the sensitivity of progressive multiple sequence alignment through sequence weighting, position-specific gap penalties and weight matrix choice. Nucleic Acids Res 22:4673-4680.

Travis A, Amsterdam A, Belanger C, Grosschedl R (1991) LEF-1, a gene encoding a lymphoid-specific protein with an $\mathrm{HMG}$ domain, regulates $\mathrm{T}$-cell receptor alpha enhancer function [corrected]. Genes Dev 5:880-894.

van de Wetering M, Oosterwegel M, Dooijes D, Clevers H (1991) Identification and cloning of TCF-1, a T lymphocyte-specific transcription factor containing a sequence-specific HMG box. Embo J 10:123-132.

Varani G, Nagai K (1998) RNA recognition by RNP proteins during RNA processing. Annu Rev Biophys Biomol Struct 27:407-445.

Vaughan TJ, Pascall JC, Brown KD (1992) Nucleotide sequence and tissue distribution of mouse transforming growth factor-alpha. Biochim Biophys Acta 1132:322-324.

Wall L, deBoer E, Grosveld F (1988) The human beta-globin gene 3' enhancer contains multiple binding sites for an erythroid-specific protein. Genes Dev 2:1089-1100.

Walther C, Gruss P (1991) Pax-6, a murine paired box gene, is expressed in the developing CNS. Development 113:1435-1449. 
Wang VY, Zoghbi HY (2001) Genetic regulation of cerebellar development. Nat Rev Neurosci 2:484-491.

Wehner R., W. Gehring (1995) Zoologie, Thieme

Wehr R, Mansouri A, de Maeyer T, Gruss P (1997) Fkh5-deficient mice show dysgenesis in the caudal midbrain and hypothalamic mammillary body. Development 124:4447-4456.

Wilkinson B, Chen JY, Han P, Rufner KM, Goularte OD, Kaye J (2002) TOX: an HMG box protein implicated in the regulation of thymocyte selection. Nat Immunol 3:272-280.

Wolpert L (1996) One hundred years of positional information. Trends Genet 12:359364.

Wood SA, Allen ND, Rossant J, Auerbach A, Nagy A (1993) Non-injection methods for the production of embryonic stem cell-embryo chimaeras. Nature 365:8789.

Yuan L, Moyon D, Pardanaud L, Breant C, Karkkainen MJ, Alitalo K, Eichmann A (2002) Abnormal lymphatic vessel development in neuropilin 2 mutant mice. Development 129:4797-4806.

Zhao L, Wu TW, Brinton RD (2004) Estrogen receptor subtypes alpha and beta contribute to neuroprotection and increased Bcl-2 expression in primary hippocampal neurons. Brain Res 1010:22-34.

Zhou C, Tsai SY, Tsai MJ (2001) COUP-TFI: an intrinsic factor for early regionalization of the neocortex. Genes Dev 15:2054-2059.

Zlatanova J, Doenecke D (1994) Histone H1 zero: a major player in cell differentiation? Faseb J 8:1260-1268. 
Zou Y, Chien KR (1995) EFIA/YB-1 is a component of cardiac HF-1A binding activity and positively regulates transcription of the myosin light-chain $2 \mathrm{v}$ gene. Mol Cell Biol 15:2972-2982. 


\section{Danksagung}

An dieser Stelle möchte ich mich bei allen bedanken, die mir bei meiner Promotion geholfen haben.

Als erstes möchte ich mich besonders bei Herrn Prof. Dr. Peter Gruss für seine Unterstützung und die Möglichkeit in seinem Labor promovieren zu dürfen, bedanken.

Herrn Prof. Dr. Hans-Joachim Fritz bin ich dankbar für die Übernahme des Korreferates, sowie allen Mitgliedern der Prüfungskommission für ihr Entgegenkommen.

Frau Prof. Dr. Italia DiLiegro und Herrn Prof. Dr. Detlef Doenecke danke ich für die Bereitstellung von Antikörpern und hilfreichen Diskussionen.

Meinen großen Dank möchte ich auch Dr. Kamal Chowdhury aussprechen, der mich in die Grundlagen der Molekularbiologie einführte und mit Erklärungen und Hilfestellungen maßgeblich zu dieser Arbeit beigetragen hat.

Dr. Anastassia Stoykova danke ich sehr für ihr hervorragendes Wissen in Fragen der Neuroanatomie und für Anregungen zur Planung weiterer Experimente.

Weiterhin richtet sich mein großer Dank an Sven Mühlfriedel für unsere erfolgreiche Kollaboration in dem Microarray-Projekt und in der Enhancer-Analyse. In Computerfragen war er mir stets ein geduldiger Ratgeber und Helfer.

Sharif Mahsur danke ich für hervorragende Zellkultur-Arbeit. Ullrich Franke sei mit herzlichem Dank erwähnt für die erfolgreiche Morula-Aggregation. Andrea Conrad, Martina Daniel und Sabine Geisendorf waren in technischen Fragen immer ansprechbar und hilfsbereit, dafür ein großes Dankeschön. Jens Krull und Kirsten Backs danke ich für die Beteiligung an zahlreichen DNA-Präparationen. Sigurd Hille sei ebenfalls mit großem Dank erwähnt für die vielen Sequenzierungen.

Frau Dr. Tanja Vogel sei gedankt für hilfreiche Diskussionen und Anregungen, v. a. im Bereich der Proteinbiochemie. 
Schließlich bin ich auch Sylvia Schrötter und Alexandra Kurth dankbar für ihre zuverlässige Arbeit. Meinen herzlichen Dank richte ich auch an Ulrike Teichmann für Hilfen in Fragen der Mausarbeit. 


\section{Publikationen}

Stuermer CA, Lang DM, Kirsch F, Wiechers M, Deininger SO, Plattner H (2001). Glycosylphosphatidyl inositol-anchored proteins and fyn kinase assemble in noncaveolar plasma membrane microdomains defined by reggie-1 and -2 . Mol Biol Cell. 12(10):3031-45.

in Vorbereitung:

F. Kirsch et al. (2004), Gene Expression Analysis of E16.5 cerebral mouse cortex identified regionally expressed genes and new marker genes for certain brain regions.

F. Kirsch et al. (2004), Expression of PIPPin during mouse development / Identification of regulatory enhancer elements of the mouse PIPPin gene. 


\section{Lebenslauf}

Name: $\quad$ Friederike Kirsch

Geburtsdatum: $\quad 15.08 .74$

Geburtsort: Lemgo

Familienstand: ledig

Staatsangehörigkeit: deutsch

1981-1985:

1985-1994:

Besuch der Ostschule in Lemgo

Besuch des Engelbert-Kämpfer-Gymnasiums in Lemgo, Abschluß: Allgemeine Hochschulreife, Mai 1994

Okt. 1994-

Mai 2000:

Nov. 2000-

Studium der Biologie an der Universität Konstanz, Diplomarbeit in der Arbeitsgruppe Entwicklungsneurobiologie, Prof. Dr. C. Stürmer, Thema: "Charakerisierung der Funktion und Verteilung von Reggie-1 und -2 mit Hilfe vorhandener und neuer Antikörper", Verleihung des Hochschulgrades DiplomBiologin

Nov. 2004:

Doktorarbeit am Max-Planck-Institut für biophysikalische Chemie in Göttingen, Abt. Molekulare Zellbiologie, Prof. Dr. Peter Gruss, Thema: "Identifizierung und Charakterisierung von Genen für die Entwicklung des cerebralen Cortex" 